\title{
Seismic Performance of GFRP-RC Exterior Beam-Column Joints with Lateral Beams
}

\author{
By \\ Shervin Khalili Ghomi \\ A Thesis submitted to the Faculty of Graduate Studies of \\ The University of Manitoba \\ in partial fulfillment of the requirements of the degree of
}

\section{Master of Science}

Department of Civil Engineering

Faculty of Engineering

University of Manitoba

Winnipeg

Copyright (C) 2014 by Shervin Khalili Ghomi 


\begin{abstract}
In the past few years, some experimental investigations have been conducted to verify seismic behaviour of fiber reinforced polymer reinforced concrete (FRP-RC) beam-column joints. Those researches were mainly focused on exterior beam-column joints without lateral beams. However, lateral beams, commonly exist in buildings, can significantly improve seismic performance of the joints. Moreover, the way the longitudinal beam bars are anchored in the joint, either using headed-end or bent bars, was not adequately addressed. This study aims to fill these gaps and investigate the shear capacity of FRP-RC exterior beam-column joints confined with lateral beams, and the effect of beam reinforcement anchorage on their seismic behaviour. Six full-scale exterior beam-column joints were constructed and tested to failure under reversal cyclic loading. Test results showed that the presence of lateral beams significantly increased the shear capacity of the joints. Moreover, replacing bent bars with headed-end bars resulted in more ductile behaviour of the joints.
\end{abstract}




\section{ACKNOWLEDEMENTS}

My first and sincere appreciation goes to my supervisor Dr. Ehab El-Salakawy, PEng, Professor of Structural Engineering and Canada Research Chair in Durability and Modernization of Civil Structures in the Department of Civil Engineering at the University of Manitoba, for his continuous guidance and support in all stages of this research program. I would also like to thank him for all I have learned from him, and for encouraging and helping me to shape my ideas and interests.

In addition I would like to express my deep gratitude to my colleagues, especially Mr. Mohamed Hasaballa who is one of the pioneer researchers in the subject of this program, and his advice and help was invaluable to me.

The financial support of the National Science and Engineering Research Council of Canada (NSERC) and Canada Research Chairs program is gratefully acknowledged.

I would like to thank Mr. Chad Klowak, PEng, and Mr. Grant Whiteside, the technical staff of the McQuade Heavy Structural Laboratory at the University of Manitoba for their technical assistance and valuable advice during the experimental program.

Last but not the least; I would like to thank my parents for their unconditional love and support, financially and spiritually, throughout my life. Without them I could not make it here. 


\section{Table of Contents}

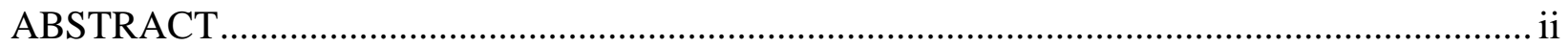

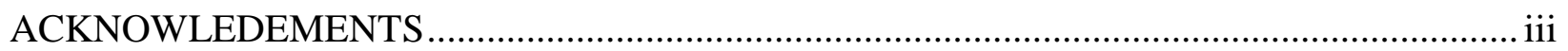

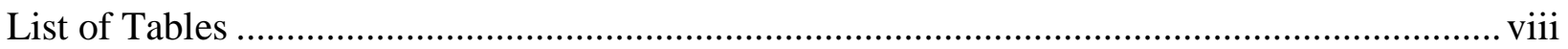

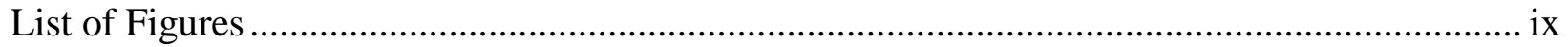

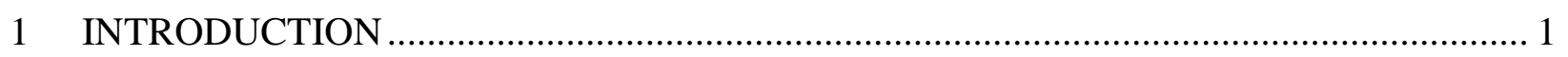

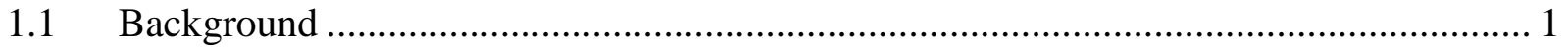

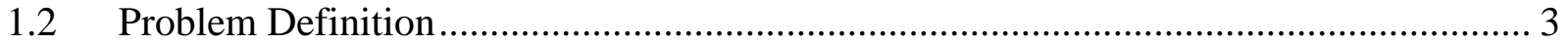

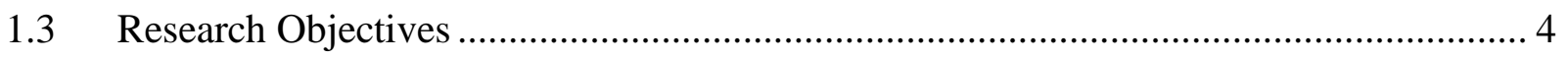

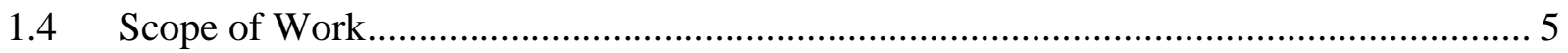

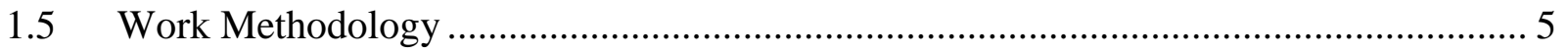

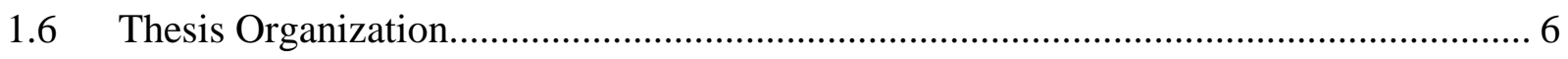

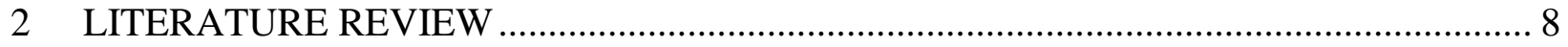

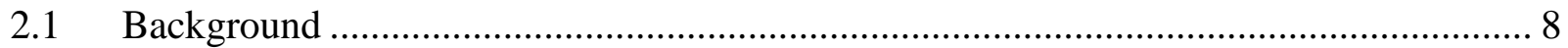

2.2 Research on Steel-RC Beam-Column Joints........................................................ 9

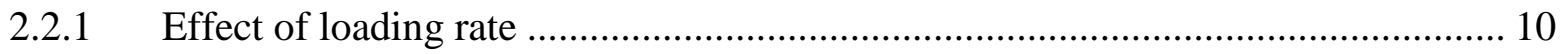

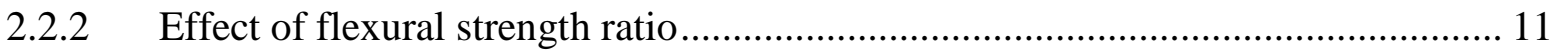

2.2.3 Effect of transverse reinforcement within the joint ......................................... 12

2.2.4 Effect of shear stress in the joint................................................................ 12

2.2.5 Effect of lateral beams and slab ................................................................... 13

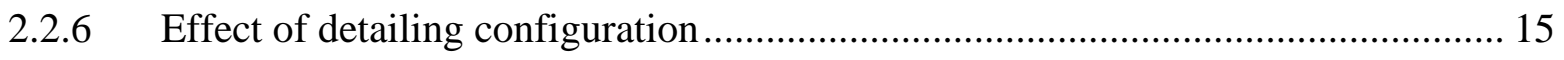

$2.3 \quad$ FRP Bars as Reinforcement for Concrete Structures ............................................... 20

2.3.1 Characteristics of FRP reinforcement ....................................................... 20

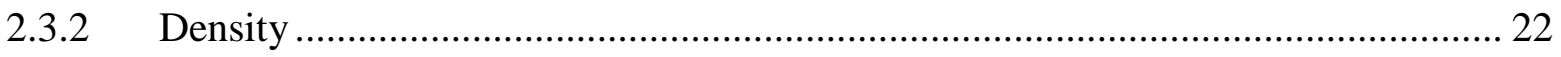

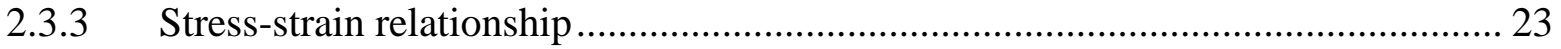

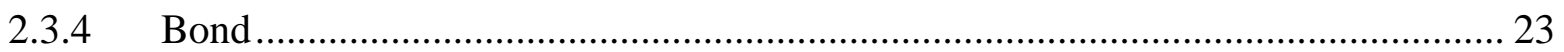

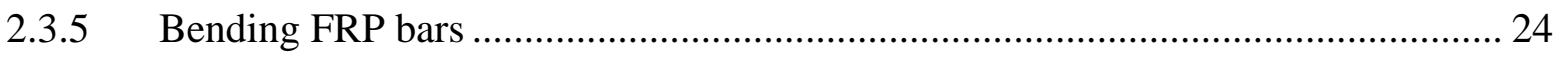

2.4 Structural Behaviour of Individual Elements Reinforced with FRP Materials.............. 24

2.4.1 Flexural behaviour of concrete beams reinforced with FRP bars ........................ 24 
2.4.2 Shear strength of concrete beams reinforced with FRP stirrups.......................... 27

2.4.3 Columns reinforced with FRP bars ................................................................ 30

2.5 Feasibility of Using FRP-RC Beam-Column Joints in Seismic Regions...................... 34

2.6 Effect of Anchorage Type on Behaviour of Beam-Column Joints ............................. 37

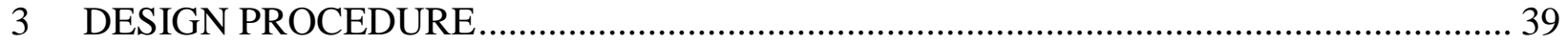

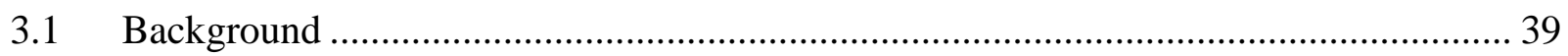

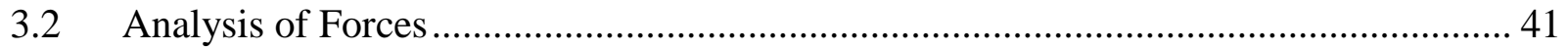

3.3 Design Procedure for Beam-Column Joints Reinforced with GFRP Bars and Stirrups 42

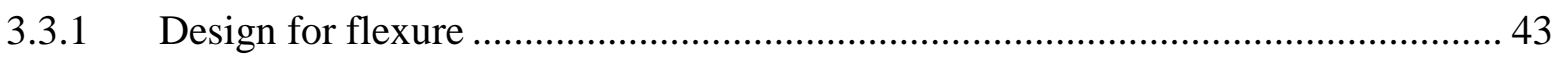

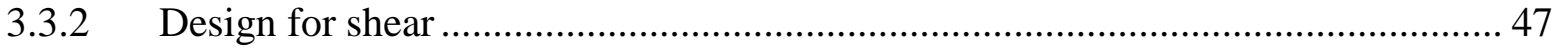

3.3.3 Joint resistance and applied shear stress ....................................................... 50

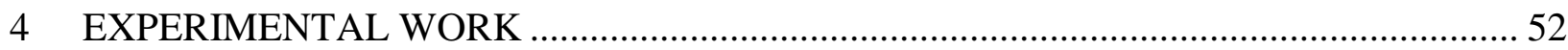

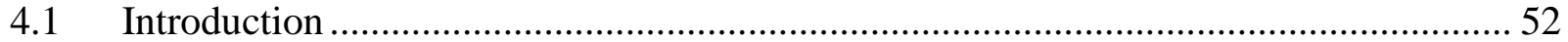

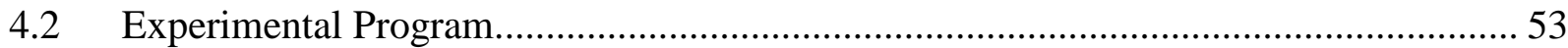

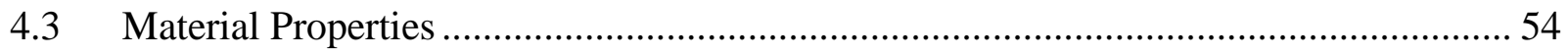

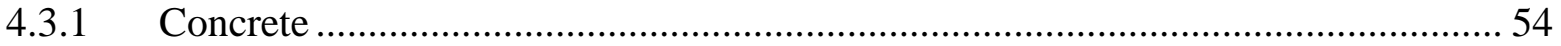

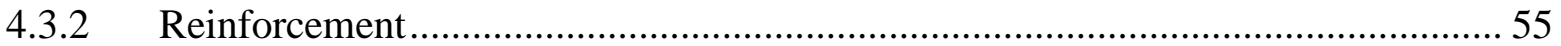

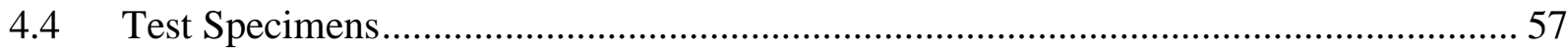

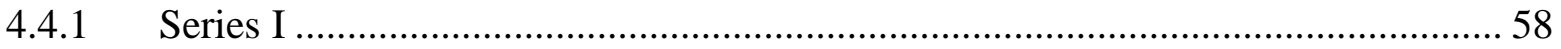

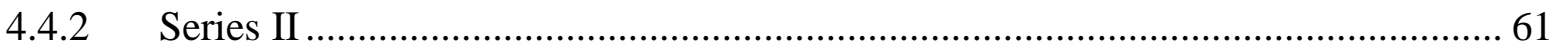

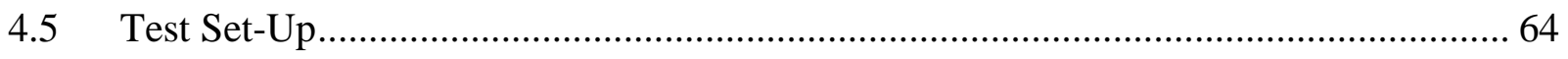

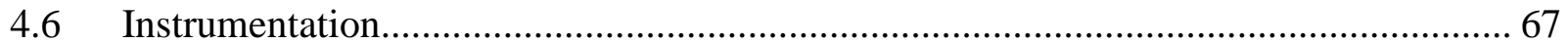

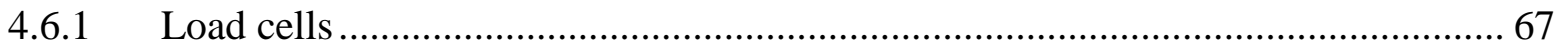

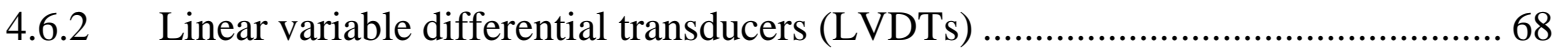

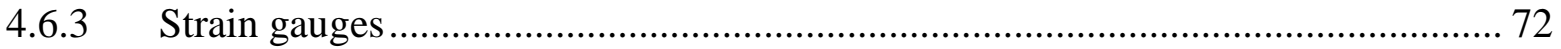

4.7 Seismic Loading Scheme and Test Procedure ...................................................... 72

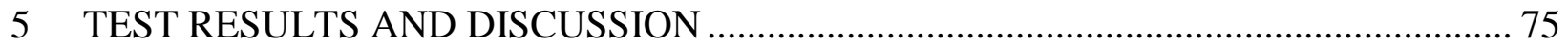

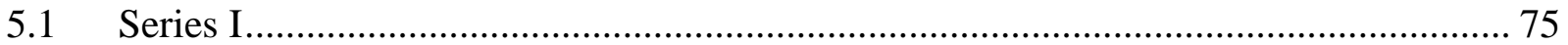

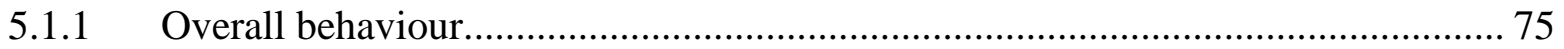

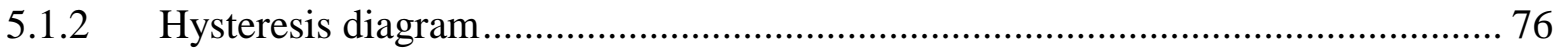

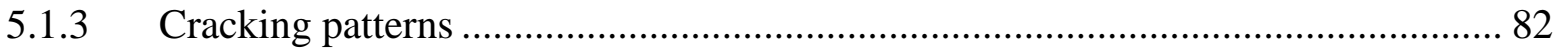




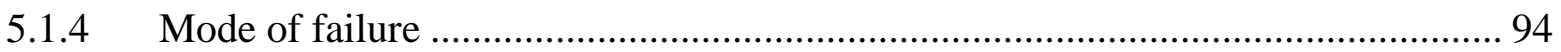

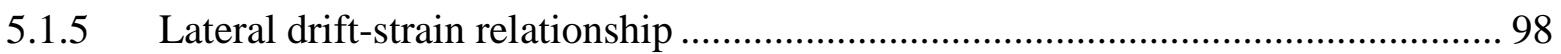

5.1.6 Components of the beam tip lateral displacement ................................................. 107

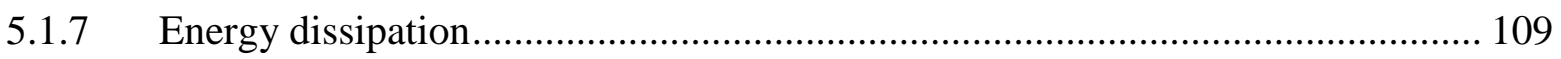

5.1.8 Lateral Stiffness .......................................................................................... 110

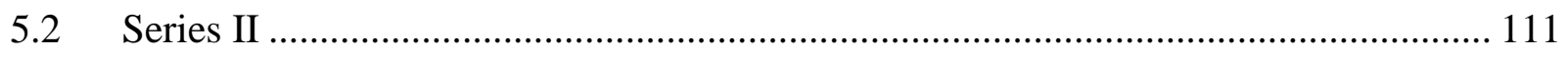

5.2.1 Overall behaviour.................................................................................................. 111

5.2.2 Hysteresis diagram...................................................................................... 112

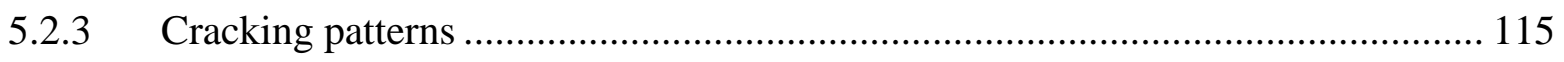

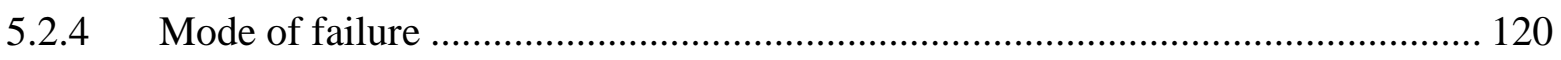

5.2.5 Lateral Drift-Strain Relationship ...................................................................... 122

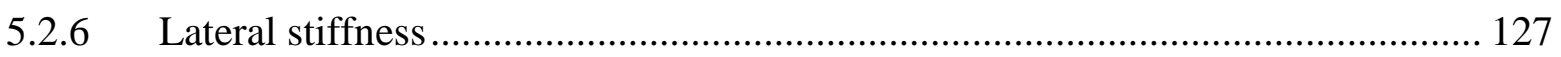

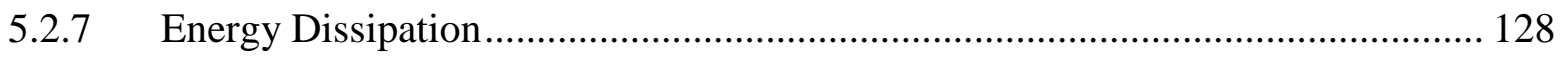

6 CONCLUSIONS AND FUTURE WORK .............................................................. 130

6.1 Summary and Conclusions....................................................................................... 130

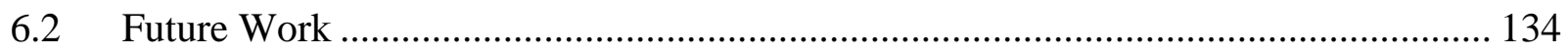

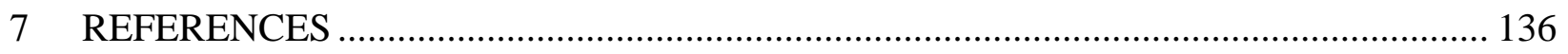

APPENDIX A : DESIGN OF SPECIMEN “G-IM" ......................................................... A-1

Design of the Main Beam for Flexural.......................................................................... A-2

Material and sectional properties............................................................................... A-2

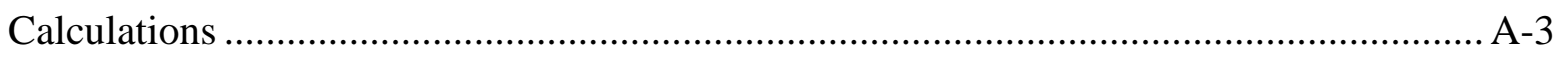

Design of Main Beam for Shear............................................................................... A-6

Material and sectional Properties: ............................................................................. A-6

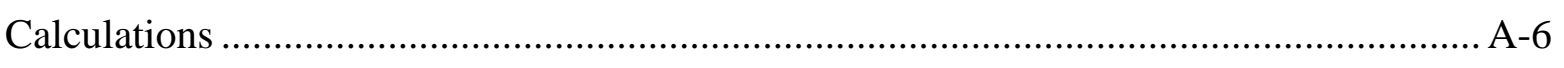

Design of Column for Flexure ……………………................................................ A-10

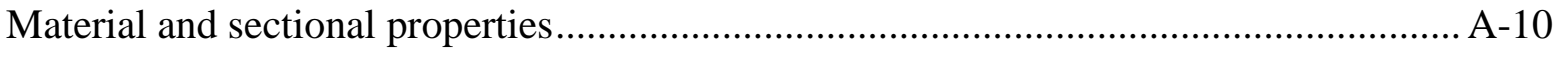

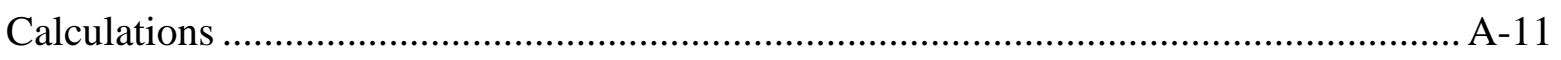

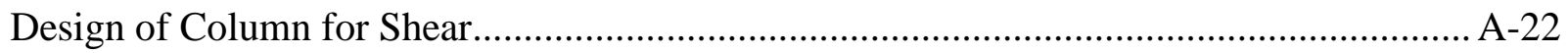

Material and sectional properties.............................................................................. A-23

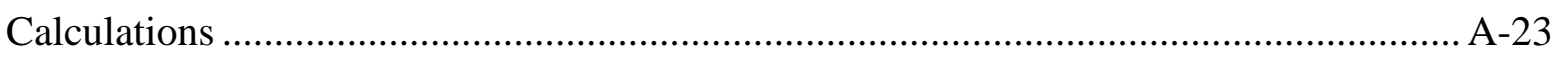

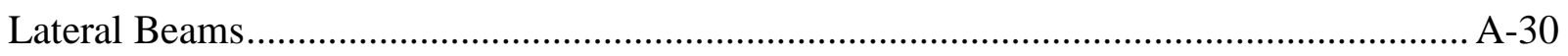




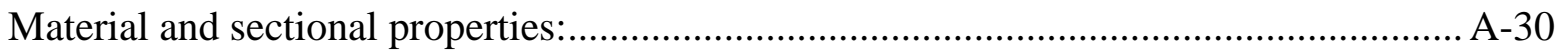

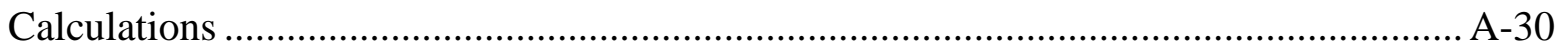

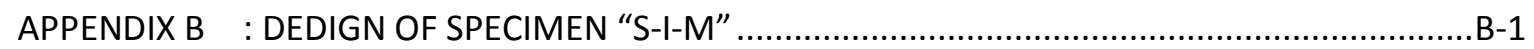

Material and Sectional Properties........................................................................ B-2

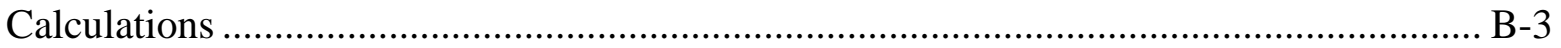

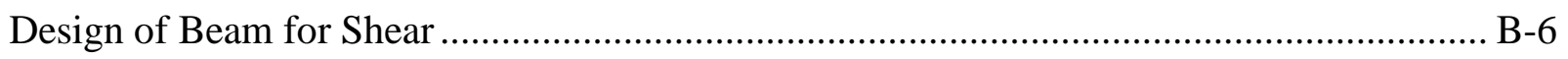

Material and sectional properties:.......................................................................... B-6

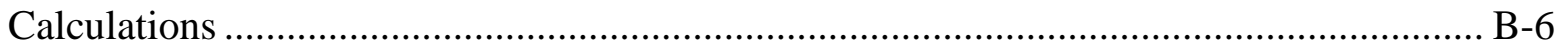

Design of Column for Flexure ............................................................................. B-9

Material and sectional properties............................................................................ B-9

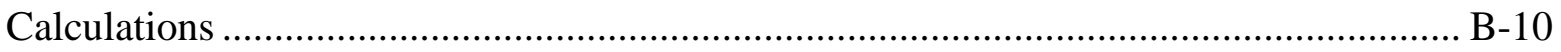

Design of Column for Shear............................................................................... B-20

Material and sectional properties.......................................................................... B-20

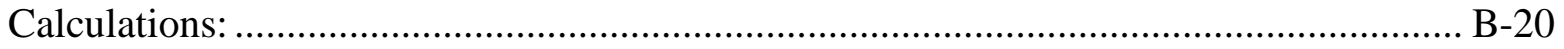

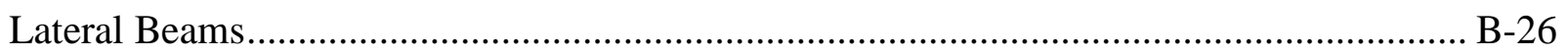

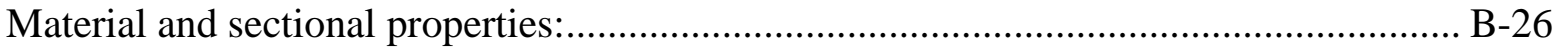

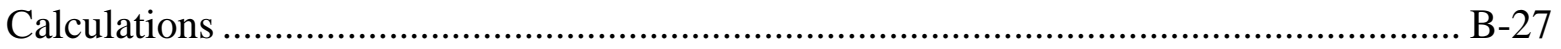

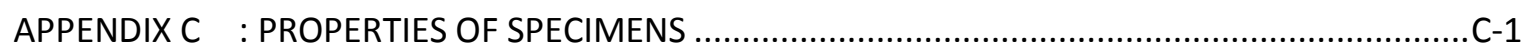




\section{List of Tables}

Table 2.1- Typical density of FRP reinforcement (ACI 440.1R-06) ........................................ 22

Table 4.1 - Compressive and tensile strengths of concrete at day of testing ............................ 55

Table 4.2 - Mechanical properties of GFRP straight bars ..................................................... 55

Table 4.3 - Size, dimensions and weights of straight bars ................................................. 56

Table 4.4 - Mechanical properties of GFRP bent bars....................................................... 56

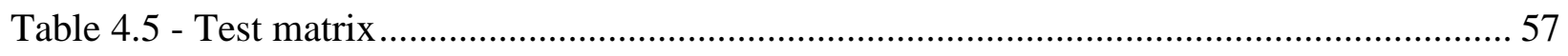

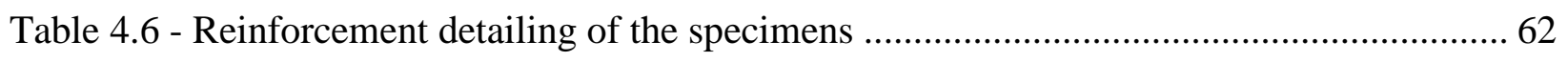

Table C.1 - Properties of the specimens .......................................................................... C-2

Table C.2 - Design and actual capacity of the specimens.................................................... C-2 


\section{List of Figures}

Figure 2.1 - Applied forces to an exterior beam-column joint (reproduced from Wight, J. and

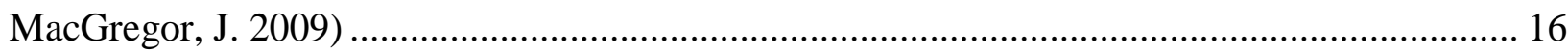

Figure 2.2 - Strut and tie model in exterior beam-column joints (reproduced from Hwang et al. 2005)

Figure 2.3 - Different anchorage method for beam longitudinal bars (reproduced from Murty et al 2003) 18

Figure 2.4 - Schematic stress-strain relationship of FRP reinforcement 23

Figure 2.5 - Proposed method of constructing FRP-RC columns interaction diagram (reproduced from Choo et al. 2006)....... 34

Figure 3.1 - (a) formation plastic hinge at beams, (b) formation of plastic hinge at columns

(reproduce from Murty, C., Rai, D., Bajpai, K. and Jain, S. 2003) ......................................... 40

Figure 3.2 - Calculation of shear in joint (reproduced from Wight, J. and MacGregor, J. 2009) 41

Figure 3.3 - Force equilibrium and strain compatibility .................................................... 45

Figure 4.1 - beam-column joints in a laterally loaded ductile frame ..................................... 53

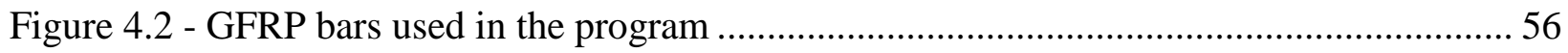

Figure 4.3 - Dimensions of test specimens (dimensions in $\mathrm{mm}$ ) .......................................... 58

Figure 4.4 - Reinforcement detailing of Series I specimens (S-I-M, G-I-L, G-I-M, G-I-H)........ 61

Figure 4.5 - Reinforcement detailing of Series II specimens (G-II-M, G-II-L) ........................ 63

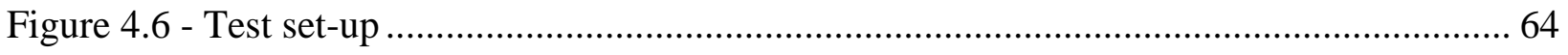

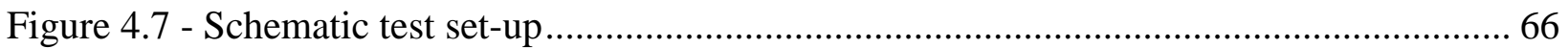




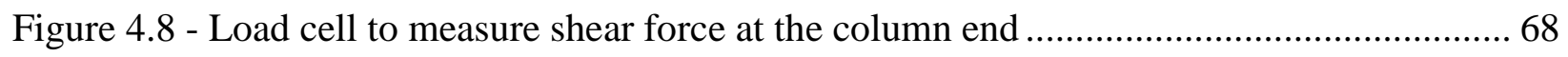

Figure 4.9 - LVDT set for measuring beam relative rotation ......................................................... 69

Figure 4.10 - LVDT set for measuring beam plastic hinge rotation .............................................. 70

Figure 4.11 - LVDT set for measuring column rotation................................................................ 71

Figure 4.12 - LVDT set for measuring Joint distortion. .............................................................. 71

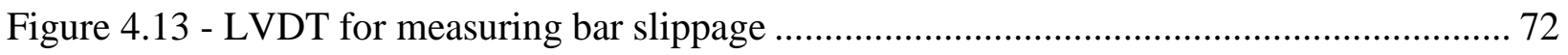

Figure 4.14 - Location of the strain gages .............................................................................. 72

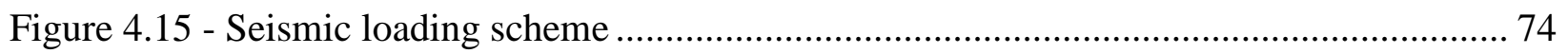

Figure 5.1 - Hysteresis diagram of Specimen S-I-M ................................................................ 77

Figure 5.2 - Hysteresis diagram of Specimen G-I-L............................................................... 77

Figure 5.3 - Hysteresis diagram of Specimen G-I-M ………….............................................. 77

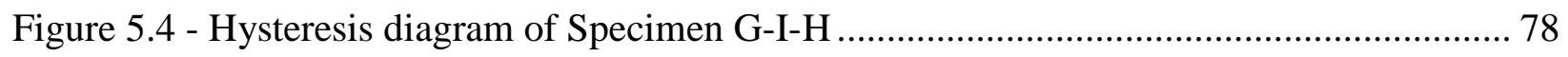

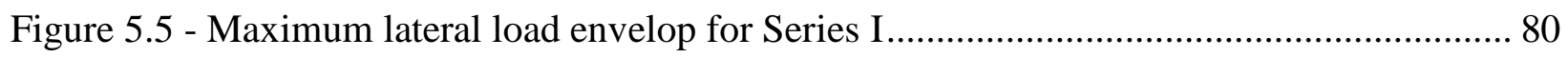

Figure 5.6 - Normalized lateral load-drift ratio relationship for specimens of Series I................. 82

Figure 5.7 - Condition of Series I specimens after 0.8 and 1\% drift ratio ...................................... 84

Figure 5.8 - Condition of Series I specimens after 1.5 and 2\% drift ratio .................................... 86

Figure 5.9 - Condition of Series I specimens after 3 and 4\% drift ratio ....................................... 88

Figure 5.10 - Condition of Series I specimens after 5 and 6\% drift ratio ....................................... 89

Figure 5.11 - Concrete push-off underneath specimens G-I-H and G-I-L ................................... 90

Figure 5.12 - Specimens S-I-M and G-I-L at 7\% drift ratio (failure) ............................................ 91

Figure 5.13 - Concrete push-off underneath specimens G-I-M .................................................... 92

Figure 5.14 - Condition of specimens G-I-M and G-I-H after 7 and 8\% drift ratio ...................... 93

Figure 5.15 - Condition of specimens G-I-M and G-I-H at 9\% drift ratio (failure) ...................... 94 


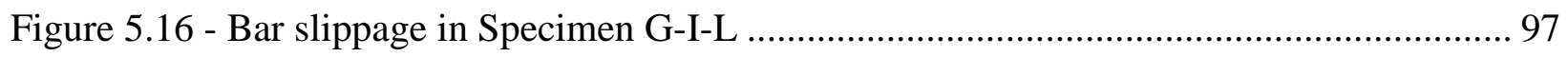

Figure 5.17 - Bar Slippage in Specimen G-I-M............................................................. 97

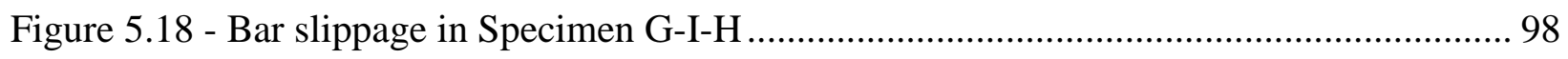

Figure 5.19 - Average joint stirrup strain in the specimens of Series I .................................. 99

Figure 5.20 - Readings of Strain Gauge No.6 in the specimens of Series I............................ 100

Figure 5.21 - Average strain in column longitudinal bars in the specimen of Series I.............. 102

Figure 5.22 - Strain flow in beam longitudinal bar (Specimen G-I-L) .................................. 103

Figure 5.23 - Strain flow in beam longitudinal bar (Specimen G-I-M) ................................ 103

Figure 5.24 - Strain flow in beam longitudinal bar (Specimen G-I-H) ................................... 104

Figure 5.25 - Strain flow in beam longitudinal bar (Specimen S-I-M) ................................... 104

Figure 5.26 - Maximum strain between strain gauges No.18 and 19 in the specimen of Series I

Figure 5.27 - Beam tip displacement components (Specimen G-I-L) ................................... 108

Figure 5.28 - Beam tip displacement components (Specimen G-I-M) ................................. 108

Figure 5.29 - Beam tip displacement components (Specimen G-I-H).................................. 109

Figure 5.30 - Beam tip displacement components (Specimen S-I-M) .................................... 109

Figure 5.31 - Cumulative energy dissipation of the specimens in Series I............................. 110

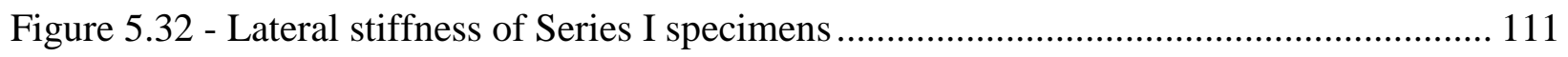

Figure 5.33 - Hysteresis diagram of Specimen G-II-M ................................................... 112

Figure 5.34 - Hysteresis diagram of Specimen G-II-L ................................................... 113

Figure 5.35 - Maximum lateral load envelop for Series II specimens................................... 114

Figure 5.36 - Condition of Series II specimens after 0.8 and $1.5 \%$ drift ratio........................ 116

Figure 5.37 - Condition of Series II specimens after 2 and 3\% drift ratio............................. 117 
Figure 5.38 - Condition of Series II specimens after 4 and 5\% drift ratio................................... 118

Figure 5.39 - Condition of Series II specimens at 6\% drift ratio (failure)................................... 119

Figure 5.40 - Bar rupture at the final stage in Specimen G-II-M .............................................. 121

Figure 5.41 - Bar deformation in Specimen G-II-L .................................................................. 122

Figure 5.42 - Average joint stirrups strain in G-II-M, G-II-L, and G-I-M .................................. 123

Figure 5.43 - Readings of Strain Gauge No.6 in G-II-M, G-II-L, and G-I-M............................ 124

Figure 5.44 - Average strain in column longitudinal bars in G-II-M, G-II-L, and G-I-M .......... 125

Figure 5.45 - Readings of Strain Gauges No.19 in G-II-M, G-II-L, and G-I-M ......................... 126

Figure 5.46 - Strain flow in beam longitudinal bars in Specimen G-II-M ................................. 127

Figure 5.47 - Strain flow in beam longitudinal bars in Specimen G-II-L.................................... 127

Figure 5.48 - Lateral stiffness of G-II-L. G-II-M, G-I-M ....................................................... 128

Figure 5.49 - Cumulative energy dissipation of the G-II-M, G-II-L, and G-I-M ......................... 129

Figure A.1 - Specimen G-I-M reinforcement detailing ………............................................... A-2

Figure A.2 - Compatibility of strain for beam cross section (G-I-M) ………......................... A-3

Figure A.3 - Beam reinforcement detailing for Specimen G-I-M ............................................. A-6

Figure A.4 - Beam reinforcement detailing for Specimen G-I-M .......................................... A-10

Figure A.5 - Compatibility of strain for column cross section (G-I-M) ................................... A-11

Figure A.6 - Axial load-moment interaction diagram of column (G-I-M) .............................. A-21

Figure A.7 - Column reinforcement detailing for Specimen G-I-M........................................ A-22

Figure A.8 - Lateral beams reinforcement detailing for Specimen G-I-M ............................... A-30

Figure B.1 - Column reinforcement detailing for Specimen S-I-M.......................................... B-2

Figure B.2 - Compatibility of strain for beam cross section (S-I-M) ......................................... B-3

Figure B.3 - Beam reinforcement detailing for Specimen G-I-M ………………………....... B-6 
Figure B.4 - Beam reinforcement detailing for Specimen S-I-M ....................................... B-9

Figure B.5 - Compatibility of strain for column cross section (S-I-M) .............................. B-10

Figure B.6 - Axial load-moment interaction diagram of column (S-I-M) ............................ B-18

Figure B.7 - Column reinforcement detailing for Specimen S-I-M.................................... B-20

Figure B.8 - Lateral beams reinforcement detailing for Specimen S-I-M........................... B-26 


\section{INTRODUCTION}

\subsection{Background}

The construction industry has used steel bars as a reinforcing material for structural concrete members for more than a hundred years. However, deterioration of reinforced concrete (RC) structures due to corrosion of steel bars embedded in concrete has been always a serious problem. Although steel, in RC structures, is initially protected against corrosion by alkalinity of concrete, with existence of cracks in concrete, it is exposed to oxygen and humidity which causes corrosion. Corrosion of steel reinforcement leads to high maintenance costs and ultimately can cause loss of integrity of RC structures. The problem is especially more severe in structures exposed to harsh environments and aggressive chemicals like marine structures, bridges, and parking garages. There are many alternatives that have been suggested to overcome the corrosion problem, such as increasing concrete cover, improving impermeability of concrete, epoxy-coating and galvanization of steel bars. However, none of these procedures can completely eliminate corrosion and only can delay the deterioration process. The most successful method of eliminating corrosion is by replacing conventional steel with none-corrodible materials. One of the recent materials that have been introduced to the construction industry and seems to be very effective is fibre reinforced polymer (FRP).

In addition to corrosion resistance, FRP materials have other attractive qualities, such as:

- Electrical and magnetic non-conductivity;

- High tensile strength; 


\section{INTRODUCTION}

- $\quad$ Light weight or high strength-to-weight ratio.

However, in order to use FRP reinforcement, the different mechanical characteristics of these materials must be considered in the design process. FRPs exhibit linear-elastic behaviour up to failure with relatively lower modulus of elasticity compared to steel. Moreover, they have different bond-to-concrete behaviour and low strength under compressive and shear stresses.

During the past decades, many experimental investigations have been conducted to verify behaviour of different concrete elements reinforced with FRP materials (Brown and Bartholimew 1993; Shehata et al. 2000; Alsayed et al. 1999). These studies usually involved investigating the behaviour of individual FRP-RC members such as simply-supported beams, slabs, and columns. Satisfactory performance of FRP-RC elements in laboratories resulted in field application of these materials in construction of bridges or parking garage slabs, especially in harsh environments.

However, up to date, none or very few researches have been conducted on integral performance of FRP-RC framed structures where two or more structural elements interact with each other (Fukuyama et al. 1995; Said \& Nehdi 2004; Mady et al. 2009; Hasaballa et al. 2011). One of the most influential regions in the integral behaviour of a frame is "beam-column joints". Beamcolumn joints play an important role in the stability of framed structures. Failure of these joints can lead to partial or even total structural collapse. Moreover, behaviour of these connections has significant influence on seismic performance of frames, especially in structures using momentresisting frame system to endure lateral loads (due to earthquakes and wind).

The first concern about using FRP materials as concrete reinforcement in beam-column joints was feasibility of using them in seismic regions. One of the main parameters resulting in a 


\section{INTRODUCTION}

satisfactory seismic performance of a joint is magnitude of energy dissipation. The amount of energy dissipation is represented by the area enclosed by the moment-curvature diagram of structural elements when they are under seismic loading. For steel-RC structures, yielding of steel exhibits desirable ductility and energy consumption; however, this phenomenon is not applicable for FRP material. The linear elastic stress-strain relationship of FRP materials may result in significantly different damping and energy dissipation characteristics for FRP-RC structures.

On the other hand, due to lower modulus of elasticity and higher strength of FRPs, FRP-RC elements can show large deformation prior to failure. This large deformation is called “deformability”. Recent researches (Mady et al. 2009; Hasaballa et al. 2011) that have been carried out on concrete beam-column joints reinforced with Glass FRP (GFRP) indicated that energy dissipation of GFRP-RC frames is lower than that of steel-RC ones. However, high deformability still allows these frames to dissipate a reasonable level of seismic energy. The results also indicated the advantage of linear behaviour of the elements which can result in minor damage after surviving a seismic event.

\subsection{Problem Definition}

Following the feasibility of using FRP-RC beam-column joints in seismic regions, it seems necessary to study different parameters that can affect behaviour of these joints. To date and due to lack of research data, the current FRP-RC design codes and guidelines (CSA S806-12; ACI 440.1R-06; ISIS Canada 2007) have no considerable seismic provisions. There are no provisions to estimate the capacity of a beam-column joint when all members are fully reinforced with FRP reinforcement. Although the CSA S806-12 in Clause 12.7 provides some provisions on using 


\section{INTRODUCTION}

FRP as transverse reinforcement to confine columns in seismic regions, there are no recommendations on how to obtain the shear capacity of the joints designed according to this clause. This lack of guidelines limits implementing FRP reinforcement in new structures.

Researches in this area are in the early stages. Only few tests have been carried out to investigate behaviour of FRP-RC beam-column joints under seismic loading (Said and Nehdi 2004; Mady et al. 2009; Hasaballa et al. 2011). These researches are only limited to some studies about exterior beam-column joints with some certain type of reinforcement detailing without considering the effects of lateral beams or slabs. There are many other aspects that still uncovered. Therefore, it is deemed necessary to investigate the behaviour of beam-column joints fully reinforced with FRP bars and stirrups with different boundary conditions, reinforcement detailing and loading schemes.

\subsection{Research Objectives}

The main objectives of this research are:

- To investigate the influence of lateral beams on the performance of exterior beam-column joints under simulated-seismic loading. The performance is evaluated in terms of carrying load capacity, mode of failure, cracking patterns, drift ratio, energy dissipation, etc.;

- To identify the safe shear capacity for exterior beam-column joints with lateral beams;

- To investigate the influence of end detailing of beam longitudinal bars on the capacity of exterior beam-column joints. 
INTRODUCTION

Also, integration of this investigation's results and those obtained from previous studies (Mady et al. 2009; Hasaballa et al. 2011) will help to have better understanding of exterior beam-column joints behaviour in general.

\subsection{Scope of Work}

Compared to various types of FRP materials, GFRP is more attractive for the construction industry due to its lower cost. Accordingly, GFRP materials are used as reinforcement in this study. Moreover, normal strength concrete is used in this study to address the normal multi-story framed structures that are commonly constructed for various purposes.

Beam-column joints can be divided in two general groups: 1) interior joints, 2) exterior joints. Exterior beam-column joints are usually more critical due to reinforcement detailing at beam ends. As a result, anchorage type and reinforcement detailing can significantly affect the behaviour of the joints. In this program, two types of bar anchorage, bent bars and headed-end GFRP bars, are studied.

Another parameter that can significantly affect the shear capacity of exterior joints is boundary condition, which is the confinement provided by lateral beams. Among different configurations of exterior joints (corner, with or without lateral beams), this study focuses on the joints with lateral beams since this type of beam-column joints are very common at the end bay of framed structures.

\subsection{Work Methodology}

This study consists of mainly an experimental program including designing, construction and testing of six full-scale beam-column joints. The specimens represent exterior beam-column 


\section{INTRODUCTION}

joints confined with lateral beams isolated from the end bay of a multi-storey structure, between the points of contra-flexure. These points are assumed to be located at mid-height and mid-span of the columns and the beams, respectively.

To focus on the seismic behaviour of the joints, quasi-static reversed cyclic loads were applied to the specimens. One of the specimens is reinforced totally with steel as a control specimen while the others are reinforced with GFRP for both flexural and shear reinforcement. The main studied parameters include:

- Beam longitudinal bars end anchorage; both headed-end and bent bars are used;

- Different reinforcement materials; GFRP and steel are used;

- Different beam longitudinal reinforcement ratios; resulting in different joint shear stresses.

\subsection{Thesis Organization}

This thesis consists of six chapters. The contents of each chapter are as follows:

Chapter one presents a short introduction about the research subject, problem definition, scope of the work, research objectives, and work methodology.

Chapter two presents a literature review of the previous studies about seismic behaviour of steel-RC beam-column joints, and different parameters that can affect this behaviour. This chapter also provides a brief review of the research programs about structural behaviour of concrete elements reinforced with FRP material including those on beam-column joints.

Chapter three presents the design concept and method that is used in this program. 


\section{INTRODUCTION}

Chapter four presents details of the experimental program. Size and reinforcement detailing of the specimens, test set-up, instrumentations, and the test procedure are provided in this chapter.

Chapter five presents analyses and discussions of the test results. The results are provided in terms of lateral load-displacement response of the specimens, mode of failure, crack patterns, lateral stiffness, energy dissipation, and strains in the reinforcement.

Chapter six includes summary of the program, conclusions derived from the test results and recommendations for future work. 


\section{LITERATURE REVIEW}

\subsection{Background}

Beam-column joints play very important role in ensuring integrity of framed structures and transfer forces from one element to another. The flow of forces within beam-column joints may be interrupted if the joint does not have adequate strength. The response of ductile steel-RC beam-column joints to inelastic cyclic loading has been studied since 1960s. However, very few researches exist on such connections when they are totally reinforced with FRP reinforcement.

The early studies on behaviour of steel-RC beam-column joints were conducted by Hanson and Conner (1967) and their results have been used since as a benchmark for later studies. They concluded that designing shear reinforcement for connections according to the equations developed for RC beams would result in satisfactory performance of the connections under cyclic loading. This issue has been investigated by other researchers and the results were used by ACI-ASCE Committee 352, Joints and Connections in Monolithic Concrete Structures, to develop its first design guidelines in 1976. At that time, it was generally assumed that the shear capacity of a joint is the sum of the joint concrete and the steel stirrups capacity. The capacity of concrete was assumed to be a function of two main parameters: type of loading (seismic or nonseismic), and joint confinement (provided by lateral beams and slabs). The capacity of the stirrups was assumed to be similar to shear stirrups in beams.

Since the first studies in 1967, many researches have been involved in investigating the parameters that can affect behaviour of beam-column joints in seismic events. According to 


\section{LITERATURE REVIEW}

further investigations, the contribution of steel and concrete to the shear capacity of joints are not separate (ACI Committee 352 1985). It is now believed that the shear capacity of a beam-column joint is strongly related to confinement of the concrete in the joint core. This confinement can come from lateral beams (external confinement) or steel stirrups inside the joint (internal confinement). In other words, the shear reinforcement does not have direct contribution to the

shear capacity of the joint, but it is the confinement provided by the stirrups that can increase the shear capacity.

Current recommendations provide the nominal shear capacity of beam-column joints with different configurations of external confinement that have sufficient amount of shear reinforcement as internal confinement. Designers need to limit the applied shear stress to the joint to the nominal shear capacity. If the ultimate shear stresses in the joint exceed that limit, the dimensions of the connection should be increased to reduce the shear stress rather than providing more transverse reinforcement.

It should be mentioned that providing more confining reinforcement causes more congestion in beam-column joints. Although the attempt of reinforced concrete codes and guidelines has been to avoid reinforcement congestion in the joints, in some cases, joints designed according to this guideline are congested and difficult to construct.

\subsection{Research on Steel-RC Beam-Column Joints}

There are several studies conducted to investigate the effect of various parameters that can influence the performance of steel-RC beam-column joints. Review of these studies can establish better understanding of the behaviour of joints subjected to considerable reversal lateral loading. The following section presents some of those effective parameters. 


\section{LITERATURE REVIEW}

\subsubsection{Effect of loading rate}

Chung and Shah (1989) studied the effect of loading rate on the seismic behaviour of beamcolumn joints. The focus of the study was the effect of loading rate on the bond between reinforcement and concrete. Twelve anchorage-bond and three small-scale beam-column joint specimens were tested at rates varying from 0.0025 to $2.0 \mathrm{~Hz}$ considering several variables including shear-to-span ratio and stirrup spacing.

Test results showed that in the anchorage-bond specimens loaded with fast rate, the majority of cracks were diagonal shear cracks initiated near the support face at early stages of loading. While the cracks in the low-rate specimens were more in numbers, spread over a longer length of the beam, and consisted of both shear and flexural cracks. However; it seemed that the effect of loading rate on the load carrying capacity and damage to the specimens was influenced by the shear reinforcement spacing. The specimens with stirrup spacing equal to $d / 2$ showed lower load carrying capacity in fast rates, while the specimens with stirrup spacing of $d / 4$ maintained their low-rate capacity in higher rates of loadings.

Based on the observed strain distribution along the beams longitudinal bars, the authors explained this different behaviour as a result of loading rate effect on the bond strength between steel and concrete. The bond strength between embedded bars and concrete increased with increase in loading rates. This caused stress concentration along the bars which can produce larger cracks. Loss of aggregate interlock due to large crack width can explain premature failure of the specimens without sufficient shear reinforcement. This shear failure was brittle in comparison to more ductile mode of failure for the low-rate specimens. 


\section{LITERATURE REVIEW}

Ehsani and Wight (1985-a) performed an experimental program to study the behaviour of fullscale exterior beam-column joints under seismic loading. Test variables were: ratio of columnto-beam flexural capacity, applied joint shear stress, and amount of transverse reinforcement in the joints. Six specimens were isolated from assumed points of contra-flexure at mid-height of the columns and mid-span of the beams. Reversal lateral quasi-static cyclic loads were applied directly at the beams tip; simulating seismic loading. The specimens were tested while the columns were positioned in the horizontal direction and the beams were in the vertical direction. The following section provides a summary describing the effect of each test variable on the behaviour of beam-column joints.

\subsubsection{Effect of flexural strength ratio}

Using strong column-weak beam concept in designing a framed structure resisting seismic event has been suggested by almost all building codes. The logic behind this concept is to prevent the formation of a plastic hinge in the column, which can lead to structural instability and cause failure of the whole frame. The flexural strength ratio $\left(M_{R}\right)$, which is defined as the sum of flexural strengths of the columns over that of the beam, has a significant effect on the location of the plastic hinge. A flexural strength ratio greater than 1.0 is suggested in CSA A23.3-04 (CSA 2004) Clause 21.4.2.2.

In this program the specimens had $M_{R}$ ranging from 1.0 to 2.0. Test results showed that for $M_{R}$ slightly greater than 1.0, although the plastic hinge formed at the beam, considerable damage penetrated to the joint. This resulted in significant deterioration of bars anchorage and led to pullout of the beam longitudinal bars and slippage of the column reinforcement, which reduced the load-carrying capacity and stiffness of the specimens. On the other hand, in the specimens 


\section{LITERATURE REVIEW}

with flexural strength ratio considerably greater than 1.0 , the damage due to the plastic hinge was mainly in the beam and away from the joint. The authors suggested a ratio of 1.4 to avoid formation of plastic hinge in the joint.

\subsubsection{Effect of transverse reinforcement within the joint}

As it was mentioned before, higher percentage of transverse reinforcement in the joint $\left(\rho_{t}\right)$ can contribute to the joint strength by providing sufficient confinement. The test results also showed improvements in the behaviour of the specimens with higher $\rho_{t}$ in comparison to counterpart specimens with lower $\rho_{\mathrm{t}}$. However, the magnitude of this improvement was influenced by the flexural strength ratio. For the specimens with low $M_{R}$ where significant damage were induced to the joint due to formation of a plastic hinge near the joint, only a slight improvement was achieved in the flexural behaviour. However, in specimens with a plastic hinge formed away from the joint, the higher $\rho_{\mathrm{t}}$ made a significant improvement.

\subsubsection{Effect of shear stress in the joint}

The higher applied shear stress accelerates the rate of damage in the joint. This damage can cause early beams’ longitudinal bars pullout and slippage of column’s reinforcement, which have a significant effect on the load-carrying capacity of the joints.

In this program, the test specimens had joint shear stress ranging from $8.8 \sqrt{f^{\prime}}$ psi $\left(0.73 \sqrt{f^{\prime}{ }_{c}} M P a\right)$ to $15.2 \sqrt{f^{\prime}}$ psi $\left(1.27 \sqrt{f^{\prime}{ }_{c}} M P a\right)$. The authors suggested that in order to reduce excessive damage in the joint, maximum shear stress should be limited to $12 \sqrt{f^{\prime}}$ psi $\left(1.0 \sqrt{f^{\prime}} \mathrm{MPa}\right)$. This may reduce beam bars pullout and column bars slippage. However, test results showed that specimens with minor bar slippage and pullout at the higher loading stages 


\section{LITERATURE REVIEW}

also showed satisfactory behaviour. As a result, to some extent, the bar slippage and pullout can be acceptable.

It should be mentioned that all these three parameters $\left(M_{R}, \rho_{\mathrm{t}}\right.$, and joint shear stress) interact with each other. The effect of one parameter can be influenced by magnitude of the other parameters. In some cases, when one of the parameters is over conservative, the limit for the others can be relaxed.

\subsubsection{Effect of lateral beams and slab}

Ehsani and Wight (1985-b) performed another experimental program to study the effect of lateral beams and slabs on behaviour of beam-column joints. Six full-scale specimens were constructed to have the same design parameters as the previous study. As a result, the primary variables were the same (flexural strength ratio, percentage of transverse reinforcement in the joint and applied shear stress in the joint).

It should be mentioned that when the columns were loaded in the pushing direction both beam top bars and slab reinforcement were in tension, while in the pulling direction only beam bottom reinforcement were in tension. This resulted in unequal yield displacement for each loading direction. Comparing hysteresis diagrams for these specimens with their counterpart in the previous study indicated that the specimens without lateral beams and slab showed higher stiffness degradation. The authors believed that the reason can be the confinement provided by the lateral beams, which represents the major cause of the stiffness reduction, the beam bars pullout and the column bars slippage. Sufficient confinement of the joints with lateral beams led to lower shear cracks, which, consequently, helped in reducing bar slippage and pullout. 


\section{LITERATURE REVIEW}

The specimens had various flexural strength ratio $\left(M_{R}\right)$ ranging from 0.87 to 1.58 . The test results showed that there are three possible locations for the plastic hinges corresponding to the value of $M_{R}$. For a ratio less than 1.0, the plastic hinge occurred at the column above the joint, while for $M_{R}$ considerably greater than 1.0, the hinge formed in the beam away from the joint. However, when the ratio was slightly greater than 1.0, especially when the joint shear stress was high, cracks and damage due to the plastic hinge formation penetrated in to the joint. According to the test results the specimens with the hinge formed outside the joint, whether in the column or the beam, showed more stable behaviour in cyclic load-displacement response.

Another primary variable in this program was the percentage of transverse reinforcement in the joint $\left(\rho_{t}\right)$. Although the increase in transverse reinforcement in the specimens without lateral beams resulted in a significant improvement in the joints behaviour, in this program the specimens with different percentage of joint shear reinforcement showed very similar behaviour. The only benefit of having more joint reinforcement was the delay of bar slippage. It seems that due to sufficient confinement provided by lateral beams, the increase in the joint shear reinforcement did not significantly improve the behaviour.

The same trend was observed for the joint shear stress. The variable had less significant effect on the joint behaviour in comparison to the specimens without lateral beams. The authors found that it was due to the fact that some of the longitudinal bars, considered in applying shear stress to the joint, were actually anchored to the lateral beams. This means that some of the assumed shear stresses in the joint were resisted by the lateral beams and, as a result, there was lower stress applied to the joint than what was calculated. 


\section{LITERATURE REVIEW}

\subsubsection{Effect of detailing configuration}

In the previous sections, it was mentioned that when a framed structure is subjected to reversal lateral loads, inelasticity (plastic hinge) may be concentrated in the beam or the column (joint). It was also mentioned that the location of the plastic hinge depends on the ratio of the columns flexural strength to that of the beam. Furthermore, it was discussed that the magnitude of applied shear stress to the joint can affect the penetration of the plastic hinge damage to the joint. Beam reinforcement anchorage and joint reinforcement detailing are also two more parameters that can affect the location of the inelasticity concentration.

In order to have better understanding of the anchorage effect, it might be useful to review the stress transfer mechanism in the joint. Figure 2.1 shows the forces acting on the joint from the beam and the columns. From these forces the horizontal shear force applied to the joint can be calculated as:

$$
V_{j h}=T_{p r}-V_{\text {column }}
$$

The shear stress is calculated by dividing the horizontal shear force by the effective joint area. Figure 2.1 shows the principal stresses coming from the shear stresses in the joint. 


\section{LITERATURE REVIEW}

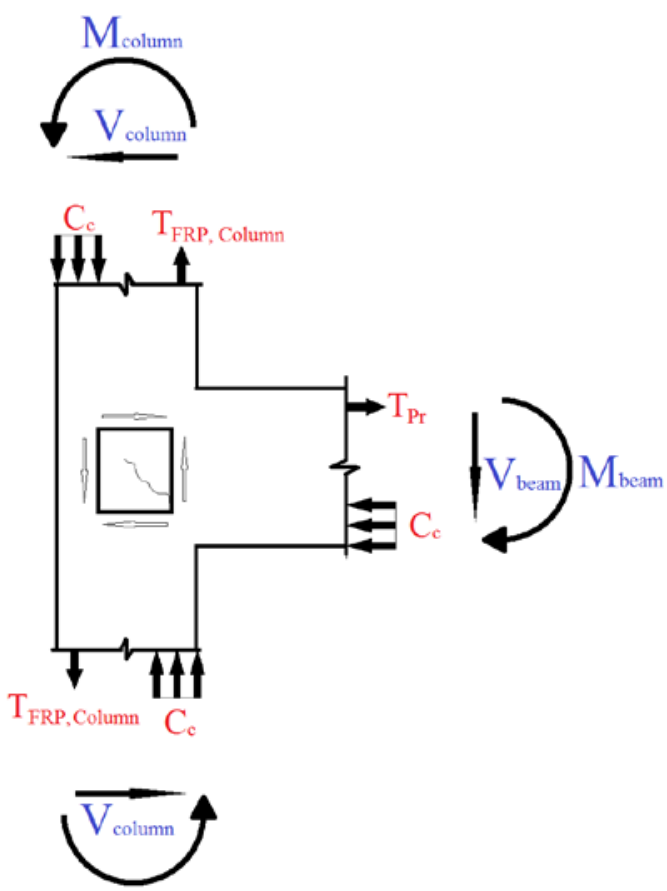

Figure 2.1 - Applied forces to an exterior beam-column joint (reproduced from Wight, J. and MacGregor, J. 2009)

When diagonal tension stress at the middle of the joint exceeds the tensile capacity of the concrete, tensile cracks appear. After initiation of cracks, strut-and-tie model shown in Figure 2.2 acts as the load transfer mechanism. Using bent bars as an anchorage method provides effective bearing for the compressive strut as the bearing stresses act in direction of the strut. Current design codes suggest bending beam longitudinal bars inside the joint; however, this may cause construction difficulties and joint reinforcement congestions. Bending of the bars outside the joint or using headed-end bars can cause ease of construction, but may not provide the best configuration to transfer the bars tensile forces to the compressive strut. The effect of using headed-end FRP bars instead of bend bars is one of the main objectives of this research. The following section provides some studies that have been carried out on the effect of reinforcement detailing on behaviour of steel-RC beam-column joints under seismic loading. 

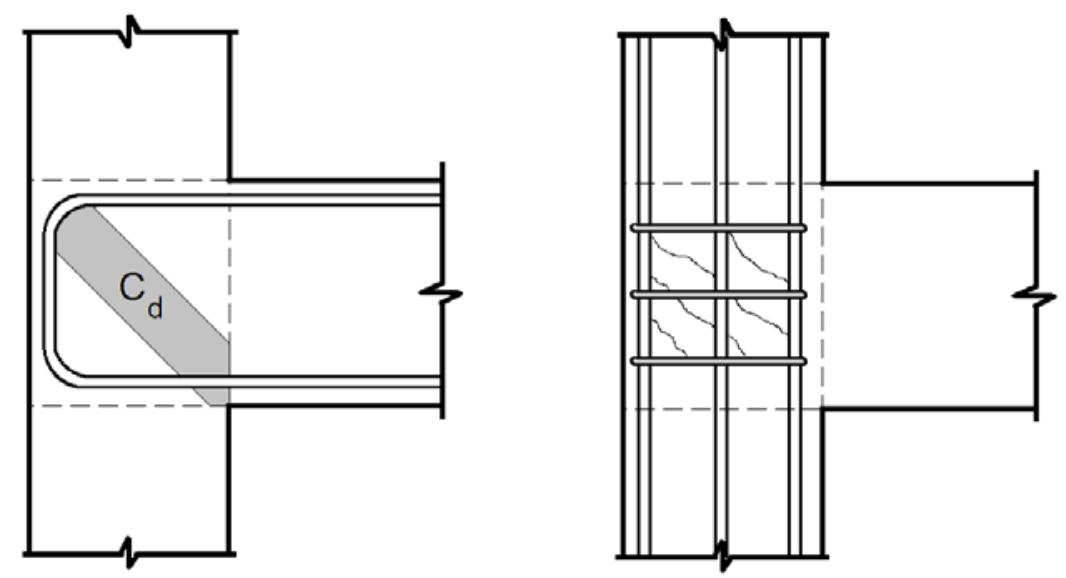

Figure 2.2 - Strut and tie model in exterior beam-column joints (reproduced from Hwang et al. 2005)

Hakuto et al. (2000) studied the behaviour of one-way interior and exterior beam column joints with substandard reinforcement detailing under seismic loading. Two exterior beam-column joints were constructed and tested in the study. The specimens were identical except for the beam bars anchorage method. In one of the specimens the bars were bent outside the joint with the tail length equal to four times the bar diameter, while in the other specimen, the bars were bent into the joint with the tail length equal to twelve times the diameter. The specimens were designed to have the plastic hinge in the beam. Both specimens; however, had small quantity of shear reinforcement in the joint.

Test results showed that the specimen with bars bent inside the joint had a stable and ductile lateral load-displacement response with the plastic hinge occurred in the beam, as it was expected. Despite the small number of shear reinforcement in the joint, the specimen was able to reach its design flexural capacity. The other specimen; however, couldn't achieve the beam design flexural capacity due to premature shear failure in the joint. 


\section{LITERATURE REVIEW}

In the specimen with the beam bars bent outside of the joint, after formation of diagonal tensile cracks, the compression strut could not effectively engage the hooks. Instead, it pushed against the column longitudinal bars and caused splitting cracks along the reinforcement. Joining diagonal cracks in the joint and the splitting cracks caused shear failure of the joint before reaching the design capacity.

Murty et al. (2003) studied the seismic performance of exterior beam-column joints with different reinforcement configurations that were common in non-seismic region constructions. Twelve specimens with four configurations for the beam longitudinal bar anchorage and three detailing of transverse reinforcement inside the joint were tested. Among them the test results for the four specimens with closed ties as shear reinforcement inside the joint and four different beam bars anchorage types are discussed here. Figure 2.3 shows these different reinforcement detailing.

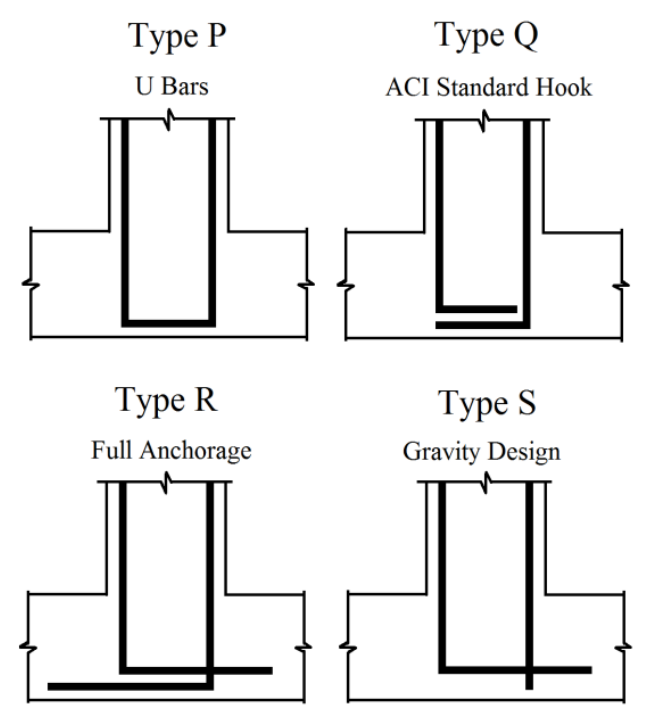

Figure 2.3 - Different anchorage method for beam longitudinal bars (reproduced from Murty et al 2003) 


\section{LITERATURE REVIEW}

The test results showed that bottom longitudinal bars in Type S specimen were pulled out because of short development length and poor anchorage. This resulted in severe pinching in the hysteresis diagram of the specimen. Among the different configurations, Type $\mathrm{R}$ anchorage showed the best performance considering strength and ductility of the joint. Type Q also showed similar behaviour to Type R. However, this type of anchorage was more preferable than Type R because of easier construction. Type P specimen on the other hand, not only showed low initial stiffness, but also had lower overall ductility in respect to the other specimens. The authors explained that tension in the beam bars was transformed to the beam compression concrete block in Type $\mathrm{P}$ and reduced the capacity.

Wallace et al. (1998) conducted an experimental program to evaluate the behaviour of exterior and knee beam-column joints reinforced with headed-end beam longitudinal bars. Two exterior beam-column joint specimens were tested. One of the specimens was designed according to Type 2 joint requirements of the 1991 version of ACI Committee 352 Report except that headedend reinforcement was used. The other specimen was designed based on requirements for a Type 1 joint that is part of non-seismic lateral-force resisting system. The behaviour of these two specimens was compared to the behaviour of the conventionally reinforced specimens in the study by Ehsani and Wight (1985a). Two side stub beams were used to represent the threedimensional effect of lateral beams on the exterior joints. No loading was applied on the stubs.

In the Type 2 specimen, damage was concentrated in the beam as it was expected. The specimen reached its design capacity in both directions. The overall behaviour of the specimen was satisfactory and similar to the counterpart specimen tested by Ehsani and Wight (1985a) using 90 degree-hook bars. At 6\% lateral drift ratio, the concrete over the reinforcement head was pushedoff which resulted in significant pinching, but the specimen maintained its carrying load 


\section{LITERATURE REVIEW}

capacity. It should be mentioned that $6 \%$ drift ratio is beyond the expected lateral movement for a reasonably designed frame. According to the test results, the authors recommended that using heads with an area equal to four times the bar area and embedded length of twelve bar diameter can provide satisfactory behaviour.

\subsection{FRP Bars as Reinforcement for Concrete Structures}

There are several methods that have been suggested to overcome the corrosion problem of embedded steel in concrete members. Among these methods, replacing steel reinforcement with a non-corrodible material is the most effective way to completely eliminate the corrosion process. FRP materials, especially Glass (G) FRPs, are one of the alternatives for steel that are economically attractive and can provide other advantages such as easier construction and nonelectrical and magnetic conductivity. In the past two decades, many researchers have been involved in investigating the behaviour of members reinforced with FRPs; however, there are many aspects still uncovered. The following section provides a brief overview of FRP characteristics and previous studies on the behaviour of FRP-RC elements that are related to this program.

\subsubsection{Characteristics of FRP reinforcement}

As mentioned earlier, it might be the corrosion resistance nature of FRP materials that makes them effective alternatives for conventional steel in RC structures; however, there are several other advantages in using FRP materials as a reinforcing medium:

- Their high strength-to-weight ratio (50 times that of concrete and 20 times that of steel); 


\section{LITERATURE REVIEW}

- They are less susceptible to environmental deterioration caused by exposure to marine environment, de-icing salt, and freeze-thaw cycles, which results in lower repair and maintenance costs over the life of structures in such environment;

- FRP's lighter weight saves on transportation coasts and results in easier and faster construction with less required man forces and equipment.

During the last 40 years FRP materials were used successfully in aerospace, automotive and marine industries, but due to their high cost, FRPs were not attractive for the construction industry. However, because of suitable properties and significant reduction in materials and manufacturing costs, FRP materials have been introduced as one of the construction materials in civil engineering in recent years. Since then FRPs are increasingly being used in civil infrastructures in applications ranging from:

- Reinforcing bars and tendons in new structures;

- Wrap and laminate for existing structures;

- Composite bridge decks;

- Composite structural system.

Since the mechanical and physical properties of steel and FRP are different, it is not possible to use current steel-RC codes and guidelines to design FRP-RC members. In order to establish an appropriate guideline for FRP-RC design, well understanding of these material characteristics is essential.

FRP bars in general are made of two main components:

- Fibers (Reinforcement) 


\section{LITERATURE REVIEW}

- Resins/Matrix (polymers)

An FRP product can be defined as a resin which is reinforced with fibers. The main function of the fibers is carrying load and providing strength. However, the fibers are able to carry loads only if they are oriented in the direction of the load. From the commercially available fibers, three are more common: 1) Carbon, 2) Aramid, and 3) Glass. The resin, on the other hand, is relatively soft in comparison with the fibers. However, existence of the resin is essential as they provide a matrix for the fibers. Three main functions can be mentioned for the resin:

- $\quad$ Transferring stresses between the fibers;

- Providing lateral support against buckling;

- Protecting the fibers from mechanical and environmental damage.

A wide variety of resins are available in the industry. The selection is based on physical and mechanical properties and the fabrication process requirements. The following sections introduce some of the main physical and mechanical characteristic of FRP bars.

\subsubsection{Density}

“Fiber Reinforced Polymer” bars have density ranging from 1250 to $2100 \mathrm{~kg} / \mathrm{m}^{3}$, which is four to six times lower than that of steel. Table 2.1 shows typical density of reinforcing bars.

Table 2.1- Typical density of FRP reinforcement (ACI 440.1R-06)

\begin{tabular}{|c|c|c|c|c|}
\hline Type & Steel & GFRP & CFRP & AFRP \\
\hline Density $\left(\mathrm{kg} / \mathrm{m}^{3}\right)$ & 7900 & 1250 to 2100 & 1500 to 1600 & 1250 to 1400 \\
\hline
\end{tabular}




\section{LITERATURE REVIEW}

\subsubsection{Stress-strain relationship}

Since the fibers can carry loads only in their own direction, FRP bars have unidirectional behaviour. Moreover, due to linear stress-strain relationship of the fibers, the bars have linear elastic behaviour up to failure and they do not exhibit any yielding plateau. Generally, FRP bars have higher strengths in tension and lower strength in compression than conventional black steel. This lower compression strength is due to buckling of fibers. FRP bars also have lower modulus of elasticity in comparison with steel ones.

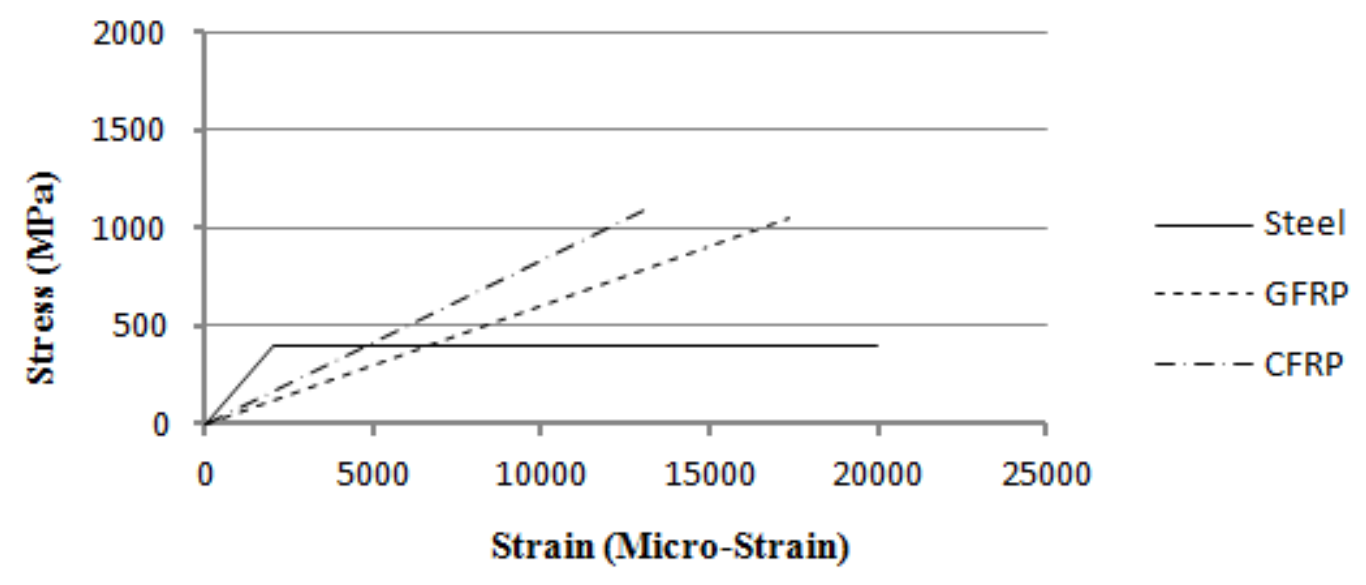

Figure 2.4 - Schematic stress-strain relationship of FRP reinforcement

\subsubsection{Bond}

Bonding behaviour of FRP bars embedded in concrete is a function of the manufacturing process, mechanical properties, environmental conditions, and bar stresses. The bond stress can be transferred between the bar and the surrounding concrete by: chemical bond, frictional resistance against slip, and mechanical interlock due to irregularity of the bar interface. 


\section{LITERATURE REVIEW}

\subsubsection{Bending FRP bars}

Except for FRP bars with thermoplastic resins, FRPs cannot be bent or reshaped after manufacturing. The deformation required for producing stirrups or bent bars should be done during the manufacturing process; however, a strength reduction of 40 to $50 \%$ relative to the tensile strength of a straight bar is expected at the bent portion. Even the straight portion of a bent bar has lower strength than a straight bar without any bent.

In contrary to steel products that have standard and certain expected properties, FRP bars properties depend on the type of fiber and resin used in the product and volumetric ratio of the fibers. Even products with the same components may have different properties if they are produced from different manufacturing process.

Investigating the behaviour of beam-column joints reinforced with FRP bars and stirrups requires a solid background about the behaviour of FRP-RC elements under axial, flexure, and shear loads. The following section represents a literature review on the behaviour of beams and columns reinforced with FRP bars in longitudinal and transverse directions.

\subsection{Structural Behaviour of Individual Elements Reinforced with FRP Materials}

\subsubsection{Flexural behaviour of concrete beams reinforced with FRP bars}

Studies showed that the main concepts and assumptions that are used for designing steel-RC beams for flexure can be also used for FRP-RC beams. However, FRP materials have linearelastic behaviour up to rupture, consequently concrete beams reinforced with them experience sudden failure if rupture of the bars is the mode of failure (under-reinforced sections). Considering this issue, it is logical to design FRP-RC beams to have the ultimate flexural failure in terms of concrete crushing (over-reinforced section). This mode of failure is considered to be 


\section{LITERATURE REVIEW}

less catastrophic than rupture of the bars. Moreover, usually in under-reinforced sections the cracking moment is very close to the ultimate moment capacity of the section, which increases the chance of sudden failure. It should be mentioned that the compression failure mode also defines the ultimate flexural limit state of steel-RC sections. Yielding of steel in under-reinforced sections does not represent the ultimate capacity as the section can go to larger deformations until crushing of concrete happens.

Many researches have been carried out on the behaviour of concrete beams reinforced with FRP bars. Brown and Bartholimew (1993) studied the flexural behaviour of FRP-RC members. The flexural behavior was studied by testing six small-scale simply supported FRP-RC beams under third-point loading. The specimens were reinforced with one $9.5 \mathrm{~mm}$ FRP bar as longitudinal reinforcement and steel stirrups as shear reinforcement.

The test results showed that the behaviour of the beams in many aspects were similar to what would be expected from steel-RC beams. The specimens showed non-brittle failure due to compression failure mode. It was concluded that the strength design method developed for steelRC beams can adequately predict the ultimate capacity of the specimens. The measured deflection of the specimens, on the other hand, was more than the anticipated deflection for the corresponding steel-RC beams. The lower stiffness of FRP bars caused larger deflections and wider cracks in the specimens. However, it should be noted that due to non-corrosive feature of FRP bars, the maximum allowable crack width can be increased.

Benmokrane et al. (1996) compared the flexural behaviour of concrete beams reinforced with FRP reinforcing bars with identical beams reinforced with steel. The cracking behaviour, load- 


\section{LITERATURE REVIEW}

carrying capacity, mode of failure, load-deflection response, strain distribution, and flexural rigidity of the specimens were compared to each other.

Eight 3300-mm-long concrete beams with 200-mm width and 300-mm height were tested. Four specimens were reinforced with FRP longitudinal bars and four were reinforced with steel. Each of the eight beams were reinforced with two longitudinal reinforcing bars (either steel or FRP) and steel stirrups. The beams were tested under four-point load condition.

The authors used the traditional equations for calculating the ultimate moment capacity as well as balance moment and mode of failure. Following equations were used for calculating balance reinforcement ratio:

$$
\begin{aligned}
\rho_{b}^{F R P} & =\frac{0.85 * \beta_{1} * f^{\prime}{ }_{c}}{f_{f y}}\left(\frac{\varepsilon_{c u}}{\varepsilon_{c u}+\varepsilon_{f y}}\right) \\
\rho_{b}^{\text {steel }} & =\frac{0.85 * \beta_{1} *{f^{\prime}}^{\prime}}{f_{y}}\left(\frac{\varepsilon_{c u}}{\varepsilon_{c u}+\varepsilon_{y}}\right)
\end{aligned}
$$

From this, compression failure for over-reinforced beams and tension failure for underreinforced beams was expected. Theoretical ultimate moments also were simply computed using the following formulas for FRP-RC and steel-RC beams, respectively:

$$
\begin{aligned}
& M_{r_{t h}}^{F R P}=A_{f} * f_{f y}\left(d-\frac{a}{2}\right) \\
& M_{r_{t h}}^{\text {steel }}=A_{s} * f_{y}\left(d-\frac{a}{2}\right)
\end{aligned}
$$

The rectangular stress block was used to calculate concrete compression depth in the specimens with compression failure mode (Equation 2.6). However, in the case of tension failure mode, Equation 2.7 was used to calculate the value of “a”: 
LITERATURE REVIEW

$$
\begin{gathered}
\left(\frac{0.85 f_{c}^{\prime}}{\rho * E_{f} * \varepsilon_{c u}}\right) a^{2}+(d) * a-\beta_{1} * d^{2}=0 \\
a=\frac{A_{f} * f_{f y}}{0.85 * f_{c} * b}
\end{gathered}
$$

The results of this investigation showed reasonable agreement between the obtained moments and the calculated moments from the theoretical part, indicating the validity of using this method for calculating the ultimate capacity and mode of failure for FRP-RC beams.

Regarding the crack pattern, the FRP-RC specimens showed similar crack spacing as the corresponding steel-RC specimens up to $25 \%$ of the ultimate moment capacity, which may be considered as the service condition. However, for higher moments, more and wider cracks were observed in the FRP-RC specimens due to lower stiffness of the reinforcement.

\subsubsection{Shear strength of concrete beams reinforced with FRP stirrups}

Stirrups, commonly located closer to concrete surface, are more vulnerable to environmental effects. Using FRP shear reinforcement can be an effective application to reduce the environmental effects, especially in structures exposed to harsh environments such as marine structures or parking garages and bridges.

In addition to the different mechanical properties of FRP materials compared to steel, the reduction in the ultimate capacity of stirrups due to bending the fibers is a major concern. Many researches have been conducted to study the capacity reduction at bent portions and different parameters that can affect stirrups strength such as bent radius, tail length, and bar diameter. However, in this program the focus is on the structural behaviour of the elements reinforced with FRP, consequently, only some studies about the structural behaviour of beams reinforced with FRP stirrups have been provided here. 


\section{LITERATURE REVIEW}

Shehata et al. (2000) studied structural performance of FRP stirrups. A total of ten large-scale RC beams were tested in part of this study to investigate the behaviour of the elements in shear when they are reinforced with FRP stirrups. Four beams were reinforced with GFRP stirrups, four with CFRP stirrups, one with steel stirrups, and one without shear reinforcement as a control specimen. Test variables were: material type of stirrups, material type of longitudinal reinforcement, and stirrups spacing. All beams were designed to fail in shear. In the specimens with steel flexural reinforcement, the bars were designed to remain in the elastic range to be comparable with the linear behaviour of FRP.

Test results indicated that concrete contribution in shear carrying capacity is lower in the specimens with CFRP flexural reinforcement in comparison with those reinforced with steel. The reason is that using FRP flexural reinforcement causes smaller depth of compression block, less dowel action, and wider cracks, which reduce the concrete shear carrying part.

Comparing the shear crack width of the specimens with stirrups spacing of $d / 2$, the results indicated that the CFRP-RC specimen had larger cracks than the GFRP-RC specimen, despite of higher stiffness. Also it was indicated that by using equivalent GFRP shear reinforcement, $\rho_{F R P, v}\left(E_{F R P, v} / E_{S}\right)$, the specimens behaved similar to the steel-RC one. The authors proposed following equations for calculating the shear capacity of beams reinforced with FRP:

$$
\begin{gathered}
V_{r f}=V_{c f}+V_{s f} \\
V_{c f}=0.2 \lambda \varphi_{c} \sqrt{f^{\prime}{ }_{c}} b_{w} d \sqrt{\frac{E_{f l}}{E_{s}}}
\end{gathered}
$$

Equation 2.8 
LITERATURE REVIEW

$$
V_{s f}=0.4 \varphi_{f} f_{f u v} \frac{A_{f v} d}{s}<0.8 \lambda \varphi_{c} \sqrt{f^{\prime}{ }_{c}} b_{w} d \sqrt{\frac{E_{f v}}{E_{s}}} \quad \text { Equation } 2.10
$$

It should be mentioned that in contrast with steel bars that have almost the same standard properties all around the world, mechanical and bond properties of FRP bars and stirrups depends on the manufacturing process. Even a product produced from the same components but in different companies may have different characteristic. Consequently any product comes with a special data sheet from the manufacturer. During recent years, significant improvements in general characteristics of FRP materials have been achieved.

El-Sayed et al. (2007) studied the shear performance of concrete beams reinforced with carbon (C)FRP stirrups. The program consisted of two phases. In Phase 1, twelve stirrups from different products and with different detailing were embedded in two concrete blocks and tested under tension by pushing the blocks away from each other. Test variables were: tail length, stirrups anchorage, bar diameter, and embedded length. The objective was selecting the desirable product and detailing. In Phase 2, two full-scale reinforced concrete T-beams were constructed and tested to study the structural behaviour of the stirrups. The beams were reinforced with steel flexural reinforcement and CFRP stirrup. The only variable was spacing of the stirrups, $d / 2$ in one of the specimens and $d / 3$ in the other.

Both specimens failed in flexure by yielding of steel reinforcement followed by concrete crushing. Stirrups strain in both specimens was similar before cracking of concrete. After cracking, as expected, the specimen with larger spacing experienced higher stress in the stirrups. However, in both specimens the maximum stress in the stirrups was lower than their ultimate tensile capacity. The maximum strain of the stirrups at failure of the beam was 2850, and 1860 micro-strain for the specimen with $d / 2$ spacing and $d / 3$ spacing, respectively. Although the 


\section{LITERATURE REVIEW}

maximum strain was below the design limit of 4000 micro-strain proposed in ACI 440.1R-03 (ACI Committee 440 2003), increase in spacing from $d / 3$ to $d / 2$ almost doubled the maximum strain.

The shear crack width was also measured in the study. The specimen with smaller spacing showed smaller crack width. This behaviour was expected since shear reinforcement increases stiffness of beams in transverse direction.

\subsubsection{Columns reinforced with FRP bars}

Paramanantham (1993) performed one of the first studies on the behaviour of columns reinforced with FRP materials. The objective of the test was developing equations for concentric and eccentric capacity of columns. Specimens reinforced with GFRP bars were tested in the program.

For the columns with concentric axial load, the capacity of the column $\left(P_{n}\right)$ was calculated as:

$$
P_{n}=0.85 f^{\prime}{ }_{c}\left(A_{g}-A_{f}\right)+0.003 E_{f} A_{f}
$$

${f^{\prime}}_{c}$ : Concrete compressive strength;

$A_{g}:$ Gross cross sectional area;

$A_{f}$ : Area of FRP bars;

$E_{f}$ : Tensile modulus of elasticity of FRP bars;

In the case of eccentric loading: 
LITERATURE REVIEW

$$
P_{n}=C_{c}+C_{F}-T_{F}
$$

The force carried by concrete: $C_{c}=0.85 f^{\prime}{ }_{c} \beta_{1} a b$

The force carried by the bars in compression: $C_{f}=0.5 A_{f} \varepsilon^{\prime}{ }_{c} E_{f c}$

The force carried by the bars in tension: $T_{f}=0.5 A_{f} \varepsilon_{t} E_{f}$

$\beta_{1}$ : Ratio of depth of rectangular compression block to depth of the neutral axis;

$a$ : depth of equivalent rectangular stress block;

$b$ : width of compression face of the member;

$\varepsilon^{\prime}:$ Compressive strain of FRP bars;

$E_{f c}$ : Compressive modulus of elasticity of FRP bars;

$\varepsilon_{t}$ : Tensile strain of FRP bars.

Alsayed et al. (1999) tested a total of 15 rectangular concrete columns to investigate the influence of replacing longitudinal and transverse steel reinforcement by an equal volume of glass FRP reinforcement on the behaviour of the columns under uniform distributed axial load. All specimens were identical except for the type of longitudinal and transverse reinforcement. The effects of the reinforcement type on the axial capacity and deformation of the columns were studied.

The authors used the modified version of Equation 10.2 in ACI 318-95 (ACI Committee 318 1995) to predict the axial capacity of the columns:

Steel-RC columns: 
LITERATURE REVIEW

$$
\begin{array}{lll}
P=0.85 f^{\prime}{ }_{c}\left(A_{g}-A_{s t}\right)+f_{y} A_{s t} & \text { for } \quad \varepsilon_{s} \geq \varepsilon_{y} & \text { Equation 2.13 } \\
P=0.85 f^{\prime}{ }_{c}\left(A_{g}-A_{s t}\right)+\varepsilon_{s} E A_{s t} & \text { for } \quad \varepsilon_{s}<\varepsilon_{y} & \text { Equation 2.14 }
\end{array}
$$

GFRP-RC columns:

$$
P=0.85 f_{c}^{\prime}\left(A_{g}-A_{s t}\right)+0.6 f_{u f} A_{s t} \quad \text { for } \quad \varepsilon_{f} \geq 0 \quad \text { Equation } 2.15
$$

Comparison of the test results with these equations showed a $10 \%$ error in predicting the capacity of the columns reinforced with steel longitudinal bars. However, the error for GFRP-RC columns was $12 \%$.

The test results showed that, up to $80 \%$ of the ultimate capacity, the specimens with GFRP ties had similar behaviour to that without any transverse reinforcement. This was due to the relatively low stiffness of the GFRP materials. However, at higher loads, GFRP ties provided effective lateral confinement to the concrete and reduced lateral expansion. This resulted in increase in the ultimate capacity of the columns. This behaviour can be compared to specimens with steel ties in which the lateral reinforcement was effective since the start of loading. These specimens had lower axial shortening with respect to the other specimens.

Using GFRP bars instead of steel reinforcement reduced the capacity of the columns. Columns with GFRP longitudinal bars had 13\% decreased in the axial capacity and the specimens with GFRP ties showed $10 \%$ decrease in axial capacity.

Choo et al. (2006) conducted a research program to investigate the behaviour of concrete columns reinforced primarily with longitudinal FRP bars. One of the main tasks performed in the research was development of axial load-moment curvature relationships to predict the behaviour of FRP-RC column cross sections. 


\section{LITERATURE REVIEW}

The authors suggested that the assumptions used for determining strength interaction diagrams for steel-RC columns are applicable for FRP-RC column cross sections. These assumptions are:

1. Plane sections remain plane under bending, so that the strain in concrete and reinforcement is proportional to the distance from the neutral axis;

2. Perfect bond exists between reinforcement and surrounding concrete; and

3. Tensile strength of concrete can be neglected.

The procedure for constructing the axial load-moment-curvature relationship was summarized as follow:

1. Dividing the cross section of the column into $N$ number of strips. The location of the neutral axis also should be assumed;

2. Assuming a value $\varepsilon_{c}$ (strain at the outermost concrete fiber in compression);

3. Assuming linear strain distribution, strain at the center of all the strips in compression and longitudinal bars can be calculated (Figure 2.5).

4. Having the stress-strain relationship for the concrete and reinforcement, corresponding stresses and forces can be calculated;

5. Based on force equilibrium, resultant axial load (P) and moment (about centre of the section can be calculated. The curvature $\varphi$ is calculated as: $\varepsilon_{c} / k d$. $k d$ is equal to the distance from the outermost fiber in compression to the neutral axis; and

6. Increasing the value of $\varepsilon_{c}$ by a small amount, $\Delta \varepsilon_{c}$, and repeating steps 4 to 6 again. 


\section{LITERATURE REVIEW}

Steps 4 through 6 were repeated until the ultimate compressive strain $\varepsilon_{c u}$ was reached. After that, a new location of the neutral axis was selected and the procedure was repeated from Step 2. It should be mentioned that in this procedure concrete stress-strain relationship presented by Ford et al (1981) used to model the instantaneous short-term concrete stress-strain behaviour.
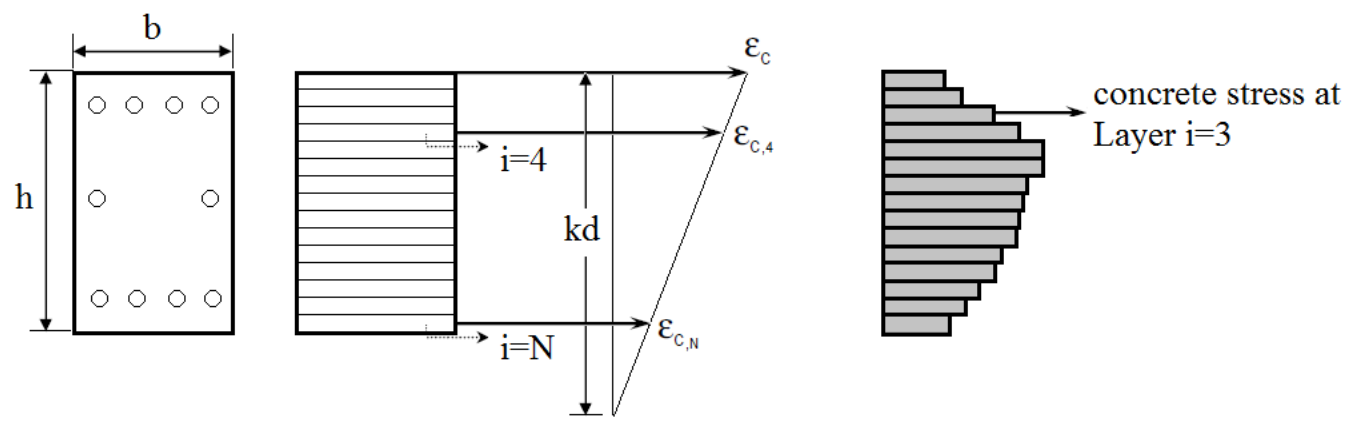

Figure 2.5 - Proposed method of constructing FRP-RC columns interaction diagram (reproduced from Choo et al. 2006)

\subsection{Feasibility of Using FRP-RC Beam-Column Joints in Seismic Regions}

During the past decades many experimental investigations have been conducted to verify behaviour of different concrete elements reinforced with FRP. These studies usually involve investigating behaviour of individual FRP-RC members such as simply-supported beams, slabs, and columns. However, it seems that more researches should be conducted on integral performance of FRP-RC framed structures, especially those subjected to seismic loading. FRP's lack of ductile behaviour, as a result of the linear elastic stress-strain relationship of the materials and lower modulus of elasticity, results in significantly different stiffness, damping, and energy dissipation characteristics for FRP-RC structures.

One of the main parameters resulting in a satisfactory seismic performance of a joint is the magnitude of energy dissipation. The amount of energy consumption is represented by the area enclosed by the moment-curvature graph of a structural element. In steel-RC structures yielding 


\section{LITERATURE REVIEW}

of steel exhibits desirable ductility and energy consumption. This phenomenon is not applicable for FRP materials, which behave in a linear-elastic manner up to failure. However, due to their lower modulus of elasticity and higher strength, FRPs experience large deformation prior to failure. This large deformation is called "deformability". Recent researches that have been conducted on GFRP-RC beam-column joints indicated that high deformability allows GFRP-RC frames to dissipate a reasonable level of seismic loads energy.

The following section provides a brief review of the investigations that have been carried out on feasibility of using FRP-RC beam-column joints in seismic regions.

Fukuyama et al. (1995) investigated the possibility of using FRP materials as longitudinal and transverse reinforcement in the concrete structures that should resist lateral loads. The experimental study was carried out on the seismic behaviour of a half-scale three-storey concrete frame. Structural performance of the frame was compared with analytical behaviour of a frame with the same dimensions, but assuming to have conventional steel reinforcement instead.

The beams in the frame were reinforced with a ratio of $0.64 \%$ and $0.48 \%$ for positive and negative moment, respectively. The columns had a constant ratio of $1.47 \%$ in all stories. To reduce the number of affecting parameters no hooks or lap splices were used for the main reinforcement.

According to the test results, three stages can be considered in the structure's behaviour:

- Drift ratio less than $0.5 \%$ : elastic range before cracking;

- Drift ratio between $0.5 \%$ and 2\%: stable plastic behaviour due to growth of cracking in members; 


\section{LITERATURE REVIEW}

- Drift ratio greater than 2\%: unstable performance with major reduction in stiffness due to crushing of concrete.

The results of the experimental and the analytical studies proved that it is possible to design FRP-RC members to be able to resist lateral loads. The frame remained elastic and showed small loop areas in lateral load-angle of rotation diagram. A stable hysteresis diagram, until 1/50 radian rotation, was reached when crushing of the concrete began.

The author concluded that it is easy to rehabilitate an FRP-RC frame that has undergone major deformations, since residual deformations of the frame are small. This indicates that limitations for the ultimate deformations can be less stringent for FRP-RC than those for steel-RC structures.

A non-linear analysis was performed for the tested structure and one imaginary structure same as the tested one but reinforced with steel reinforcement instead of FRP. The comparison of the results indicated that at a specific level of drift, the FRP-RC frame was stronger than its counterpart frame reinforced with steel.

Said \& Nehdi (2004) compared seismic performance of an exterior T-shape beam-column joint totally reinforced with GFRP and another joint totally reinforced with steel. The specimens were identical except for reinforcement configurations. The area of the beam longitudinal reinforcement in the GFRP-RC specimen was selected to provide the same flexural capacity as the control steel-RC specimen; consequently, the same shear stress was applied to the joints. The specimens then were tested under reversal cyclic loading 


\section{LITERATURE REVIEW}

The test results showed that the GFRP-RC beam-column joint showed very low plasticity features. This resulted in lower energy dissipation of GFRP-RC specimen compared to the conventional steel-RC one. Also the GFRP-RC beam-column joint showed lower stiffness. This behaviour is attributed to the linear stress-strain relationship of FRP materials and heir lower stiffness.

Despite of lower drift capacity of GFRP specimen than steel, the GFRP-RC specimen showed satisfactory drift capacity, according to the minimum required ductility for a ductile frame building recommended by codes and guidelines, mostly 3\%.

Mady et al. (2009) conducted a research program to study the seismic behaviour of exterior beam-column joints reinforced with GFRP bars and stirrups. Several specimens have been tested among which test results of two specimens are provided here. One prototype totally reinforced with conventional steel reinforcement and another totally reinforced with GFRP bars and stirrups were tested under reversal lateral quasi-static loading to compare the seismic behaviour.

The test results showed that GFRP bars and stirrups can be used as reinforcement for beamcolumn joints subjected to seismic loadings. The GFRP-RC specimen could reach $4 \%$ drift ratio without any permanent damage, which showed that large elastic strain of FRP materials can compensate part of the ductile behaviour of steel reinforcement in seismic regions.

\subsection{Effect of Anchorage Type on Behaviour of Beam-Column Joints}

Hasaballa et al. (2011) performed a test program to further investigate seismic performance of GFRP-RC exterior beam-column joints. Four full scale exterior T-shape joints were constructed and tested under simulated seismic loading. Test parameters were the type of longitudinal and transverse reinforcement as well as detailing of beam longitudinal reinforcement. 


\section{LITERATURE REVIEW}

One control specimen (S0) reinforced with steel was designed according to CSA A23.3-04 (CSA 2004). Beam longitudinal reinforcement was bent in to the joint according to CSA standard hook detail. One of the specimens (G1) had GFRP bars as longitudinal reinforcement and steel stirrups as transverse reinforcement. Same as S0, beam longitudinal bars in G1 were bent into the joint with 90 degree hook. Another specimen (G2) was constructed totally reinforced with GFRP bars for both longitudinal and transverse reinforcement. Straight bars were used as beam longitudinal bars. The last specimen (G3) was identical to G2 except that beam bars were extended in to 200mm stub to provide better anchorage.

The test results showed that both Specimen G1 and G3 showed acceptable behaviour regarding anchorage of the beam longitudinal bars, while bar slippage occurred in specimen G2.

Measured capacity of specimen G1was in good agreement with the designed capacity; however, failure of the specimen occurred due to failure in some of the lap splices of beam longitudinal bars. This slippage resulted in tension increase in the other bars and led to failure of the specimen by rupture of FRP bars, despite of compression failure design. Specimen G2, on the other hand, failed due to beam bars slippage because of insufficient anchorage length inside the joint. As a result of premature slippage of the bars, the specimen didn't reach its designed capacity. However, the behaviour of specimen G3 showed that increasing the development length of straight bars by adding 200-mm stub on the other side of the joint can provide sufficient anchorage. The specimen reached its full designed compression failure capacity. 


\section{DESIGN PROCEDURE}

\subsection{Background}

Three general structural systems, for resisting lateral forces, are used in the construction: 1) shear wall systems, 2) moment-resisting frame systems, and 3) dual systems (consisting of a combination of shear walls and moment-resisting frames that work together). Desirable seismic load resistance structure is the one with the ability of avoiding sudden collapse and absorbing earthquakes seismic energy. Ductility is one of the main features of such frames. More ductile structural systems can be safely designed for lower seismic forces than systems with limited ductility. This is handled by defining a response modification coefficient, $\mathrm{R}$, which is larger for more ductile structural systems. In general, shear wall systems are less ductile than either moment-resisting frames or dual systems.

Gravity loads in a structure are collected by means of slabs, and beams transfer these forces to columns at the location of joints. Finally, columns carry all loads and transfer them to foundations. Consequently, any damage to columns can cause part of a frame or even whole structure collapse. To avoid forming plastic hinges in columns during earthquakes with high deformations, strong column-weak beam concept shall be considered in the design process. It means that the summation of columns flexural capacities must be more than the summation of flexural capacities of the beams that are connected to the same joint. 


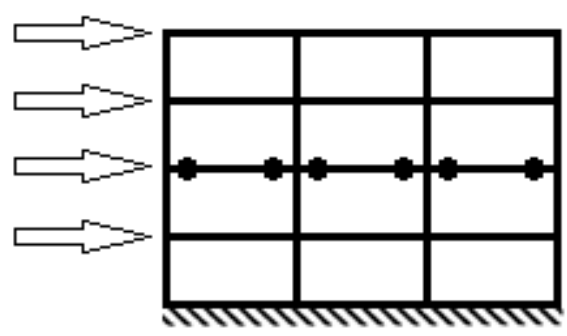

(a)

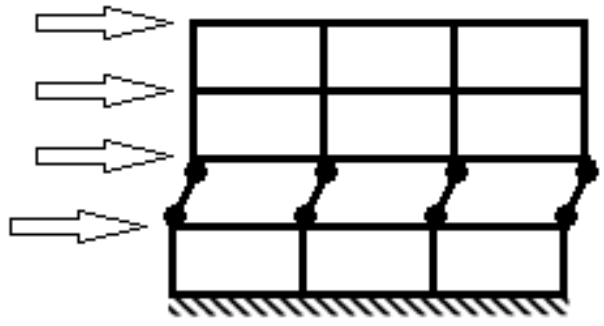

(b)

Figure 3.1 - (a) formation plastic hinge at beams, (b) formation of plastic hinge at columns (reproduce from Murty, C., Rai, D., Bajpai, K. and Jain, S. 2003)

All the calculations related to isolated beams and columns are based on the assumption that they can be joined together to develop continuity. To achieve this assumption in a structure, beamcolumn joints should be designed to have more capacity than any other adjoining members. This is to ensure that failure in joints will not cause collapse of structures, and frames will show integral behaviour under loading.

Park and Paulay (1975) described that a joint with satisfactory performance should have the following features:

- Strength of a joint should not be less than that of the adjoining members, and the joint should be able to sustain the most critical load comminutes that the adjoining members can be subjected to.

- Also ease of construction should be taken in to account since performance of a joint can be affected if the member is congested with reinforcement. 
DESIGN PROCEDURE

\subsection{Analysis of Forces}

The function of beam-column joints in a frame is to transfer loads and moments at beams ends in to columns. Consequently, in order to design a joint, designers should know the forces that are transferred trough the joint and the likely ways that the transfer can occur.

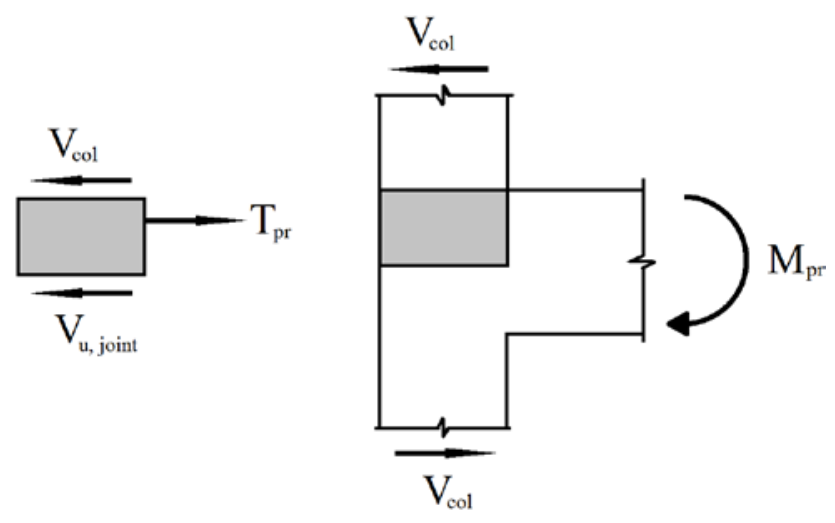

Figure 3.2 - Calculation of shear in joint (reproduced from Wight, J. and MacGregor, J. 2009)

The shaded area in Figure 3.2 shows the upper half of an exterior beam-column joint in a reinforced concrete frame that the upper column is deflecting to the left side in response to the loads. The free-body diagram of the shaded area is also shown in Figure 3.2. The horizontal shear at the mid-height of the joint can be calculated as:

$$
V_{j h}=T_{p r}-V_{c o l}
$$

Equation 3.1

The joint shear is equal to the probable force in the beam reinforcement that is entered to the joint, minus the shear applied to the joint due to sway of the column. The column sway shear, $V_{c o l}$, can be obtained from frame analysis. For most of practical cases the points of contraflexure are assumed to be located at the mid-height of each story. A rational estimation of $V_{c o l}$ can be achieved by using basic static equilibrium relationships: 
DESIGN PROCEDURE

$$
V_{c o l}=\frac{M_{b}+0.5 * t * V_{b}}{l_{p c}}
$$

$M_{b}$ : Flexural moment applied at the beam end,

$V_{b}$ : Shear force applied at the beam end,

$t$ : Column depth,

$l_{p c}$ : The distance between contra-flexure points in the columns above and below the joint,

As it was mentioned before, the force $T_{p r}$ is the tension in the reinforcement in the beam at its maximum probable capacity. For steel-RC elements $T_{p r}$ is calculated as:

$$
T_{p r}=\alpha A_{s} f_{y}
$$

Factor $\alpha$ is intended to account for the strain-hardening of steel. It is taken to be at least 1.25 for Type-2 frames, which require considerable ductility. However, since there is no strain hardening in FRP materials, $T_{p r}$ is corresponding to the nominal capacity of the beam.

\subsection{Design Procedure for Beam-Column Joints Reinforced with GFRP Bars and Stirrups}

Design procedure for beam-column joints subjected to seismic loading has been well established for steel-RC structures. Current steel-RC seismic codes provide connections with acceptable energy dissipation through reversal deformations into the inelastic range. On the other hand, there are no comprehensive provisions for seismic designing of FRP-RC beam-column joints.

The following section introduces a summary of the proposed design procedure introduced by Hasaballa (2009). The same procedure was used to design the specimens of this study. Detailed design calculations of test specimens are provided in Appendix A and Appendix B. 
DESIGN PROCEDURE

\subsubsection{Design for flexure}

As it was previously mentioned in Chapter 2, the general flexural behaviour of FRP-RC members is comparable to the behaviour of steel-RC ones. However, different mechanical properties of FRP materials from steel, such as: linear stress-strain relationship and lower compressive strength, must be considered in the design process. The following assumptions are made for flexural design of FRP-RC members (basic assumptions are similar to steel-RC members):

- Plane sections remain plane under bending, so that the strain in the concrete and reinforcement is proportional to the distance from the neutral axis;

- The failure strain of concrete in compression is 0.0035 ;

- FRPs are linear elastic to failure;

- $\quad$ Perfect bond exists between the reinforcement and surrounding concrete;

- The tensile strength of concrete is neglected; and

- $\quad$ Compressive strength of FRP bars is neglected.

Sudden failure prevention is a major concern in seismic design. In steel-RC structures this can be achieved by high deformation of yielded steel. Due to FRP's linear behaviour CSA S806-12 (CSA 2012) suggested a flexural design based on the compression failure mode through crushing of concrete. This mode of failure provides better deformability of concrete sections (based on the inelastic behaviour of concrete before crushing) compared to the brittle (sudden) failure due to rupture of FRP bars. 


\section{DESIGN PROCEDURE}

In general, three main flexural modes of failure can be defined for any FRP-RC section:

- Balanced mode of failure: the outermost fibre of FRP reinforcement and outer most fibre of compressive concrete block reach their ultimate strains simultaneously. In this case the reinforcement ratio is defined as balanced reinforcement ratio $\left(\rho_{F R P, b}\right)$. This is a hypothetical case.

- Compression mode of failure (over-reinforced section): occurs when the outermost fibre of concrete reaches the ultimate compressive strain of the concrete $\left(\varepsilon_{c u}=0.0035\right)$ before the outermost fibre of FRP reinforcement reaches its ultimate tensile strain $\left(\varepsilon_{F R P, u}\right)$. In this case the reinforcement ratio provided in the section $\left(\rho_{F R P}\right)$ should be greater than the balanced reinforcement ratio $\left(\rho_{F R P, b}\right)$.

- Tension mode of failure (under-reinforced section): occurs when the outermost fibre of FRP reinforcement reaches its ultimate tensile strain before the outermost fibre of concrete reaches the ultimate compressive strain of the concrete. In this case the reinforcement ratio $\left(\rho_{F R P}\right)$ should be less than the balanced reinforcement ratio $\left(\rho_{F R P, b}\right)$.

From force equilibrium equations, the balanced reinforcement ratio is calculated by:

$$
\rho_{F R P, b}=\alpha_{1} * \beta_{1} * \frac{\phi_{c}}{\phi_{F R P}} * \frac{f_{c}^{\prime}}{f_{F R P, u}} *\left(\frac{\varepsilon_{c u}}{\varepsilon_{c u}+\varepsilon_{F R P, u}}\right)=\frac{A_{F R P}}{b_{w} * d} \quad \text { Equation } 3.4
$$

$\rho_{F R P, b}:$ FRP balanced reinforcement ratio (\%)

$\phi_{F R P}:$ FRP reinforcement resistance factor

$f_{F R P, u}$ : The ultimate tensile strength of FRP reinforcement

$\varepsilon_{c u}$ : The ultimate compressive strain of concrete 


\section{DESIGN PROCEDURE}

$\varepsilon_{F R P, u}$ : The ultimate tensile strain of FRP bars

$A_{F R P}:$ Area of FRP longitudinal reinforcement

It should be mentioned that Equation 3.4 is applicable to a sections with one layer of reinforcement. If more than one layer of bars exists, corresponding tensile stress for each layer should be considered in the design. In other word, multiple layers cannot be converted to one lumped layer.

From force equilibrium and strain compatibility (Figure 3.3) stress at FRP reinforcement can be calculated as below:

$$
f_{F R P}=\frac{1}{2} * E_{F R P} * \varepsilon_{c u} *\left[\left(1+\frac{4 * \alpha_{1} * \beta_{1} * \varphi_{c} * f_{c}^{\prime}}{\rho_{F R P} * \varphi_{F R P} * E_{F R P} * \varepsilon_{F R P}}\right)^{0.5}-1\right] \quad \text { Equation } 3.5
$$

Detailed calculations of the beam flexural design for one of the GFRP-RC specimens can be found in Appendix A.

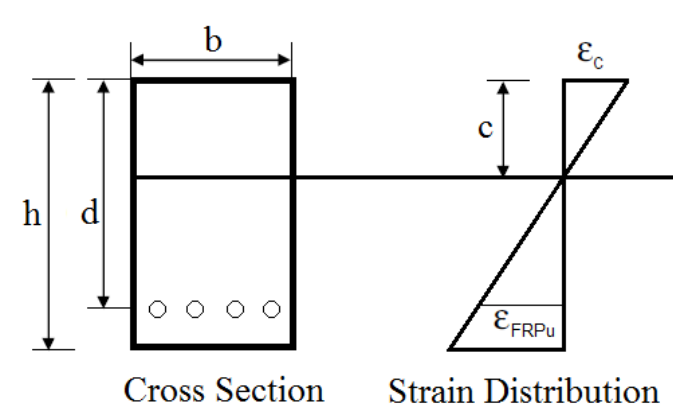

Cross Section Strain Distribution

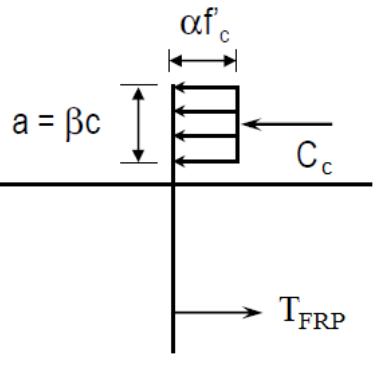

Loads

Figure 3.3 - Force equilibrium and strain compatibility

Similar to steel-RC columns, axial load applied on a FRP-RC column influences its flexural capacity (Choo et al. 2006). This influence can be found from the axial load-moment interaction diagram. The interaction diagrams for the specimens in this program were drawn according to 


\section{DESIGN PROCEDURE}

the procedure introduced by the literatures provided in Chapter 2. This procedure has been used by Hasaballa (2009) in the previous studies on the seismic behaviour of GFRP-RC exterior beam-column joint.

The FRP-RC column cross section interaction diagram may exhibit a failure point before reaching the pure bending condition. This failure is classified as brittle-tension failure. The failure is caused when the outermost FRP reinforcing bars reach their ultimate strain in tension

$\left(\varepsilon_{F R P, u}\right)$ before the outermost concrete fibre reaches its limiting strain in compression $\left(\varepsilon_{c u}=\right.$ 0.0035). To avoid having this kind of brittle tension failure, a reinforcement ratio $(\rho)$ larger than the balanced ratio $\left(\rho_{b}\right)$ should be provided in the column. The balanced ratio is the ratio of the reinforcement in which the outermost fibre of FRP reinforcement and outer most fibre of concrete reach their ultimate strains simultaneously. Detailed calculations can be found in

\section{Appendix A.}

As mentioned in Chapter 2, column-to-beam flexural strength ratio is one of the main parameters that controls the plastic hinge location. Higher ratio is more desirable to ensure formation of the hinge in the beam. CSA A23.3-04 (CSA 2004) for steel-RC structures requires that:

$$
\sum M_{n c} \geq \sum M_{p b}
$$

Equation 3.6

As it was mentioned before $M_{p b}$ is the probable moment in a beam which is calculated by using $1.25 f_{y}$ instead of $f_{y}$, taking in to account the strain hardening of steel. Since GFRP bars have linear elastic behaviour with no yielding or strain hardening, it can be assumed that the probable moment corresponds to the actual stress developed in GFRP bars when a compression failure in concrete takes place. Accordingly, Equation 3.6 should be revised as: 
DESIGN PROCEDURE

$$
\sum M_{n c} \geq \sum M_{n b}
$$

\subsubsection{Design for shear}

According to CSA S806-12 (CSA 2012) Members subjected to shear should be designed so that:

$$
V_{r} \geq V_{f}
$$

The shear resistance $\left(V_{r}\right)$ shall be determined as follows (with FRP stirrups):

$$
V_{r}=V_{c}+V_{S F} \leq V_{c}+0.6 * \lambda * \varphi_{c} * \sqrt{f^{\prime}}{ }_{c} * b_{w} * d
$$

Equation 3.8

$V_{c}$ : shear resistance of concrete

$V_{S F}$ : shear resistance of FRP stirrups

For section having minimum amount of shear reinforcement the contribution of concrete in shear resistance is given by:

$$
V_{c}=0.035 * \lambda * \phi_{c}\left(f_{c}^{\prime} * \rho_{w} * E_{F} * \frac{V_{f}}{M_{f}} * d\right)^{\frac{1}{3}} * b_{w} * d
$$

$\rho_{w}:$ FRP longitudinal reinforcement ratio (\%)

$V_{f}$ : factored shear force at section under consideration

$M_{f}$ : factored bending moment at section under consideration

According to the code $V_{c}$ should be taken between $0.1 \lambda \phi_{c} \sqrt{f^{\prime}}{ }_{c} b_{w} d$ and $0.2 \lambda \phi_{c} \sqrt{f^{\prime}}{ }_{c} b_{w} d$. Also the quantity of $\left(\frac{V_{f}}{M_{f}} * d\right)$ shall not be taken larger than 1.0. However, due to considerable 


\section{DESIGN PROCEDURE}

deformation in beams at vicinity of columns in a seismic event, contribution of concrete in resisting shear forces is significantly reduced. Consequently, it is proposed to assume no contribution of concrete in resisting shear forces in beam sections (i.e. $V_{c}=0$ ). However, the concrete contribution is taken in to account in the shear capacity of columns, assuming no is damage induced to the column based on strong column-weak beam concept.

The minimum amount of transverse reinforcement is given by Clause 8.4.5.2 in CSA S806-12 (CSA 2012):

$$
A_{v}=\frac{0.3 * \sqrt{f^{\prime}} * b_{w} * S}{f_{F h}}
$$

$A_{v}$ : Area of shear reinforcement perpendicular to the axis of the member within the distance $\mathrm{S}$

$s$ : Spacing of shear reinforcement, measured parallel to the longitudinal axis of the member

$f_{F h}$ : design stress of the transverse FRP reinforcement equal to $\varphi_{F R P} * f_{F R P, u}$, or the stress corresponding to a strain of 0.004 in the FRP, or the stress corresponding to failure of corners, hooks, bends, and laps, whichever is least.

In addition to those expressions for $f_{F h}$ in the equation above, in design of the specimens two other expressions provided by ISIS Manual No.3 2007 (ISIS Canada 2007) were used to calculate strength of the stirrups. These expressions are based on stirrups configurations, accounting for the bent radius and the embedment length as follows:

$F_{F h}$ : is smaller of:

$$
\left(0.4+0.015 \frac{l_{F R P d}}{d_{e}}\right) \text { or }
$$


DESIGN PROCEDURE

$$
\left(0.05 \frac{r_{b}}{d_{b}}+0.3\right) * f_{F R P, u}
$$

$l_{F R P d}$ : FRP stirrup tail length measured after the bent part

$d_{e}$ : Effective bar diameter

$r_{b}$ : Radius of bent portion of FRP stirrup

The contribution of FRP shear reinforcement, $V_{S F}$, is given by CSA S806-12 (CSA 2012) Clause 8.4.4.6:

$$
V_{S F}=\frac{0.4 * \varphi_{F} * A_{v} * f_{F R P, u} * d}{s}
$$

CSA S806-12 (CSA 2012), Clause 12.7 provides the amount of ties that is required for column confinement. According to this clause, RC columns in seismic regions should be confined with transverse reinforcement of at least what is given by:

$$
\begin{gathered}
A_{F h}=* S * h_{c} * \frac{f_{c}^{\prime}}{f_{F h}} *\left(\frac{A_{g}}{A_{c}}-1\right) * \frac{\delta}{\sqrt{k_{c}}} * \frac{P_{f}}{P_{r o}} \\
\frac{P_{f}}{P_{\text {ro }}} \geq 0.2 \\
\left(\frac{A_{g}}{A_{c}}-1\right) \geq 0.3
\end{gathered}
$$

For rectangular transverse reinforcement:

$$
K_{c}=0.15 * \sqrt{\frac{h_{c}{ }^{2}}{S * S_{l}}}
$$

$h_{c}$ : Cross-sectional dimension of column core 


\section{DESIGN PROCEDURE}

$A_{g}:$ Gross area of section

$A_{c}$ : Cross-sectional area of the core of a compression member measured to the centreline of the perimeter hoop or spiral

$\delta$ : Design lateral drift ratio (i.e., horizontal drift / building height)

$P_{f}$ : Factored axial load

$P_{\text {ro }}$ : factored axial load resistance at zero eccentricity

$K_{C}$ : Confinement coefficient

$s_{l}$ : Spacing of tie legs or the spacing of grid openings in the cross-sectional plane of the column

Also Clause 12.7.2 limits the spacing of transverse reinforcement by minimum of the following values:

- One-quarter of the minimum member dimension;

- $150 \mathrm{~mm}$;

- 6 times the diameter of the smallest longitudinal bar; or

- $\quad$ The requirements of Clauses 8.4.3.2 and 8.4.3.3. (i.e. shear design for sections).

\subsubsection{Joint resistance and applied shear stress}

Although the amount of required stirrups to confine a column is provided in Clause 12.7 CSA S806-12 (CSA 2012), the clause has not expressed the shear capacity of the joints that have been confined according to this clause. 


\section{DESIGN PROCEDURE}

As mentioned in Chapter 2, applied joint shear stress significantly influences the element's behaviour. CSA A23.3-04 (CSA 2004) in clause 21.5 limits the factored shear resistance of steelRC beam-column joints as follows:

For confined joints:

$$
2.2 * \lambda * \varphi_{c} * \sqrt{f^{\prime}}{ }_{c} * A_{j}
$$

For joints confined on three faces or on two opposite faces:

$$
1.6 * \lambda * \varphi_{c} * \sqrt{f^{\prime}}{ }_{c} * A_{j}
$$

For other joints:

$$
1.3 * \lambda * \varphi_{c} * \sqrt{f^{\prime}}{ }_{c} * A_{j}
$$

$A_{j}$ : The Cross-sectional area of the joint,

$f^{\prime}{ }_{c}$ : The characteristic compressive strength of concrete.

However, there are not such expressions for FRP-RC joints. Few researches have been carried out to investigate the shear capacity of exterior beam-column joints; however, in none of them the effect of the confinement provided by lateral beams was considered. One of the main objectives of this research is to investigate the joint shear capacity for exterior beam-column joints confined with lateral beams. 


\section{EXPERIMENTAL WORK}

\subsection{Introduction}

As explained in Chapter 2, it has been well established that the behaviour of beam-column joints is influenced by many factors such as anchorage type of beam longitudinal reinforcement, column-to-beam flexural strength ratio, applied joint shear stress, confinement reinforcement in the joint, specified concrete strength, presence of axial load on the column, and geometry of the joint with respect to the attached structural members.

Only few researches have been carried out on the shear capacity of exterior beam-column joints fulfilling CSA S806-12 (CSA 2012) Clause 12.7 (Said \& Nehdi 2004; Mady et al. 2009; Hasaballa et al. 2011). All previous works considered the behaviour of joints without lateral beams. On the other hand, it is very common that exterior joints are confined by means of lateral beams. As it was mentioned in Chapter 2, presence of lateral beams can provide more confinement to the joint, which increases the shear capacity and improves seismic behaviour. The shear capacity of such exterior beam-column joints was investigated in this research.

Another major objective of this research was to investigate the influence of beam longitudinal bars anchorage method on the seismic behaviour of the joints. In this program, two types of anchorage: bent bars and headed-end bars were studied. Bent bars are widely common in steelRC constructions since straight bars can be bent at the site. Therefore, using headed-end bars which may need more preparation process seems to be more tedious. However, in FRP-RC construction reinforcement bending cannot be done on the site. Bent reinforcement is 


\section{EXPERIMENTAL WORK}

manufactured with special process according to the configuration that is provided by constructors and then is delivered to the site. Considering this fact, both headed-end bars and bent bars should be pre-ordered. However, using headed-end bars is more preferable because of considerable ease of construction in comparison with bent bars. Moreover, due to manufacturing process bending FRP reinforcement reduces strength of the bars. It is also worth mentioning that nowadays it is common to order pre-formed bent bars, made in the machine shop, even when steel bars are used.

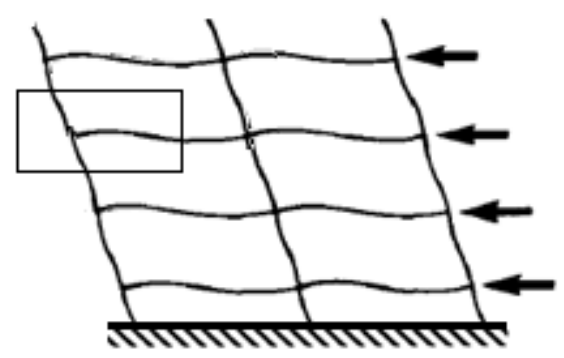

Figure 4.1 - beam-column joints in a laterally loaded ductile frame

This experimental program includes designing, construction, and testing of six full-scale test prototypes representing exterior beam-column joints in a multi-story RC structure with moment resisting system. The specimens were isolated from points of contra-flexure. It is assumed that these points occur at the columns mid-height and the beams mid-span. Figure 4.1 shows the points of contra-flexure in a structural frame.

\subsection{Experimental Program}

The experimental program was divided into two series. Series I included four exterior beamcolumn joints confined by lateral beams. Three specimens were reinforced with GFRP bars and stirrups and one with steel as control. For the GFRP-RC specimens, headed-end bars were used 


\section{EXPERIMENTAL WORK}

to anchor beam longitudinal bars inside the joint. The specimens were identical except for the beam reinforcement ratio. Different reinforcement ratios resulted in different magnitude of shear stress applied to the joints. The steel-RC specimen was designed according to CSA A23.3-04 code (CSA 2004), with beam bars bent inside the joint. The specimens were tested under cyclic reversal loading to investigate the shear capacity of the joints as a multiple of $\sqrt{f^{\prime}}$. The results obtained from this series were used in selecting Series II specimens.

In Series II, the objective was to determine the influence of anchorage type of beam longitudinal bars on the behaviour of exterior GFRP-RC joints. Therefore, this series included two exterior beam-column joints, one with and one without lateral beams. Both specimens had the beam flexural reinforcement bent inside the joint in a similar manner to the control steel-RC specimen.

The design of GFRP-RC specimens was carried out according to the design procedure discussed earlier in Chapter 3. Design calculations for one of the test specimens reinforced with GFRP is presented in Appendix $\boldsymbol{A}$ and design calculations for the steel-RC specimen is provided in

\section{Appendix B.}

\subsection{Material Properties}

\subsubsection{Concrete}

Ready-mix concrete was used to cast all the specimens. The target 28-day compressive strength of concrete was $35 \mathrm{MPa}$. The concrete was normal-weight with a maximum aggregate size of 20mm. All specimens were covered after casting and wet cured for 7 days. The actual compressive and tensile strengths of concrete were monitored on regular bases by testing standard cylinder specimens of $100 \times 200 \mathrm{~mm}$ and $150 \times 300 \mathrm{~mm}$, respectively. The compressive and tensile strengths of concrete for all specimens at the day of testing are provided at Table 4.1. 
Table 4.1 - Compressive and tensile strengths of concrete at day of testing

\begin{tabular}{|c|c|c|}
\hline Specimen & $\begin{array}{c}\text { Compressive } \\
\text { Strength } \\
\text { (MPa) }\end{array}$ & $\begin{array}{c}\text { Tensile } \\
\text { Strength } \\
\text { (MPa) }\end{array}$ \\
\hline G-I-L & 44.4 & 3.9 \\
\hline G-I-M & 47.8 & 4.1 \\
\hline G-I-H & 42.2 & 3.6 \\
\hline S-I-M & 40.8 & 3.6 \\
\hline G-II-L & 41.7 & 3.6 \\
\hline G-II-M & 46.6 & 3.9 \\
\hline
\end{tabular}

\subsubsection{Reinforcement}

CSA grade G400 deformed regular steel bars were used for constructing the control specimen. Three samples of the steel reinforcement were tested according to CSA A23.1-04 (CSA 2004) and the average yielding strength was found to be $460 \mathrm{MPa}$.

Deformed GFRP ComBar ${ }^{\mathrm{TM}}$ (Schöck Bauteile GmbH) bars were used as reinforcing bars for the other specimens. Mechanical properties of GFRP reinforcement was provided by the manufacturer. However, standard tests according to CSA S806-12 (CSA 2012) were carried out on GFRP bar samples. The laboratory-obtained properties and those provided by the manufacturer were very similar. The mechanical characteristics and dimensions of used GFRP reinforcement are provided in following tables.

Table 4.2 - Mechanical properties of GFRP straight bars

\begin{tabular}{|c|c|c|}
\hline \multicolumn{2}{|c|}{ Property } & Value \\
\hline Ultimate tensile strength & $f_{u}$ & $1100 \mathrm{MPa}$ \\
\hline Modulus of elasticity & $E_{f}$ & $60 \mathrm{GPa}$ \\
\hline Ultimate strain & $\varepsilon_{f u}$ & $1.83 \%$ \\
\hline
\end{tabular}


EXPERIMENTAL WORK

Table 4.3 - Size, dimensions and weights of straight bars

\begin{tabular}{|c|c|c|c|c|}
\hline ComBar ${ }^{\circledR}$ bar & $\begin{array}{l}\text { Core diameter } \\
(\mathbf{m m})\end{array}$ & $\begin{array}{l}\text { Exterior diameter } \\
(\mathbf{m m})\end{array}$ & $\begin{array}{l}\text { Cross-sectional area } \\
\left(\mathbf{m m}^{\mathbf{2}}\right)\end{array}$ & $\begin{array}{l}\text { Weight } / \mathrm{m} \\
(\mathbf{K g} / \mathbf{m})\end{array}$ \\
\hline No. 12 & 12 & 13.5 & 113 & 0.3 \\
\hline No. 16 & 16 & 18 & 201 & 0.53 \\
\hline No. 20 & 20 & 22 & 314 & 0.8 \\
\hline
\end{tabular}

Table 4.4 - Mechanical properties of GFRP bent bars

\begin{tabular}{|c|c|c|c|}
\hline \multicolumn{2}{|l|}{ Property } & 12-mmdiameter & 20-mm diameter \\
\hline $\begin{array}{c}\text { Ultimate tensile } \\
\text { strength/straight portion }\end{array}$ & $f_{u \text { (straigth) }}$ & $1000 \mathrm{MPa}$ & $850 \mathrm{MPa}$ \\
\hline Ultimate tensile strength/bent & $\mathrm{f}_{\mathrm{u} \text { (bent) }}$ & $700 \mathrm{MPa}$ & $550 \mathrm{MPa}$ \\
\hline portion & & $\geq 50 \mathrm{MPa}$ & $\geq 50 \mathrm{MPa}$ \\
\hline Modulus of elasticity & $\mathrm{E}_{\mathrm{f}, \text { bent }}$ & & \\
\hline
\end{tabular}

Figure 4.2 shows photographs of the GFRP bars that were used in the program.
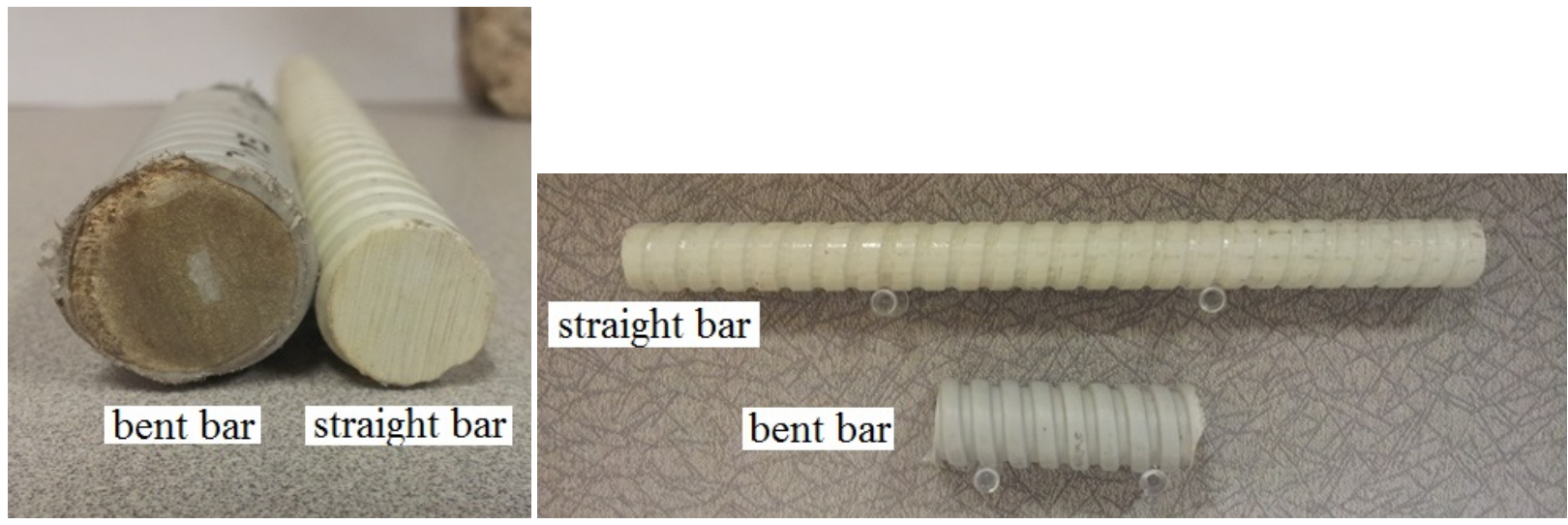

Figure 4.2 - GFRP bars used in the program 


\section{EXPERIMENTAL WORK}

\subsection{Test Specimens}

The specimens were coded using three letters. The first letter represents the type of reinforcement, “G” for GFRP and "S" for steel. The second letter represents the series number either "I" or "II". The third letter describes the shear applied to the joint; L, M or H which stand for low, moderate or high shear stress, respectively. In this study, the shear stress for low, moderate and high shear levels was $0.80 \sqrt{f^{\prime}}, 1.0 \sqrt{f^{\prime}}$, and $1.1 \sqrt{f^{\prime}}$, respectively. Table 4.5 provides the test matrix.

Table 4.5 - Test matrix

\begin{tabular}{|c|c|c|c|c|c|c|}
\hline \multirow{2}{*}{ Specimen } & \multirow{2}{*}{$\begin{array}{c}f^{\prime}{ }_{c} \\
(\mathrm{MPa})\end{array}$} & \multirow{2}{*}{$\begin{array}{c}\text { Beam } \\
\frac{\rho}{\rho_{b a l}}\end{array}$} & \multicolumn{2}{|c|}{$M_{R}(\mathrm{kN} . \mathrm{m})$} & \multirow{2}{*}{$\begin{array}{c}\text { Flexural } \\
\text { Ratio }\end{array}$} & \multirow{2}{*}{$\begin{array}{l}\text { Joint } \\
\text { Shear } \\
\text { Ratio }\end{array}$} \\
\hline & & & Column & Beam & & \\
\hline G-I-L & 44.4 & 1.64 & 247 & 307.01 & 1.61 & 0.806 \\
\hline G-I-M & 47.8 & 2.65 & 257 & 349.63 & 1.47 & 0.961 \\
\hline G-I-H & 42.2 & 3.62 & 240 & 356.43 & 1.35 & 1.065 \\
\hline S-I-M & 40.8 & - & 263 & 303.05 & 1.73 & 1.003 \\
\hline G-II-L & 41.7 & 1.58 & 236 & 302.63 & 1.56 & 0.872 \\
\hline G-II-M & 46.6 & 2.27 & 254 & 351.53 & 1.45 & 0.960 \\
\hline
\end{tabular}

The full-scale specimens represent beam-column joints isolated from the end bay of a multistory, multi-bay RC structure near the points of contra-flexural at columns mid-height and beams mid-span. All specimens had the same dimensions. Five specimens were confined with two lateral beams at the joint, one on each side, and one specimen was without any lateral confinement. Figure 4.3 shows the overall concrete dimensions of the specimens. The column measured 3650-mm long, 450-mm deep, and 350-mm wide. The beam measured 2100-mm long, 400-mm deep, and 350-mm wide. The lateral beams had a length, depth, and width of, 1000-mm, 350-mm, and 300-mm, respectively. 


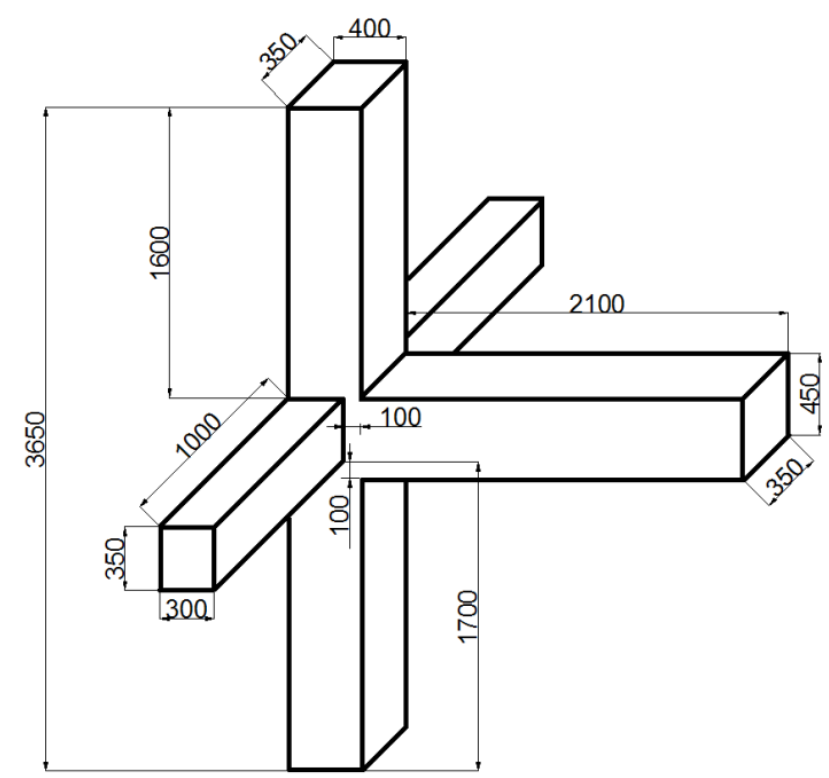

(a) With lateral Beams

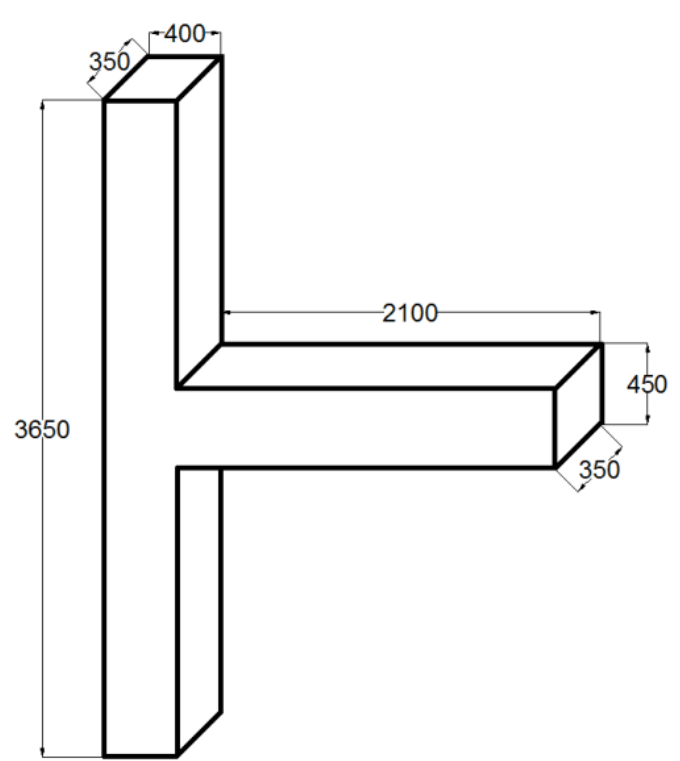

(b) without lateral beams

Figure 4.3 - Dimensions of test specimens (dimensions in $\mathrm{mm}$ )

\subsubsection{Series I}

The main objective of this series was to investigate the shear capacity of exterior beam-column joints reinforced with headed-end GFRP bars and U-shaped stirrups and confined with lateral beams. Four specimens were tested in this series, three totally reinforced with GFRP in both longitudinal and transverse directions, and one totally reinforced with steel.

In the three GFRP-RC specimens, G-I-L, G-I-M, and G-I-H, headed-end bars were used as longitudinal beam reinforcement. The only variable was the shear stress acting on the joint, $0.80 \sqrt{f^{\prime}}, 1.0 \sqrt{f^{\prime}{ }_{c}}$ and $1.1 \sqrt{f^{\prime}}$, respectively. The objective was to introduce one of these magnitudes as the shear capacity of exterior beam-column joints reinforced with headed-end GFRP bars. 


\section{EXPERIMENTAL WORK}

The steel-RC specimen, S-I-M with a shear stress ratio of $1.0 \sqrt{f^{\prime}}$, was designed according to CSA A23.3-04 (CSA 2004) code. The applied joint shear stress was calculated according to the actual yielding strength obtained from the test of steel reinforcement (460 MPa). Table 4.5 and Figure 4.4 show the reinforcement details of Series I specimens.
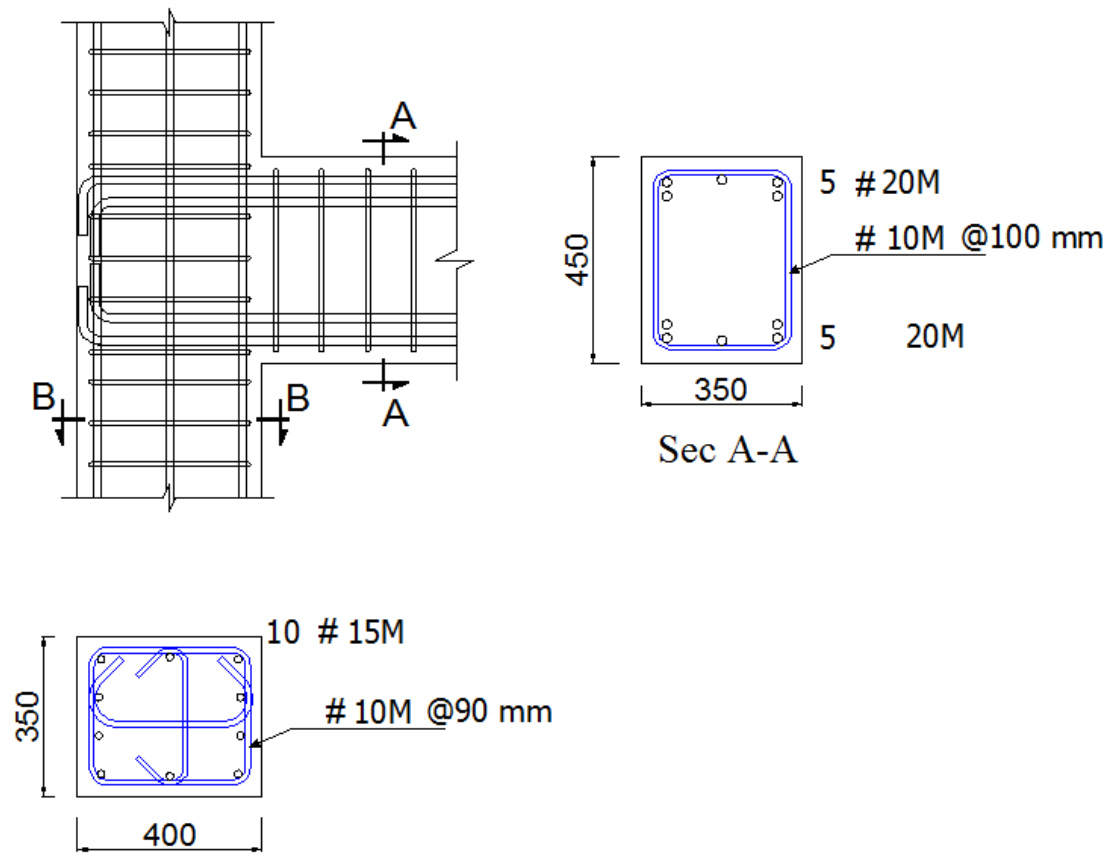

Sec B-B

(a) Specimen S-I-M 

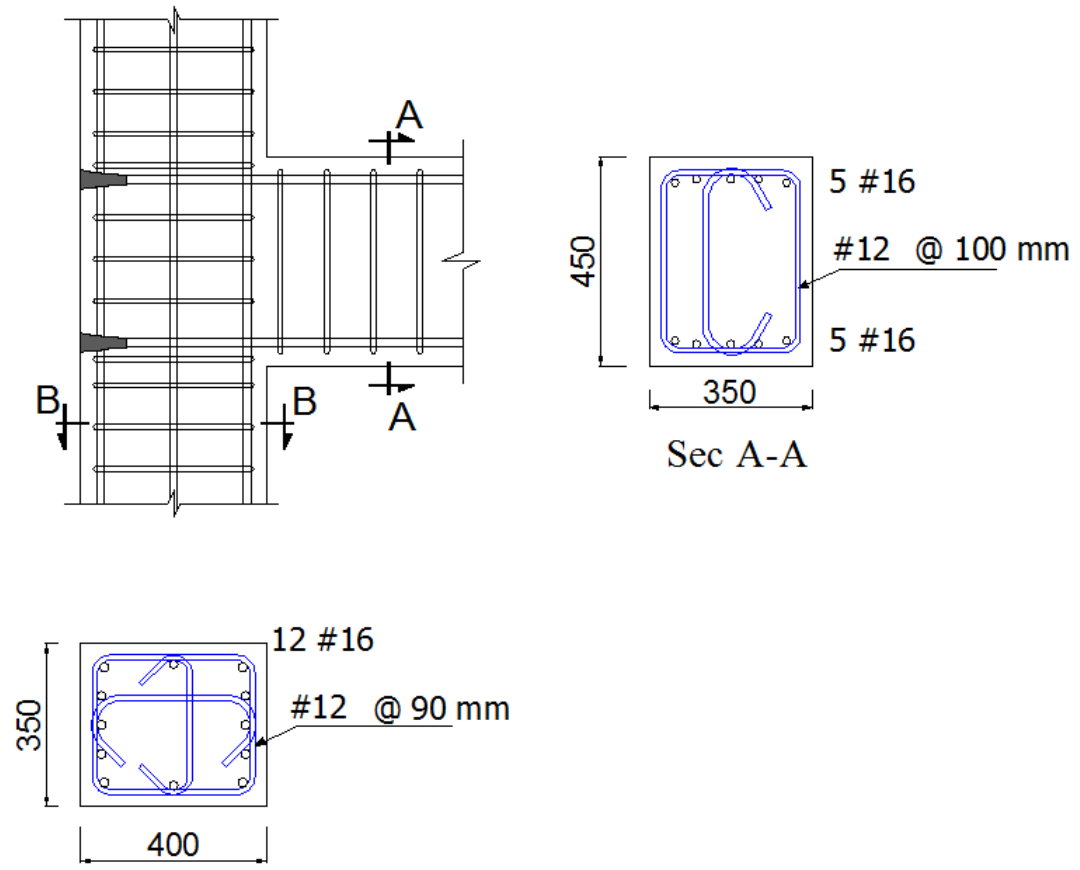

(b) Specimen G-I-L
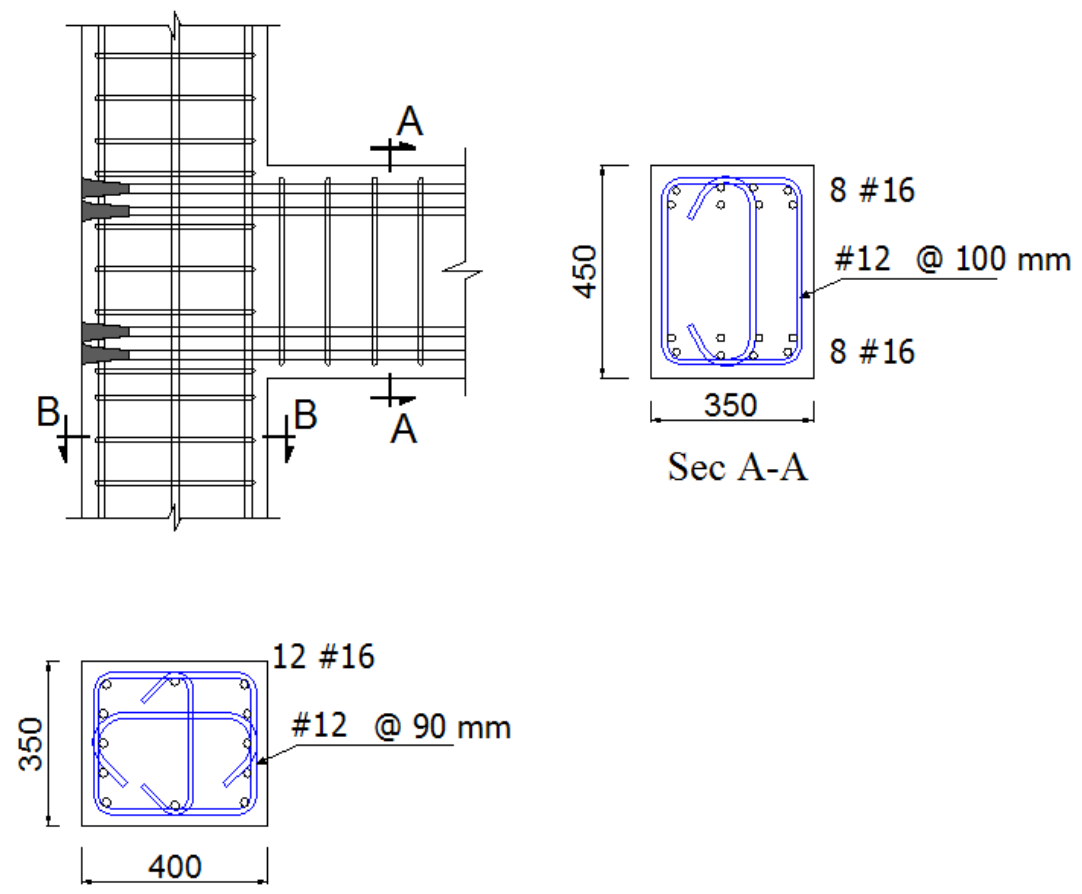

Sec B-B

(c) Specimen G-I-M 

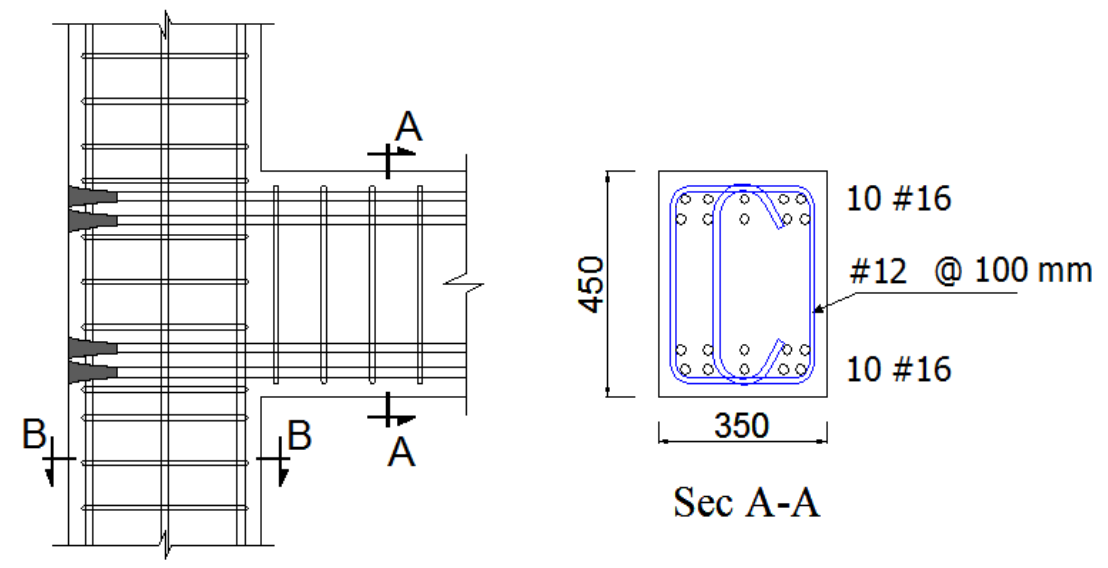

Sec A-A

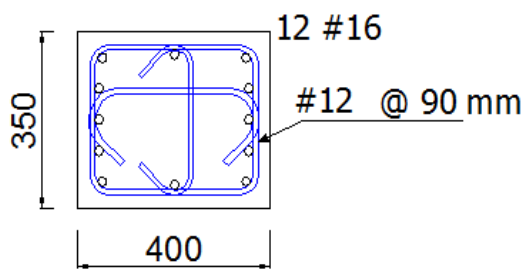

(d) Specimen G-I-H

Figure 4.4 - Reinforcement detailing of Series I specimens (S-I-M, G-I-L, G-I-M, G-I-H)

\subsubsection{Series II}

This series included two specimens, G-II-L and G-II-M, using GFRP bent bars as beam longitudinal reinforcement. The objective of Series II was to study the effect of beam longitudinal bars anchoring method on the seismic behaviour of exterior beam-column joints.

Based on the test results of Series I, the joint shear stress of $1.0 \sqrt{f^{\prime}}$ (corresponding to the specimen with moderate shear stress "M") was selected as the shear capacity of exterior beamcolumn joints reinforced with headed-end GFRP bars. Therefore, Specimen G-II-M was designed similar to Specimen G-I-M except that bent bars were used for the beam longitudinal reinforcement. 


\section{EXPERIMENTAL WORK}

The specimen without lateral beams, G-II-L, was designed based on the results of a previous study on shear capacity of exterior beam-column joints without lateral beams conducted at the University of Manitoba (Hasaballa and El-Salakawy 2012). The reinforcement details of Series II specimens are shown in Table 4.5 and Figure 4.5.

Table 4.6 - Reinforcement detailing of the specimens

\begin{tabular}{|c|c|c|c|c|c|c|c|c|}
\hline \multirow[b]{2}{*}{ ID } & \multirow{2}{*}{$\begin{array}{l}\text { Lateral } \\
\text { Beams }\end{array}$} & \multirow{2}{*}{$\begin{array}{c}\text { Anchorage } \\
\text { Type }\end{array}$} & \multicolumn{3}{|c|}{ Flexural Reinforcement } & \multicolumn{3}{|c|}{ Shear Reinforcement } \\
\hline & & & Туре & Beam & Column & Type & Beam & Column \\
\hline G-I-L & Yes & Headed-End & GFRP & $\begin{array}{l}5 \# 16 \\
\text { T\&B }\end{array}$ & $12 \# 16$ & GFRP & 3 \#12@100 & 3 \#12@90 \\
\hline G-I-M & Yes & Headed-End & GFRP & $\begin{array}{l}8 \# 16 \\
\text { T\&B }\end{array}$ & $12 \# 16$ & GFRP & 3 \#12@100 & 3 \#12@90 \\
\hline G-I-H & Yes & Headed-End & GFRP & $10 \# 16$ & $12 \# 16$ & GFRP & 3 \#12@100 & 3 \#12@90 \\
\hline S-I-M & Yes & Bent & Steel & $520 M$ & $1015 M$ & Steel & 2 \#10M@10 & 3 \#10M @90 \\
\hline G-II-L & No & Bent & GFRP & $4 \# 20$ & $12 \# 16$ & GFRP & 3 \#12@100 & 3 \#12@90 \\
\hline $\begin{array}{c}\text { G-II- } \\
\text { M }\end{array}$ & Yes & Bent & $\begin{array}{c}\text { GFR } \\
\mathrm{P}\end{array}$ & $6 \# 20$ & $12 \# 16$ & GFRP & 3 \#12@100 & 3 \#12@90 \\
\hline
\end{tabular}



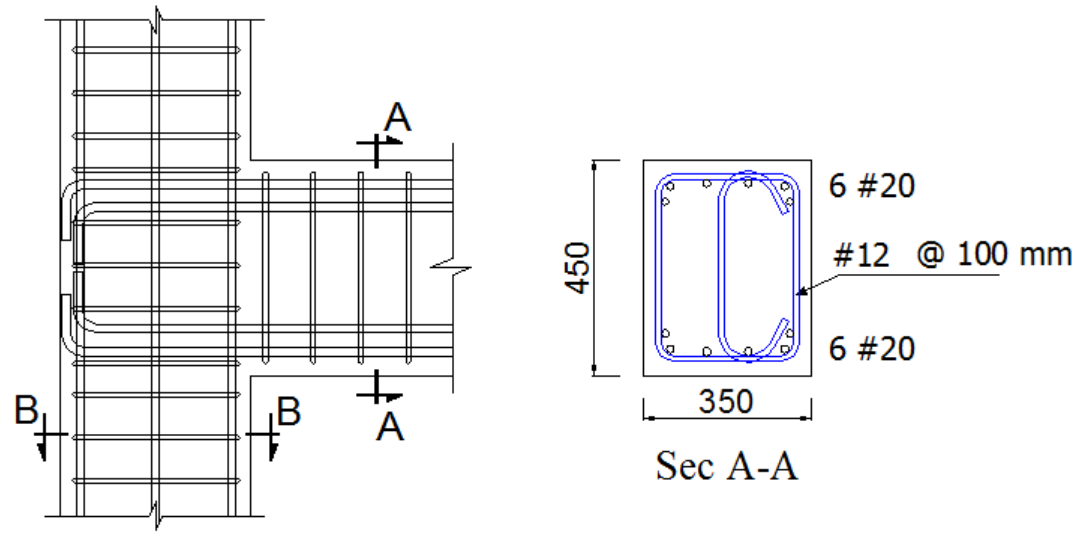

Sec A-A

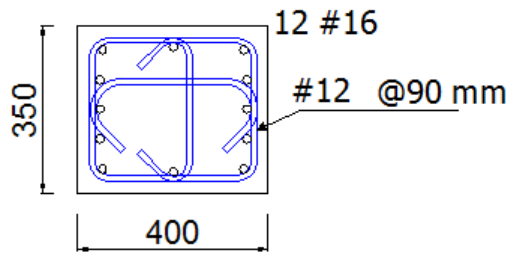

Sec B-B

(a) Specimen G-II-M
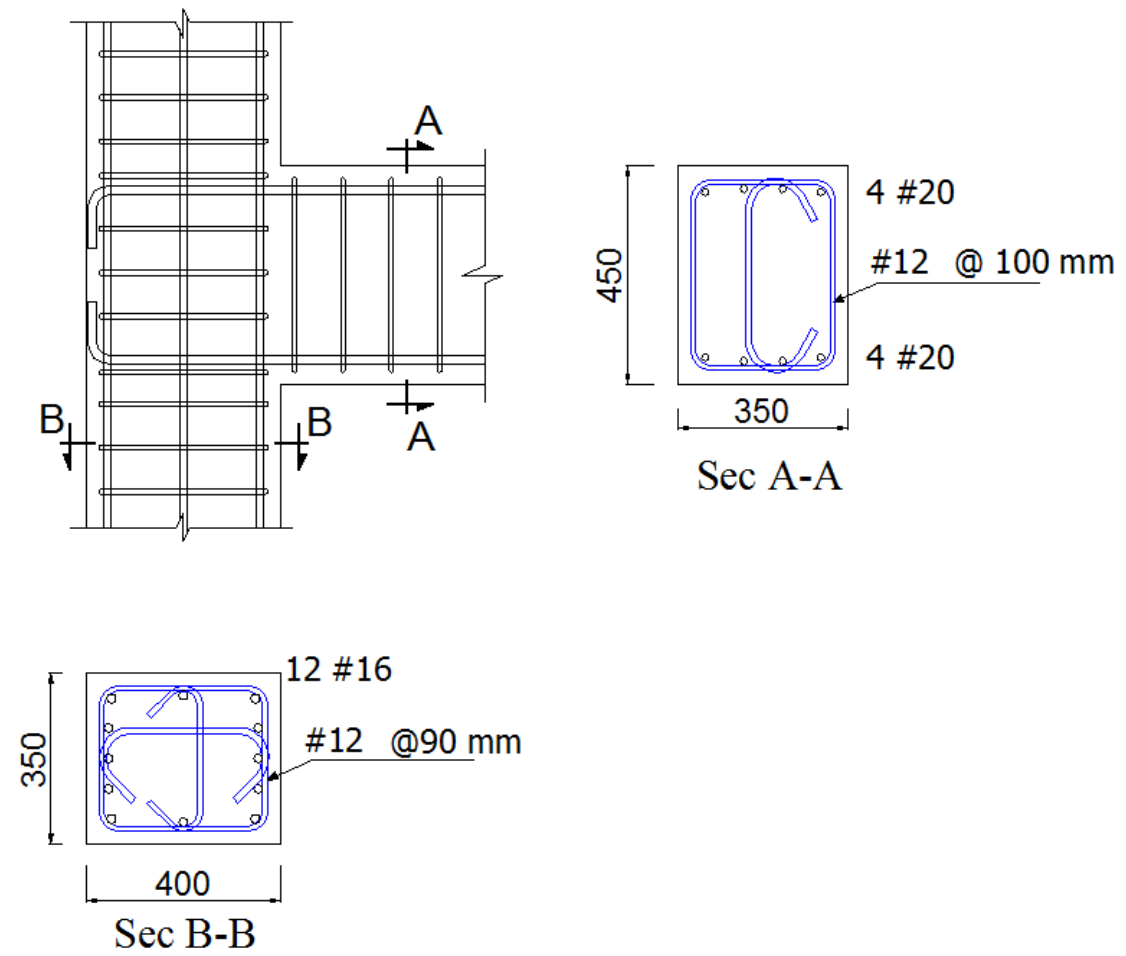

(b) Specimen G-II-L

Figure 4.5 - Reinforcement detailing of Series II specimens (G-II-M, G-II-L) 


\subsection{Test Set-Up}

All specimens were tested under reversal cyclic loading. In the test set-up, the columns were lying in a horizontal position and were subjected to an axial load by means of a 1000-kN capacity hydraulic jack. The magnitude of the columns axial load was kept constant, at a value equal to $15 \%$ of the maximum concentric axial capacity of the column. A fully dynamic actuator with $1000-\mathrm{kN}$ capacity and $500-\mathrm{mm}$ stroke was attached to the tip of the beam, applying horizontal reversal cyclic load. The actuator was attached to a rigid RC reaction wall.

Both ends of the column were restrained against vertical and horizontal displacements; however, their rotation was allowed in order to simulate a hinged boundary condition. A heavy strong reaction steel frame was pre-stressed to the strong floor to sustain the column reactions against the hydraulic jack load. A roller supports at each end, tied down to the strong floor, restrained vertical displacements of the column.
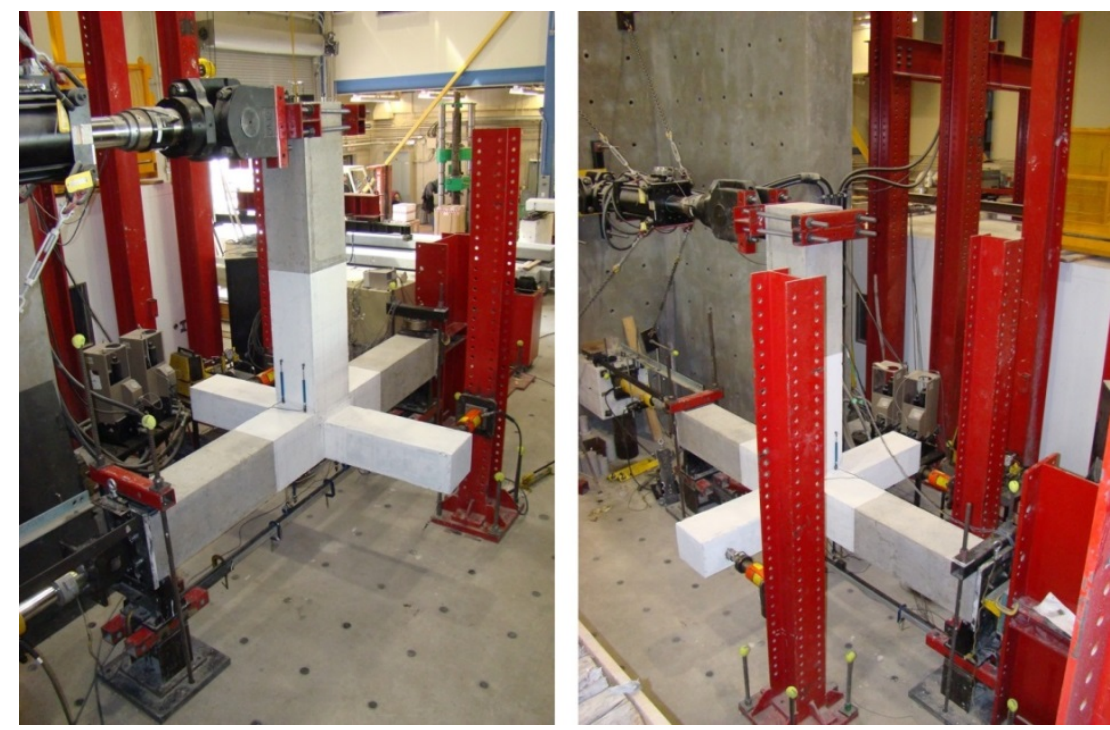

Figure 4.6 - Test set-up 


\section{EXPERIMENTAL WORK}

Two heavy steel plates, 38-mm thick each, were fixed to the column faces at both ends (using steel bolts embedded in concrete while casting) to prevent concentration of stresses. A solid steel rod was installed between the steel plate at the column end and the reaction frame, lying on the horizontal centre line of the column cross section. The hydraulic jack was attached to the other side of the column by means of a swivel head. The steel hinge and the swivel head ensured the concentric application of the load to the column section.

For the specimens with lateral beams, two hydraulic jacks were used to apply constant load on the lateral beams at the distance of $825-\mathrm{mm}$ from the column face. Same as the actuator and the column hydraulic jack, the lateral beams jacks were connected to the specimens by means of a swivel head to prevent inducing moments or torsions. Two heavy steel columns were prestressed to the strong floor in order to support the two hydraulic jacks on each side of the specimen. Figure 4.7 shows the schematic view of the test set-up 


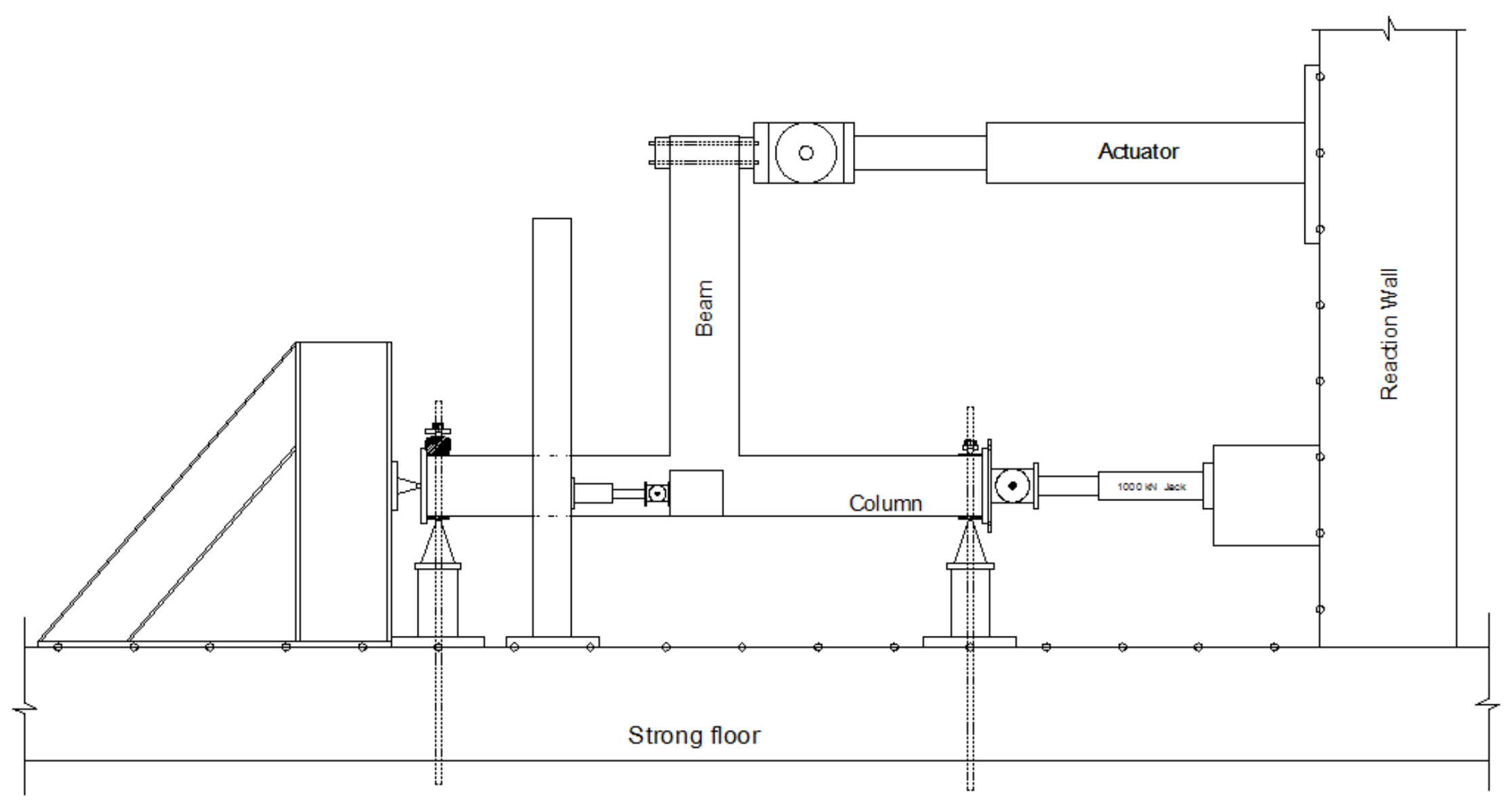

Figure 4.7 - Schematic test set-up 


\subsection{Instrumentation}

All specimens were heavily instrumented to monitor their behaviour during the test. A Data Acquisition (DAQ) system was used to collect readings from all instruments including: load

cells, linear variable displacement transducers (LVDTs), and strain gauges. However, crack patterns were monitored visually and marked after each loading stage. For each specimen, a total of 19 strain gauges were mounted on longitudinal and transverse reinforcement to detect strains at specific locations during the test. Also a group of load cells and LVDTs was used to monitor values of the applied loads and displacements at different locations. Details of the instrumentations are discussed in the following section.

\subsubsection{Load cells}

There were four load cells used in the test set-up. Three hollow-core load cells were used; one for measuring the column axial load and two for measuring the applied loads on the lateral beams. In addition, one load cell was placed at the hinged end of the column to monitor the upward vertical reaction force (Figure 4.8). The beam’s horizontal load and displacement were directly obtained from the actuator controller. 


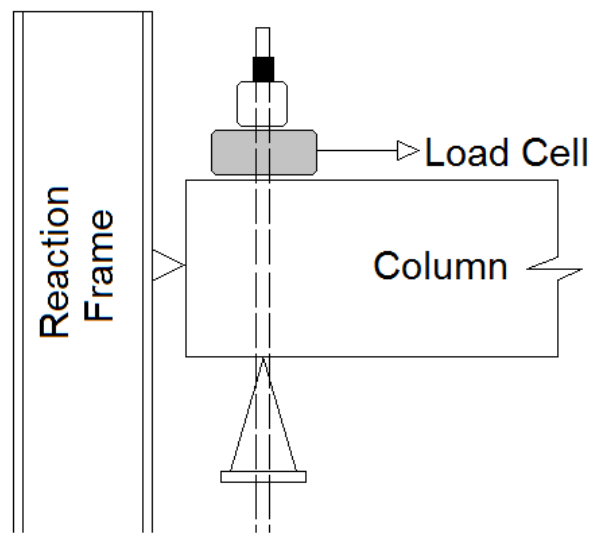

Figure 4.8 - Load cell to measure shear force at the column end

\subsubsection{Linear variable differential transducers (LVDTs)}

During the application of lateral displacement to the beam tip, the drift value can be divided into five main components. These components are:

- Elastic rotation of the beam at the face of the column due to the loading;

- Rotation in the anticipated beam plastic hinge (inelasticity centre) zone;

- Rotation due to local slippage and large strains developed in the beam bars within the joint;

- Rotation due to overall column rotation; and

- Distortion of the joint.

A group of six Linear Variable Differential Transducers (LVDTs) were used for rotation measurements in the specimens with lateral beams. Due to presence of lateral beams, joint distortion measurement was not possible; however, two more LVDTs were used to measure joint distortion in the specimen without lateral beams. 


\section{EXPERIMENTAL WORK}

In order to measure the rotation of the beams with respect to the columns, a set of two LVDTs were mounted vertically on both sides of the beam. One end of the LVDTs was attached to the beam and the other end was attached to the top surface of the column (Figure 4.9). The distance between those two LVDTs was set to be 500-mm. During the lateral movement of the beam tip, one of the LVDTs was expanding while the other one was contracting. The difference between readings of the two LVDTs divided by their horizontal spacing (i.e. $500 \mathrm{~mm}$ ) gives the relative rotation of the beam.

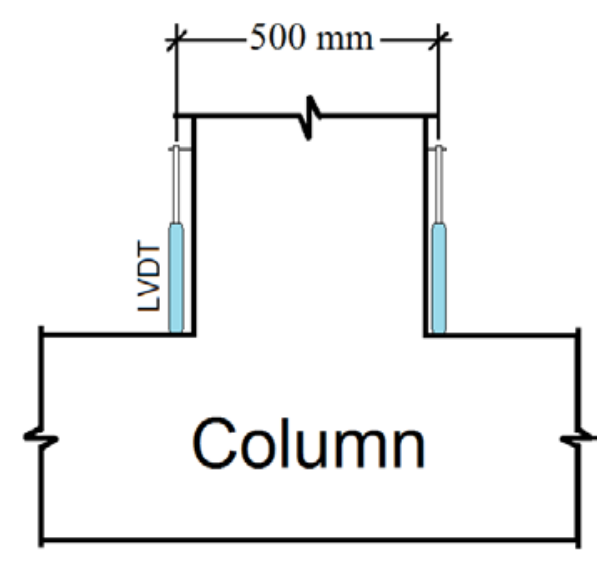

Figure 4.9 - LVDT set for measuring beam relative rotation

In order to measure rotation of the beams corresponding to the plastic hinges (inelasticity center), the same procedure was followed as describe above. A set of two LVDTs were attached vertically on either sides of the beam, but with both ends attached on the beam this time. The distance between the LVDTs was set to be $500-\mathrm{mm}$ as well, and the rotation was calculated in the same manner (Figure 4.10). 


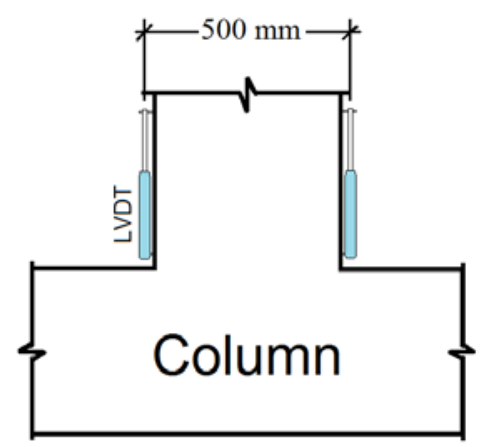

Figure 4.10 - LVDT set for measuring beam plastic hinge rotation

The rotation of columns was monitored by using two vertical LVDTs spaced at a distance of 300-mm from the vertical centerline of the beam as shown in Figure 4.11. Similar to previous cases, the rotation was equal to the difference between the readings of the LVDTs divided by their horizontal spacing.

In order to measure distortion of the joint; two LVTDs were attached diagonally to the joint, as shown in Figure 4.12. The distortion value $(\gamma)$ can be calculated from the LVTDs readings by substituting the values in the following equation:

$$
\gamma=\frac{\delta-\delta^{\prime}}{2 l}(\tan \alpha+\cot \alpha)
$$

$\delta, \delta^{\prime}$ : are readings of LVDTs where elongations have positive sign;

$l$ : Initial distance between mounting rods;

$\alpha$ : Initial inclination of LVDTs to the horizontal (i.e. $36^{\circ}$ degree). 


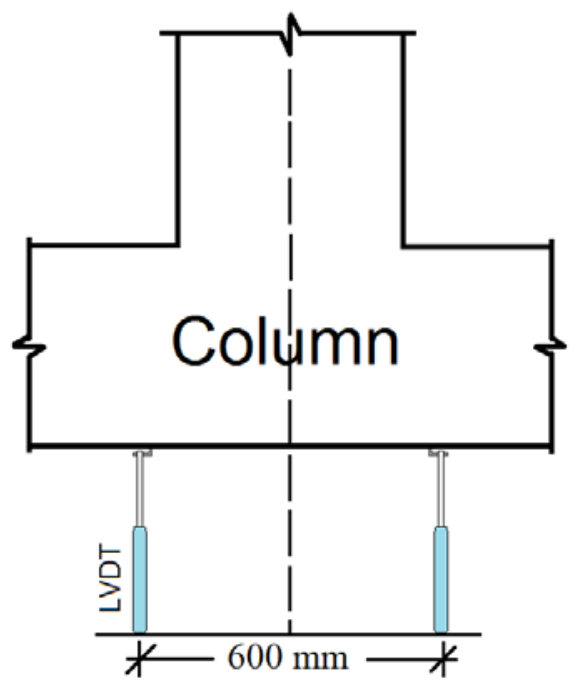

Figure 4.11 - LVDT set for measuring column rotation
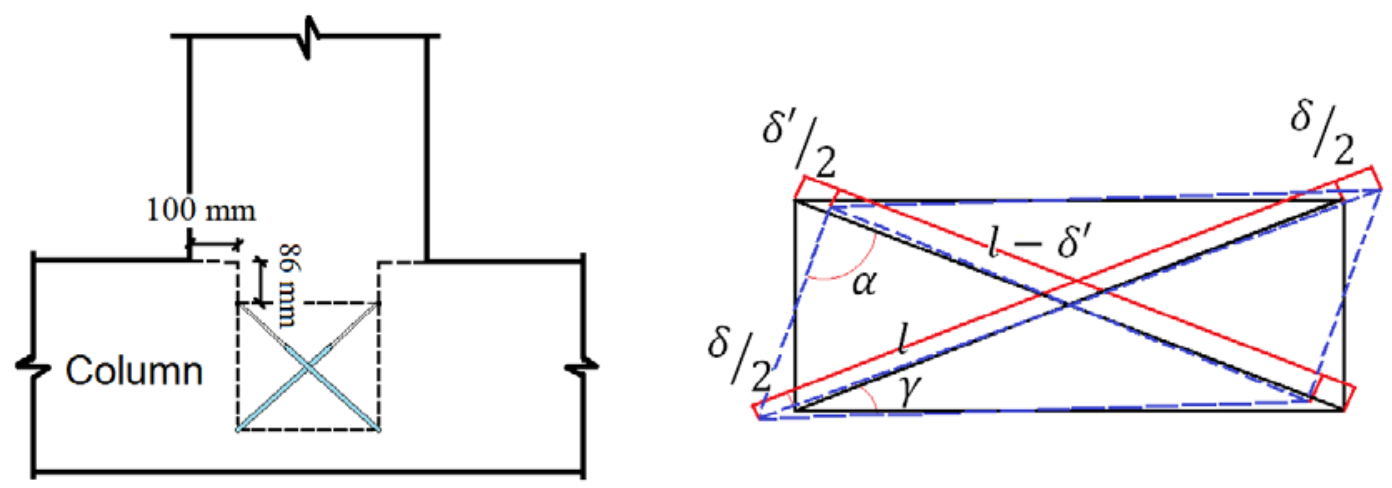

Figure 4.12 - LVDT set for measuring Joint distortion.

A High accuracy $(0.001 \mathrm{~mm})$ LVDT was attached to the specimens at the bottom of the joint to monitor slippage of longitudinal beam reinforcement in all specimens containing headed-end bars. The concrete cover at the tip of the bars was removed to provide clear space for the LVDT to touch the head of the bars (Figure 4.13). 


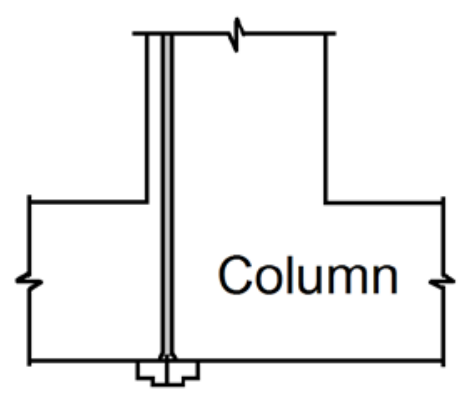

Figure 4.13 - LVDT for measuring bar slippage

\subsubsection{Strain gauges}

Figure 4.14 shows the location of the strain gauges. Five gauges were mounted on the column longitudinal reinforcement and six gauges were attached to the main beam flexural reinforcement to monitor strains at critical locations. It should be mentioned that strain gauges No.3 and No.7 were duplication of strain gauges No.2 and No.6, respectively. They were mounted at the same location on a parallel bar. Developed strains in transverse reinforcement due to shear stresses were captured at seven locations, where shear cracks were anticipated.
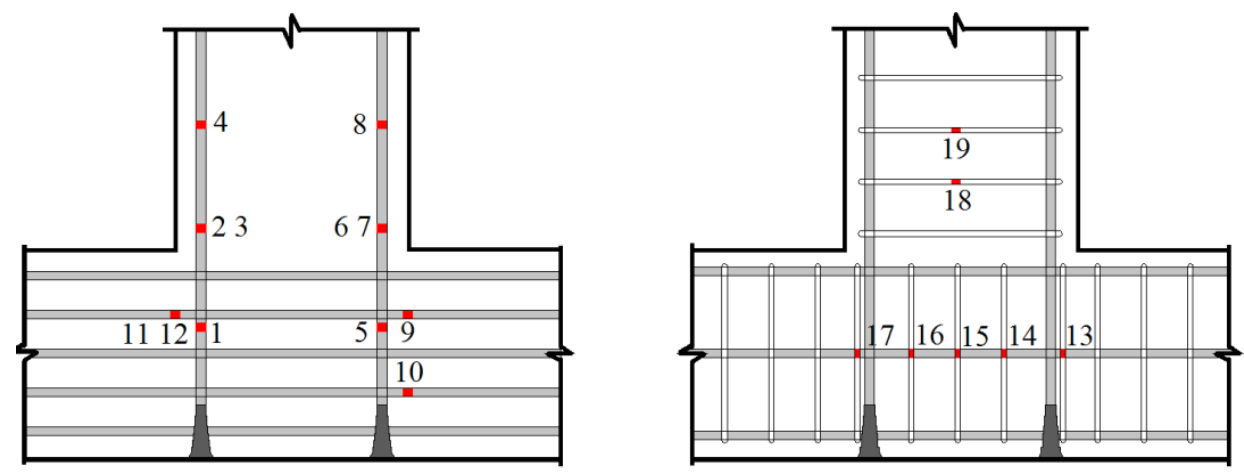

Figure 4.14 - Location of the strain gages

\subsection{Seismic Loading Scheme and Test Procedure}

During testing, the column and the lateral beams were under a constant load by means of hydraulic jacks while the actuator was set to apply reversal quasi-static cyclic loading to the 


\section{EXPERIMENTAL WORK}

beam tip. The magnitude of the axial load on the column was equal to approximately $15 \%$ of the maximum concentric axial capacity of the column $(670 \mathrm{kN}$ to $820 \mathrm{kN})$. The magnitude and direction of the loads on the lateral beams also were to simulate the service condition. The constant loads were applied before starting the cyclic loading.

According to ACI 374.1-05 report on acceptance criteria for moment frames based on structural testing (ACI Committee 374 2005), displacement-controlled loading phases were applied at a rate of $0.01 \mathrm{~Hz}$. The loading consisted of applying variable amplitude of displacement cycles (represents increasing drift ratios) in several steps. Each step consisted of three identical (constant amplitude) displacement cycles, in order to insure stable formation of cracking patterns. Figure 4.15 shows the loading scheme that was used to simulate a seismic event. The vertical axis shows the amplitude of the beam tip displacement in terms of drift ratio. Drift ratio is defined as the angular rotation of the column centreline with respect to that of the beam. In this test set-up the beam was attached vertically to the actuator, as a result the drift ratio was defined as the ratio of the beam tip displacement to the distance between the loading point and the column centreline, which was 2200-mm.

After $2 \%$ drift ratio loading stage, one loading cycle with the peak load equal to service load level was applied under load-controlled mode after each loading stage. The load-controlled cycles were used to assess stiffness degradation of the test specimens due to applying the prescribed seismic loading scheme, if any. Service loading was assumed as the load corresponding to $25 \%$ of GFRP ultimate tensile strain or $60 \%$ of yielding stress of steel. 


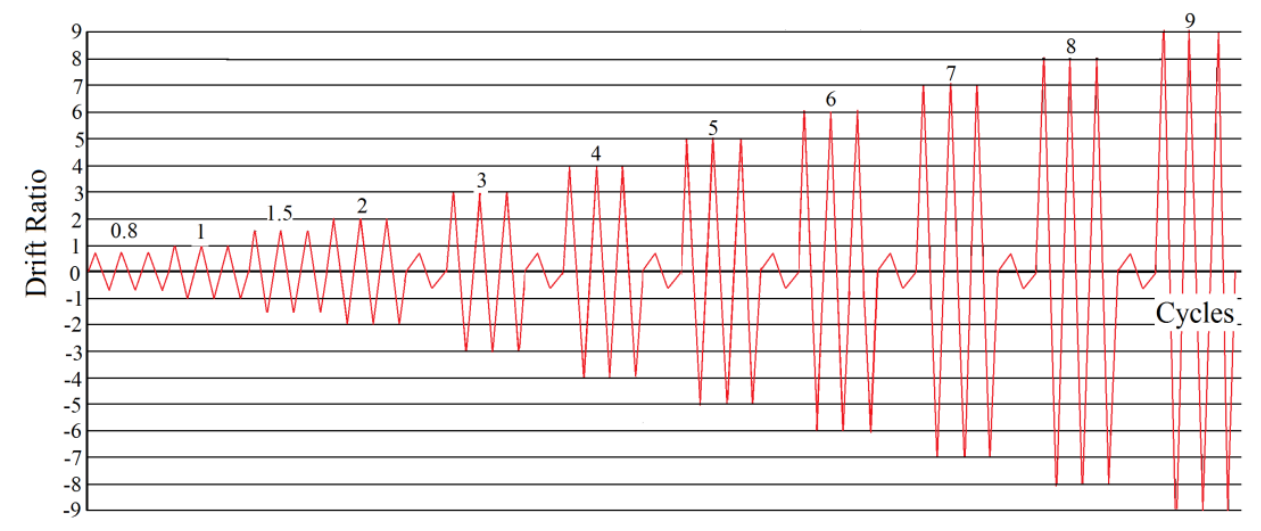

Figure 4.15 - Seismic loading scheme

It should be mentioned that before starting the displacement-controlled cycles, one loadcontrolled cycle with the maximum of $25 \mathrm{kN}$ for the GFRP-RC specimens and $30 \mathrm{kN}$ for the steel-RC specimen was applied in order to check the instrumentations and produce initial cracks in the specimen. 


\section{TEST RESULTS AND DISCUSSION}

The data obtained from the instrumentations were collected by data acquisition (DAQ) system and recorded by a computer. The behaviour of test specimens is presented in terms of lateral load-drift response of the beam-column joints, cracking patterns, mode of failure, magnitude of strains in different locations of the reinforcement, lateral stiffness, energy dissipation, and different components of the beam tip lateral displacement and rotations.

The test results are presented in two separate sections, each related to one of the series in this program.

\subsection{Series I}

\subsubsection{Overall behaviour}

All specimens in this series not only reached their flexural designed capacity, but also fulfilled the lateral drift ratio limits suggested by National Building Code of Canada (NBCC 2005) which is 2.5\%. Specimen G-I-L showed linear behaviour up to failure. Failure in this specimen occurred in the main beam, and no signs of shear failure were observed in the joint. Specimens G-I-M and G-I-H, on the other hand, showed both shear damage in the joint and flexural damage in the main beam, and the failure occurred simultaneously in the beam and the joint. The behaviour of these two specimens was similar to each other up to $5 \%$ drift ratio; however, due to higher shear stress induced to the joint, Specimen G-I-H showed higher lateral load capacity degradation after $5 \%$ drift ratio. Consequently, a joint shear ratio of $1.0 \sqrt{f^{\prime}}$ c was chosen as the 


\section{TEST RESULTS AND DISCUSSION}

joint shear capacity of exterior beam-column joints reinforced with headed-end GFRP bars and confined with lateral beams.

According to the test results from specimens G-I-L, G-I-M, and G-I-H, the beam reinforcement ratio in Specimen S-I-M was selected to induce a joint shear stress equal to $1.0 \sqrt{f_{c}^{\prime}}$, which was similar to G-I-M. Specimen S-I-M showed ductile behaviour as it was anticipated for steel-RC beam-column joints. All the damage was concentrated in the beam at the vicinity of the column. No joint damage was anticipated since the shear ratio of $1.0 \sqrt{f^{\prime}}$ was lower than $1.6 \sqrt{f^{\prime}}$, the maximum shear capacity of such joints suggested by CSA A23.3-04 (CSA 2004).

\subsubsection{Hysteresis diagram}

In this section, beam tip lateral load-drift ratio response for Series I specimens is presented. The dashed lines in the graphs show the design capacity of the specimens. The design capacity was calculated by considering a strain hardening equal to $25 \%$ of the yielding stress for the steel-RC specimen.

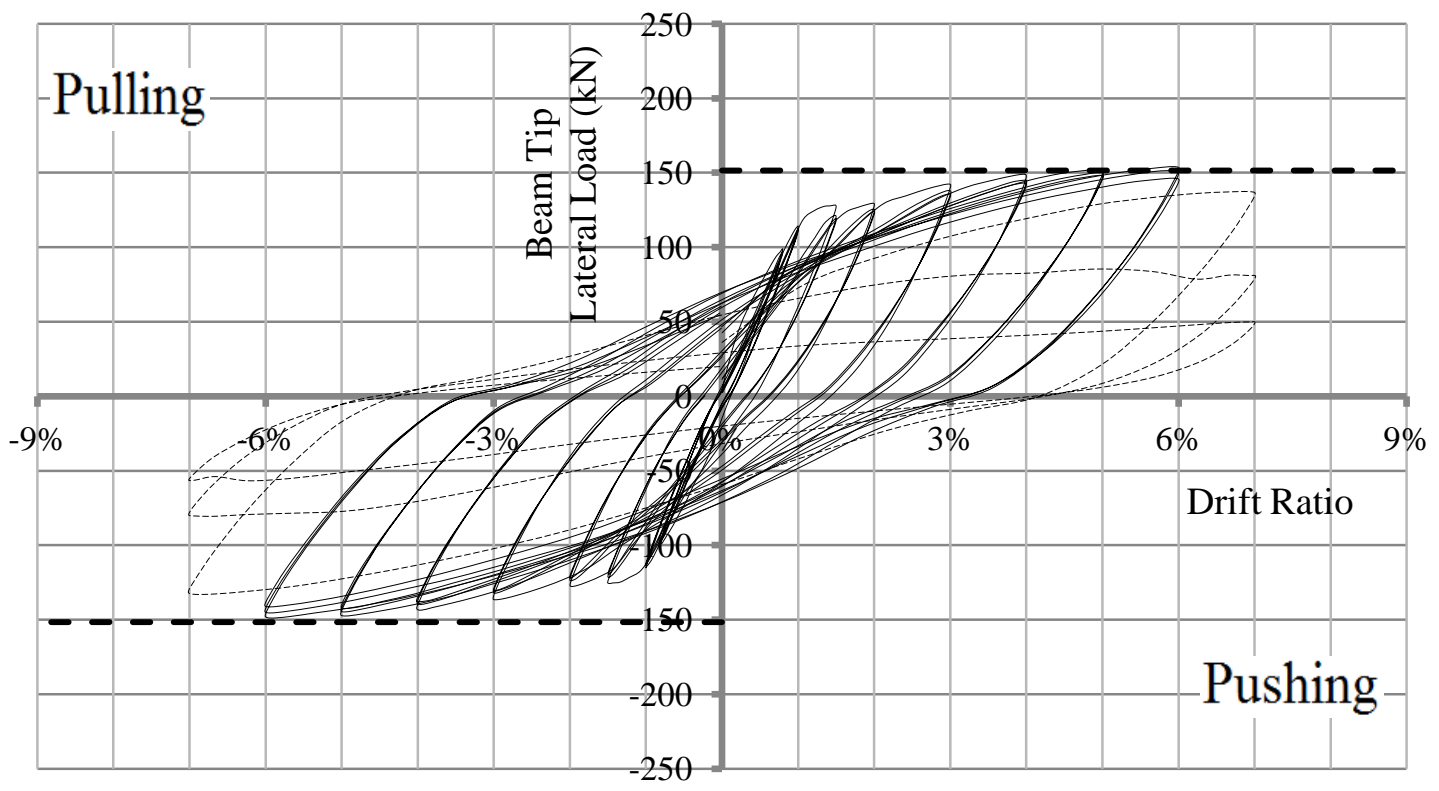




\section{TEST RESULTS AND DISCUSSION}

Figure 5.1 - Hysteresis diagram of Specimen S-I-M

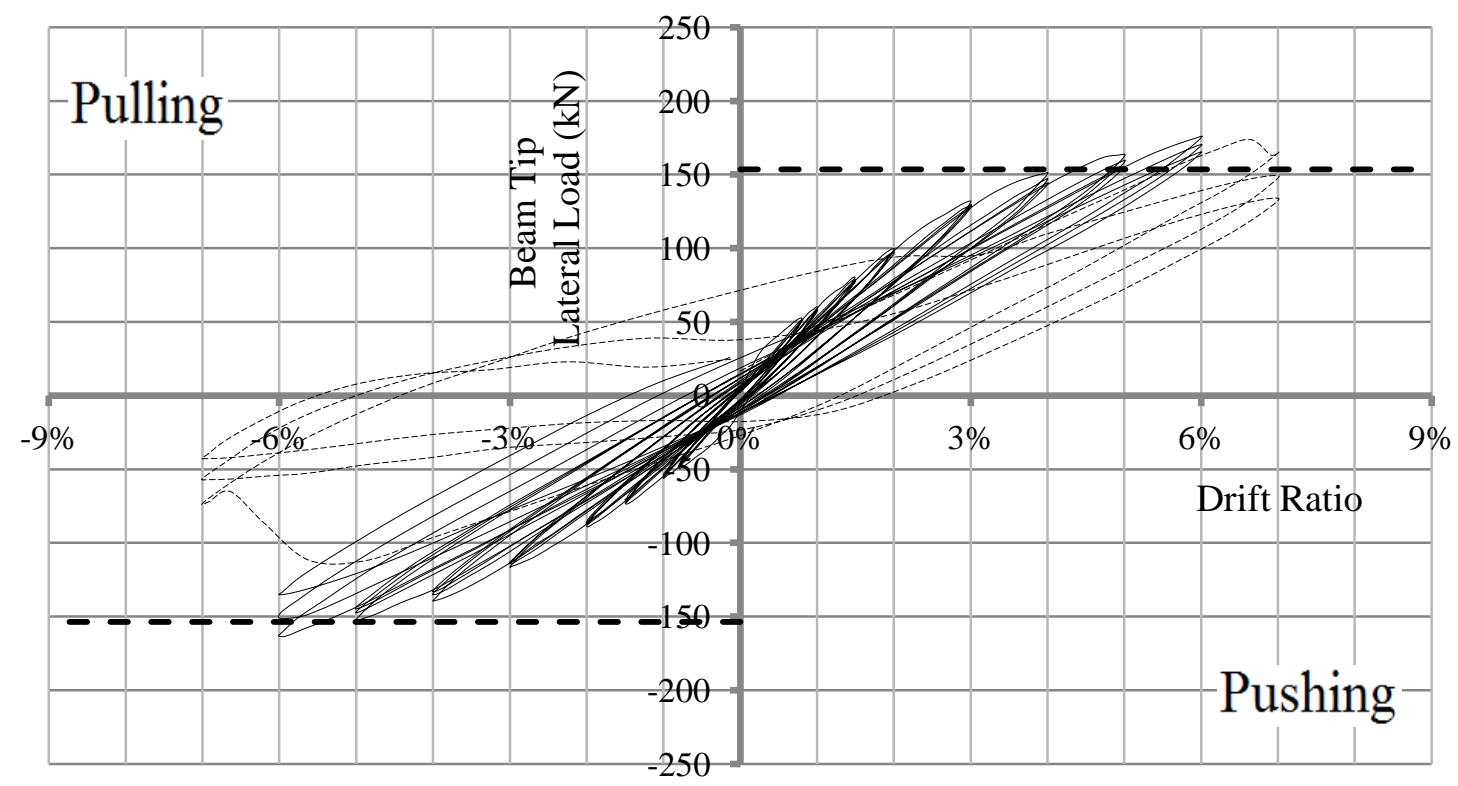

Figure 5.2 - Hysteresis diagram of Specimen G-I-L

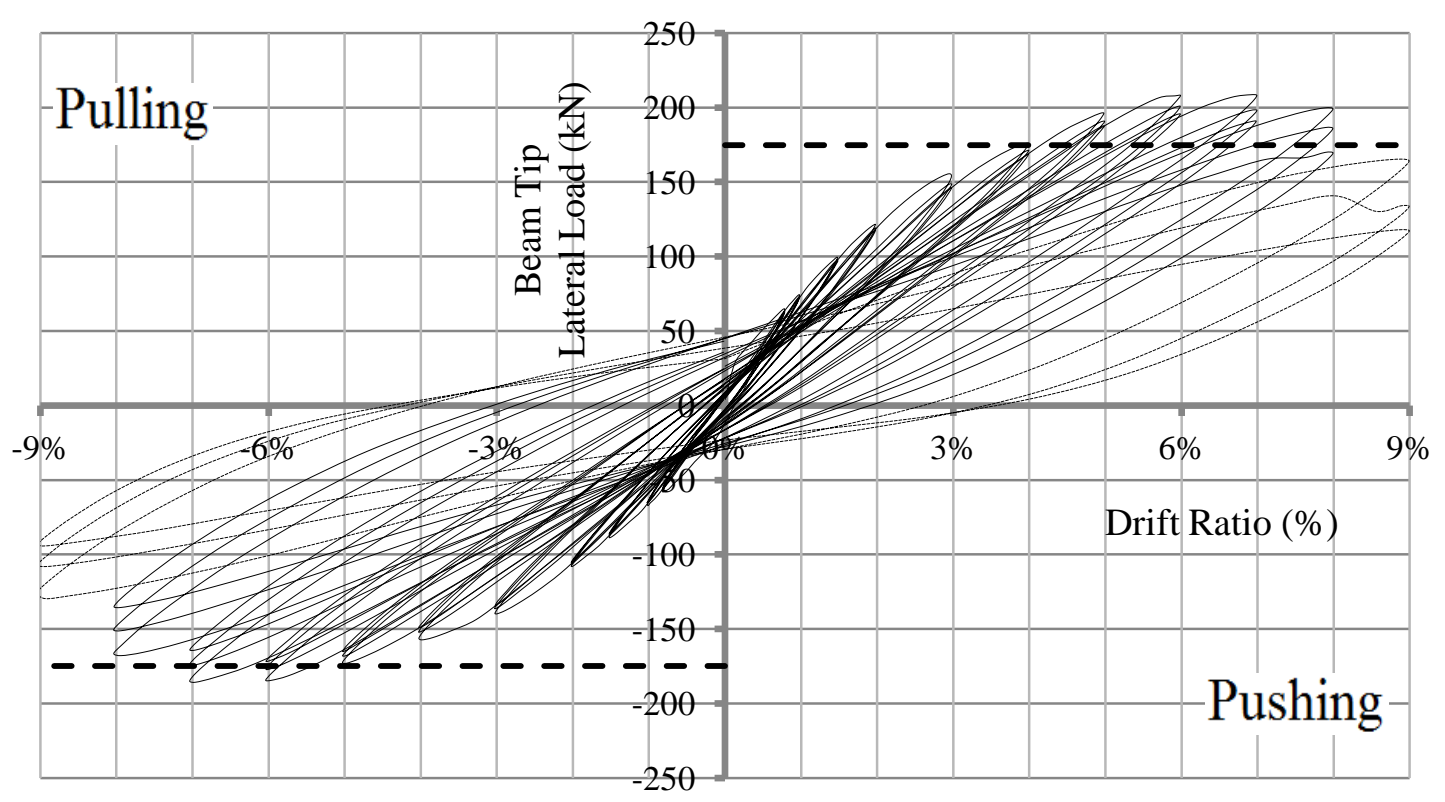

Figure 5.3 - Hysteresis diagram of Specimen G-I-M 


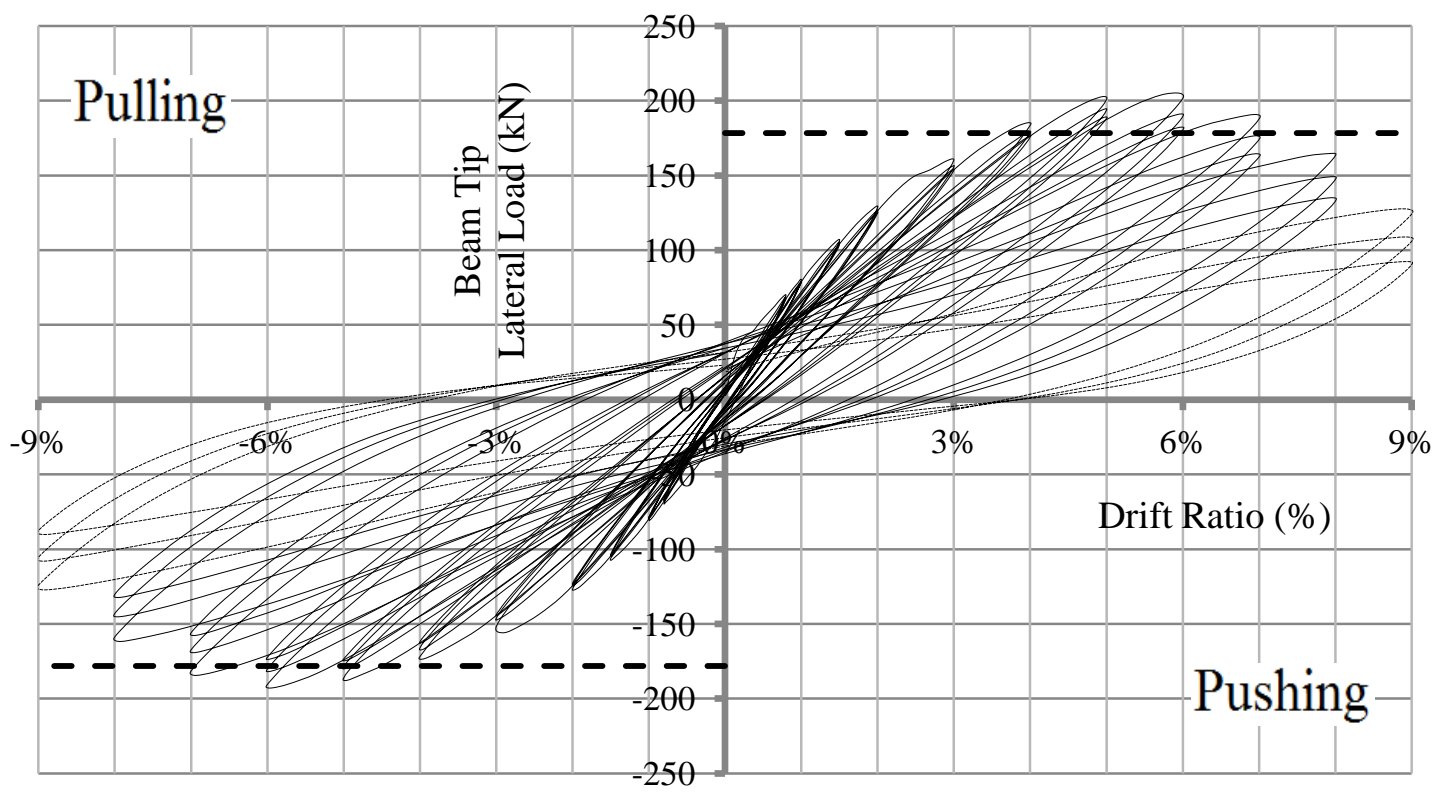

Figure 5.4 - Hysteresis diagram of Specimen G-I-H

As shown in Figure 5.1, Specimen S-I-M showed linear behaviour up to $1 \%$ drift ratio. After that, due to yielding of the steel reinforcement, the rate of increase in the lateral capacity of the specimen decreased and remained almost constant up to $2 \%$ drift ratio. However, because of steel strain hardening, after $2 \%$ drift ratio the lateral capacity started to increase slightly up to $6 \%$ drift ratio. The specimen failed at $7 \%$ drift ratio.

Starting at $1.5 \%$ drift ratio, residual displacement at the zero-load state became more considerable in Specimen S-I-M. This phenomenon is called pinching. Pinching can be because of extensive concrete damage and unclosed cracks, slippage of beam longitudinal bars, or yielding of the reinforcements. In this case, yielding of the reinforcement seemed to be the main reason since no slippage or severe concrete damage was observed at such early loading stages. Pinching of the specimen increased at higher drift ratios. 


\section{TEST RESULTS AND DISCUSSION}

Figure 5.2 shows the hysteresis diagram of Specimen G-I-L. This specimen, in contrary to specimen S-I-M, showed linear behaviour up to failure. The linear behaviour was from the linear stress-strain relationship of the GFRP bars. Also, the pinching was insignificant up to 6\% drift ratio. It should be mentioned that $6 \%$ drift ratio is beyond the lateral displacement of a reasonably designed framed structure. It can be concluded that GFRP-RC beam-column joints can endure a seismic event and behave linearly with minor residual damage after the event. This feature reduces the post-event repair cost of the framed structure.

According to Figure 5.3, Specimen G-I-M exhibited linear behaviour up to 6\% drift ratio, where the nonlinear behaviour started after. The lateral load capacity of the specimen remained almost constant between 6 and 8\% drift ratio; however, a considerable decrease in the capacity occurred at $9 \%$, and the test was stopped due to the strength degradation. Considerable pinching was observed starting at $7 \%$ drift ratio.

Specimen G-I-H showed similar behaviour to Specimen G-I-M in general; however, due to higher applied joint shear stress, more damage was induced to the joint in Specimen G-I-H at high drift ratios (after 6\%). The consequence was the sharp decrease in lateral capacity of Specimen G-I-H at those drift ratios (Figure 5.6). 


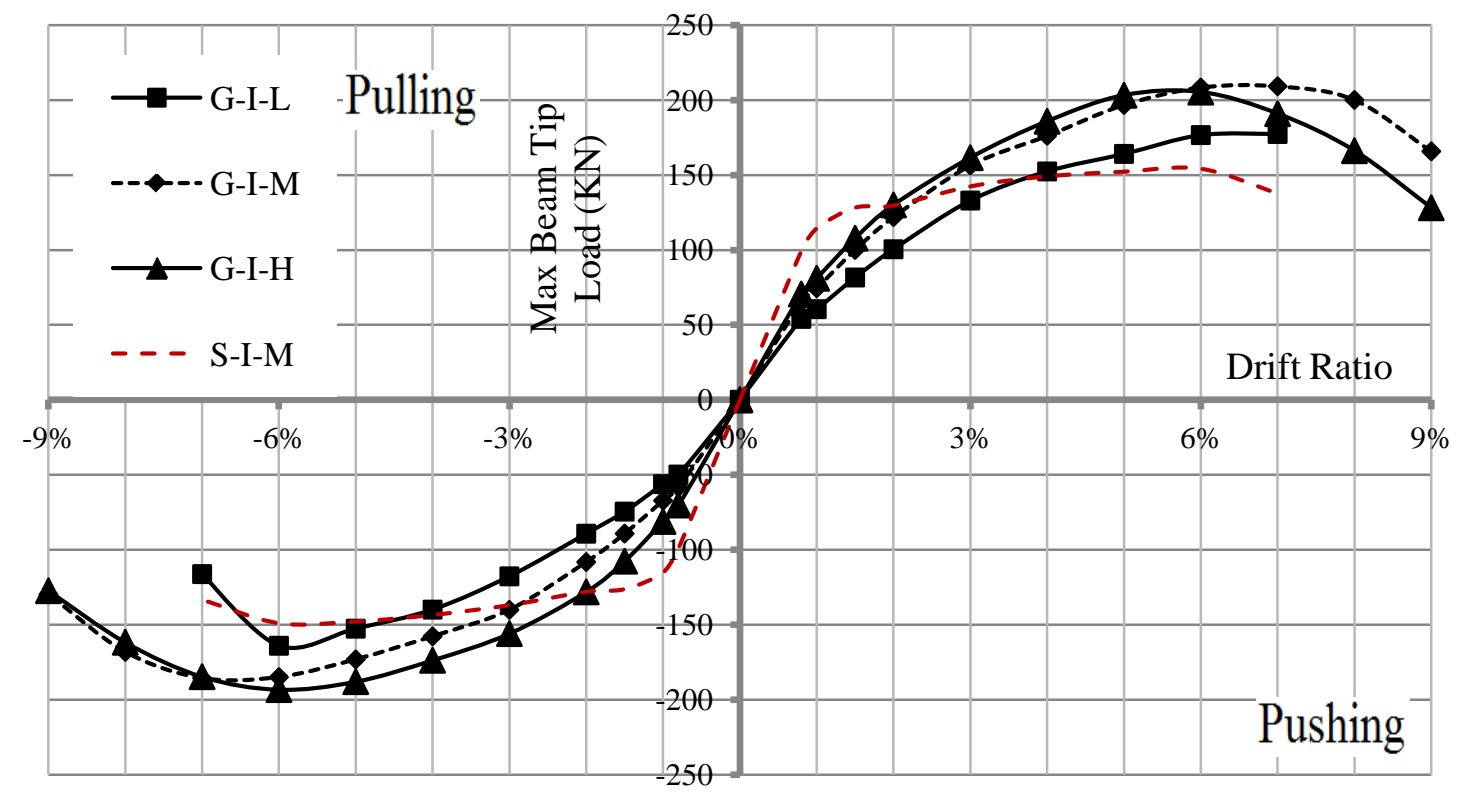

Figure 5.5 - Maximum lateral load envelop for Series I

Figure 5.5 shows the maximum applied lateral load in each loading stage versus the corresponding drift ratio for Series I specimens.

The GFRP-RC specimens showed lower lateral stiffness in comparison to Specimen S-I-M, due to lower stiffness of the GFRP reinforcing bars. The modulus of elasticity for the GFRP bars used in Series I was $60 \mathrm{GPa}$, while the modulus of elasticity for the steel reinforcement was 200 GPa.

Specimen G-I-L not only reached its design capacity, but also exceeded that limit in both pushing (positive) and pulling (negative) directions. The specimen maintained its load resistance capacity up to $7 \%$ drift ratio.

The figure shows the nonlinear behaviour of specimens G-I-M and G-I-H despite the linear characteristic of the GFRP reinforcements. The reason for this deformable behaviour in contrary to Specimen G-I-L is discussed in upcoming section entitled "Mode of failure". 


\section{TEST RESULTS AND DISCUSSION}

All specimens reached their design capacity at 4 and 5\% drift ratio in the pushing and pulling directions, respectively, indicating lower lateral load carrying capacity in the pulling direction. There are two reasons for the lower capacity of the specimens in the pulling direction. The first is that the loading cycles were always started by pushing the beam toward the positive direction. The crack propagation and concrete damage induced to the specimen at that stage reduced the capacity of the joint when the beam was pulled to the negative direction afterward.

The second reason was the loading of the lateral beams. As mentioned in Chapter 4, the lateral beams were under constant load during the test. This load was applying a lateral moment to the joint perpendicular to the direction of the main beam's moment. This lateral moment resulted in tension in the lateral beams bars in one side of the joint, and compression in the concrete on the other side. This lateral tension reduced the bond strength of the main beam longitudinal bars embedded in the joint by producing micro cracks and causing concrete damage in the joint. The longitudinal bars in the main beam that were under tension while the beam was pulled to the negative direction were located at the tension side of the joint (the side that the lateral beams were applying tension). The bond strength reduction of these bars led to minor slippage of the bars and reduced stiffness of the specimens in that direction. Figure 5.11 and Figure 5.13 show that the damage at the joint face (underneath) was concentrated at the tension side of the joint, indicating the effect of lateral beams loading. 
TEST RESULTS AND DISCUSSION

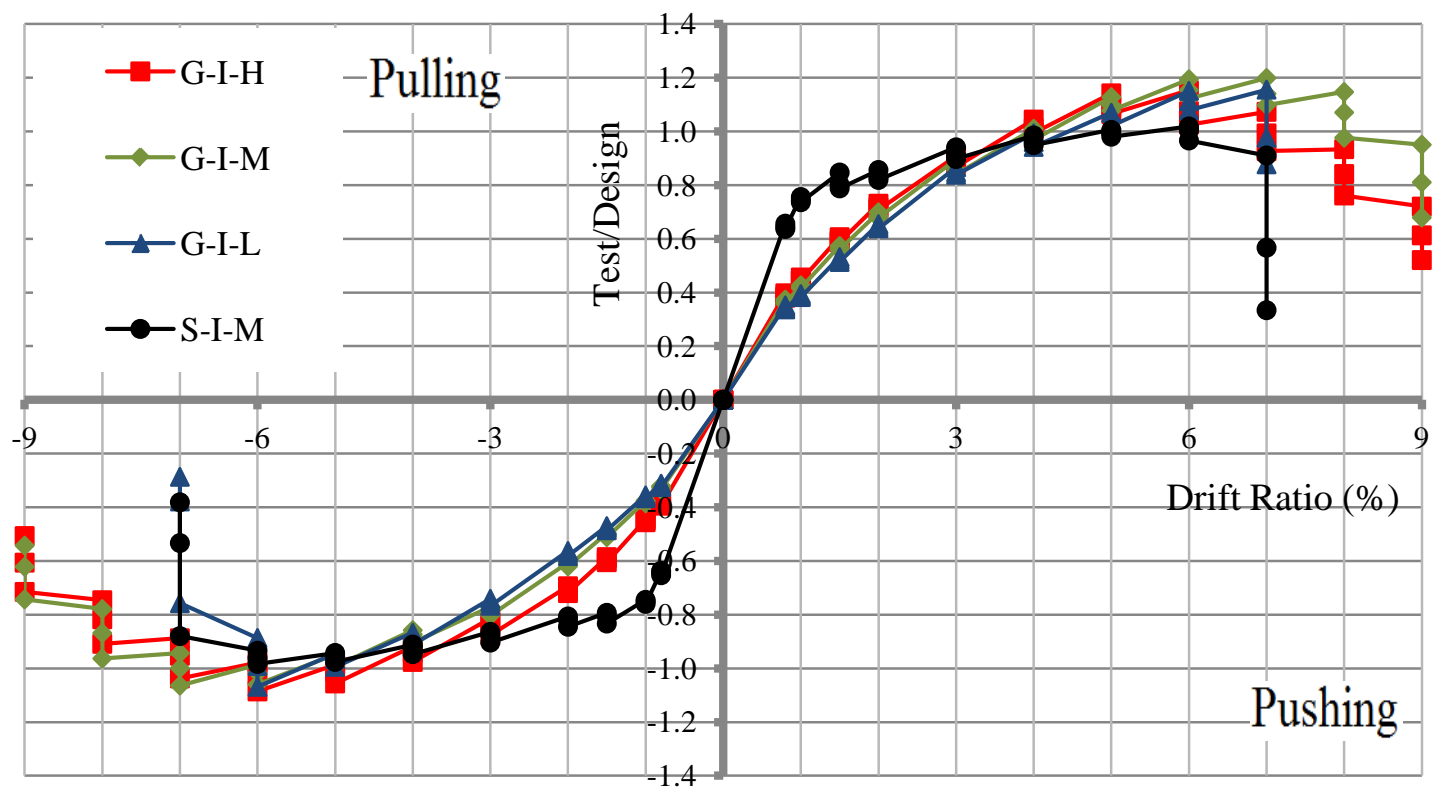

Figure 5.6 - Normalized lateral load-drift ratio relationship for specimens of Series I

Figure 5.6 compares the behaviour of the specimens in Series I. The vertical axis shows the ratio of the normalized lateral load-to-design capacity of the specimens, while the horizontal axis represents the drift ratio. According to the graph, the joint shear ratio corresponding to specimen G-I-M $\left(1.0 \sqrt{f_{c}^{\prime}}\right)$ can be introduced as the safe shear capacity of exterior beam-column joints confined with lateral beams and reinforced with headed-end GFRP bars. Although specimens GI-M and G-I-H showed similar behaviour up to 5\% drift ratio, the strength reduction was faster at the higher drift ratios in G-I-H. This was due to the higher joint shear stress in Specimen G-I-H. Based on the results of this series, Specimen G-II-M was designed to have the same joint shear stress as Specimen G-I-M.

\subsubsection{Cracking patterns}

For all specimens, cracks were inspected visually and were marked after each loading stage; however, at high drift ratios, a video camera was used to record the behaviour and damage 
mechanism of the specimens. The following section provides the pictures that were taken to show the specimens condition at the end of each loading stage.

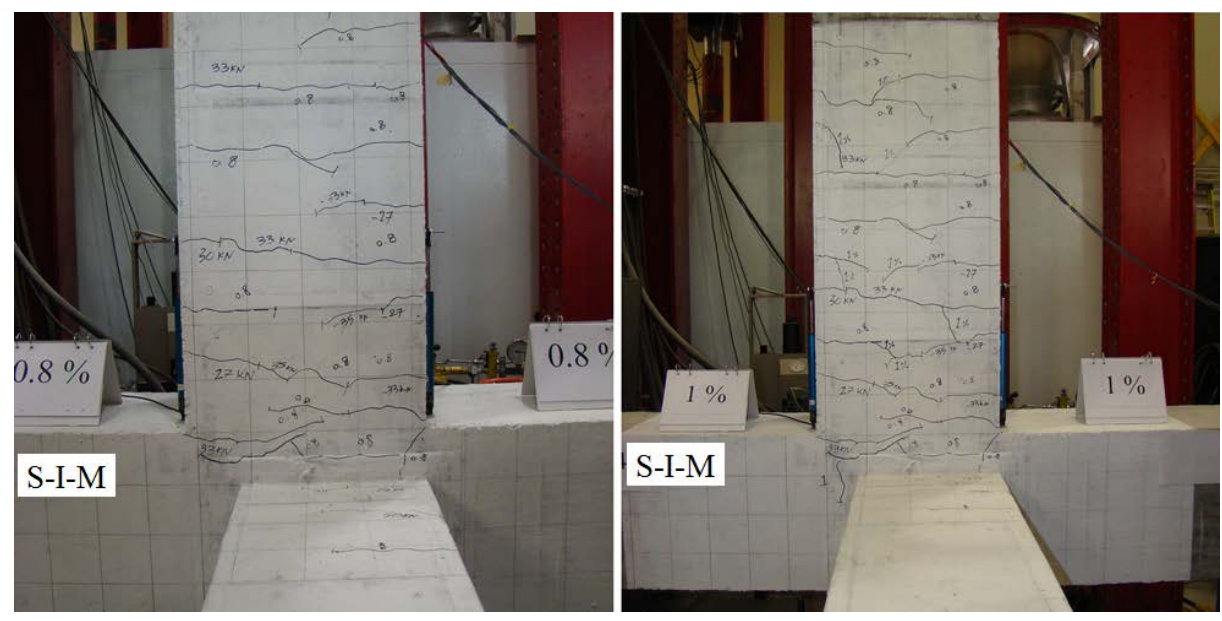

(a) Specimen S-I-M

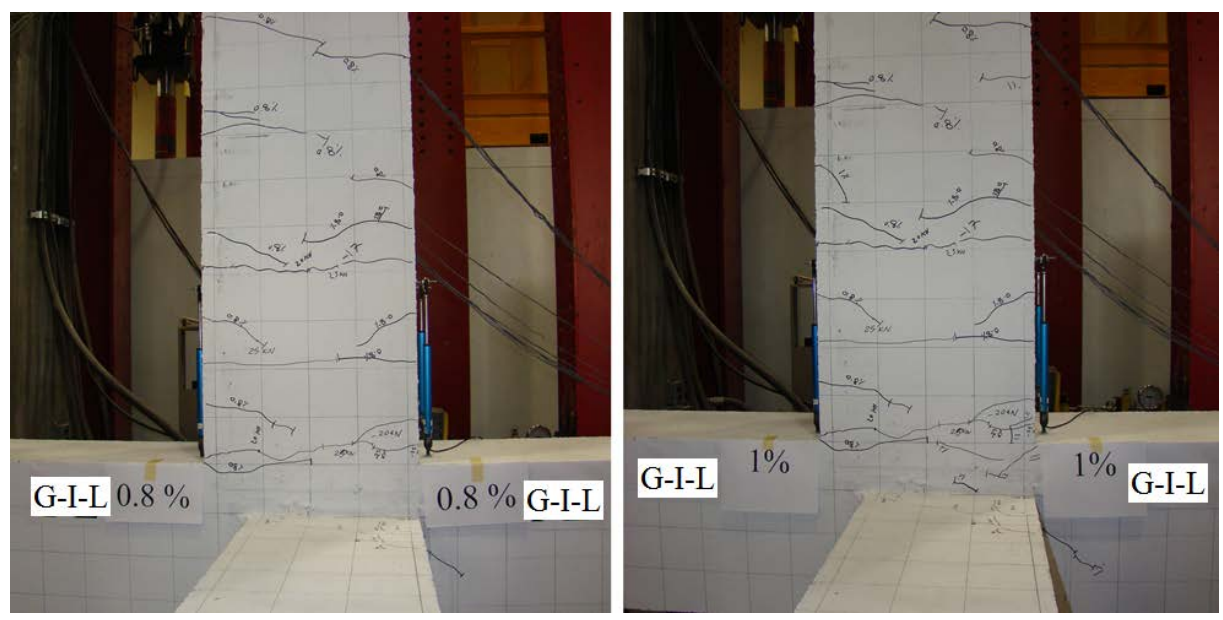

(b) Specimen G-I-L 


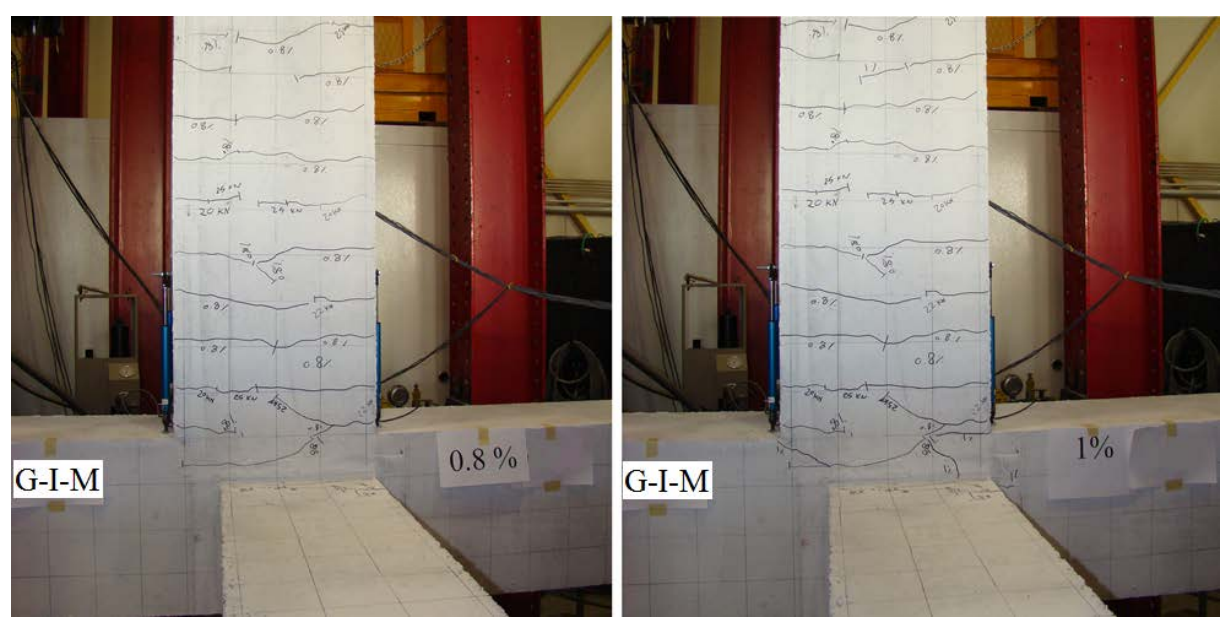

(c) Specimen G-I-M
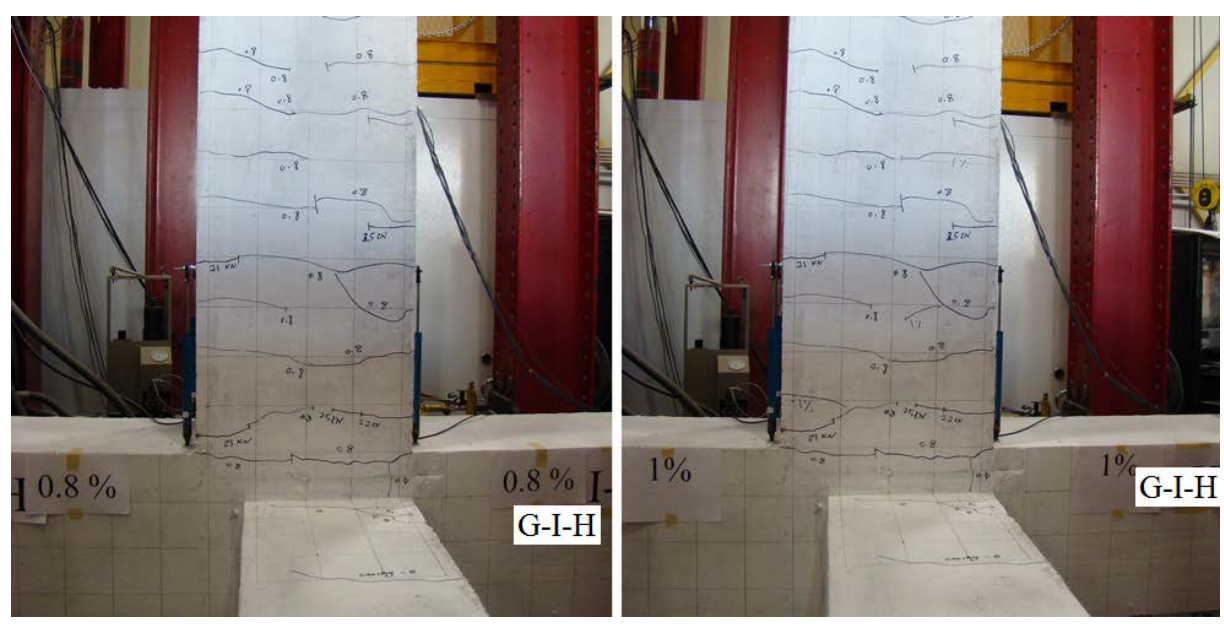

(d) Specimen G-I-H

Figure 5.7 - Condition of Series I specimens after 0.8 and 1\% drift ratio

According to Figure 5.7, in GFRP-RC specimens, up to $1 \%$ drift ratio, only flexural cracks were observed, and there were no significant shear cracks in the beam. In Specimen S-I-M, however, due to high applied lateral loads, shear cracks occurred in the beam at $1 \%$ drift ratio. There were no significant shear cracks inside the joint area of any specimen up to this stage. 


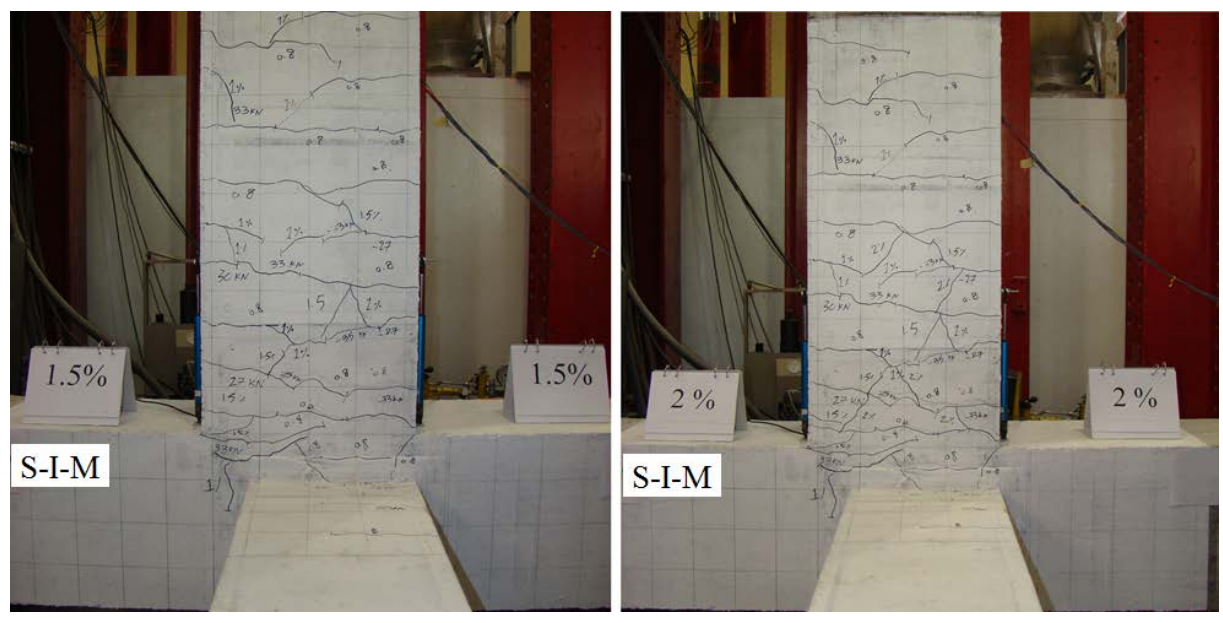

(a) Specimen S-I-M

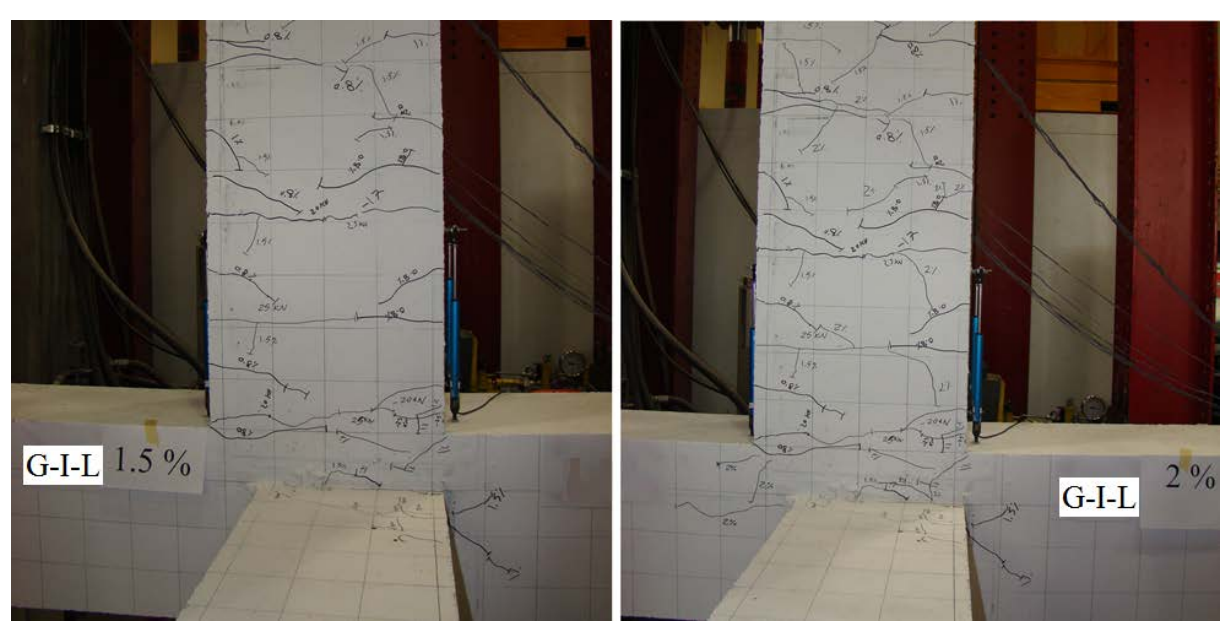

(b) Specimen G-I-L

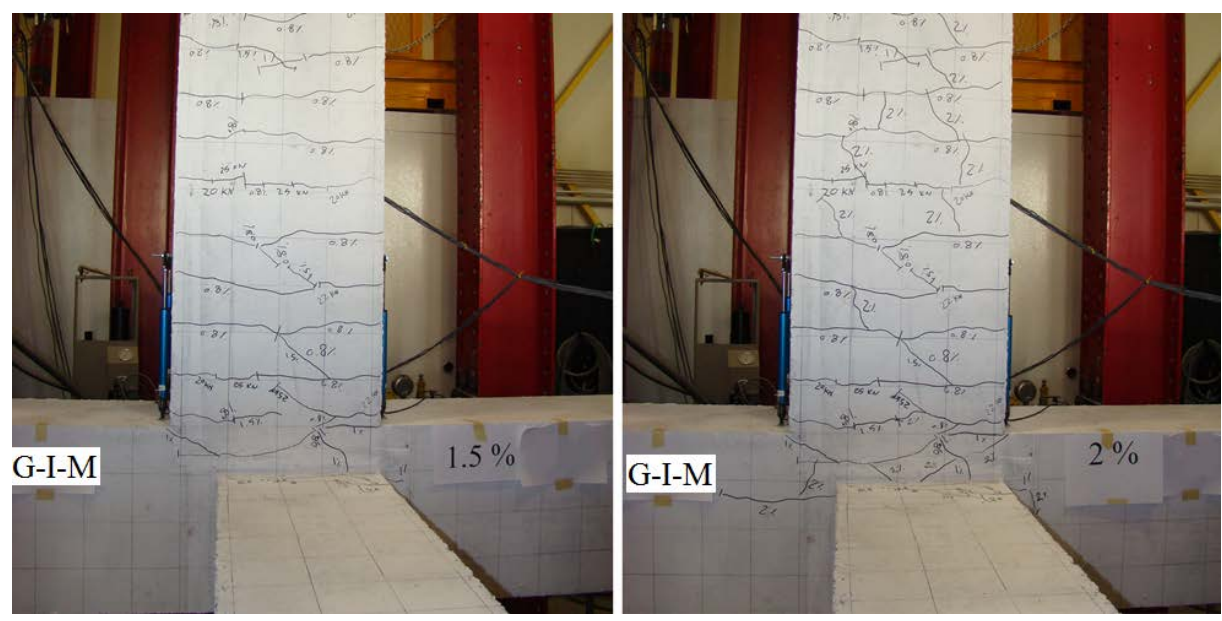

(c) Specimen G-I-M 
TEST RESULTS AND DISCUSSION

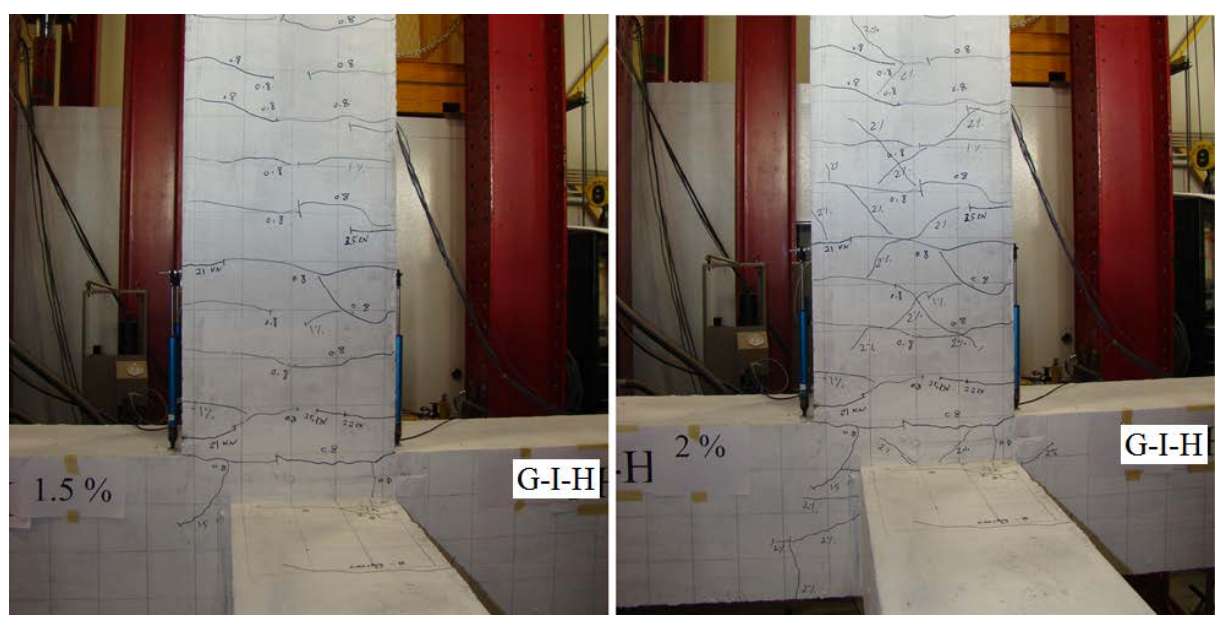

(d) Specimen G-I-H

Figure 5.8 - Condition of Series I specimens after 1.5 and 2\% drift ratio

At $2 \%$ drift ratio, formation of diagonal shear cracks in the main beam started in the GFRP-RC specimens. Penetration of the shear cracks into the joint in steel-RC and GFRP-RC specimens started at 1.5 and $2 \%$ drift ratio, respectively.
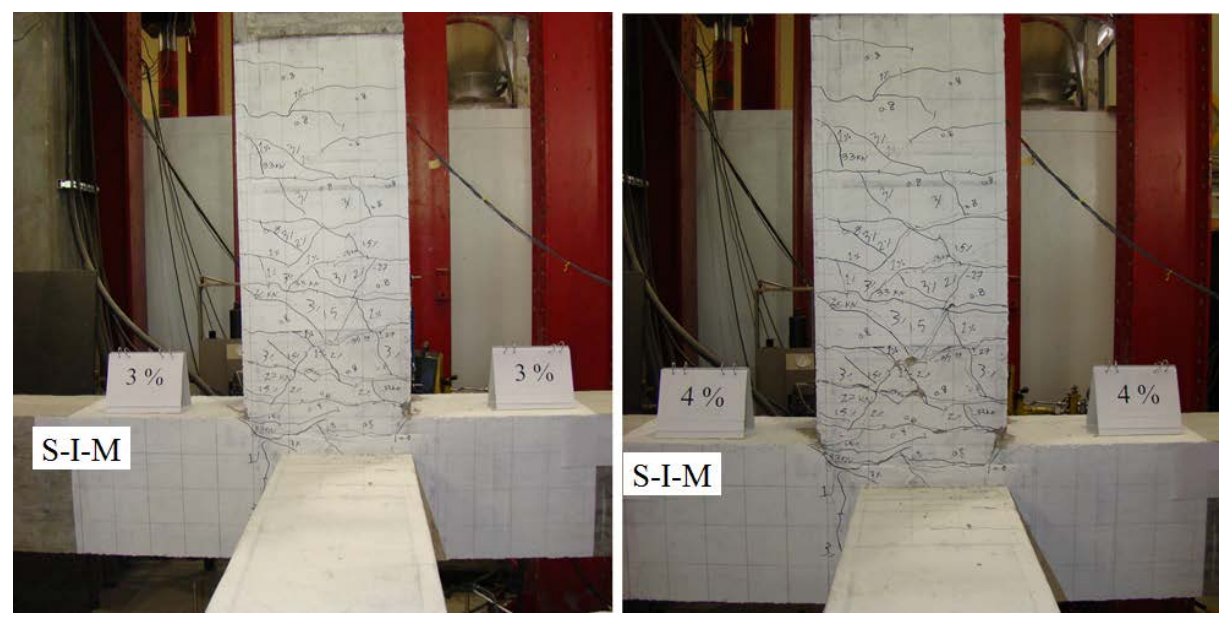

(a) Specimen S-I-M 


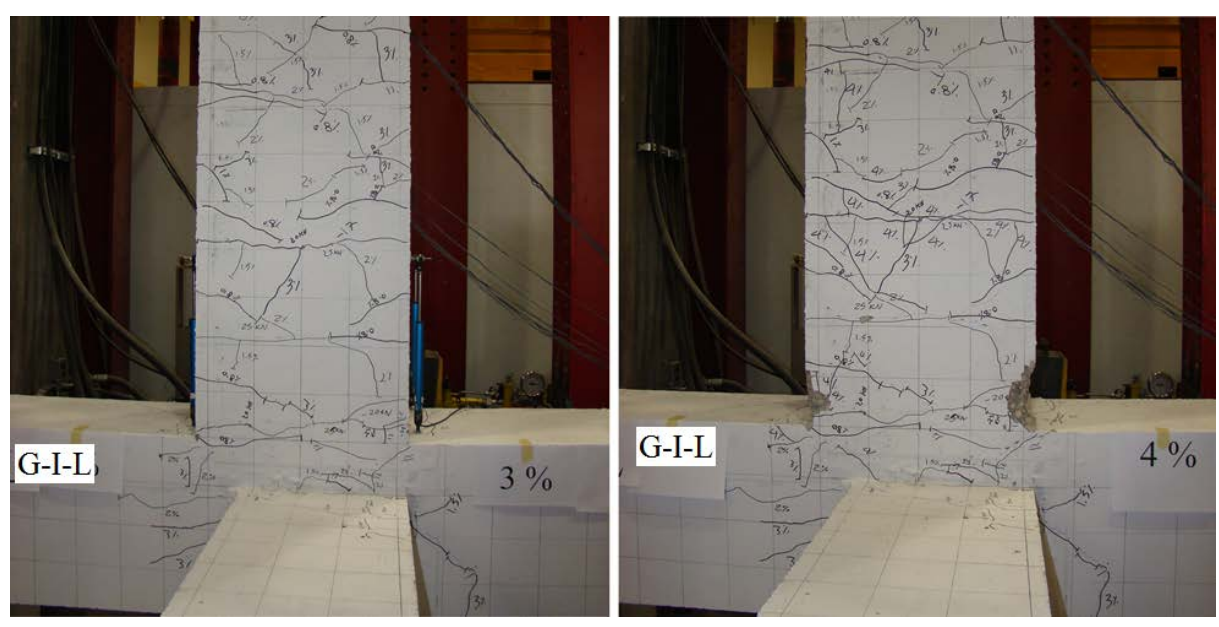

(b) Specimen G-I-L

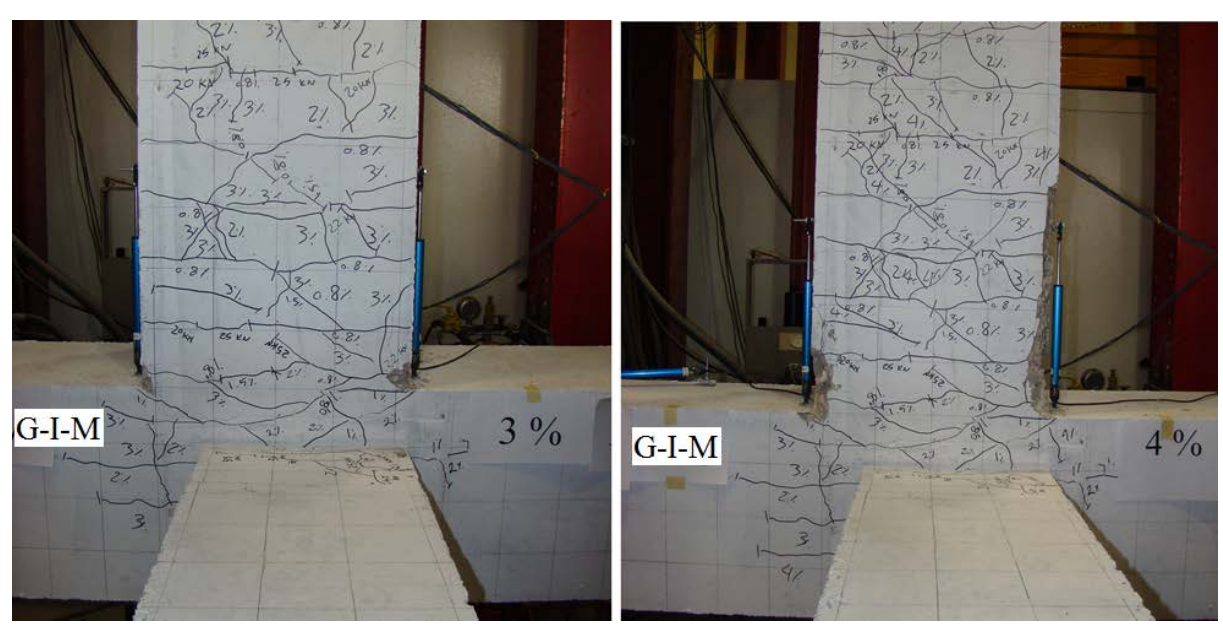

(c) Specimen G-I-M

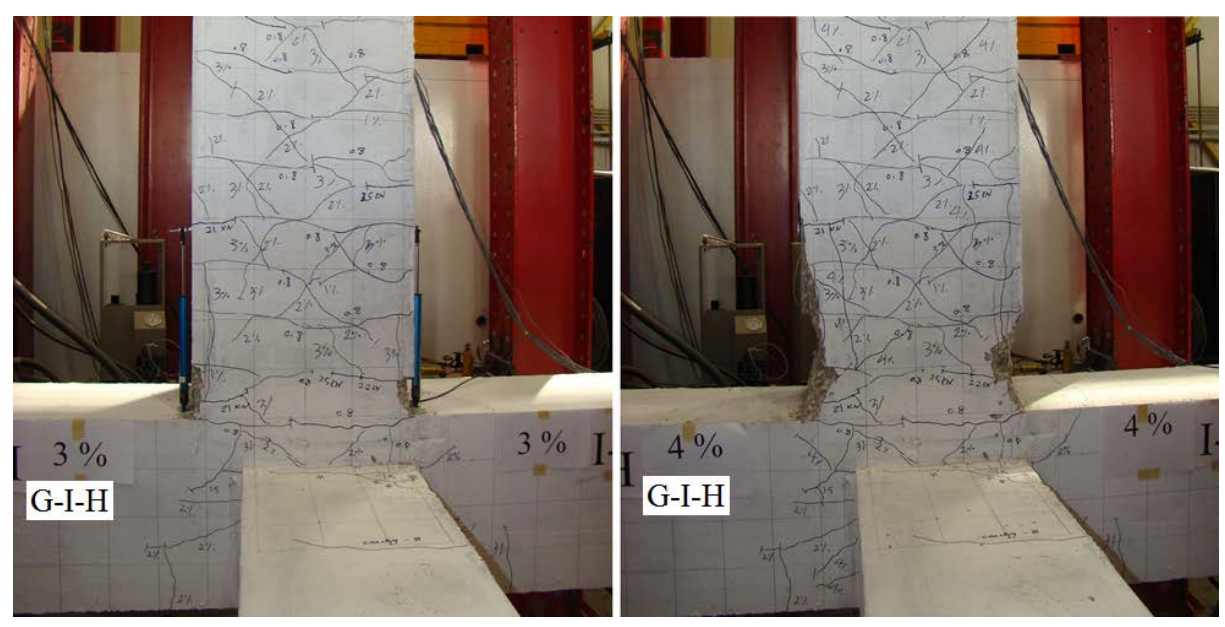

(d) Specimen G-I-H 


\section{TEST RESULTS AND DISCUSSION}

Figure 5.9 - Condition of Series I specimens after 3 and 4\% drift ratio

The first sign of concrete crushing at the beam-column interface was observed at 3\% drift ratio for all specimens, except for G-I-L, in which the damage started at $4 \%$ drift ratio. The concrete crushing in the beam cover expanded rapidly in specimens G-I-M and G-I-H at 4\% drift ratio. The shear cracks propagation inside the joint was significant in the GFRP-RC specimens at $4 \%$ drift ratio, in comparison to S-I-M, which had only few numbers of shear cracks inside the joint at that stage.
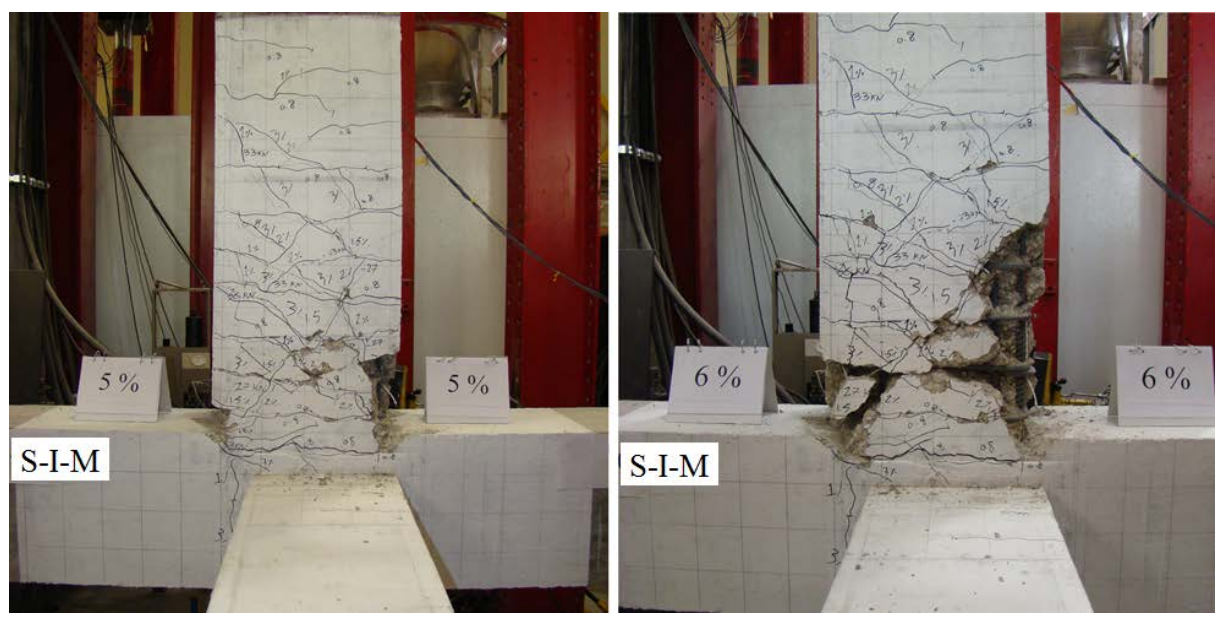

(a) Specimen S-I-M
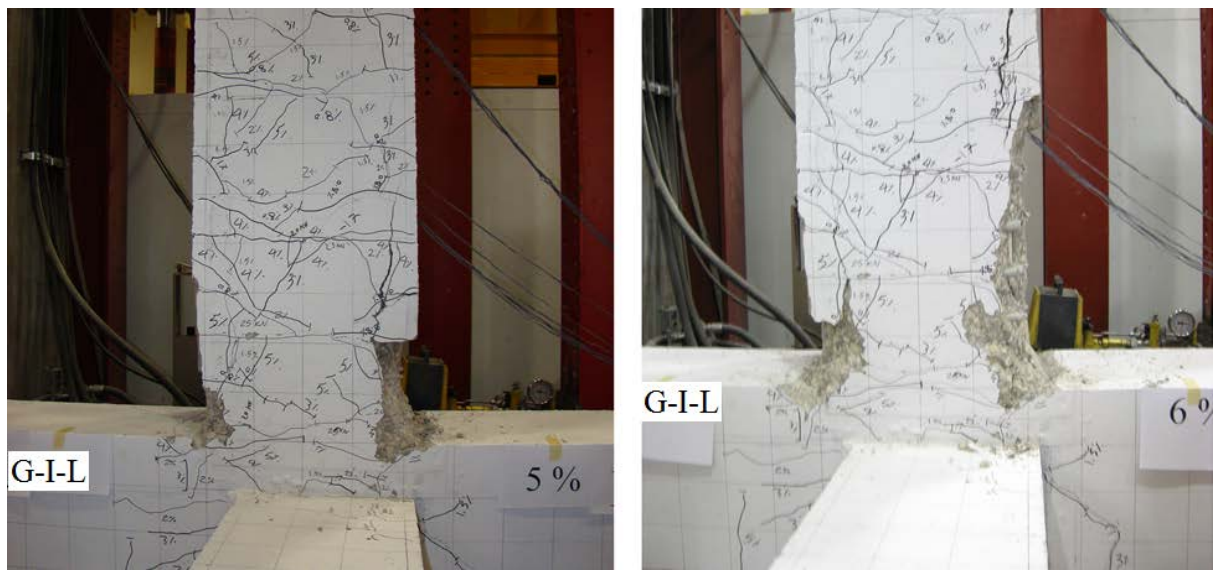

(b) Specimen G-I-L 

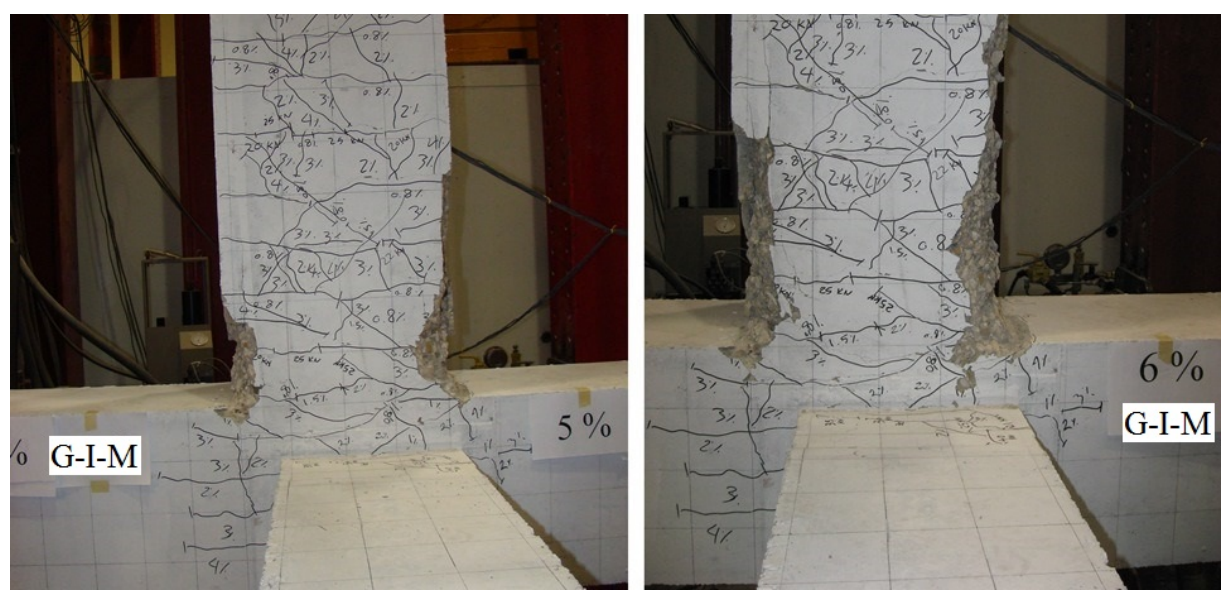

(c) Specimen G-I-M
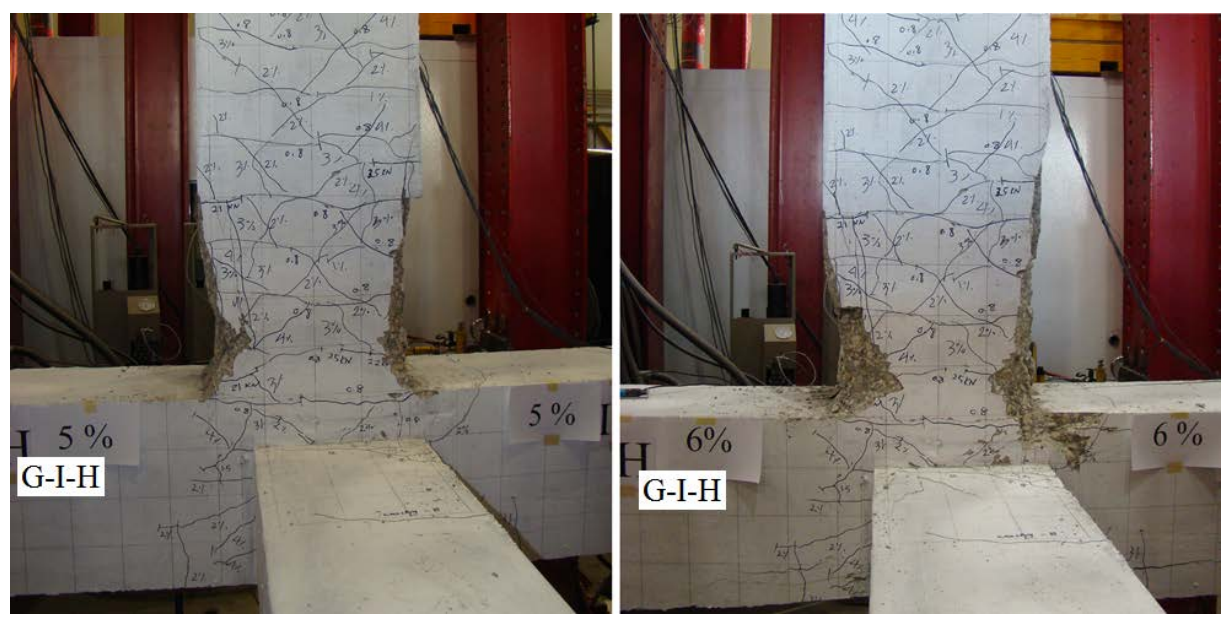

(d Specimen G-I-H

Figure 5.10 - Condition of Series I specimens after 5 and 6\% drift ratio

At 5\% drift ratio, the concrete spalling in the beam cover expanded in the specimens. The damage was more severe in specimens G-I-L and S-I-M. In both specimens all of the concrete cover was removed from the sides of the beam and the longitudinal reinforcement was exposed. Expansion of the damage resulted in failure of these specimens at 7\% drift ratio.

Specimens G-I-M and G-I-H, however, showed more stable behaviour. Although there was some damage in the beam, it didn't penetrate into the joint. However, comparing the shear cracks at 


\section{TEST RESULTS AND DISCUSSION}

the joints indicates that diagonal cracks propagation was faster in Specimen G-I-H comparing to Specimen G-I-M. It was expected since the applied joint shear stress in Specimen G-I-H was higher.

The first sign of concrete push-off underneath the joint area in specimens G-I-H and G-I-L was observed at 5 and 6\% drift ratio, respectively. The damage occurred at the side of the joint that the lateral beams were applying tension. As explained earlier, this tension reduced the bond strength between the beam longitudinal bars and the joint concrete, which resulted in more bar movements. The movement of the bars, while they were under compression loads, pushed off the concrete cover underneath the specimen (Figure 5.11).
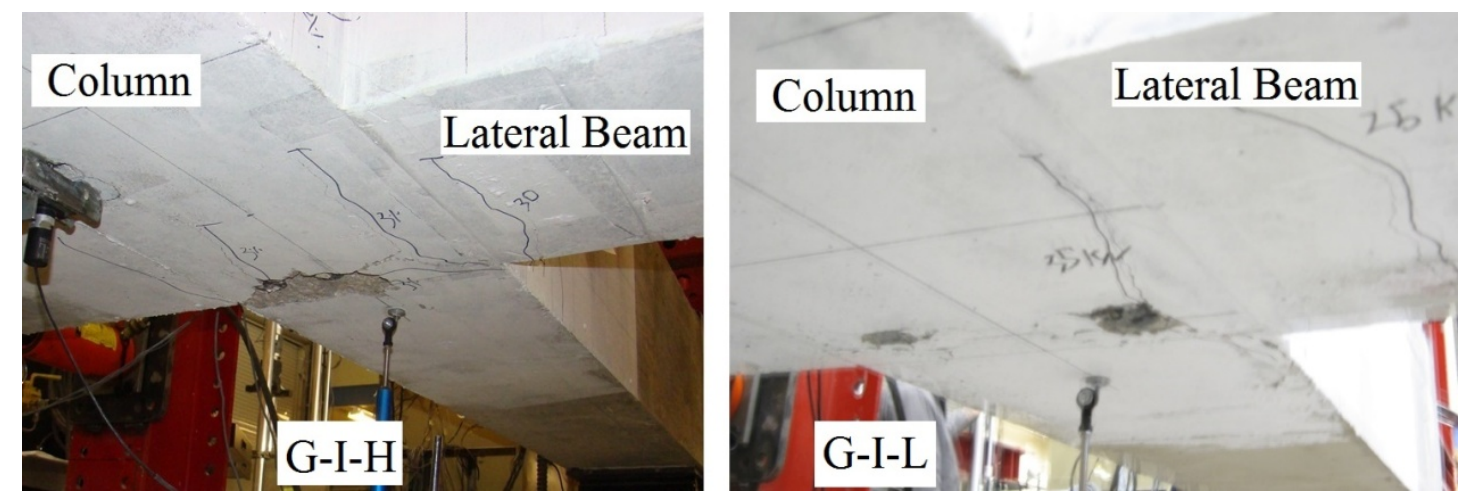

Figure 5.11 - Concrete push-off underneath specimens G-I-H and G-I-L 

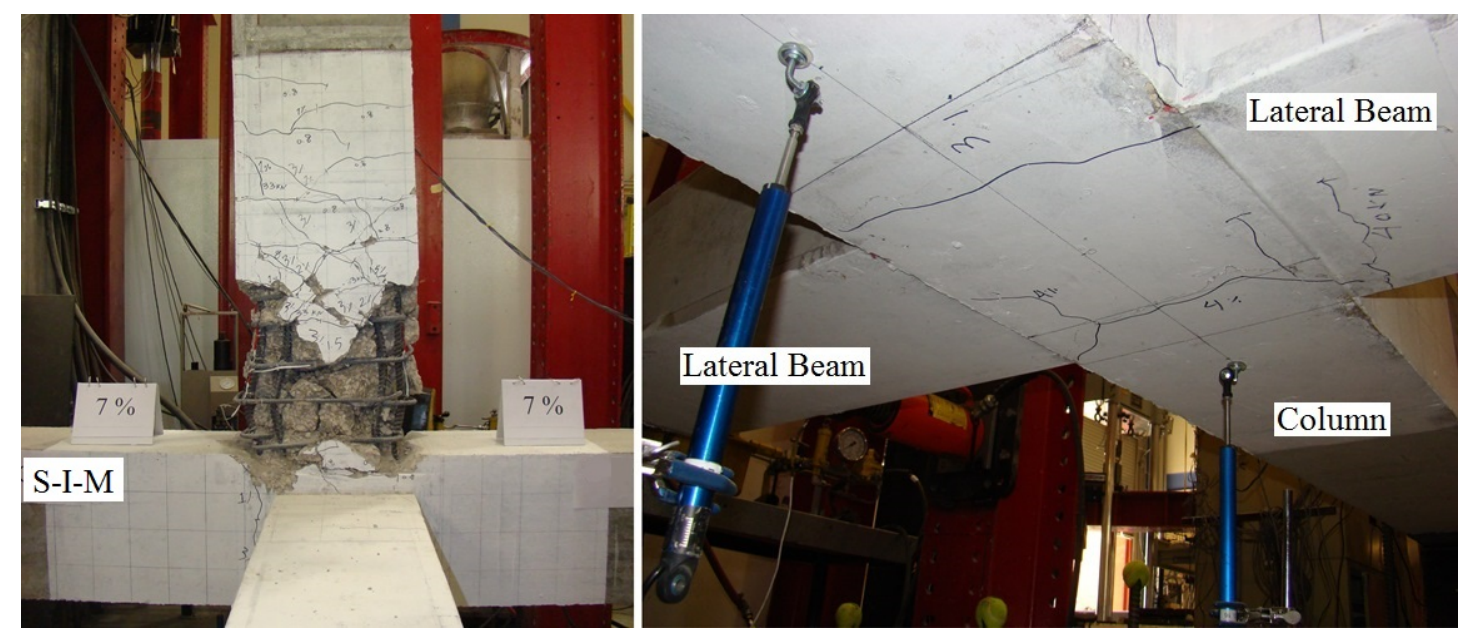

(a) Specimen S-I-M
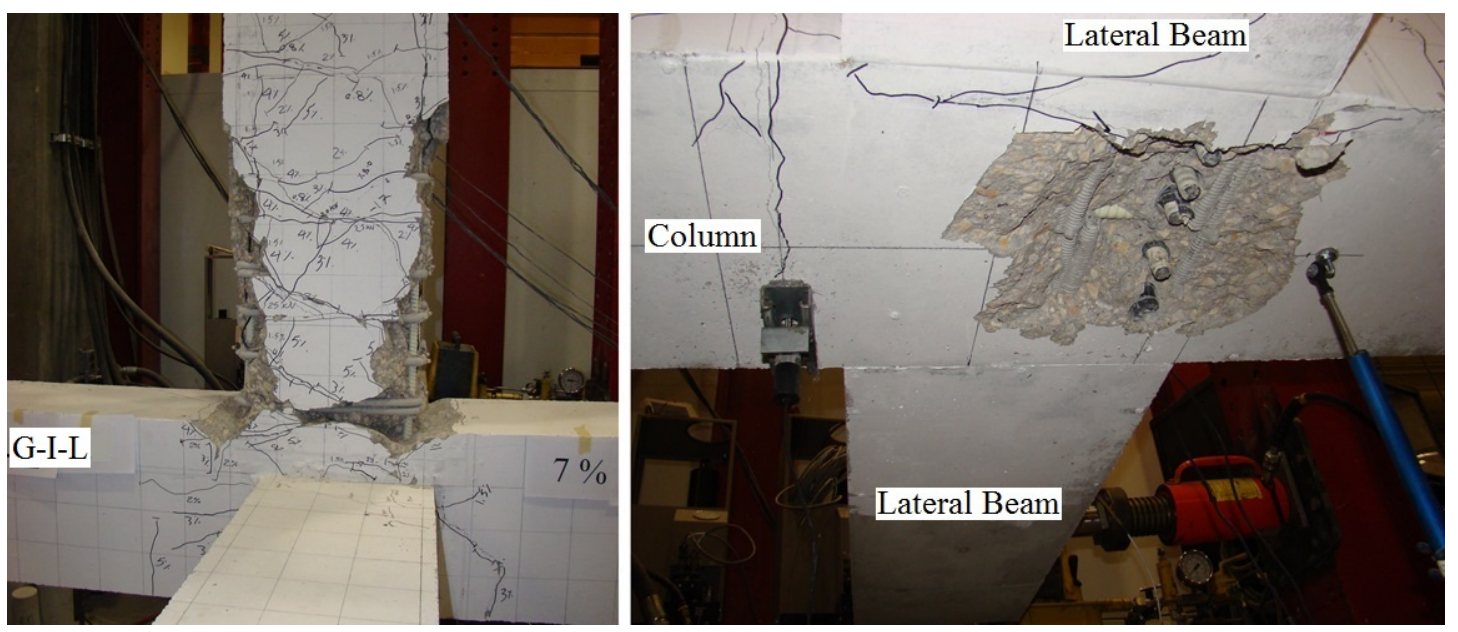

(b) Specimen G-I-L

Figure 5.12 - Specimens S-I-M and G-I-L at 7\% drift ratio (failure)

Lack of the reinforcement confinement in S-I-M resulted in buckling of the beam longitudinal bars and failure of the specimen at 7\% drift ratio. Specimen G-I-L also failed at 7\% drift ratio due to rupture of the beam longitudinal bars. Figure 5.12 shows the face of the joint (underneath specimen) after failure of the specimens. Due to sufficient anchorage and low joint shear stress, in respect to the steel-RC beam-column joints shear capacity, there was no sign of concrete pushoff underneath Specimen S-I-M. 


\section{TEST RESULTS AND DISCUSSION}

However, because of slippage of the bars, concrete push-off at the tension side of the joint was observed in Specimen G-I-L. The Figure 5.12 shows that the head portion of the bars was removed, facilitating movement of the bars inside the joint.

The first sign of concrete push-off was observed at 7\% drift ratio underneath Specimen G-I-M (Figure 5.13). In this specimen initiation of the damage was not limited to the tension side of the joint only; however, the damage was more severe at that side.

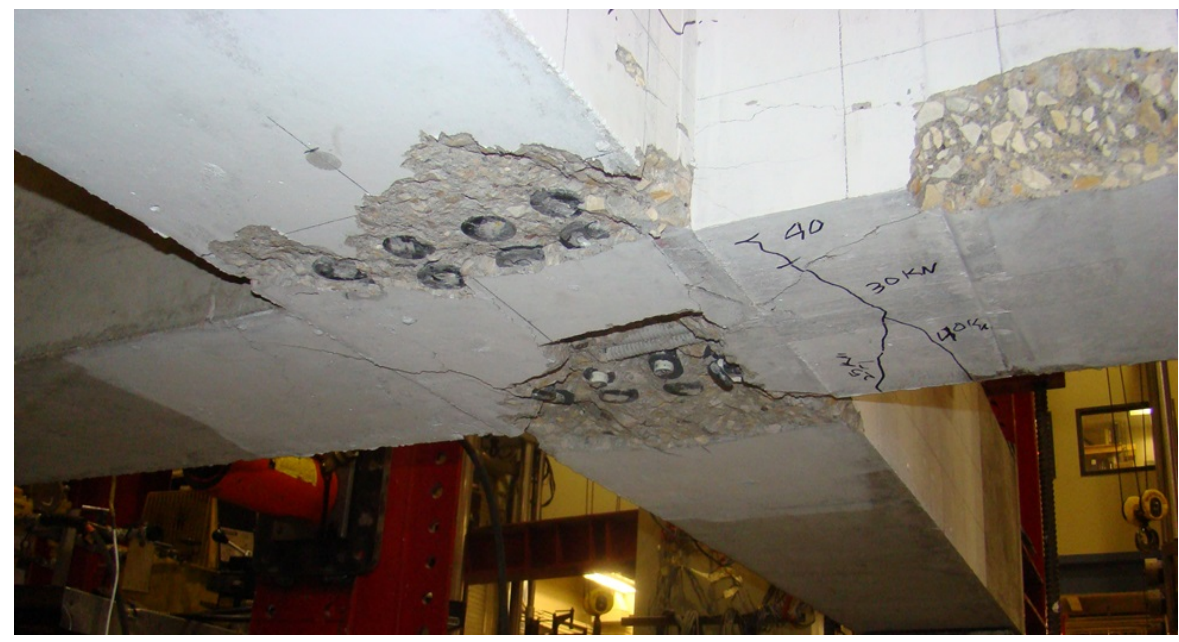

Figure 5.13 - Concrete push-off underneath specimens G-I-M
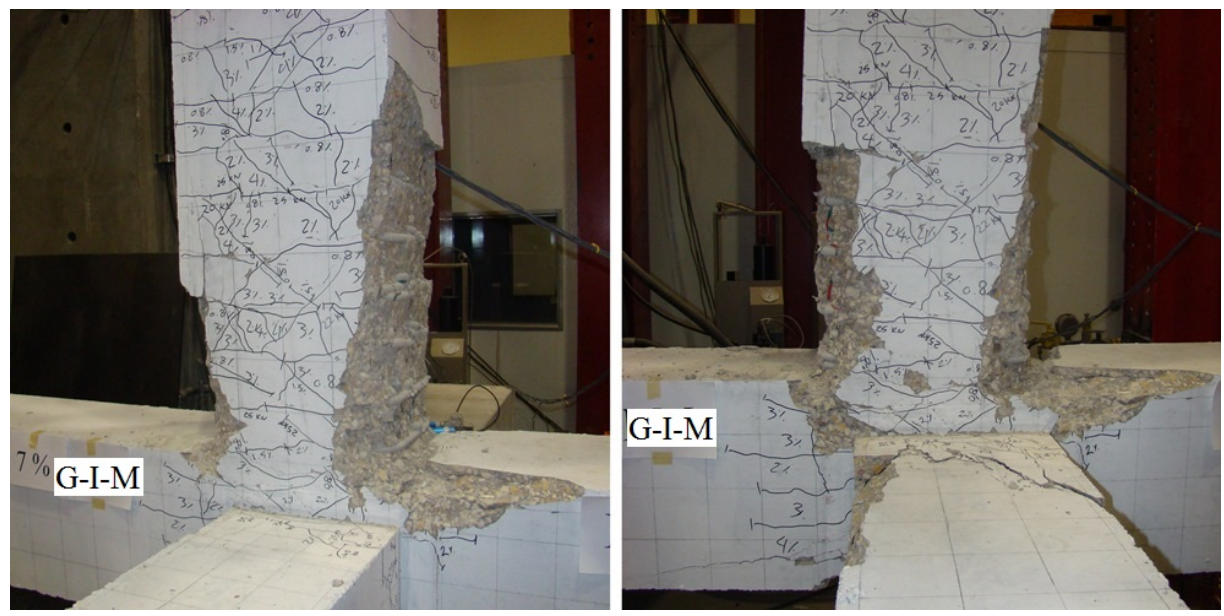

(a) Specimen G-I-M 


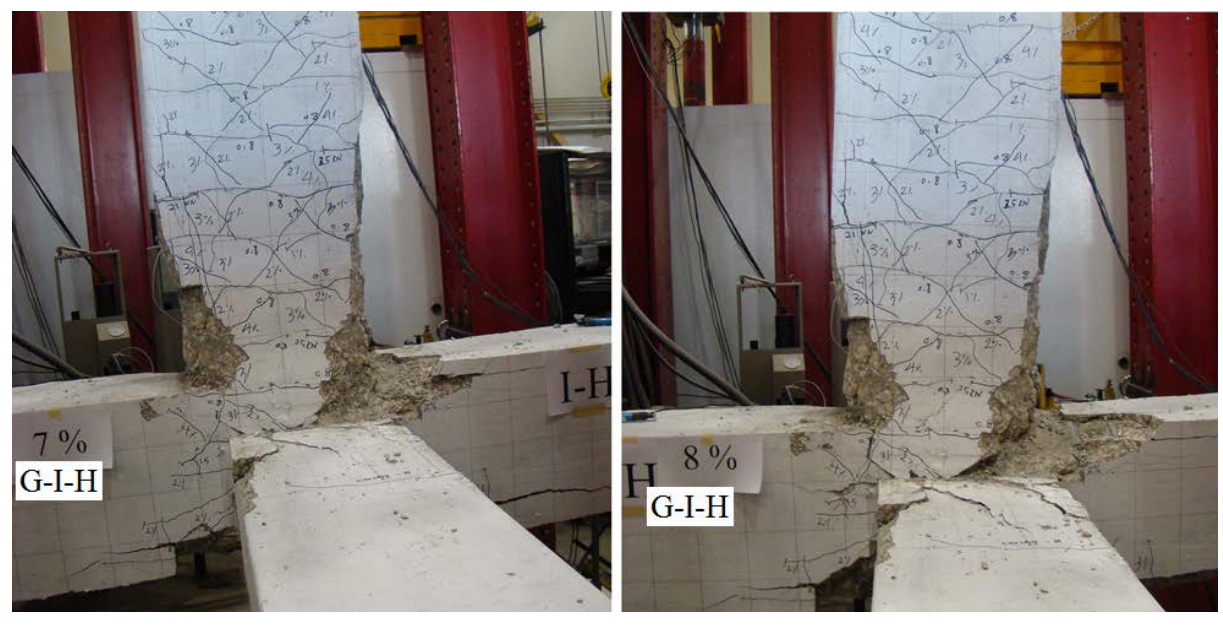

(b) Specimen G-I-H

Figure 5.14 - Condition of specimens G-I-M and G-I-H after 7 and 8\% drift ratio

Specimen G-I-H showed similar behaviour to Specimen G-I-M at low drift ratios; however, after 6\% drift ratio, damage and strength degradation was more severe in Specimen G-I-H.
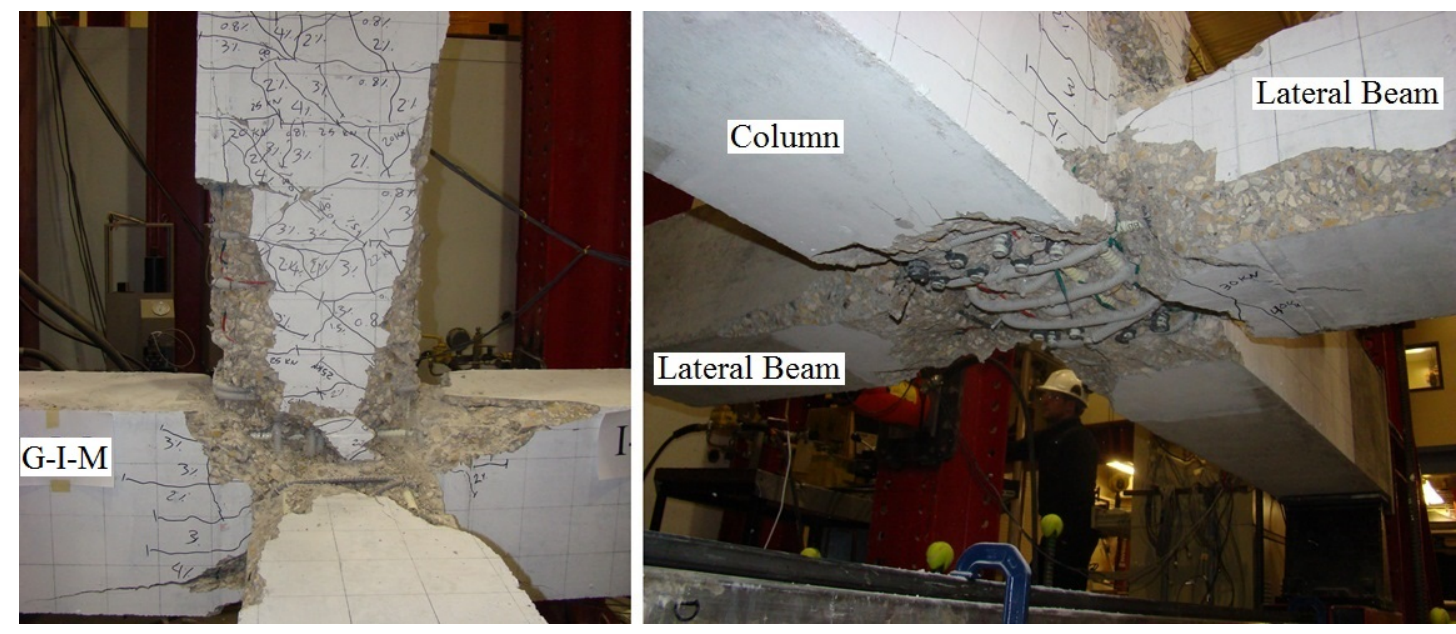

(a) Specimen G-I-M 
TEST RESULTS AND DISCUSSION
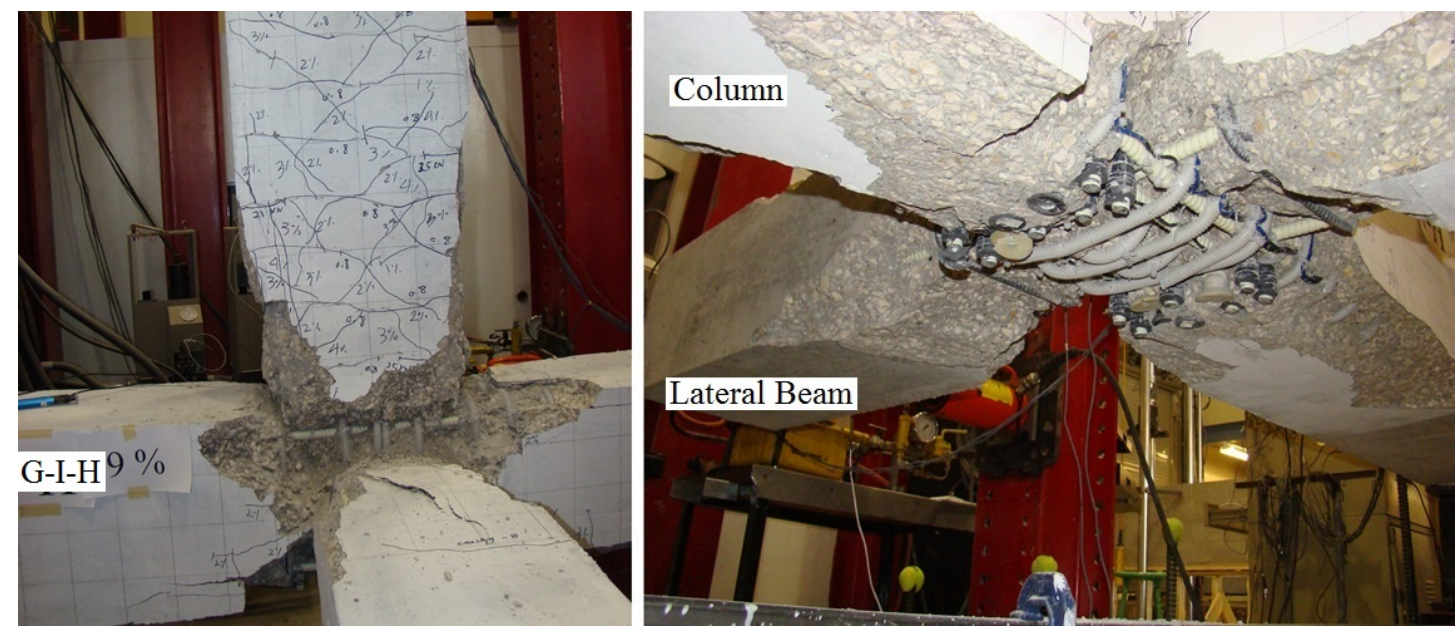

(b) Specimen G-I-H

Figure 5.15 - Condition of specimens G-I-M and G-I-H at 9\% drift ratio (failure)

Figure 5.15 shows the condition of specimens G-I-M and G-I-H after failure. The damage was extended to the lateral beams and the columns. However, there were no signs of bar rupture in column reinforcement. The magnitude of the damage explains the capacity reduction of the specimens at the final stage. According to the figure, center of the damage was closer to the joint in Specimen G-I-H. That was because of the lower beam-to-column flexural strength ratio in this specimen.

\subsubsection{Mode of failure}

In Specimen S-I-M, except for a few numbers of diagonal cracks, no damage penetration to the joint was observed. High column-to-beam flexural strength ratio of the specimen resulted in the formation of the plastic hinge in the beam, away from the joint. Moreover, because of the low applied shear stress in the joint $\left(1.0 \sqrt{f^{\prime}}\right)$, compared to the maximum allowable value in CSA A23.3-04 (CSA 2004) $\left(1.6 \sqrt{f^{\prime}}\right.$ ), the joint remained intact during the test. 


\section{TEST RESULTS AND DISCUSSION}

Specimen S-I-M exhibited ductile behaviour with wide hysteresis loops and considerable pinching, as expected for steel-RC beam-column joints. Excessive concrete damage in the beam, due to formation of the plastic hinge, reduced confinement of the embedded beam longitudinal bars. The failure occurred due to buckling of the bars at $7 \%$ drift ratio. There were no signs of concrete damage underneath the joint, indicating sufficient anchorage and no bar slippage.

Specimen G-I-L showed linear behaviour up to failure, at 7\% drift ratio. The failure occurred due to rupture of the beam longitudinal bars, while the specimen was pulled toward the negative direction. The tensile failure mode of G-I-L was in contrast with the compressive failure mode design of the beam. The tensile failure occurred due to slippage of the beam longitudinal bars. By some of the beam bars slippage, the forces that had been carried by the slipped bars were redistributed among the remaining un-slipped bars. This process can be interpreted as reduction of the reinforcement ratio. Since the reinforcement ratio reduction was considerable, the section acted as an under-reinforced section and tensile rupture of the bars occurred prior to the concrete crushing.

In contrary to specimen G-I-L, where the main damage was due to flexural failure in the beam, Specimen G-I-M had both beam flexural and joint shear damage. However, it should be mentioned that the first sign of damage penetration to the joint was observed at $7 \%$ drift ratio, which was beyond the expected lateral story drift in an actual building. The specimen showed stable behaviour with the minimum damage up to $6 \%$ drift ratio; however, the joint concrete damage increased sharply afterwards, reflected as considerable pinching and wide loops in the hysteresis diagram. 


\section{TEST RESULTS AND DISCUSSION}

The specimen behaved nonlinearly after 6\% drift ratio, in contrast to the expected linear behaviour of a GFRP-RC element. The reason can be explained by the different mode of failure of the specimen compared to Specimen G-I-L. Specimen G-I-L failed due to flexural failure in the beam while the joint remained intact during the test. Consequently, the joint was able to provide a sufficient anchorage for the beam longitudinal reinforcement up to the rupture of the bars. As a result, the specimen maintained its stiffness, and behaved linearly until the failure of the beam occurred. In Specimen G-I-M, on the other hand, the damage induced to the joint was considerable due to the high joint shear stress. Moreover, using headed-end bars could not provide sufficient anchorage at high drift ratios. Therefore, significant bar slippage occurred in the specimen. The joint damage and slippage of the bars significantly reduced the stiffness of the specimen, and resulted in a deformable behaviour (increase in the beam tip deflection while the lateral load remained constant).

Same as Specimen G-I-M, simultaneous flexural damage in the beam and shear damage in the joint resulted in failure of Specimen G-I-H (Figure 5.15). The specimen showed linear behaviour up to $6 \%$ drift ratio; however, after that stage concrete damage gradually reduced stiffness and strength of the specimen. The test was stopped at $9 \%$ drift ratio due to considerable capacity loss. The gradual decrease in lateral stiffness of the specimen resulted in significant deformability and nonlinear behaviour at high drift ratios. It should be mention that the nonlinear behaviour occurred at drift ratios higher than $6 \%$, which was beyond the actual lateral displacement of a rationally designed framed structure.

Figure 5.16 to Figure 5.18 show the maximum displacement of the beam longitudinal bars inside the joint. The displacement was captured by the high accuracy LVDT attached to the beam longitudinal bars head. The upper line indicates the maximum upward displacement of the bars 


\section{TEST RESULTS AND DISCUSSION}

(into the joint when bars in tension) from the initial position and the lower line indicates the maximum downward displacement (outside the joint when bars in compression). It should be mentioned that the LVDT was attached to the bars in compression side of the joint (the side that lateral beams apply compression). According to the graphs, bar slippage in Specimen G-I-L was insignificant during all loading stages. Specimens G-I-M and G-I-H, on the other hand, exhibited considerable slippage at drift ratios higher than $4 \%$.

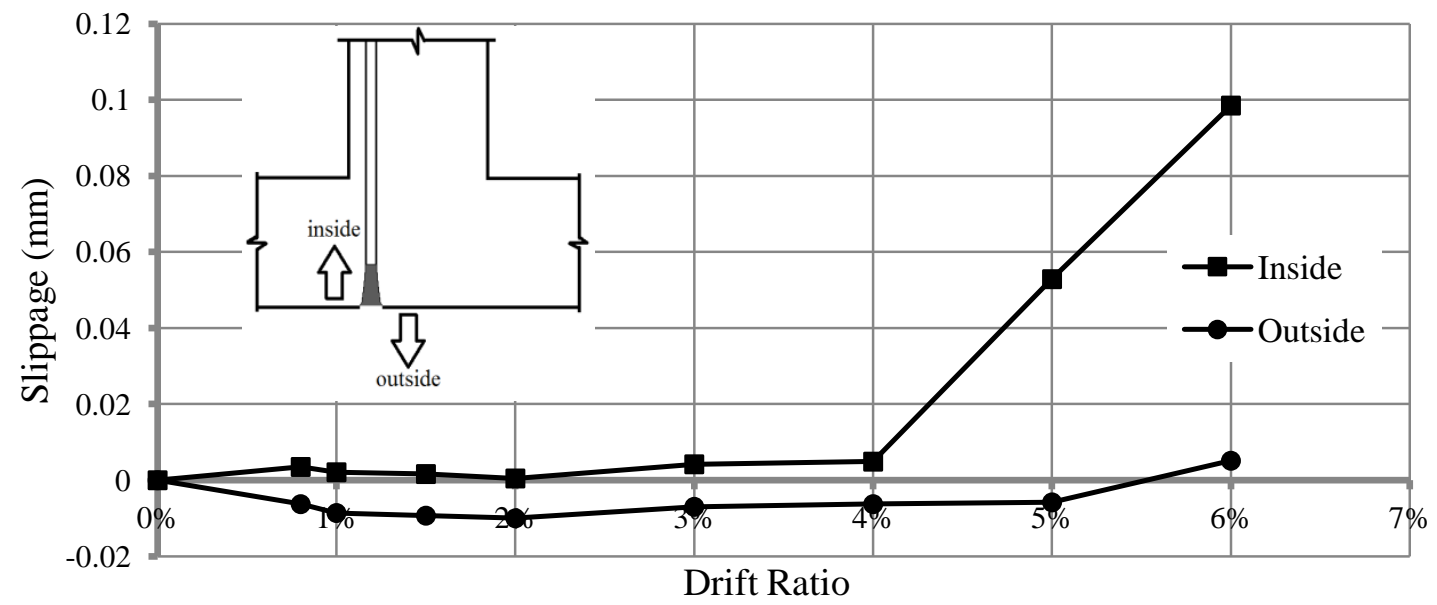

Figure 5.16 - Bar slippage in Specimen G-I-L

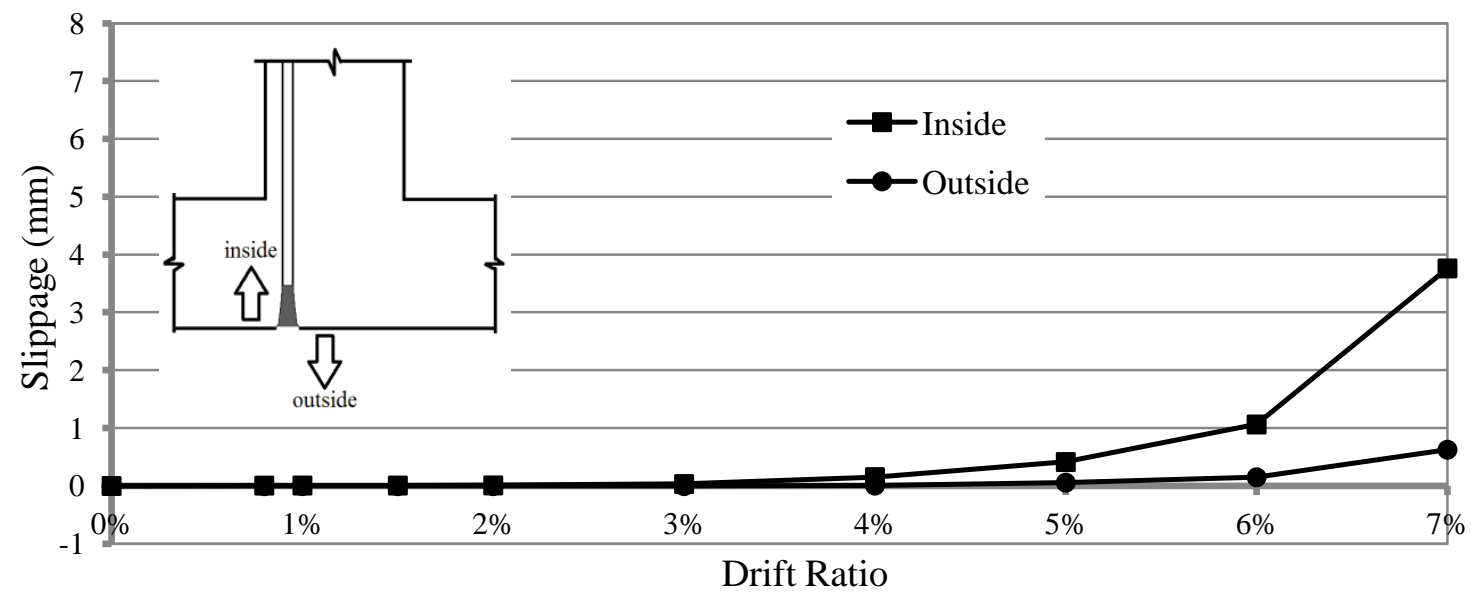

Figure 5.17 - Bar Slippage in Specimen G-I-M 
TEST RESULTS AND DISCUSSION

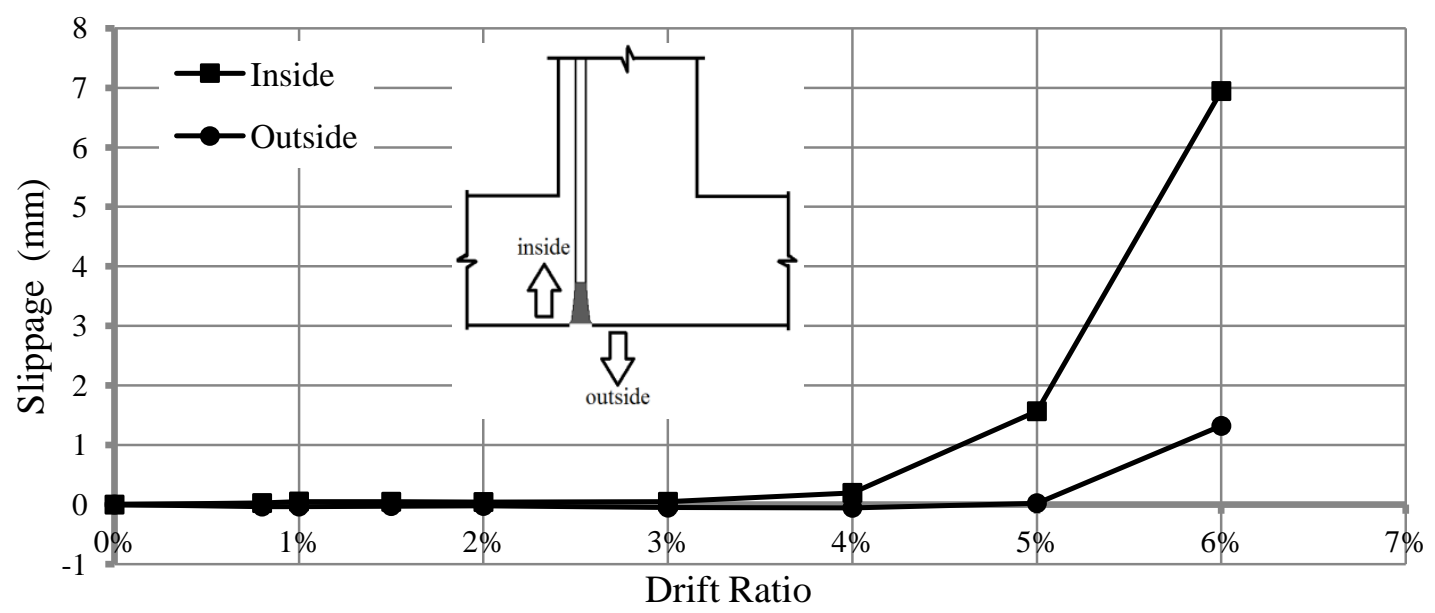

Figure 5.18 - Bar slippage in Specimen G-I-H

\subsubsection{Lateral drift-strain relationship}

For each specimen, a total number of 19 strain gauges were installed at different locations on the reinforcing bars and stirrups. Readings of these strain gauges were monitored and stored on a computer during the test by means of a data acquisition (DAQ) system with a rate of 8 readings per second. The following section discusses some of the observations from the specimens' behaviour.

Figure 5.19 shows average of the strain values obtained from the stirrups located in the joint area (strain gauges No.13 to 17). The measured strain in Specimen S-I-M was generally lower than the specimens reinforced with GFRP stirrups. This was expected since modulus of elasticity of the steel reinforcement was considerably higher than that of the GFRP bars. However, it should be mentioned that higher stiffness of steel, on the other hand, resulted in higher shear forces induced to the joint at low drift ratios. This explains the higher strains of the steel stirrups, compared to GFRP stirrups, in drift ratios lower than $2 \%$. 


\section{TEST RESULTS AND DISCUSSION}

For the GFRP-RC beam-column joints, as expected, specimens with higher joint shear ratios showed higher values of stress in the stirrups. The rate of strain in Specimen G-I-M increased considerably after 5\% drift ratio. This was due to the concrete damage induced to the joint, which increased the share of stirrups in carrying the applied shear loads. The strain gauges malfunctioned after 7\% drift ratio in G-I-M.

The average strain in the stirrups in Specimen G-I-H decreased after $7 \%$ drift ratio due to excessive stiffness degradation of the Specimen. Caused by softening of the joint, decrease in the lateral load capacity of the specimen resulted in lower stress in the beam longitudinal bars. This in turn reduced the applied shear stress in the joint. This was in agreement with the readings of the strain gauges installed on the beam longitudinal bars, which are presented later.

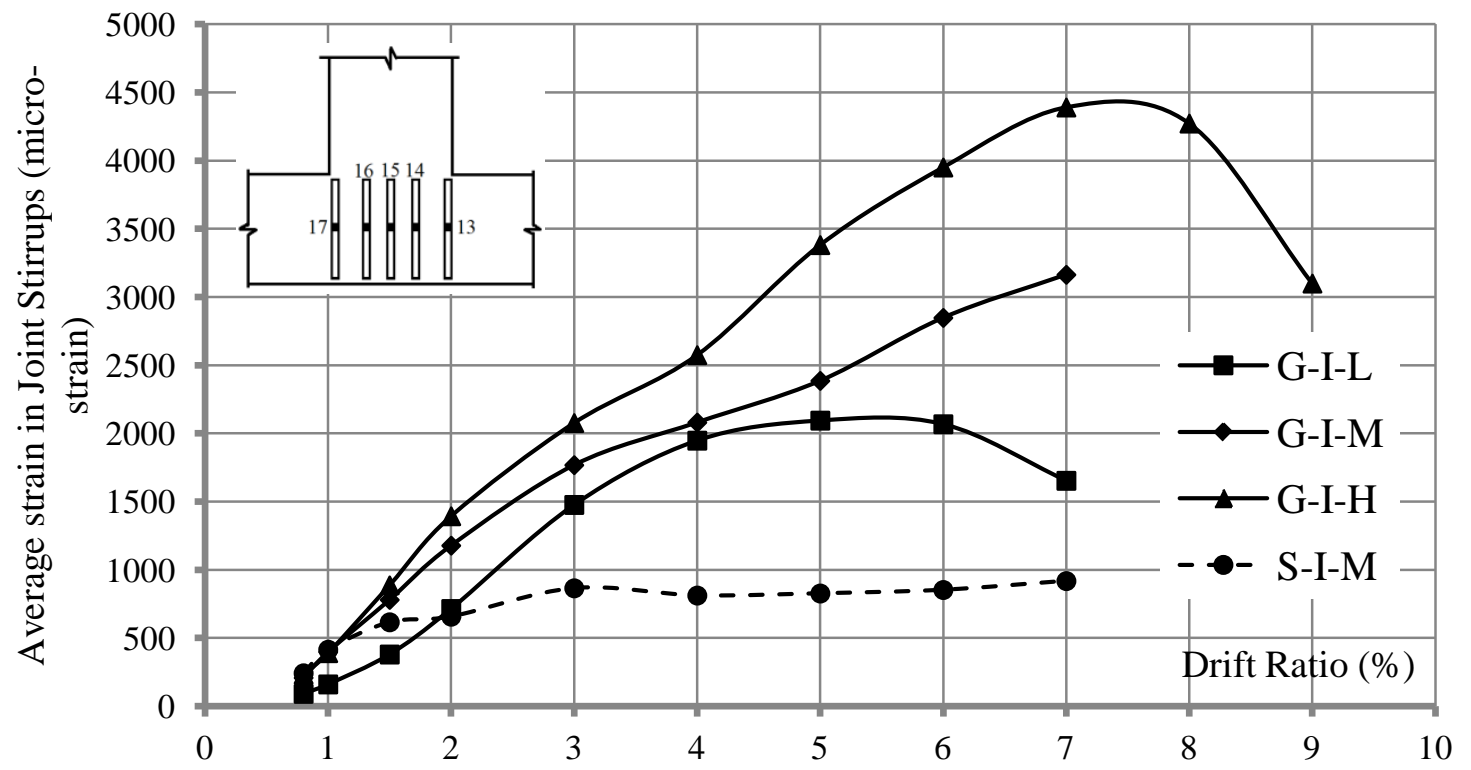

Figure 5.19 - Average joint stirrup strain in the specimens of Series I

Figure 5.20 shows the maximum strain that was captured from Strain Gauge No. 2 (attached to the beam longitudinal bars at the vicinity of the column face) at different drift ratios. As 


\section{TEST RESULTS AND DISCUSSION}

mentioned earlier, the beam longitudinal reinforcement in Specimen S-I-M yielded at $1.0 \%$ drift ratio. Therefore it was expected to observe large strains after that stage. The strain gauge malfunctioned after 3\% drift ratio in Specimen S-I-M.

All three GFRP-RC specimens showed very similar behaviour; however, there was a slight difference in the behaviour of G-I-M and G-I-H at high drift ratios. The strain increased linearly in Specimen G-I-M up to 6\% drift ratio and then the strain gauge malfunctioned. Specimen G-I$\mathrm{H}$, on the other hand, showed nonlinear behaviour starting from $5 \%$ drift ratio. This nonlinear behaviour was because of the excessive damage induced to the joint, which resulted in softening of the specimen and decrease in the beam bars stress. The trend of the max strain-drift ratio curve of Specimen G-I-H was in very good agreement with the hysteresis diagram of the specimen, which indicates the direct relationship between the lateral load carrying capacity and the developed stress in the beam longitudinal bars.

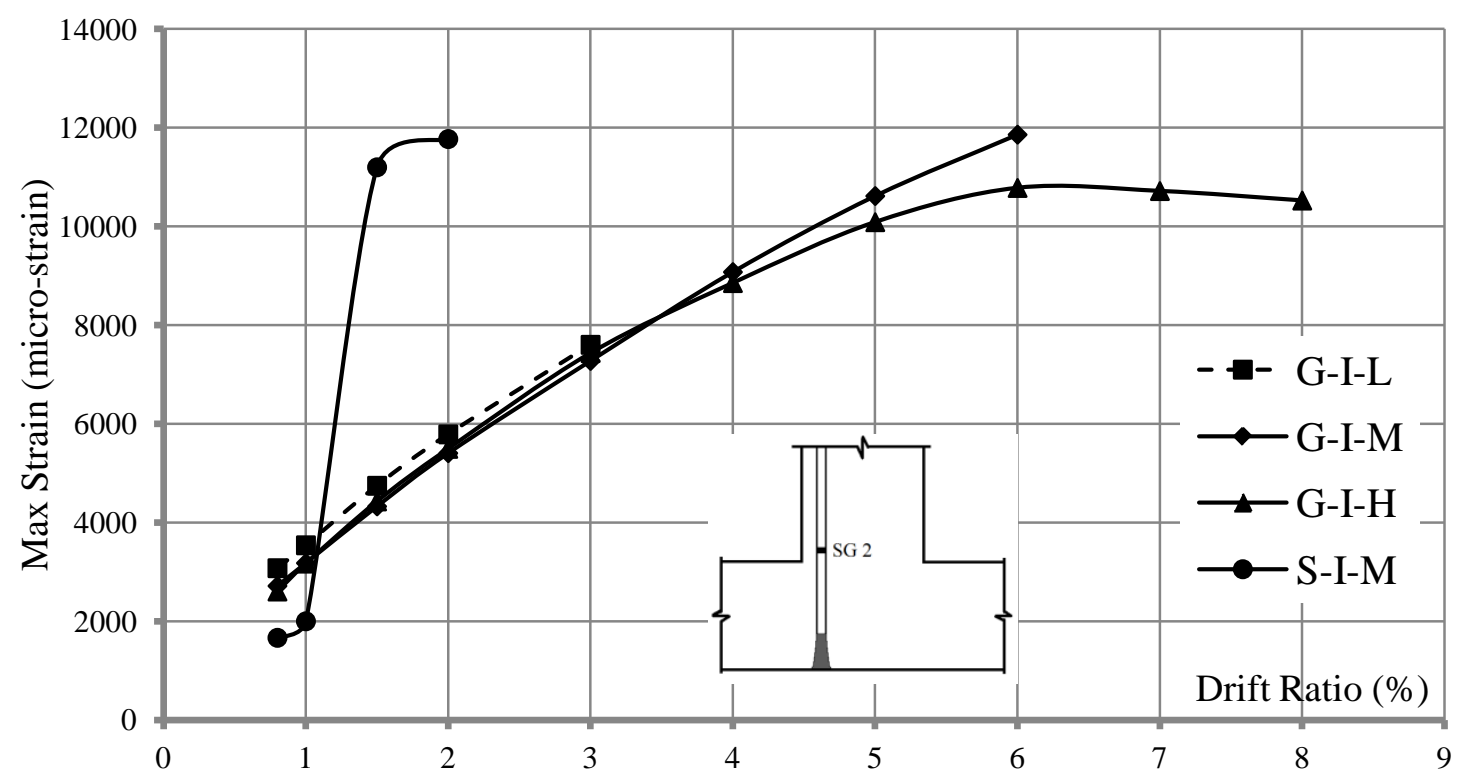

Figure 5.20 - Readings of Strain Gauge No.6 in the specimens of Series I 


\section{TEST RESULTS AND DISCUSSION}

Figure 5.21 shows the strains in the column longitudinal bars at the vicinity of the joint area (average reading of strain gauges No.9 and 10). In Specimen S-I-M, the rate of increase in values of the strains decreased after $1.5 \%$ drift ratio. This behaviour followed the same trend as the maximum lateral load envelop of the specimen. Yielding of the beam longitudinal bars reduced the lateral load carrying capacity of the specimen; consequently, prevented the column bars from gaining higher strains. Despite the large drift ratios in the beam, the applied moment at the column face showed only minor increase. It should be mentioned that the maximum strain captured from the strain gauges was about 850-micro-strains, which was much lower than yielding strain of steel (2300-micro-strain). This indicates that the damage in the specimen was concentrated at the beam, and the column remained intact.

The overall strain trend in the GFRP-RC specimens was also matching with their maximum lateral load envelope. The maximum lateral load, and consequently the maximum applied moment on the column face, was in direct relationship to the strains in the column longitudinal bars. However, because of the excessive damage induced to the joint, a considerable drop in the strains occurred in specimens G-I-M and G-I-H at the final loading stages. 
TEST RESULTS AND DISCUSSION

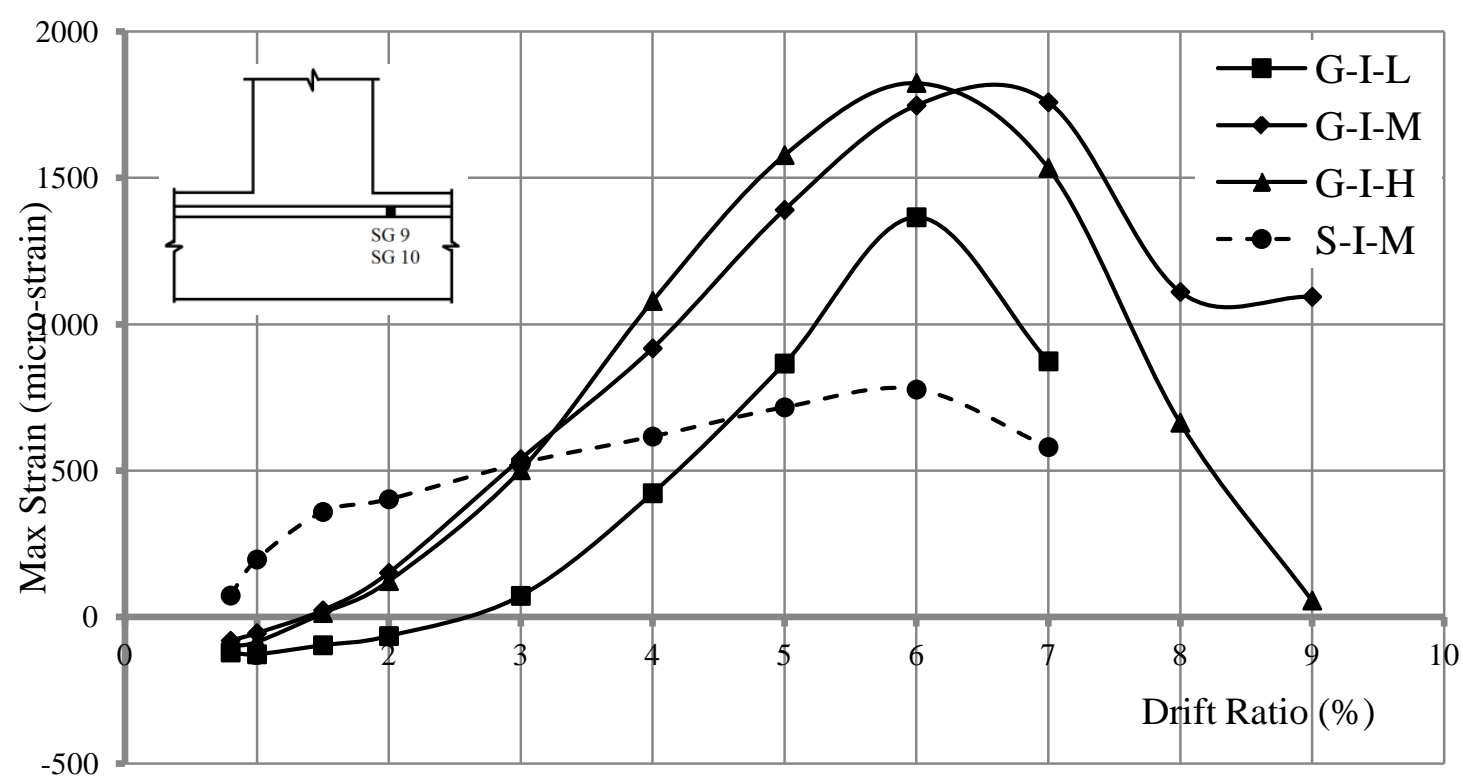

Figure 5.21 - Average strain in column longitudinal bars in the specimen of Series I

Figure 5.22 to Figure 5.25 show the strain flow in the beam longitudinal bars of the specimens in Series I. The figures show the readings of strain gauges No.5, 6 and 8 versus their locations. Defining the location of Strain Gauge No.6 at the column face as the origin (zero), Strain Gauge No.8 was located at 200-mm and Strain Gauge No.5 was located at -240-mm. 


\section{TEST RESULTS AND DISCUSSION}

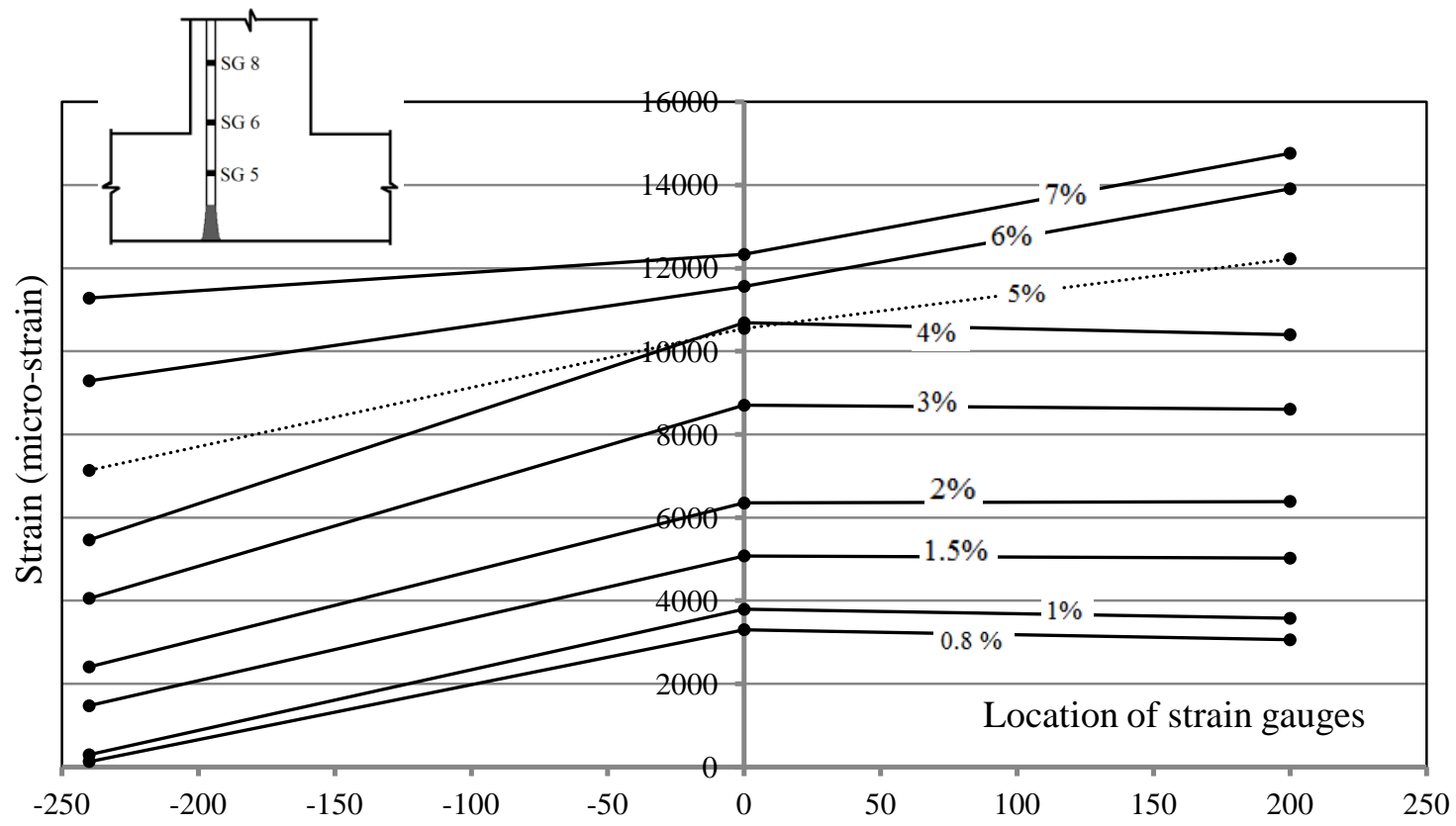

Figure 5.22 - Strain flow in beam longitudinal bar (Specimen G-I-L)

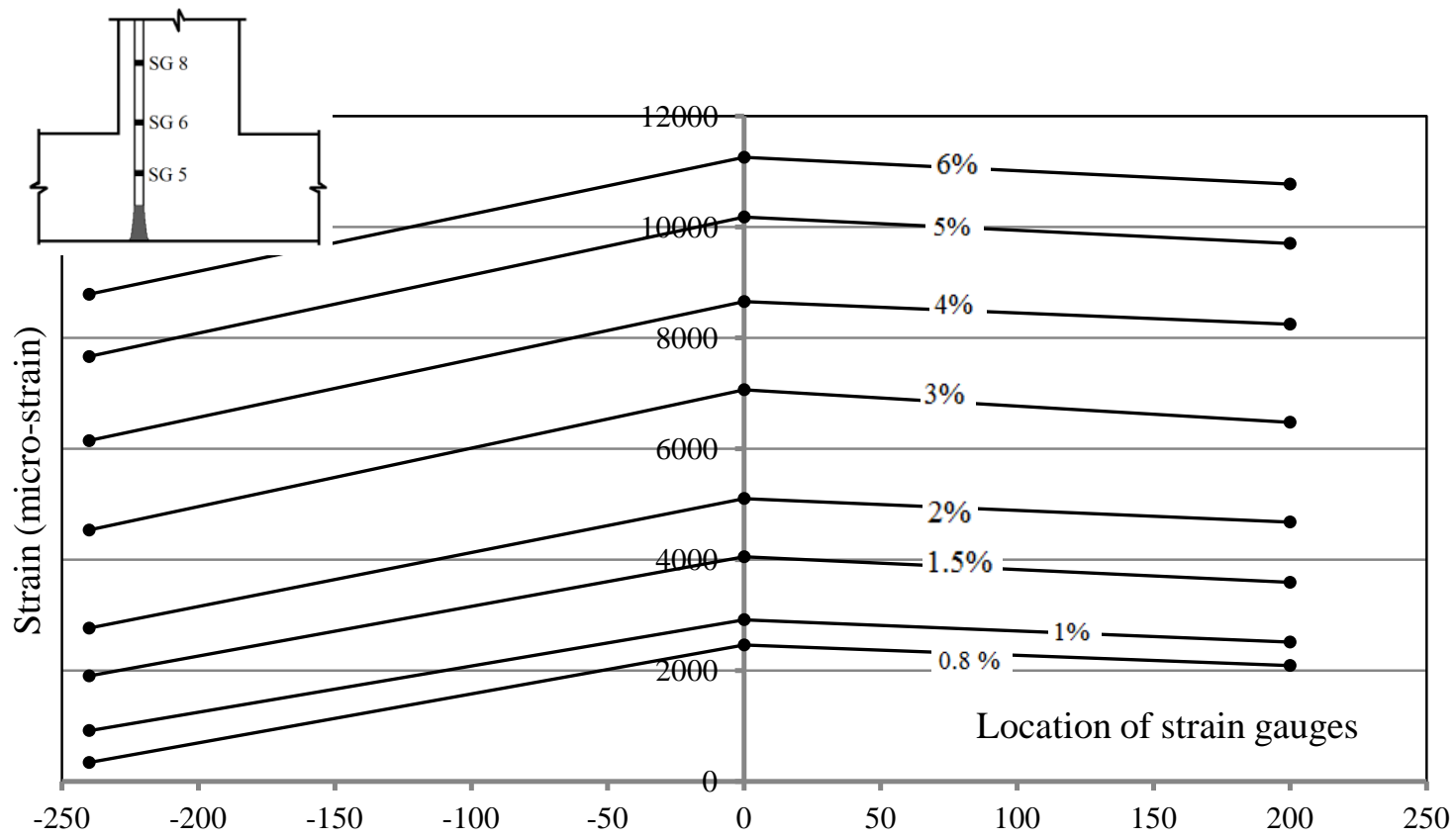

Figure 5.23 - Strain flow in beam longitudinal bar (Specimen G-I-M) 
TEST RESULTS AND DISCUSSION

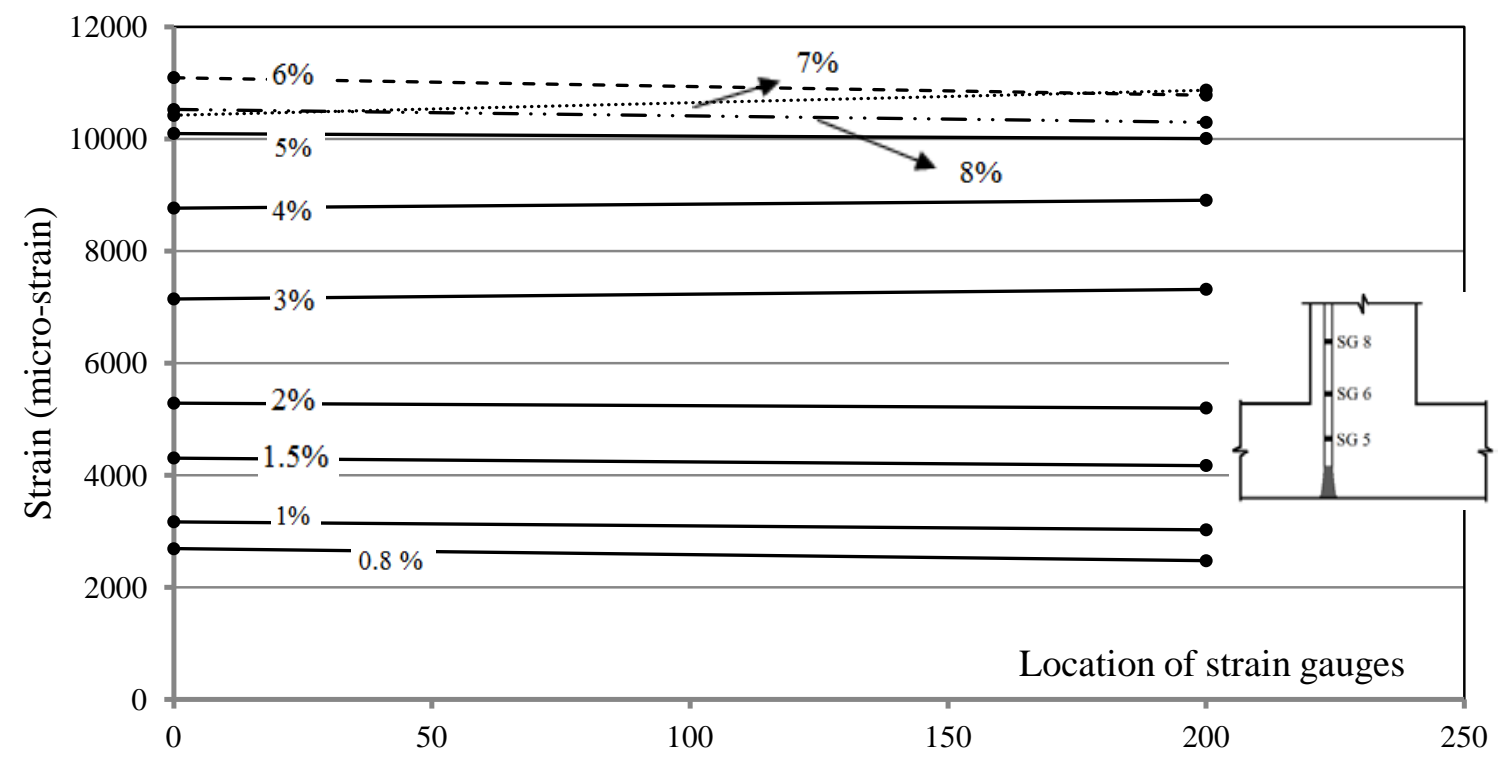

Figure 5.24 - Strain flow in beam longitudinal bar (Specimen G-I-H)

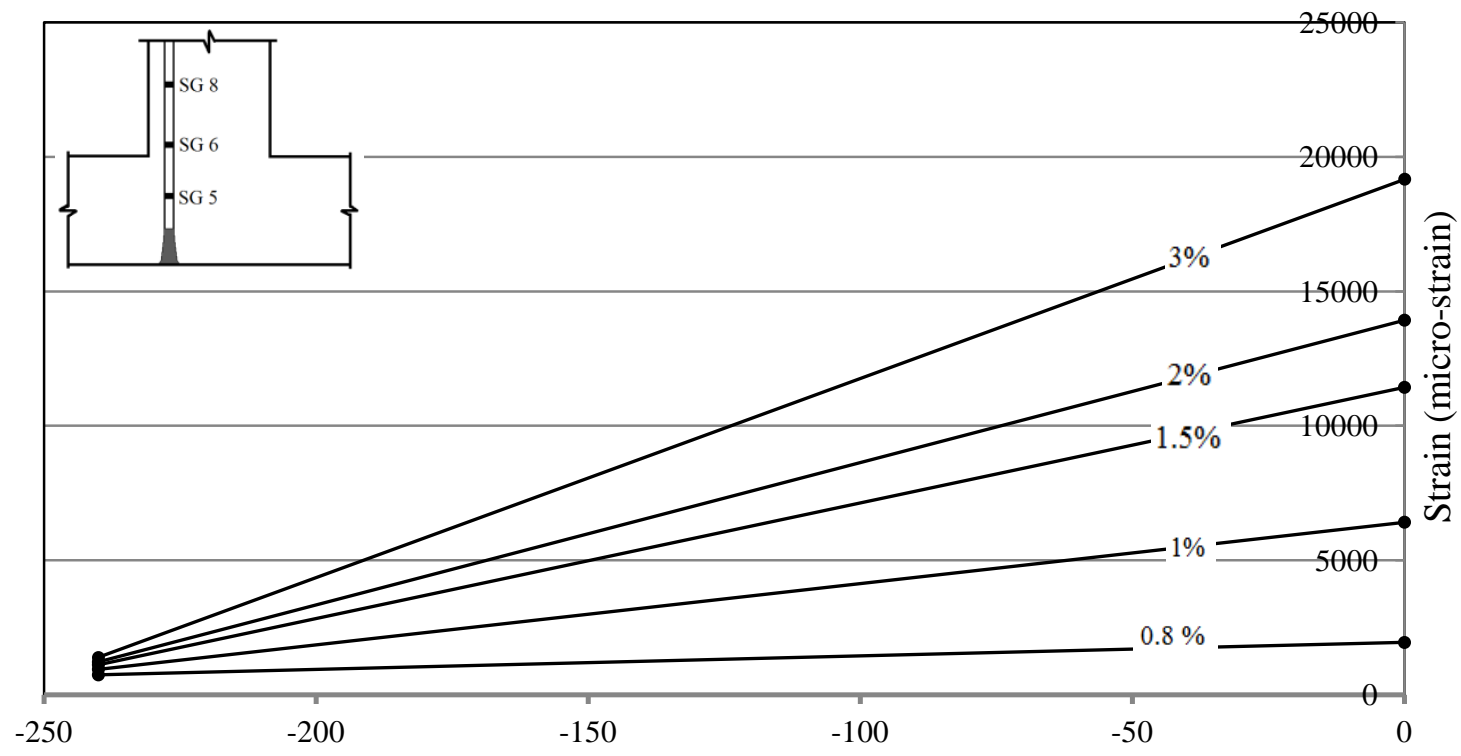

Figure 5.25 - Strain flow in beam longitudinal bar (Specimen S-I-M)

In Specimen G-I-L, up to 1\% drift ratio, the strains inside the joint remained almost zero, which indicates that no damage was induced to the joint up to that drift ratio. Starting from $1.5 \%$ drift ratio, the strain inside the joint started to increase, showing minor strain penetration into the 


\section{TEST RESULTS AND DISCUSSION}

joint. Readings of Strain Gauge No.5 were lower than readings of Strain Gauge No.6 at first, but the strains became closer after 4\% drift ratio, indicating bond loss of the bar inside the joint.

Starting from 5\% drift ratio, strains at $200-\mathrm{mm}$ became higher than the strains at the column face indicating that majority of the damage was concentrated away from the joint. High column-tobeam flexural strength ratio and low joint shear stress were the reasons of inelastic concentration shift away from the joint. These observations are in agreement with the presented pictures of Specimen G-I-L. According to Figure 5.12 concrete damage was extended to 650-mm away from the column face.

Figure 5.23 shows that Specimen G-I-M had stable behaviour up to 6\% drift ratio (strain gauges malfunctioned after that). Relative strains of the three points remained approximately constant during the test. In other word, by increasing the lateral displacement, all strain gauges showed the same magnitude of strain increase. The strain increase inside the joint indicates that the bonding between the bar and the concrete was not sufficient, and majority of the stress was transferred to the head of the bar. In contrary to Specimen G-I-L, strains at the column face was slightly higher than strains at 200-mm in Specimen G-I-M, indicating shift of the inelasticity center toward the joint.

Strain Gauge No.5 malfunctioned prior to starting the test in Specimen G-I-H. However, Figure 5.24 shows the captured strains at the face of the column and $200-\mathrm{mm}$ inside the beam. According to the figure, similar to Specimen G-I-M, the strains in these two points were approximately the same in all loading stages. The decrease in the stress at 7 and $8 \%$ drift ratio was due to the decrease in the lateral load capacity of the specimen, which resulted in the bars stress reduction. 


\section{TEST RESULTS AND DISCUSSION}

In specimen S-I-M Strain Gauge No.8 malfunctioned before starting the test. However, comparing the strains inside the joint and at the column face indicated a perfect bonding between the bar and the concrete. At all loading stages strain in the joint remained almost zero. Strain Gauge No.6 malfunctioned after 6\% drift ratio.

Figure 5.26 shows the maximum strain captured in each loading stage from strain gauges No.18 and 19. The graph shows that for the GFRP-RC specimens, the maximum strain in G-I-H, G-I-M and G-I-L was in ascending order. This indicates that the inelasticity centre was moving toward the joint in these specimens, respectively. Column-to-beam strength ratio was the main parameter that affects location of the inelasticity centre. The strength ratio for Specimen G-I-L, G-I-M, and G-I-H was 1.6, 1.5, and 1.4, respectively.

In specimen S-I-M, due to yielding of the steel bars, the maximum strain remained constant from 2 to $4 \%$ drift ratio. However, severe concrete damage reduced the capacity of the concrete in shear resisting, which in turn increased share of the steel stirrups in carrying the shear loads at high drift ratios.

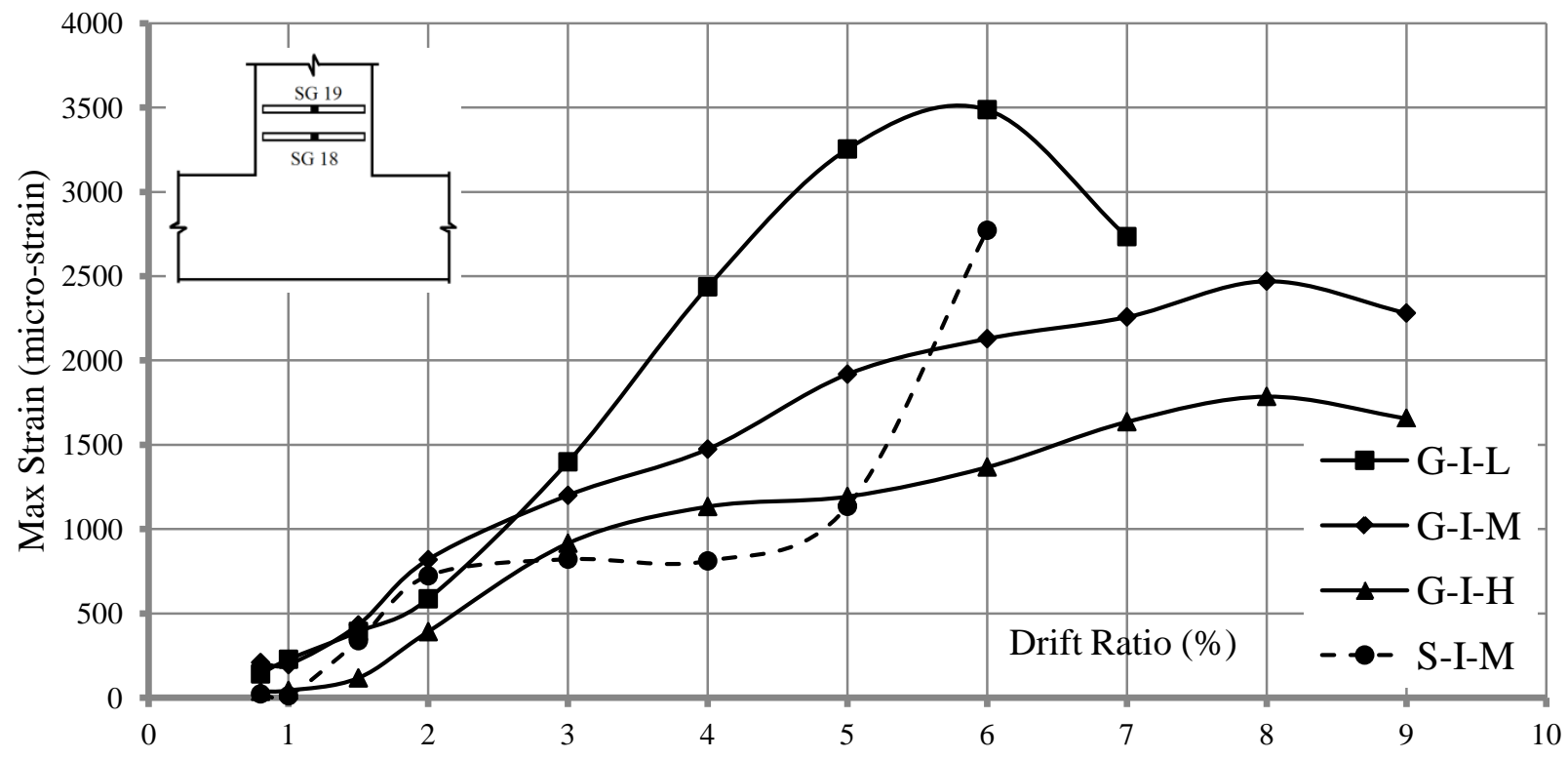


TEST RESULTS AND DISCUSSION

Figure 5.26 - Maximum strain between strain gauges No.18 and 19 in the specimen of Series I

\subsubsection{Components of the beam tip lateral displacement}

As stated in Chapter 4, the main components of beam tip lateral displacement are:

- Elastic rotation of the beam due to the loading;

- Rotation in the anticipated beam plastic hinge (inelasticity) zone;

- Rotation due to local slippage and large strains developed in the beam bars within the joint;

- Rotation due to overall column rotation; and

- Distortion of the joint.

It should be mentions that a plastic hinge occurs due to the excessive concrete damage caused by yielding of steel, which is not the case in GFRP-RC structures. However, due to low modulus of elasticity and high strength of GFRP bars, GFRP-RC elements can experience severe damage due to large deformations. Therefore, the term "virtual plastic hinge" is used in the case of GFRP-RC elements.

In this program, column rotation, rotation due to the beam plastic hinge, and rotation of the beam relative to the column were measured. The following figures show the column rotation and the rotation due to the plastic hinge as the percentage of the total beam tip rotation. The rest of the graph indicates the share of bar slippage, joint distortion and etc. in the total rotation.

According to the figures, in the GFRP-RC specimens the percentage of the column rotation and virtual plastic hinge in the total rotation was approximately constant, while the steel-RC 


\section{TEST RESULTS AND DISCUSSION}

specimen showed a significant increase. This indicates the considerable share of plastic hinge in the total rotation of the beam tip in Specimen S-I-M, due to yielding of steel.

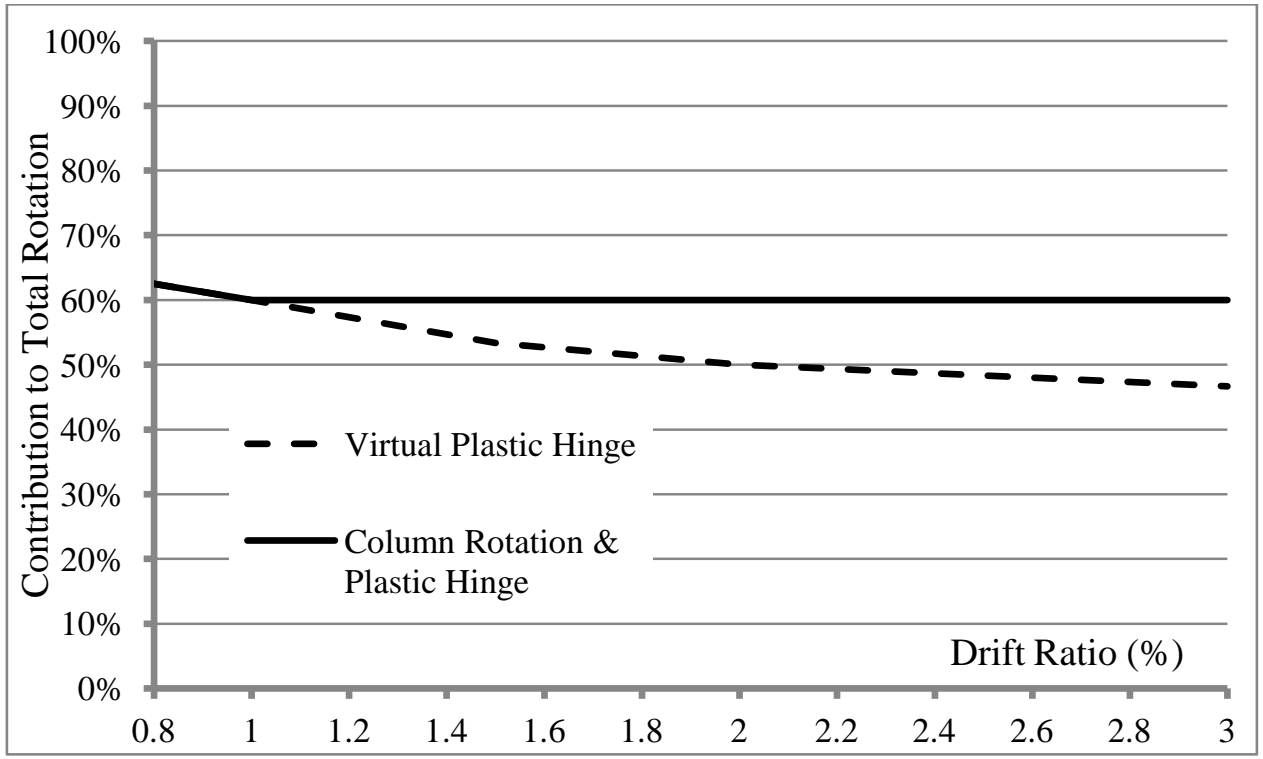

Figure 5.27 - Beam tip displacement components (Specimen G-I-L)

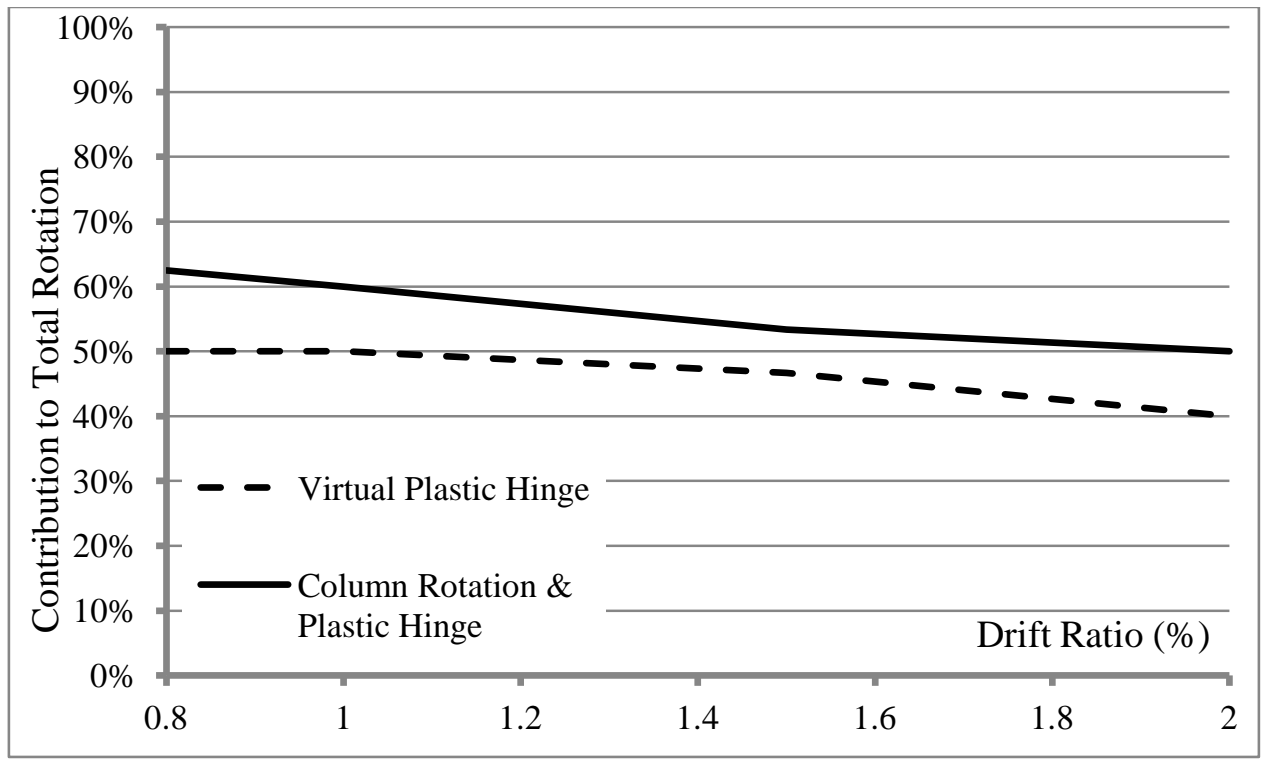

Figure 5.28 - Beam tip displacement components (Specimen G-I-M) 


\section{TEST RESULTS AND DISCUSSION}

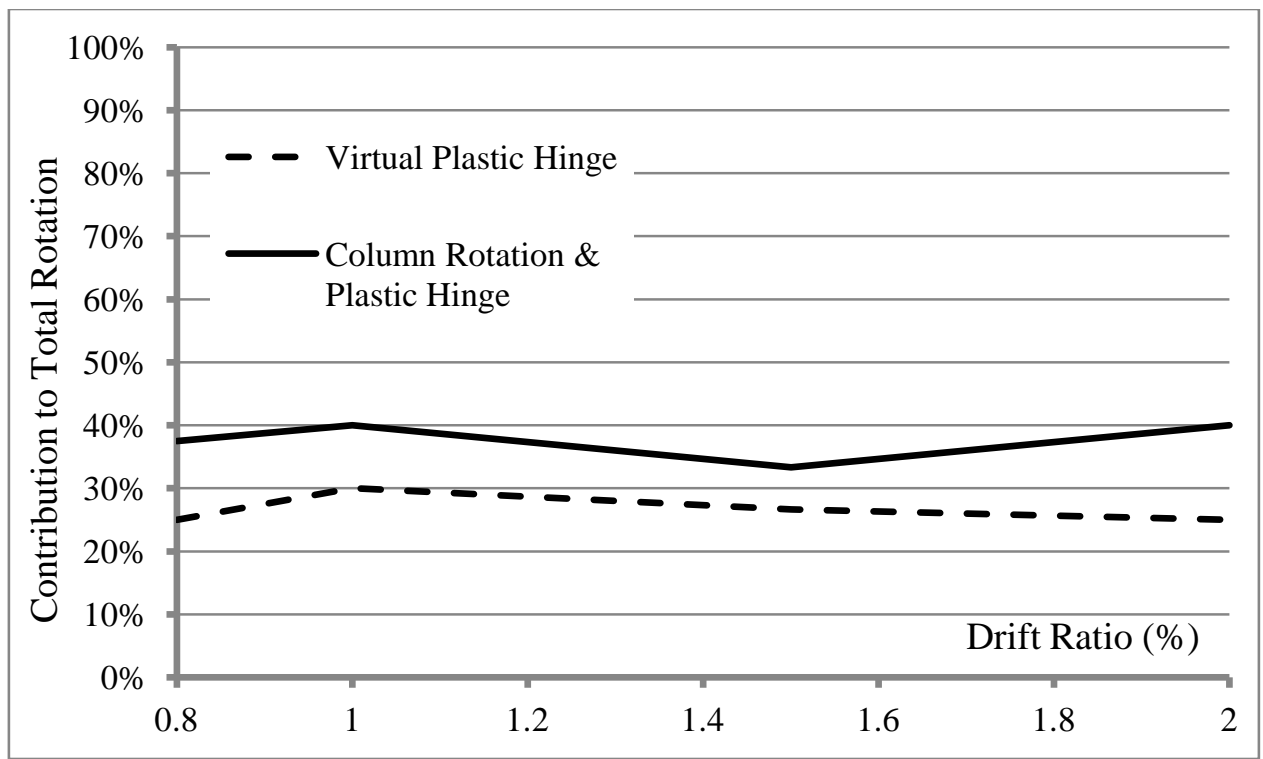

Figure 5.29 - Beam tip displacement components (Specimen G-I-H)

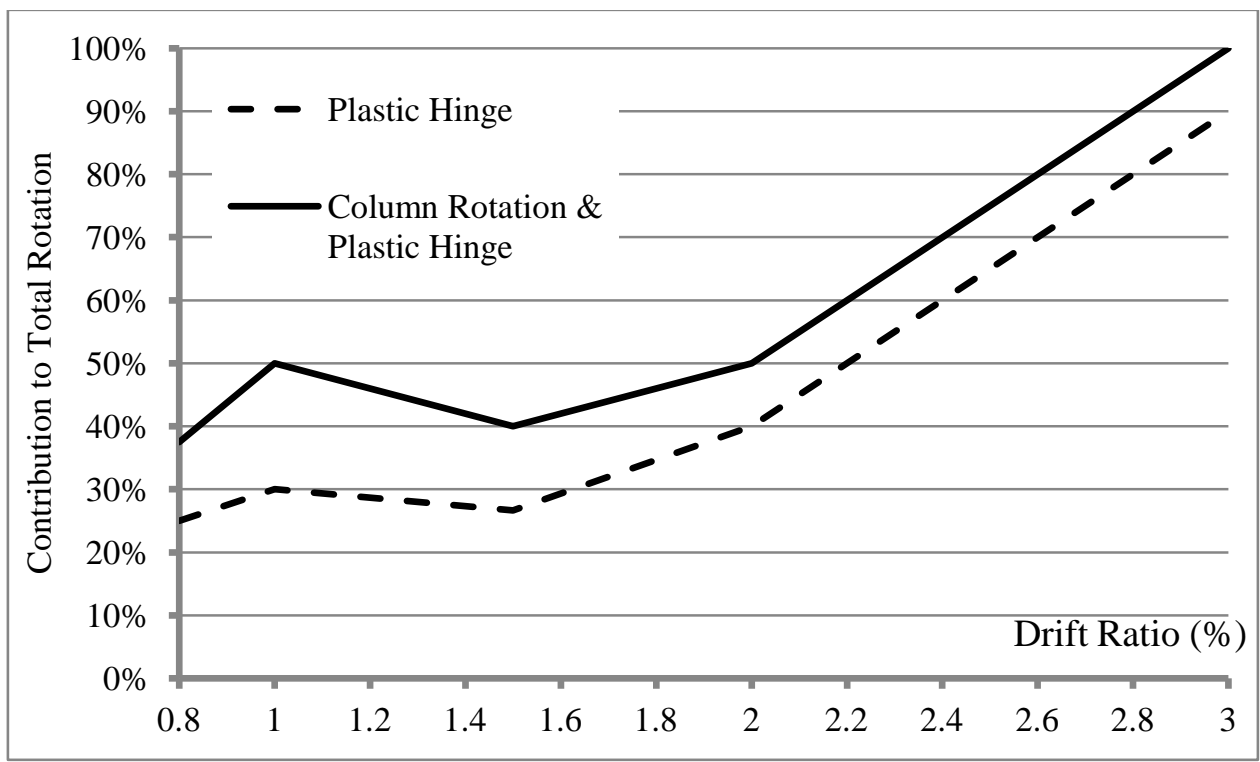

Figure 5.30 - Beam tip displacement components (Specimen S-I-M)

\subsubsection{Energy dissipation}

Figure 5.31 shows the cumulative dissipated energy for all specimens in Series I. Energy dissipation of the GFRP-RC specimens was significantly lower than the steel-RC specimen. This 


\section{TEST RESULTS AND DISCUSSION}

was due to yielding of the steel reinforcement which allowed the specimen to go to large deflections in plastic mode and produce wide loops in its hysteresis diagram.

GFRP-RC specimens approximately showed the same values of energy dissipation up to 4\% drift ratio. However, at the higher drift ratios, the specimens with higher joint shear stresses showed higher energy dissipation. Increase in joint shear stress resulted in more damage induced to the joint, which led to more energy dissipation. It should be mentioned that $4 \%$ drift ratio is higher than the lateral drift ratio limits suggested by NBCC 2005 (2.5\%).

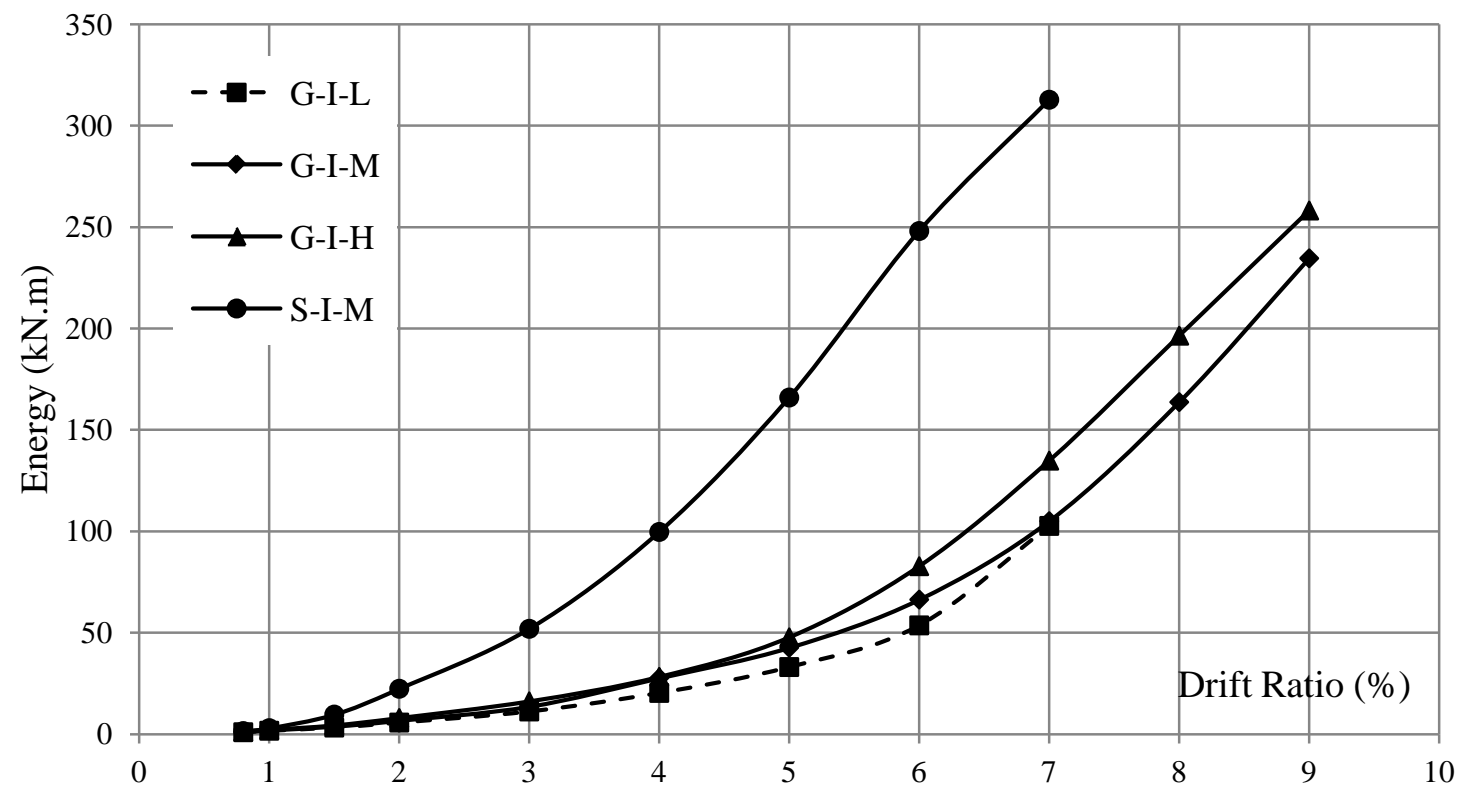

Figure 5.31 - Cumulative energy dissipation of the specimens in Series I

\subsubsection{Lateral Stiffness}

Figure 5.32, shows the lateral stiffness of the specimens in Series I at the pushing (positive) and pulling (negative) direction. The stiffness was calculated by dividing the maximum beam tip loads in each loading direction by its corresponding beam tip displacement. The negative values represent the lateral stiffness in the pulling direction and positive values show the stiffness in the pushing direction. 


\section{TEST RESULTS AND DISCUSSION}

The stiffness at $0.0 \%$ drift ratio represents the initial stiffness of the specimens. The initial stiffness was defined as the ratio of the load at which the first crack was observed to its corresponding displacement during the first load-controlled stage (before cyclic loading). The stiffness degradation from 0.0 to $0.8 \%$ drift ratio was higher in GFRP-RC specimens compared to the steel-RC one. However, because of the excessive damage induced to the joint due to yielding of steel, the rate of lateral stiffness degradation after $0.8 \%$ drift ratio was higher in the steel-RC specimen.

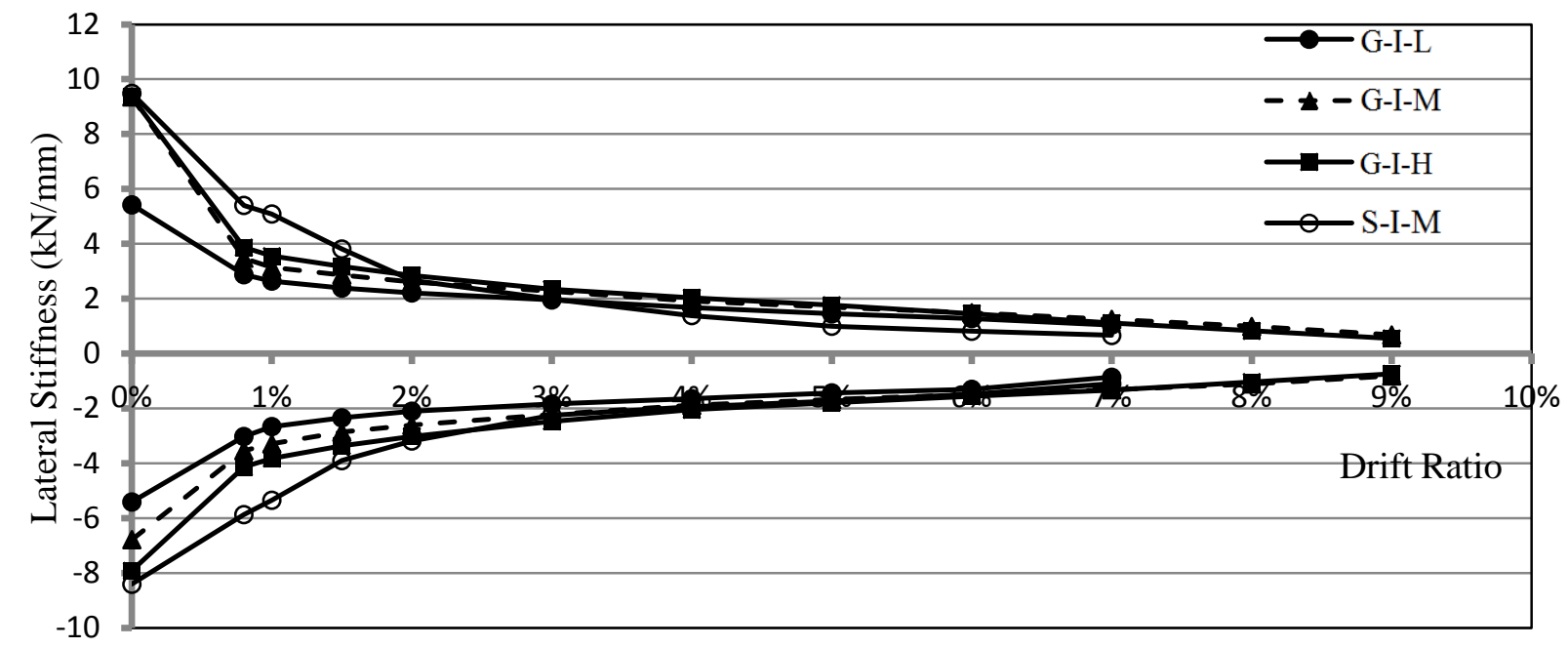

Figure 5.32 - Lateral stiffness of Series I specimens

\subsection{Series II}

\subsubsection{Overall behaviour}

Specimen G-II-M was designed to have the same joint shear stress as Specimen G-I-M $\left(1.0 \sqrt{f^{\prime}}\right)$. The only difference between the two specimens was the beam longitudinal bars anchorage type. Test results showed a significant difference in the behaviour of the specimens. In contrary to Specimen G-I-M that behaved nonlinearly, Specimen G-II-M exhibited linear lateral load-drift response up to failure. Moreover, Specimen G-II-M failed at 6\% drift ratio, while 


\section{TEST RESULTS AND DISCUSSION}

Specimen G-I-M was able to reach 9\% drift ratio. This different behaviour resulted from the different mode of failure of the specimens, which is discussed in the next sections.

Specimen G-II-L was designed to have a joint shear ratio equal to $0.8 \sqrt{f^{\prime}}{ }_{c}$. Despite having lower joint shear stress than Specimen G-II-M, Specimen G-II-L failed at the same drift ratio of $6 \%$. The behaviour of the specimen clearly indicated the effect of confinement provided by lateral beams on the seismic performance of exterior beam-column joints. The behaviour of Specimen G-II-L was also compared with its counterpart specimen at previous studies conducted by Hasaballa and El-Salakawy (2012) at the University of Manitoba. The results of this comparison will be published in another document.

\subsubsection{Hysteresis diagram}

Error! Reference source not found. and Figure 5.34 shows the hysteresis diagrams of Series II specimens, the dashed lines indicate the design capacity of the specimens.

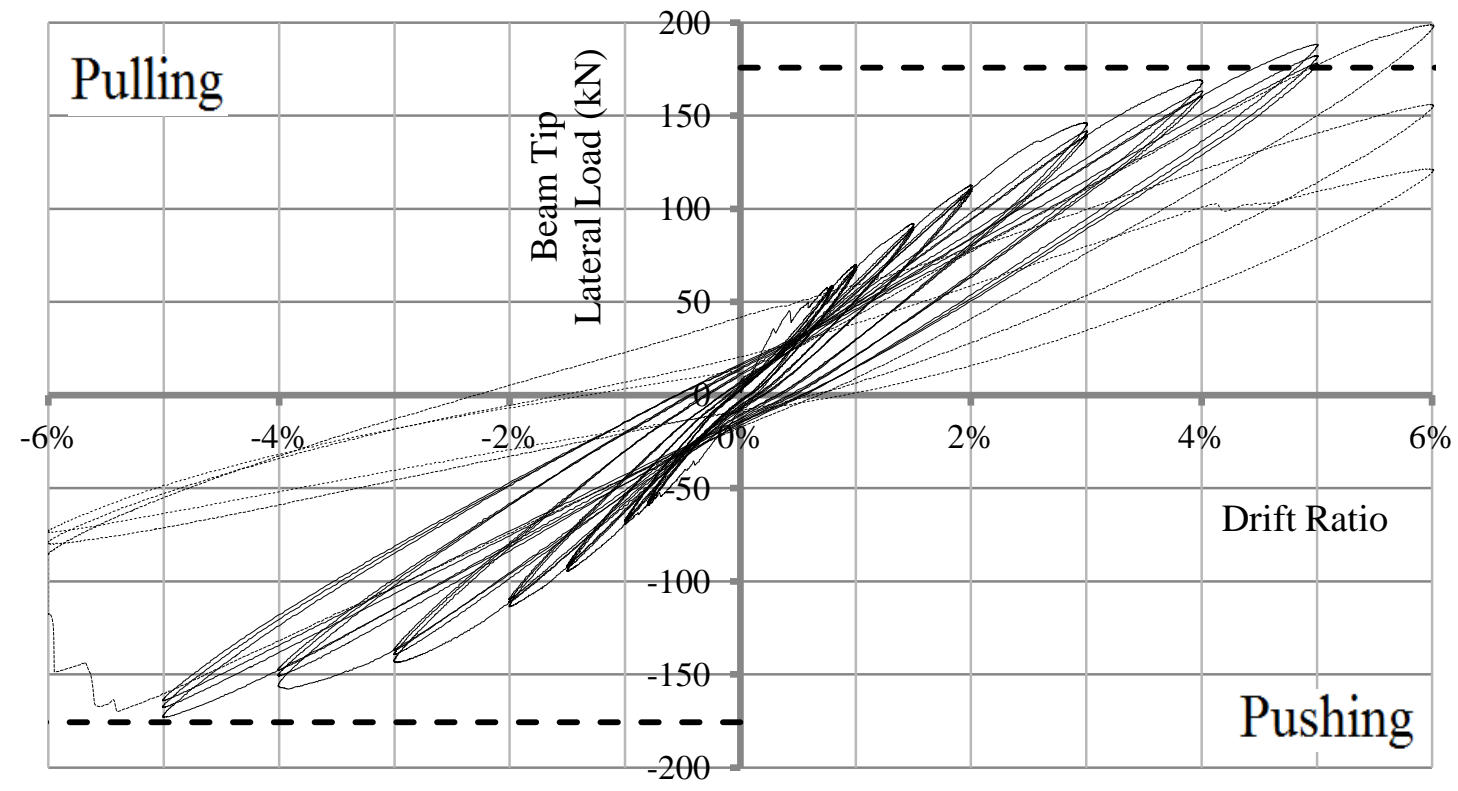

Figure 5.33 - Hysteresis diagram of Specimen G-II-M 
TEST RESULTS AND DISCUSSION

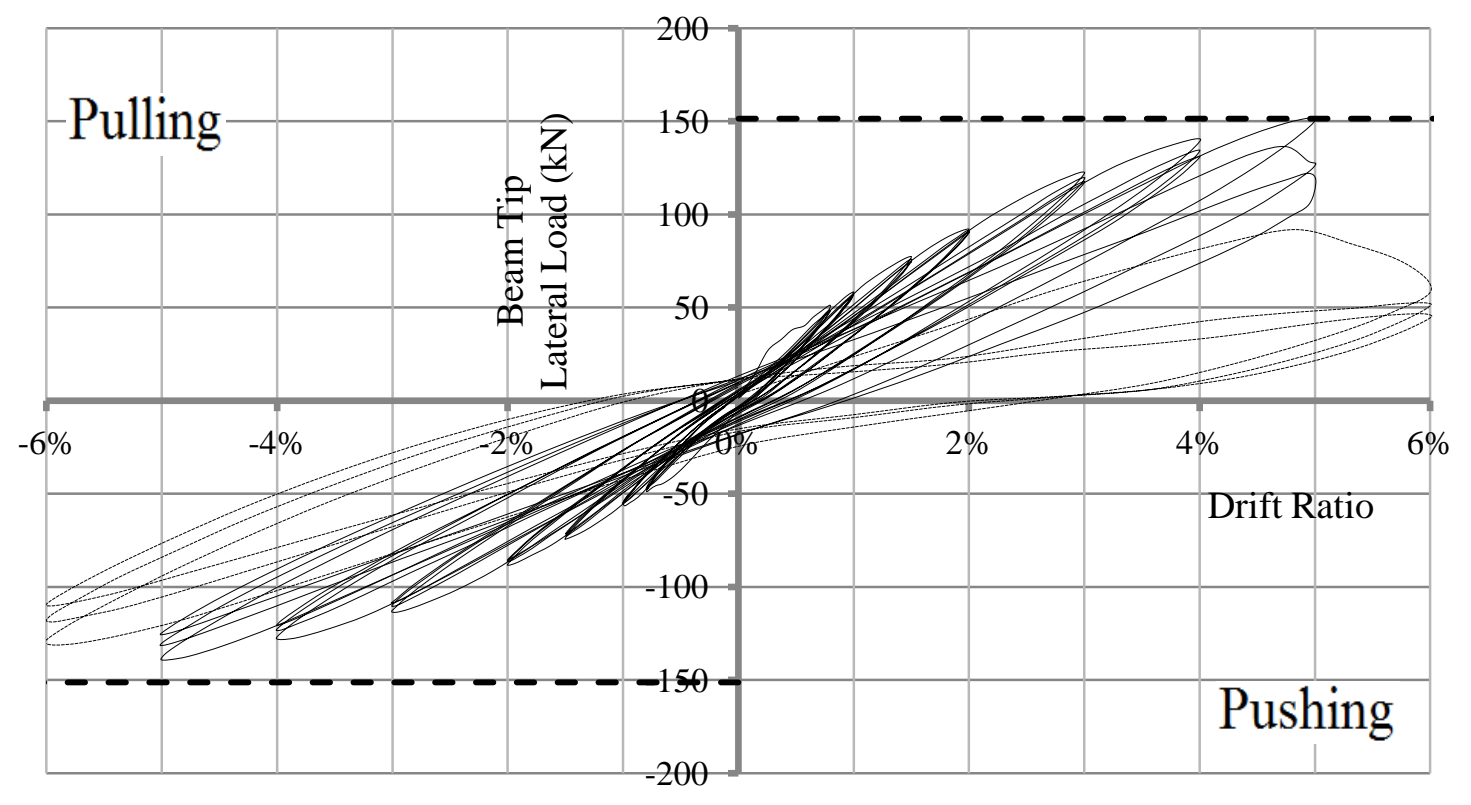

Figure 5.34 - Hysteresis diagram of Specimen G-II-L

According to Figure 5.33 , Specimen G-II-M behaved linearly with small stiffness reduction up to failure. The failure was brittle and occurred at $6 \%$ drift ratio while the specimen was pulled toward the negative direction. The specimen reached its design capacity at 4 and 5\% drift ratio in the pushing and the pulling direction, respectively.

Specimen G-II-L was identical to its counterpart specimen in previous studies conducted at the University of Manitoba (Hasaballa and El-Salakawy 2012), except for the beam longitudinal anchorage method (bent bars were used in Specimen G-II-L instead of headed-end bars). The comparison of the specimens' behaviour will be presented somewhere else. In this document, behaviour of Specimen G-II-L is compared with the other specimens of this program.

Although the applied joint shear stress in Specimen G-II-L was lower than Specimen G-II-M, the specimen showed less stable behaviour. The reason was the lack of lateral beams confinement in 


\section{TEST RESULTS AND DISCUSSION}

the joint. The specimen showed linear behaviour up to 5\% drift ratio. The failure occurred at the first loading cycle of $6 \%$ drift ratio in the pushing direction.

The design capacity was reached at 5\% drift ratio in the pushing direction; however, the specimen could barely reach the design capacity in the pulling direction (at $5 \%$ drift ratio). The specimen did not show any increase in the lateral load carrying capacity after that stage. Due to asymmetric damage to the joint, pinching was observed mainly at the pushing direction.

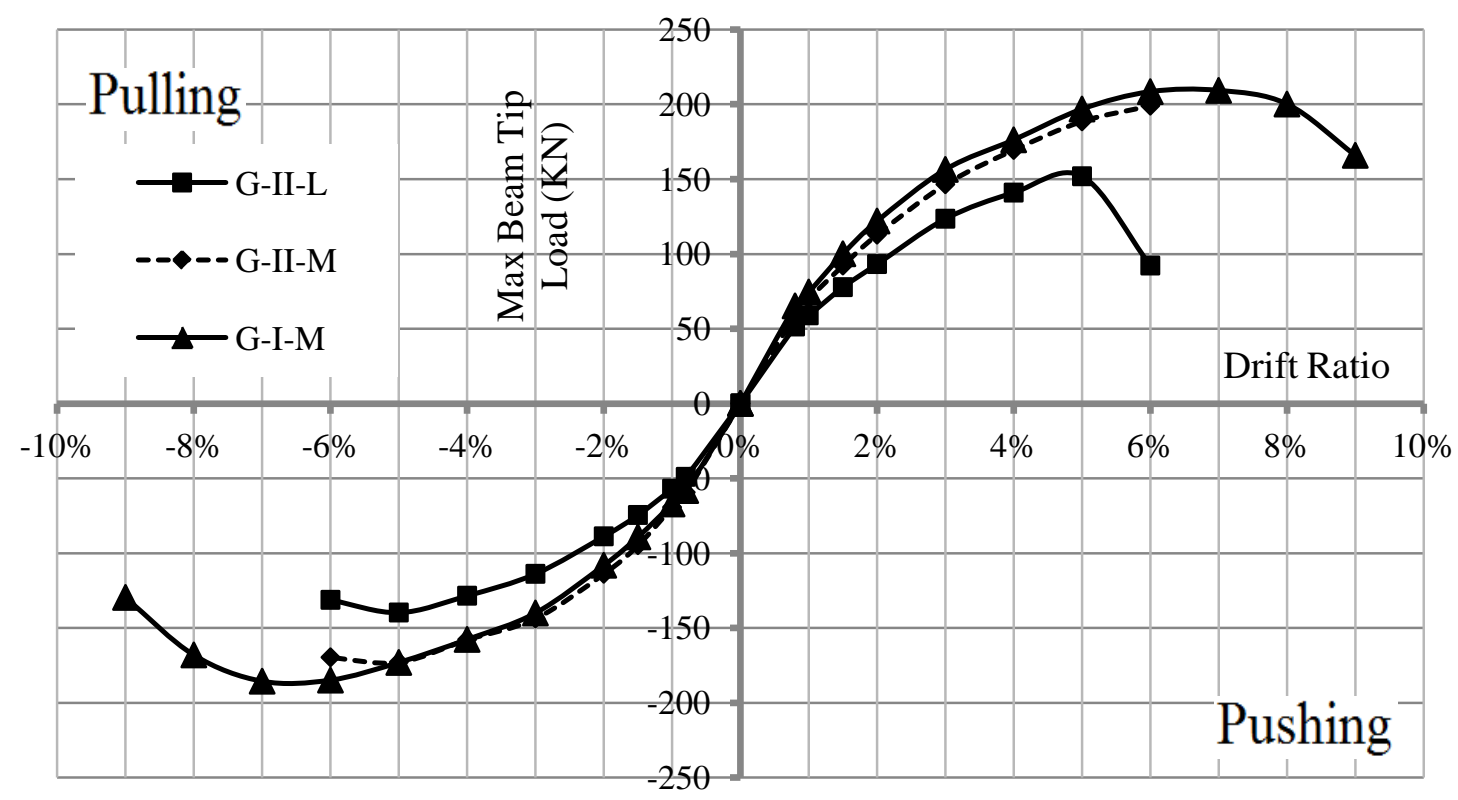

Figure 5.35 - Maximum lateral load envelop for Series II specimens

Figure 5.35 shows the maximum lateral load envelop of Series II specimens compared to Specimen G-I-M from Series I. The hysteresis diagram of Specimen G-II-M was very similar to Specimen G-I-L, indicating the similar mode of failure of the specimens. However, the behaviour of Specimen G-II-M should be compared to Specimen G-I-M, since both had the same joint shear stress. 


\section{TEST RESULTS AND DISCUSSION}

According to the graph, Specimen G-II-M showed similar behaviour to Specimen G-I-M until $6 \%$ drift ratio where the failure occurred. This behaviour indicated that using headed-end bars didn't increase the load carrying capacity of the specimen, but it improved the behaviour in terms of deformability (maximum drift ratio).

Compared to Specimen G-II-M, Specimen G-II-L showed lower stiffness due to fewer numbers of beam longitudinal bars and more concrete damage.

\subsubsection{Cracking patterns}

The following section provides the pictures of Series II specimens after each loading stage. The numbers written next to the lines in the pictures indicate the drift ratio at which the crack was observed.

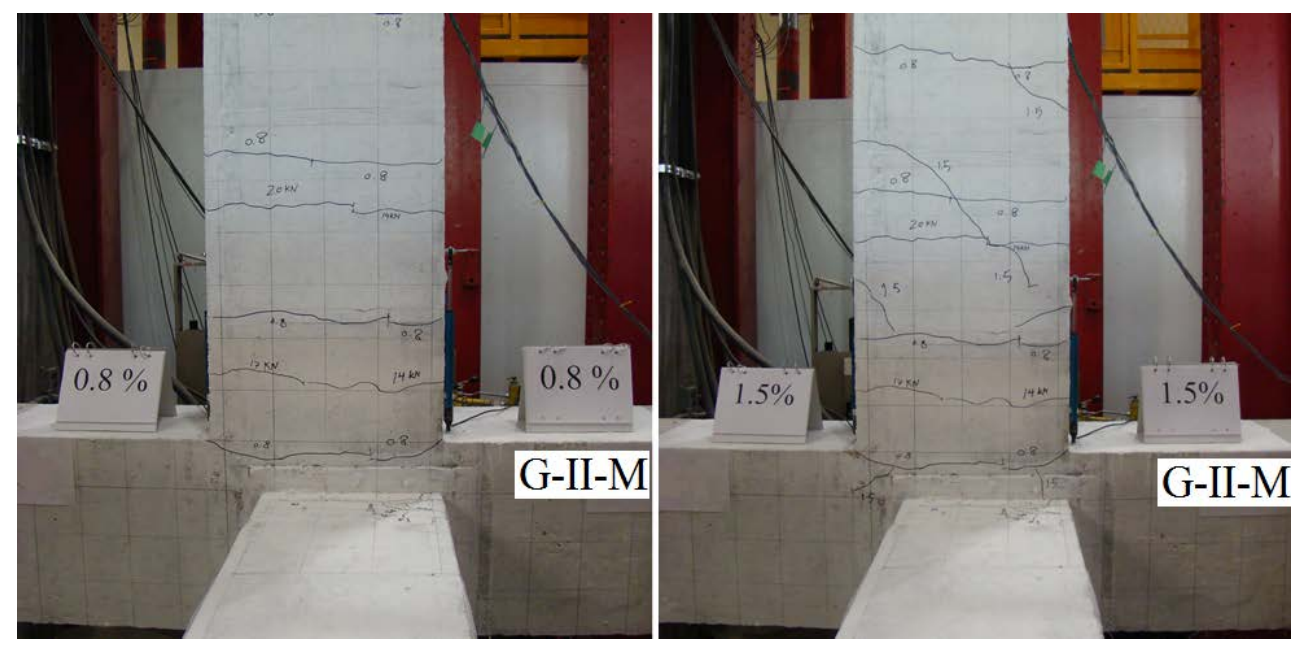

(a) Specimen G-II-M 
TEST RESULTS AND DISCUSSION
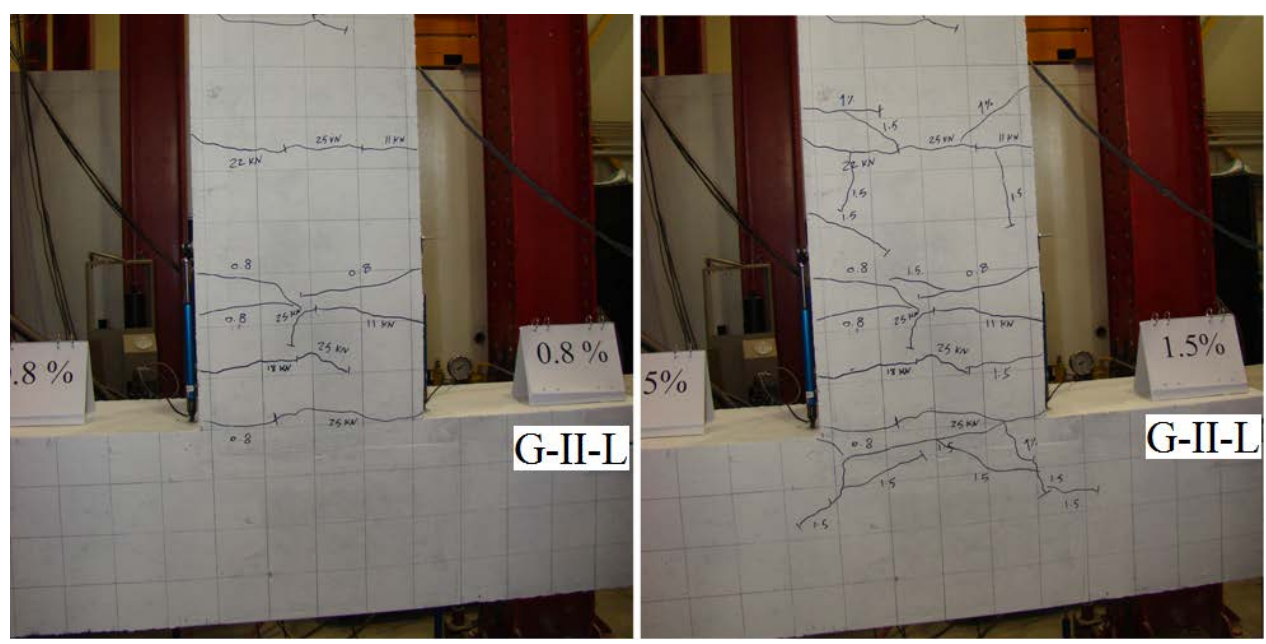

(b) Specimen G-II-L

Figure 5.36 - Condition of Series II specimens after 0.8 and $1.5 \%$ drift ratio

Comparing to G-I-M, Specimen G-II-M had fewer number of flexural cracks at low drift ratios. The reason could be the different surface properties of the bent and headed-end bars used in this program (Figure 4.2). The bent bars had a separate deformed cover layer around the core of the bars. The layer had a smooth and flexible surface, which resulted in lower bond stress between the bars and the concrete, which in turn resulted in lower number of cracks.

The first diagonal shear crack occurred in the beam of Specimen G-II-M and G-II-L was observed at $1.5 \%$ drift ratio and was relatively away from the joint face. Penetration of the cracks to the joint also started at $1.5 \%$ drift ratio in G-II-L, while there was no significant crack penetration in G-II-M at that stage. 


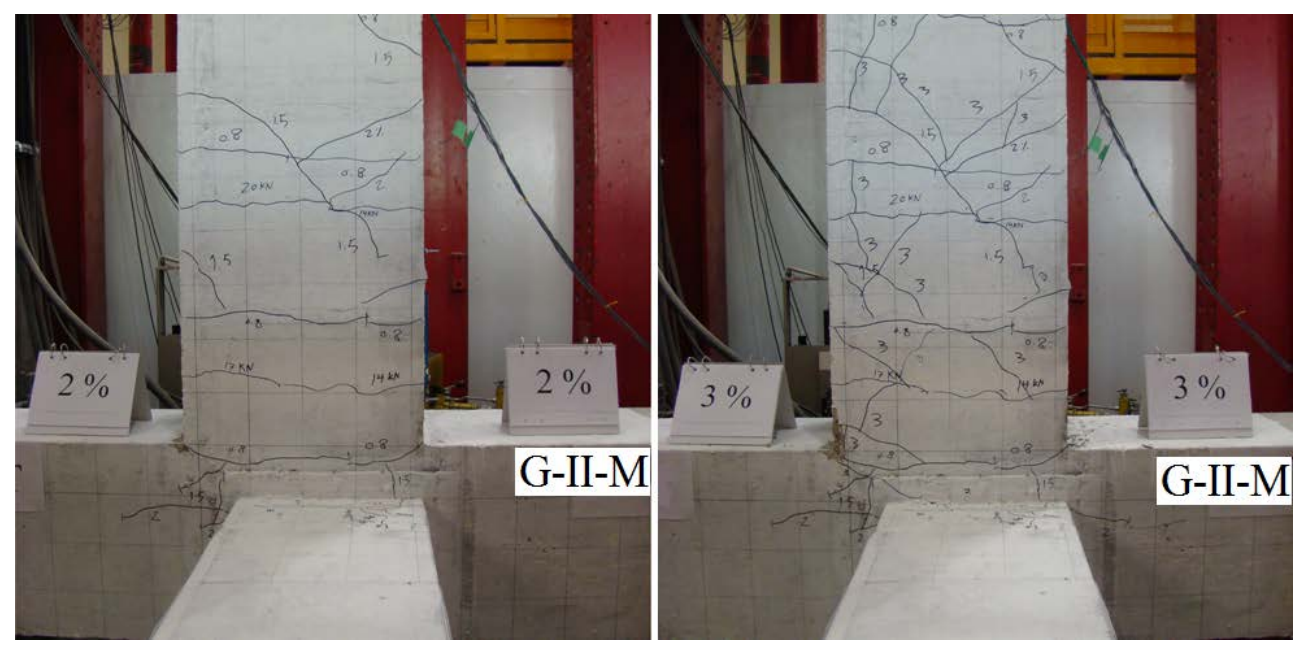

(a) Specimen G-II-M
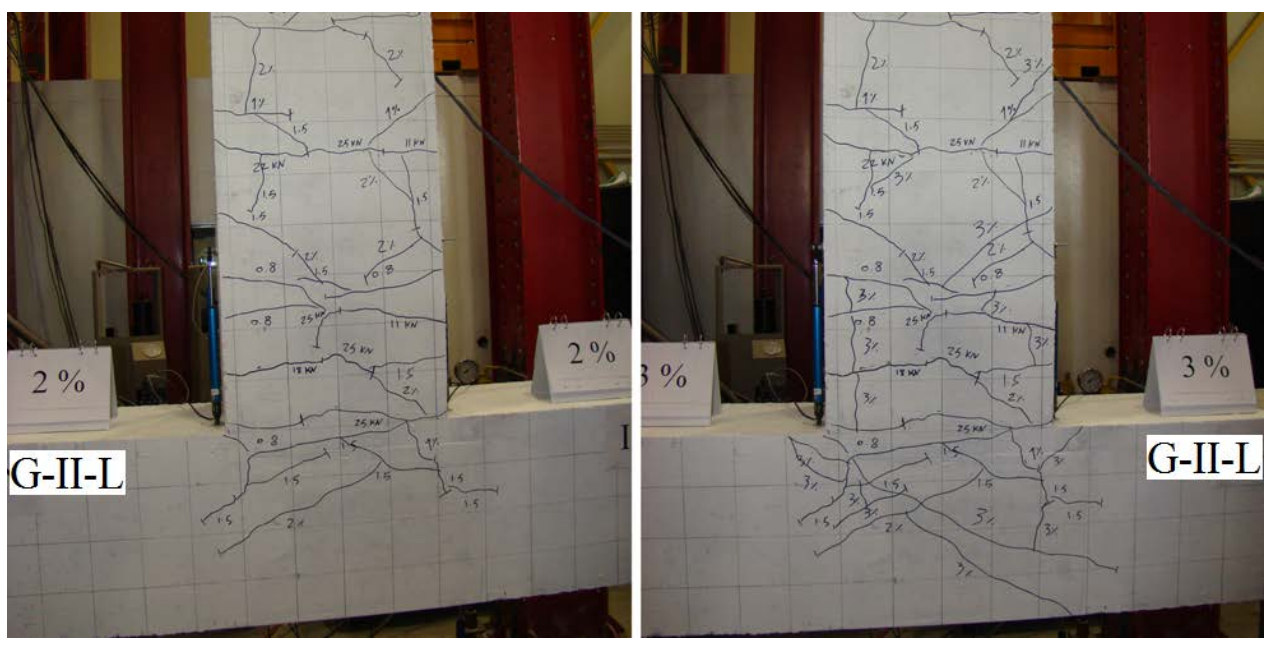

(b) Specimen G-II-L

Figure 5.37 - Condition of Series II specimens after 2 and 3\% drift ratio

A significant number of diagonal cracks were observed in the joint of G-II-L at 3\% drift ratio. Comparison of specimens G-II-L and G-II-M at that stage, indicated fewer number of flexural and shear cracks for Specimen G-II-M. 


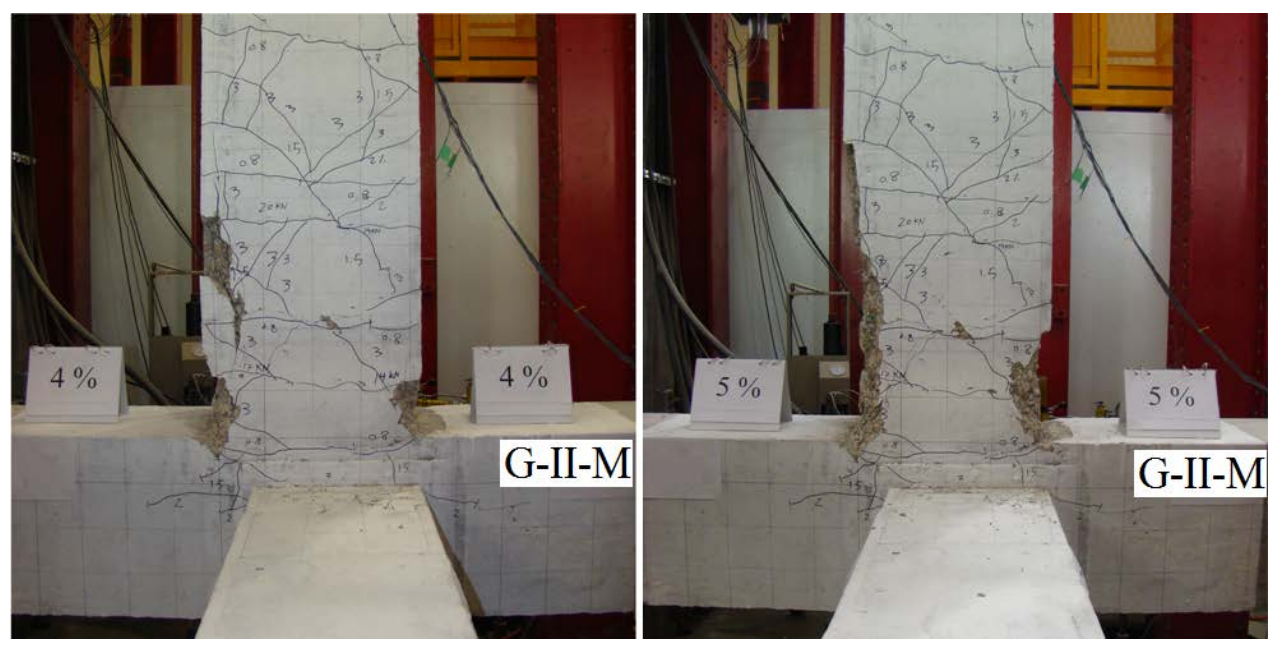

(a) Specimen G-II-M
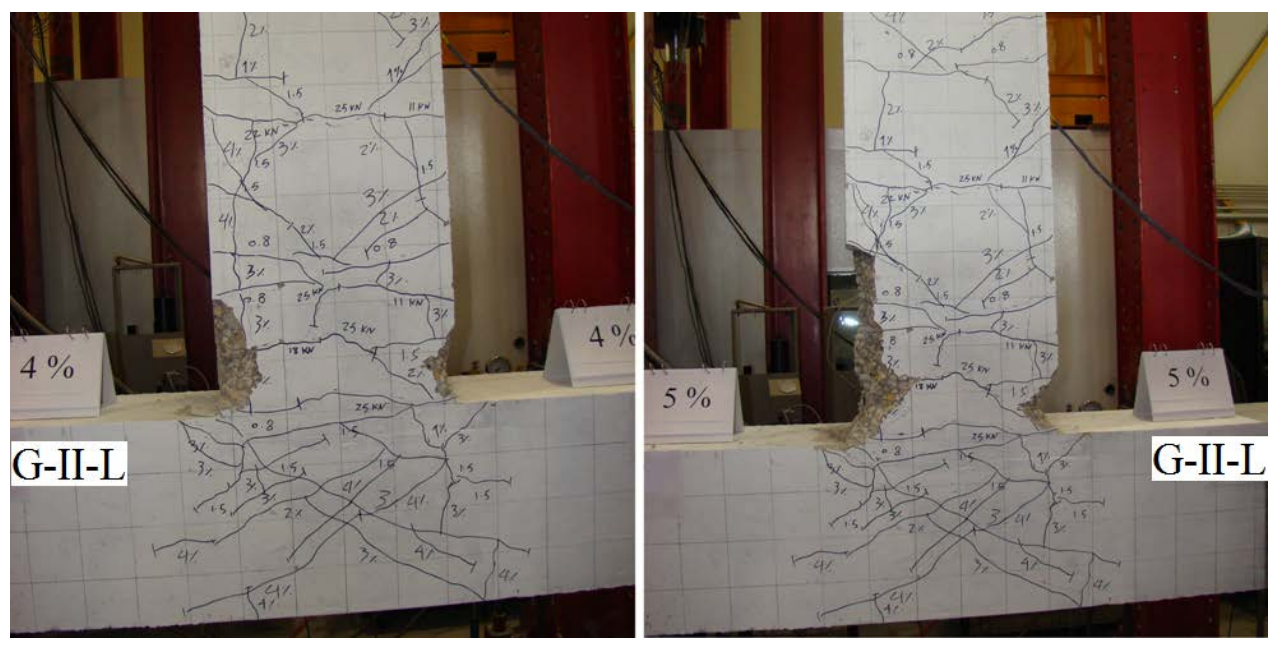

(b) Specimen G-II-L

Figure 5.38 - Condition of Series II specimens after 4 and 5\% drift ratio

The first sign of concrete spalling at the sides of the beam in G-II-M and G-II-L occurred at 3 and $4 \%$ drift ratio, respectively and the rate of damage in the beams increased rapidly afterwards. 

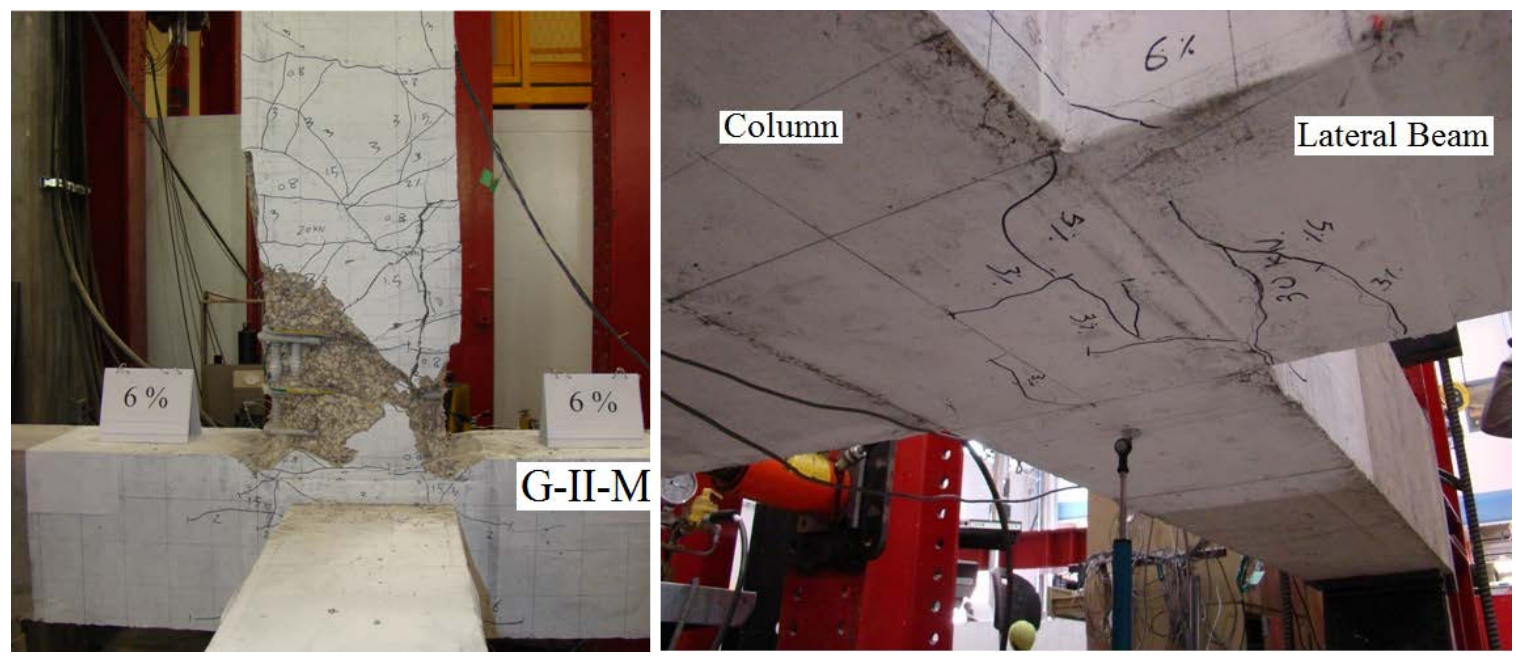

(a) Specimen G-II-M
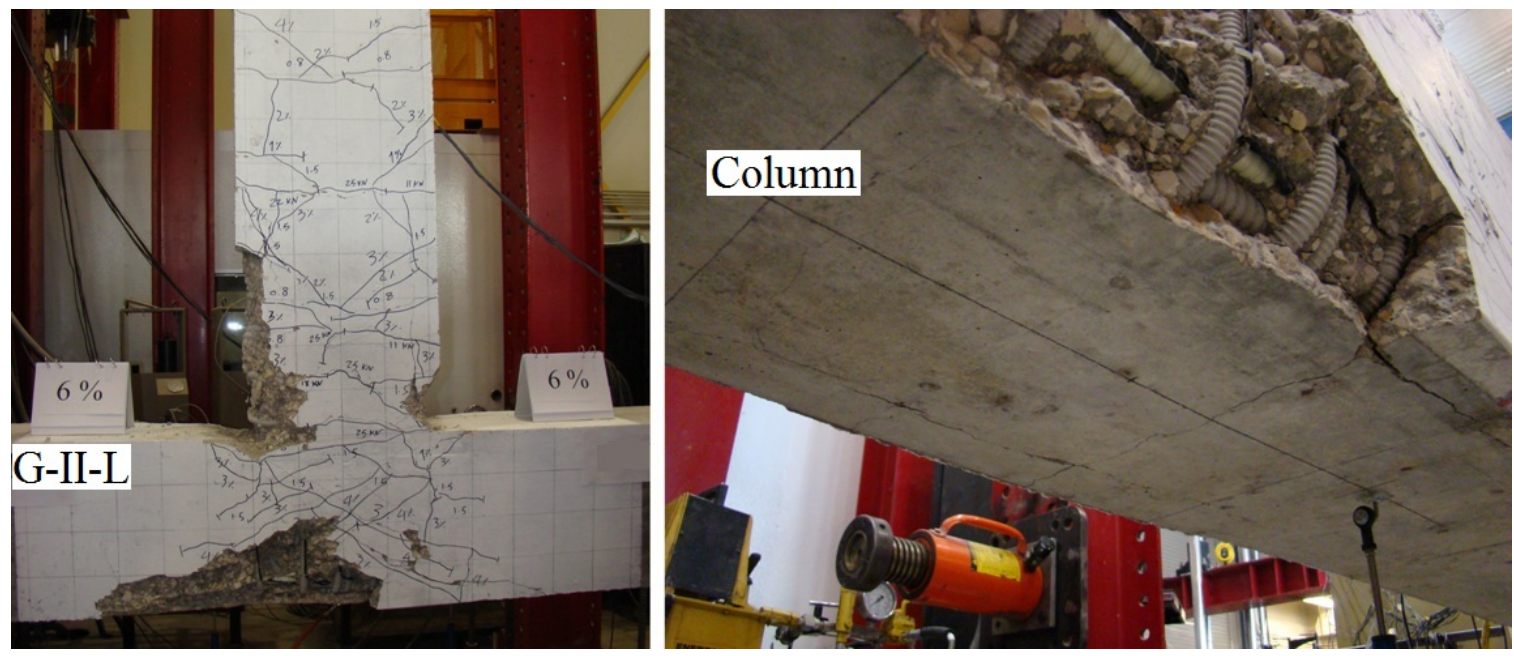

(b) Specimen G-II-L

Figure 5.39 - Condition of Series II specimens at 6\% drift ratio (failure)

Loading of specimen G-II-M was stopped after 6\% drift ratio due to flexural failure of the beam.

The failure occurred due to rupture of beam longitudinal bars while the specimen was loaded to the pulling direction. Specimen G-II-L showed stable behaviour up to 5\% drift ratio; however, at $6 \%$ drift ratio severe concrete swelling occurred at the joint area. Since there were no lateral beams to prevent the swelling, it resulted in concrete spalling at the joint area. This behaviour 


\section{TEST RESULTS AND DISCUSSION}

clearly showed the effectiveness of the confinement provided by lateral beams on the shear capacity and mode of failure of exterior beam-column joints.

Because of using bent bars, no signs of concrete push-off were observed underneath the specimens; however, due to lack of lateral confinement in Specimen G-II-L, concrete spalling at the sides of the joint occurred.

\subsubsection{Mode of failure}

Specimen G-II-M showed linear behaviour up to $6 \%$ drift ratio, where rupture of the beam longitudinal bars occurred. The mode of failure of Specimen G-II-M was similar to Specimen GI-L. The joint area remained intact during the test, providing sufficient anchorage for the beam bars. Because of this sufficient anchorage, the beam bars were able to reach their maximum tensile capacity.

The tension failure of the beam was in contrast with the compression failure mode design of the specimen. The same reason as the case of Specimen G-I-L can explain this different mode of failure. Due to slippage of some longitudinal bars in the beam, tensile stress increased in the other longitudinal bars and resulted in their rupture.

Specimen G-II-M not only reached its design capacity, but also exceeded that limit with no shear

damage inside the joint. This indicated that the applied shear ratio of $1.0 \sqrt{f^{\prime}}$ was lower than the joint shear capacity of exterior beam column joints reinforced with bent GFRP bars. Moreover, the linear lateral load-drift response, accompanied with insignificant pinching, indicated the stable behaviour of the joint. 


\section{TEST RESULTS AND DISCUSSION}

In contrary to Specimen G-I-M, that experienced severe damage in the joint, Specimen G-II-M, despite of having the same joint shear stress, showed no signs of damage penetration into the joint. The better anchorage that the bent bars provided, in comparison to the headed-end bars, prevented movement of the bars inside the joint during the reversal loading. Consequently, concrete push-off at the face of the joint (underneath specimen) did not occur. Moreover, the bent and the tail portion of the bars provided more confinement to the joint, which increased the shear capacity of the specimen.
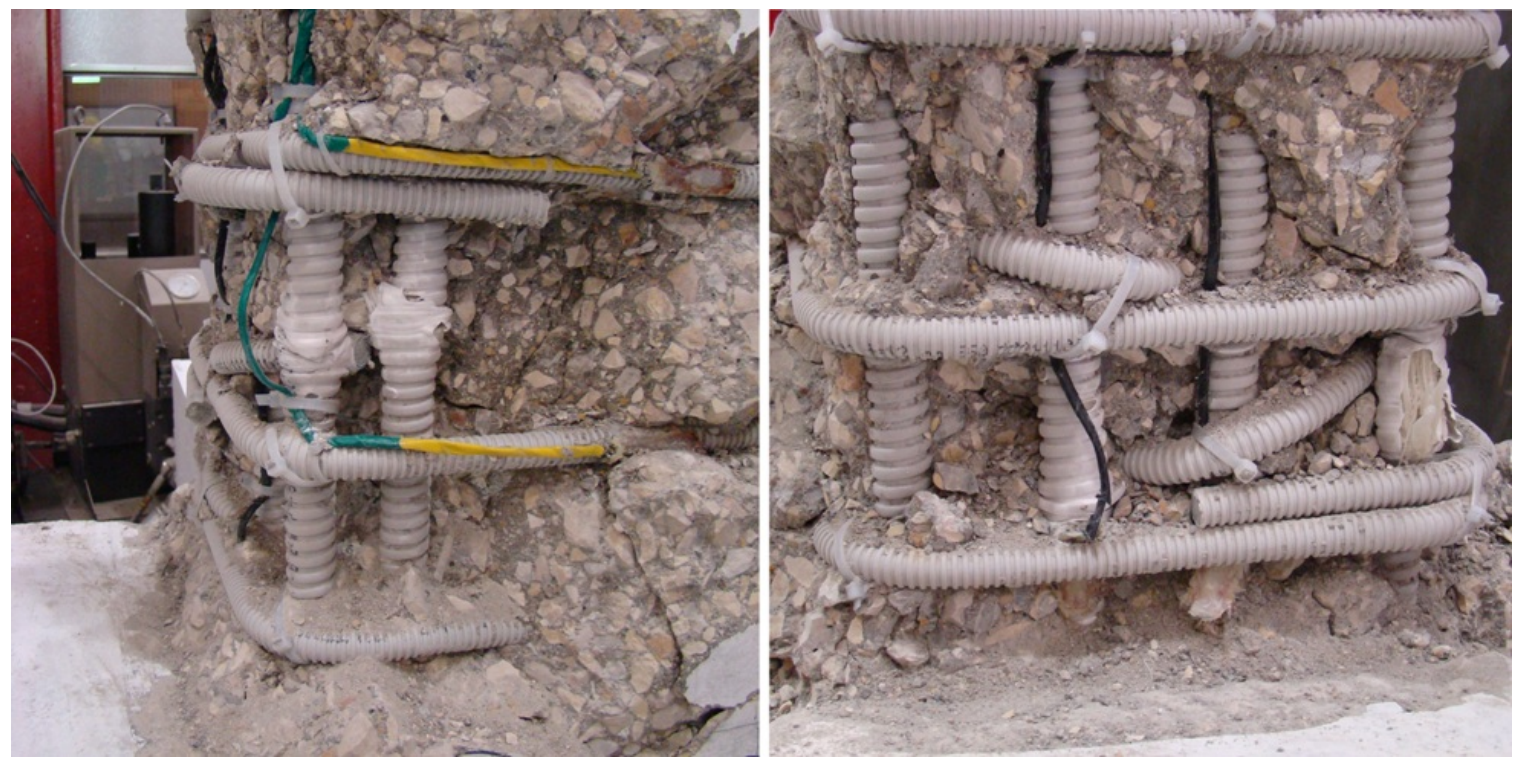

Figure 5.40 - Bar rupture at the final stage in Specimen G-II-M

The failure in Specimen G-II-L occurred due to concrete crushing of the joint. The inspections after testing indicated that the cover layer was significantly damaged in the bent portion in some of the beam longitudinal reinforcement (Figure 5.41). Due to the damage of the bent portion and the surrounding concrete, the bars were not able to provide sufficient support for the compressive concrete strut. Consequently the concrete strut pushed against the column longitudinal bars and caused the concrete push-off at the column. 

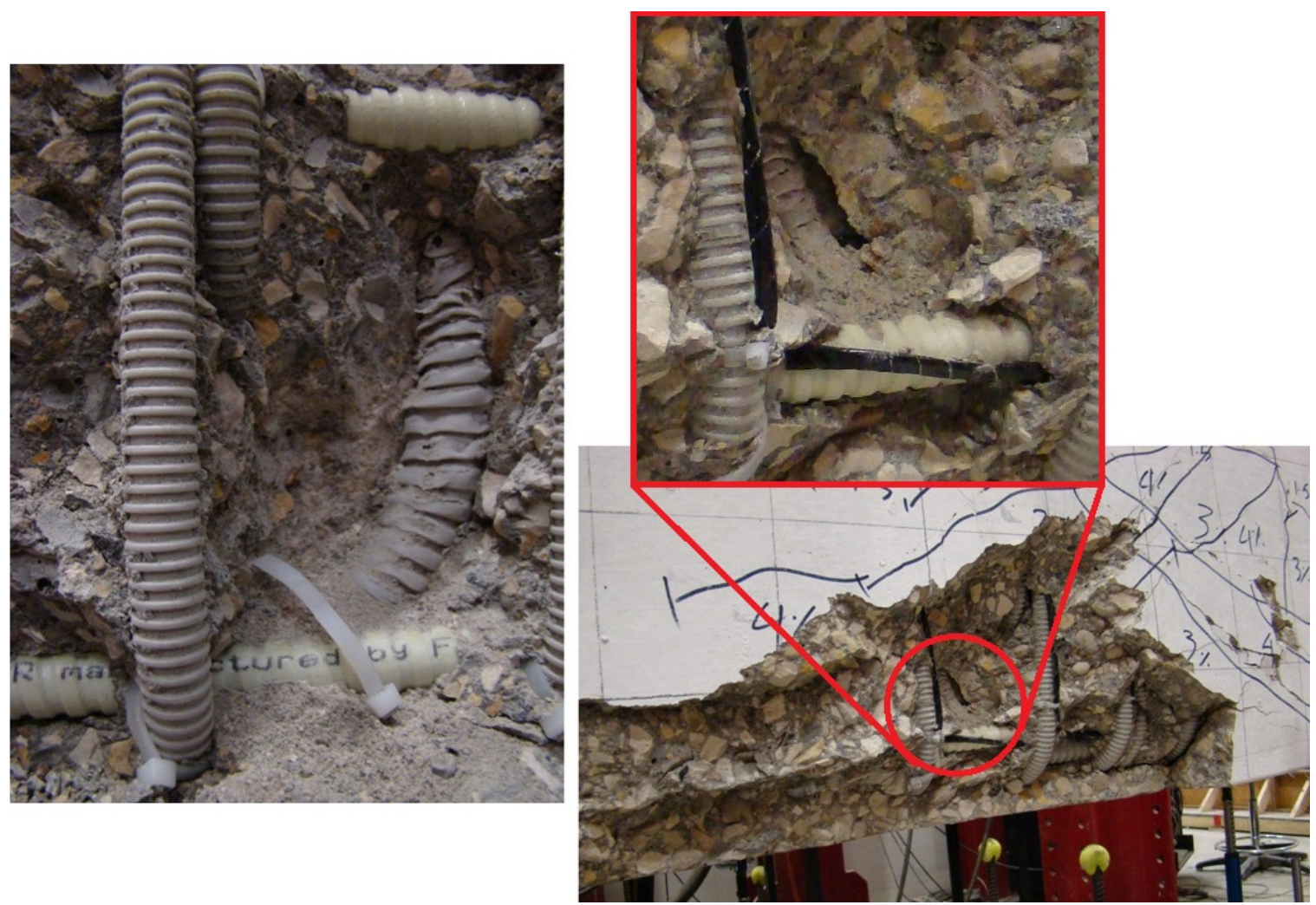

Figure 5.41 - Bar deformation in Specimen G-II-L

\subsubsection{Lateral Drift-Strain Relationship}

Figure 5.42 shows average of the joint stirrups strain in specimens G-I-M, G-II-M, and G-II-L. Specimens G-I-M and G-II-L both showed an ascending rate of increase in the average strain after $4 \%$ drift ratio. This was due to the joint damage in the specimens, which increased the share of stirrups in carrying the shear stresses. This can be compared to the descending rate of increase in Specimen G-II-M, which exhibited no damage in the joint. For G-II-M, the behaviour of the joint strain was very similar to the maximum lateral load envelop of the specimen.

Although Specimen G-II-M and G-I-M had approximately the same applied joint shear stress at all loading stages, Figure 5.42 shows that the average strain was higher in Specimen G-II-M, after $2 \%$ drift ratio. This was in contrast with the fact that there was less concrete damage in Specimen G-II-M and consequently, the share of stirrups in carrying the shear should have been 


\section{TEST RESULTS AND DISCUSSION}

lower in this specimen. However, in this case, the graph might be misleading since in Specimen G-II-M, Strain Gauge No.14 malfunctioned before starting the test and Strain Gauge No.13 malfunctioned at $1.5 \%$ drift ratio. As a result, average of the readings from the other strain gauges could not represent the whole joint area properly.

Specimen G-II-L, despite of having lower shear ratio than G-I-M, showed approximately the same values of average strain in the stirrups. Lack of joint confinement by lateral beams in Specimen G-II-L resulted in more concrete damage (cracks and crushing) in the joint, in comparison to G-I-M, and led to higher stresses in the stirrups.

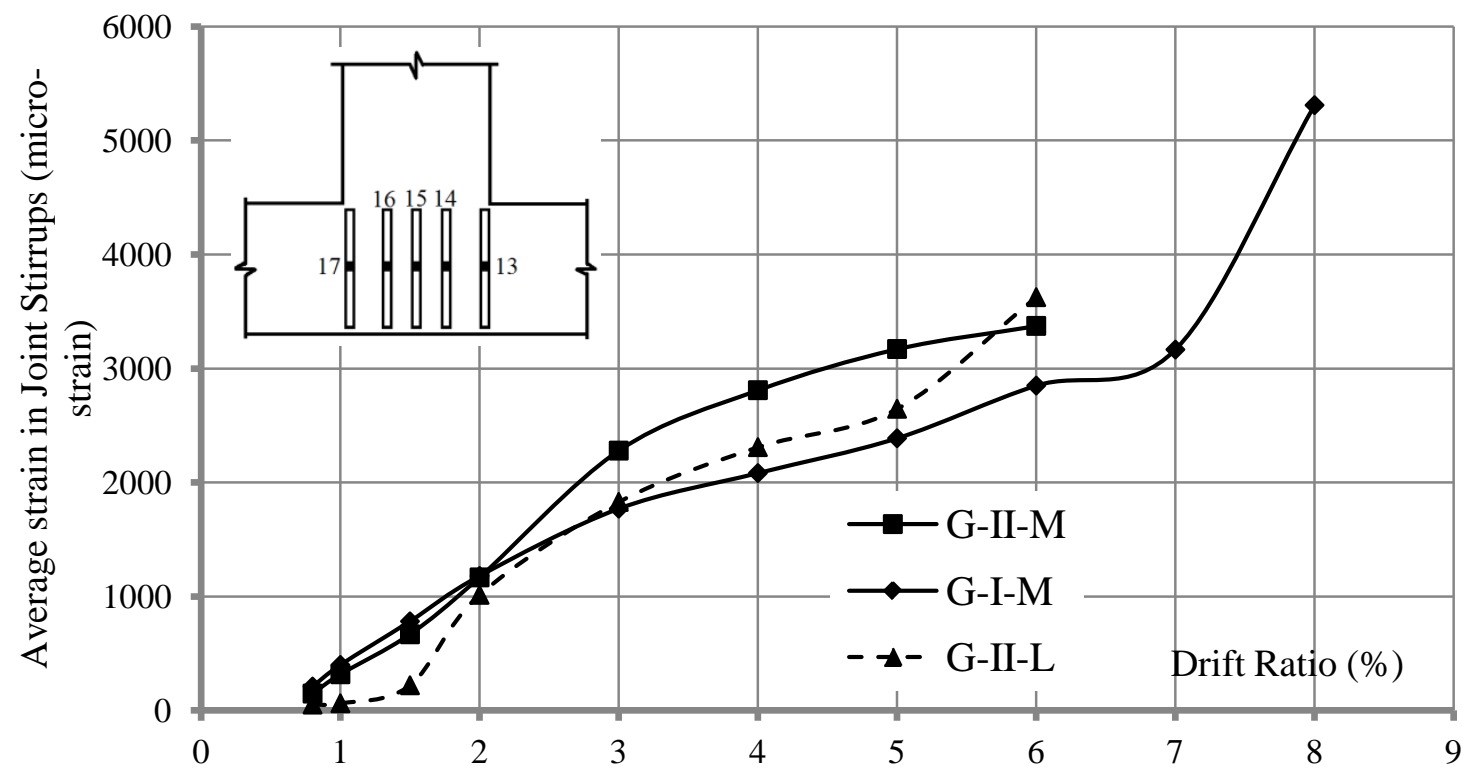

Figure 5.42 - Average joint stirrups strain in G-II-M, G-II-L, and G-I-M

Figure 5.43 compares the maximum strain value of Strain Gauge No.6 in specimens G-II-L, GII-M, and G-I-M at different drift ratios. The graph shows that all specimens had approximately the same behaviour up to $3 \%$ drift ratio (the strain gauges in specimen G-II-M and G-II-L malfunctioned after 3\% drift ratio). 
TEST RESULTS AND DISCUSSION

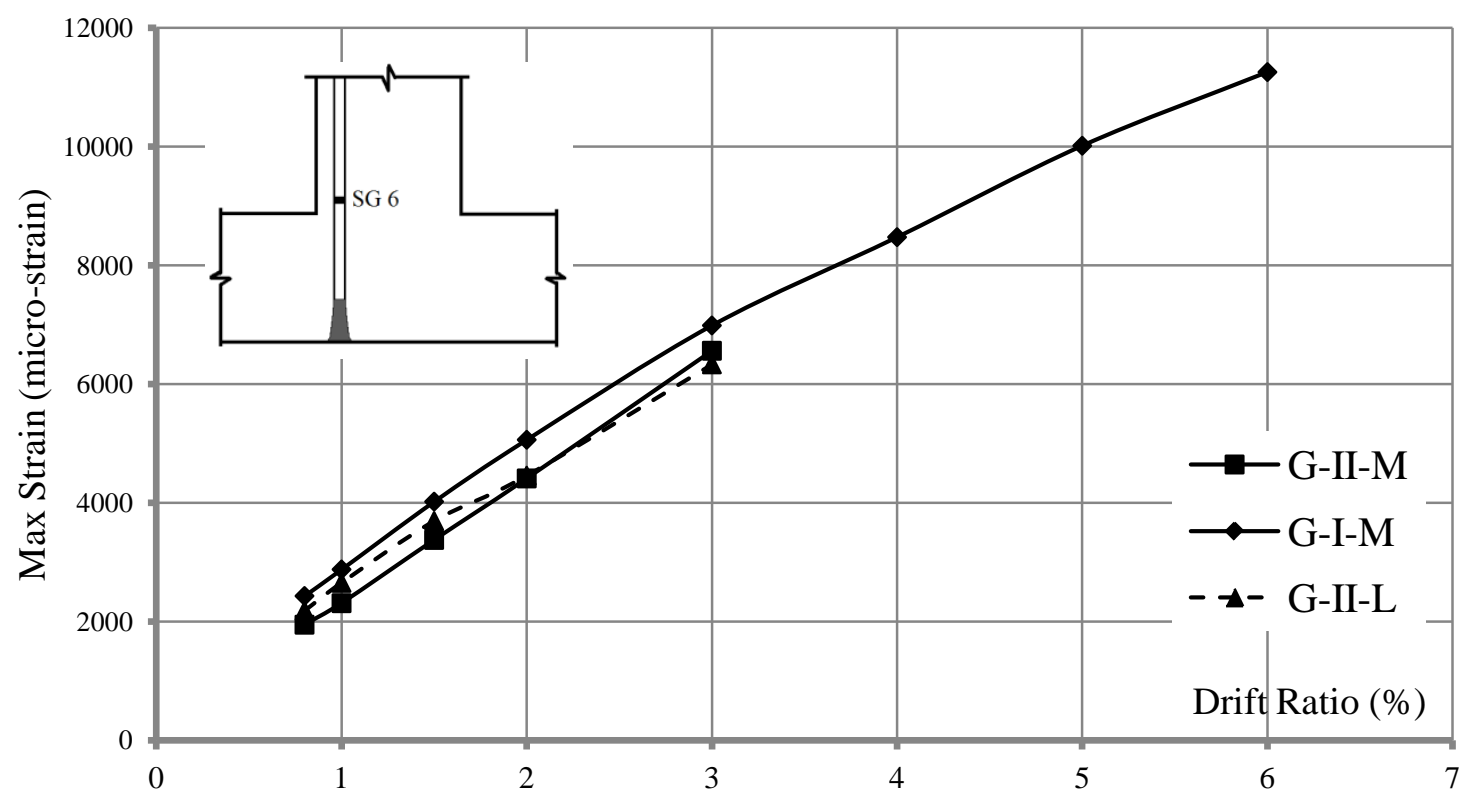

Figure 5.43 - Readings of Strain Gauge No.6 in G-II-M, G-II-L, and G-I-M

Similar to Series I specimens, the trend of the strain in the column longitudinal bars generally followed the same trend as the maximum lateral load envelop of the specimens. In other words, increasing in the beam lateral load resulted in the column bars strain increase. However, at 6\% drift ratio (the final loading stage), the strain in Specimen G-II-M remained constant despite of the increase in the beam lateral load. A possible explanation for this behaviour can be a minor slippage of the column longitudinal bars.

It should be mentioned that, despite the fact that magnitude of beam tip lateral loads in specimens G-II-M and G-I-M was approximately the same at all loading stages, the joint concrete damage was significantly higher in Specimen G-I-M. The damage penetrated into the column adjacent to the joint area in G-I-M and resulted in higher recorded strains in the column longitudinal bars. 
TEST RESULTS AND DISCUSSION

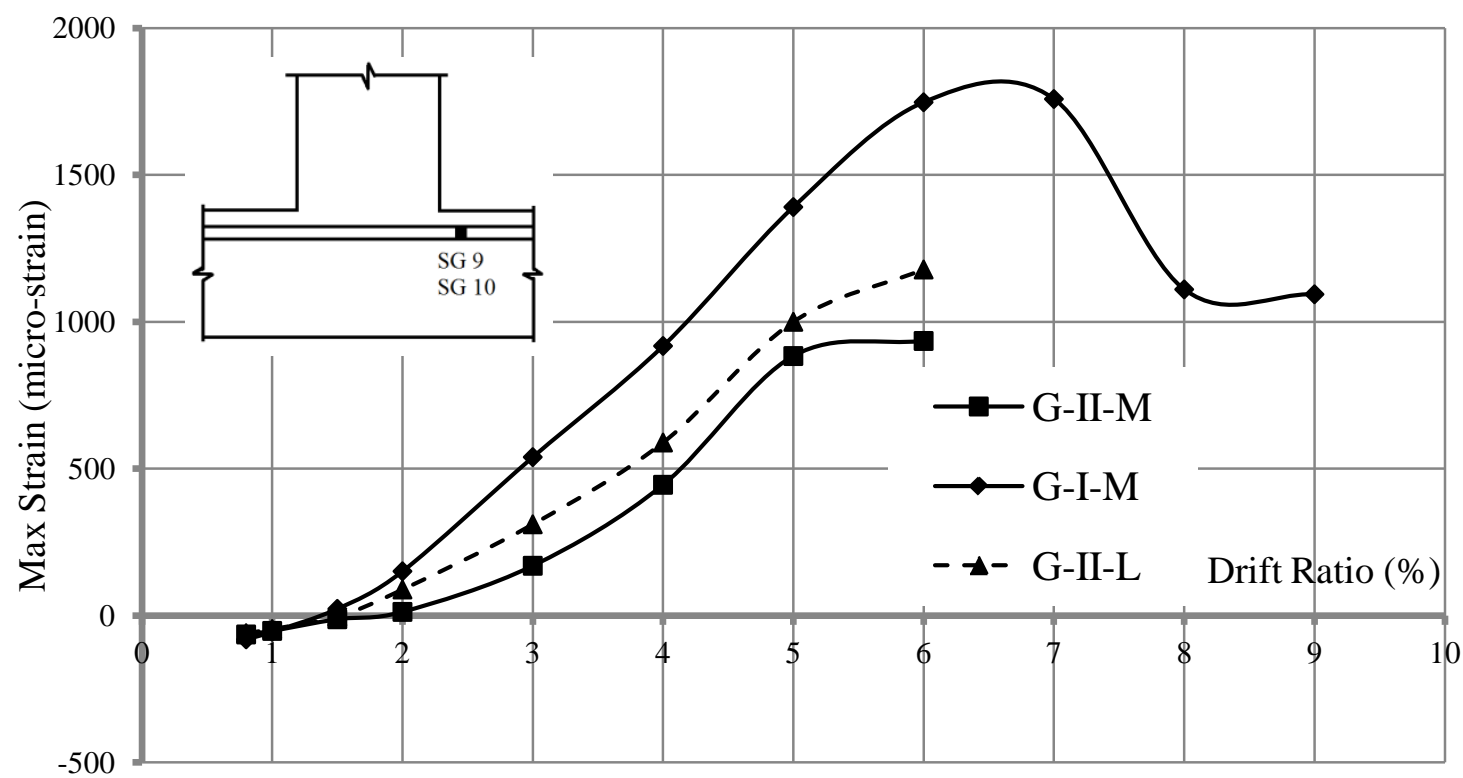

Figure 5.44 - Average strain in column longitudinal bars in G-II-M, G-II-L, and G-I-M

Figure 5.45 shows the readings of Strain Gauge No.19 at different drift ratios for Series II specimens and Specimen G-I-M from Series I. A 2000-micro-strain jump in readings in G-II-M at the final loading stage was due to the significant concrete damage in the beam (Figure 5.39). The fluctuation of the strain in Specimen G-I-M was due to the excessive concrete damage in the beam and change in the specimen's stiffness. Lower strain in G-II-L was expected since the applied lateral load during the test was lower in comparison to the other specimens.

Specimen G-II-M showed lower strains than G-I-M despite the fact that they were under equal lateral loads. Comparing the figures in section 5.2.3, indicates that Specimen G-II-M had fewer numbers of shear cracks at the beam in comparison to Specimen G-I-M (up to 5\% drift ratio). Since the strain in the transverse reinforcement significantly increases when the cracks pass through the stirrups, Specimen G-I-M showed higher strains than G-II-M. 
TEST RESULTS AND DISCUSSION

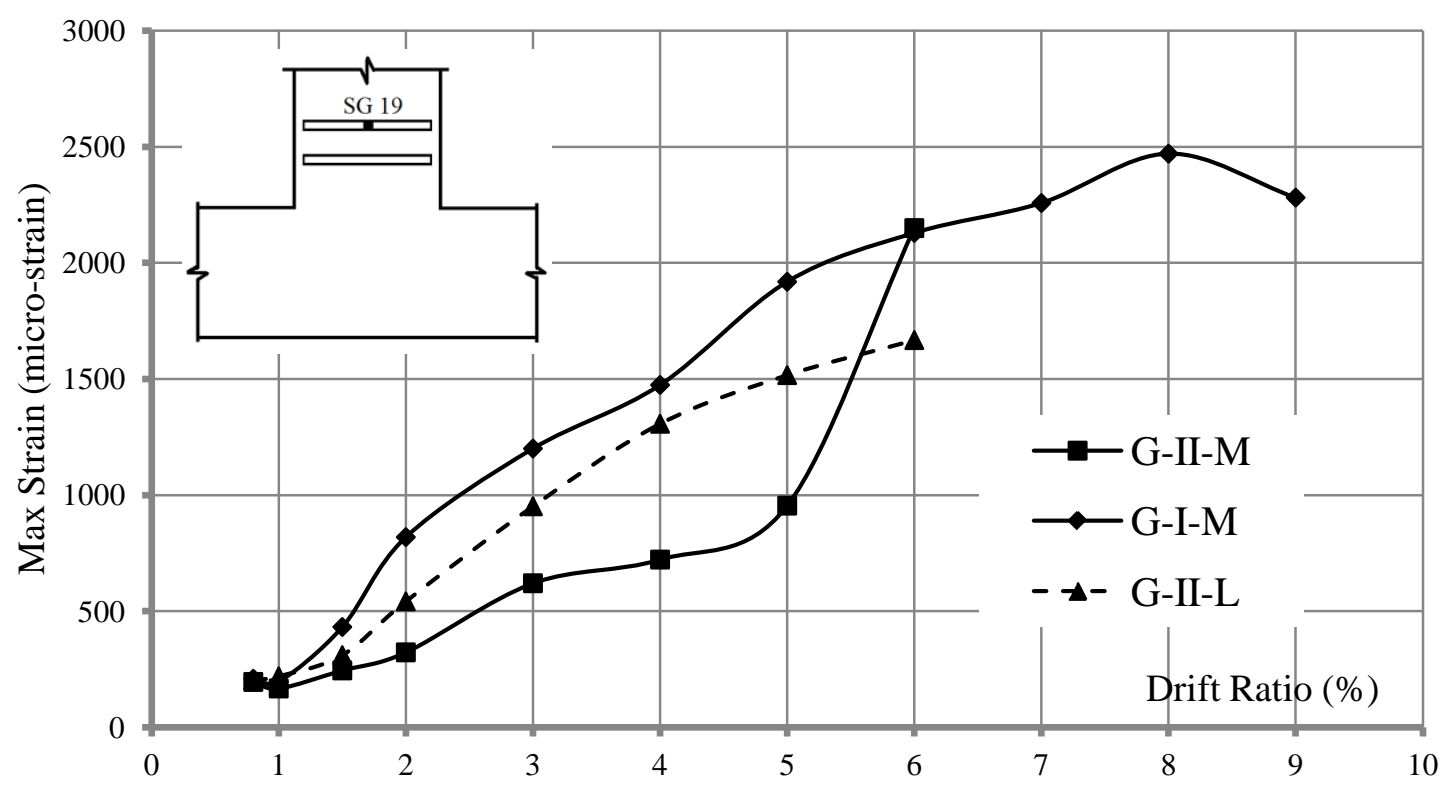

Figure 5.45 - Readings of Strain Gauges No.19 in G-II-M, G-II-L, and G-I-M

Figure 5.46 and Figure 5.47 show the strain flow in the beam longitudinal bars of the specimens in Series II. Same as the graphs for Series I, the location of Strain Gauge No.6 was assumed to be at the origin, consequently, Strain Gauge No.5 and 8 were located at $-240-\mathrm{mm}$ and 200-mm, respectively.

Lower strain inside the joint in respect to the strain at the column face in Series II specimens indicates the sufficient bond strength between the bars and the concrete. This behaviour can be compared to the behaviour of the specimens reinforced with headed-end GFRP bars, where the difference between the strains reading inside the joint and at the column face was lower. This indicates more stress penetration inside the joint. 
TEST RESULTS AND DISCUSSION

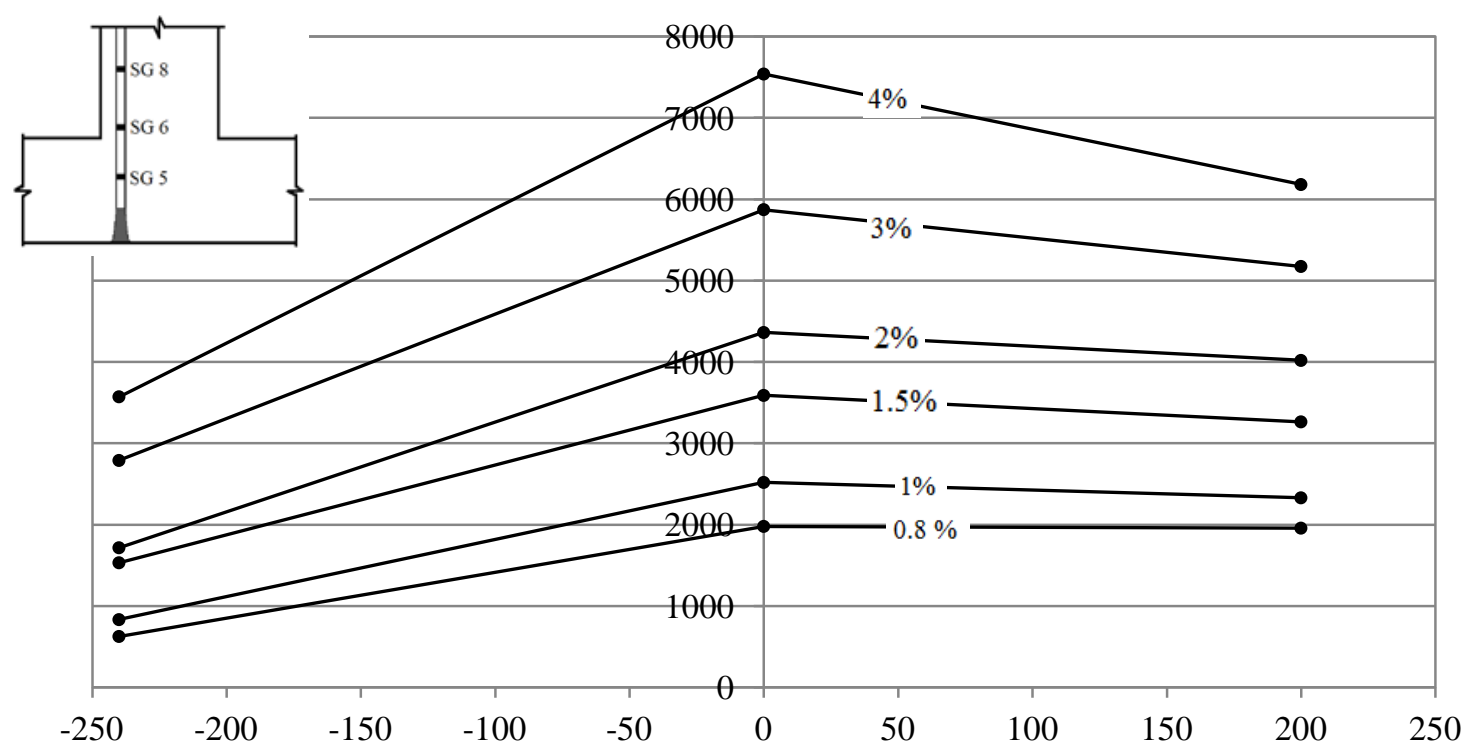

Figure 5.46 - Strain flow in beam longitudinal bars in Specimen G-II-M

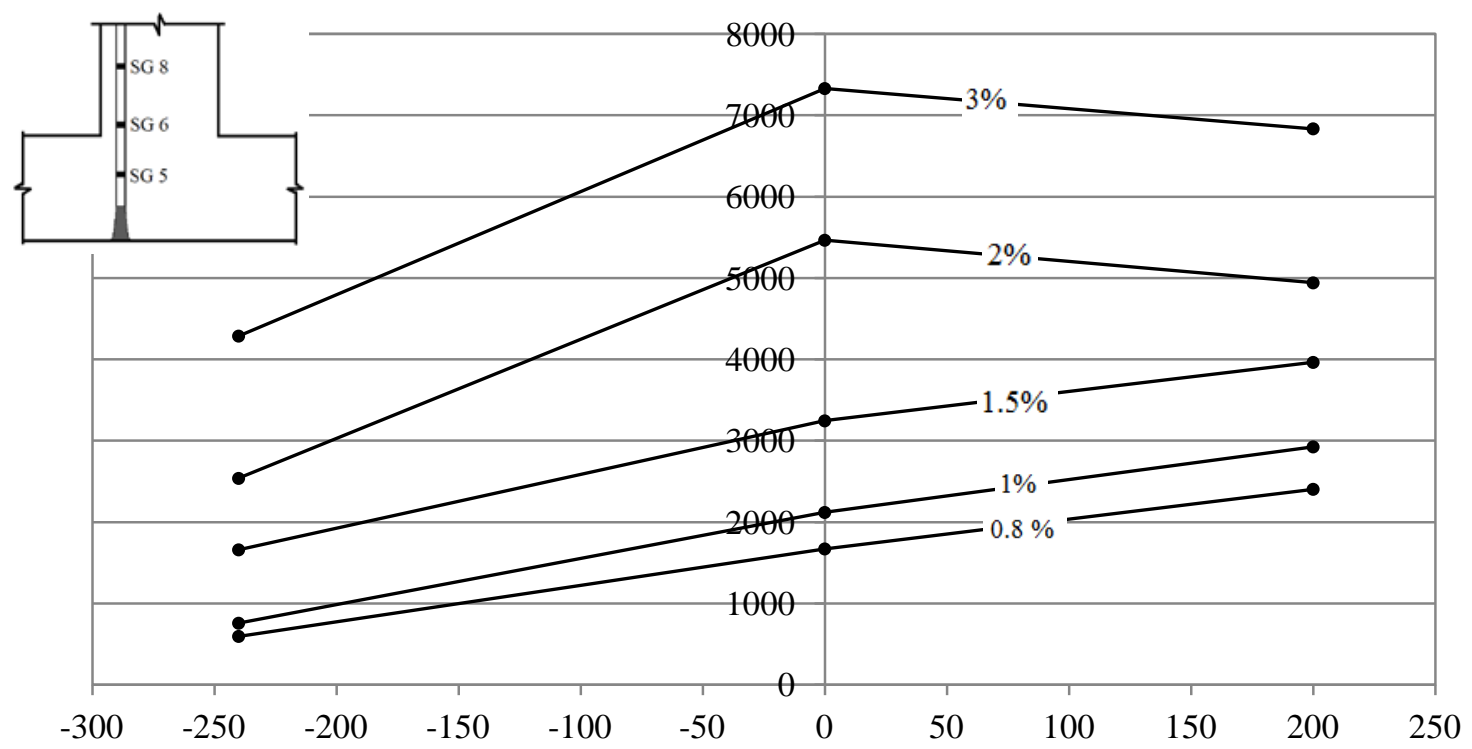

Figure 5.47 - Strain flow in beam longitudinal bars in Specimen G-II-L

\subsubsection{Lateral stiffness}

Figure 5.48 shows lateral stiffness of G-II-L, G-II-M, and G-I-M in different loading stages. Specimens G-I-M and G-II-M showed similar behaviour, since the specimens had close values of $A_{F R P} * E_{F R P}$. Specimen G-II-L showed lower stiffness than the other two specimens due to lower number of bars inside the beam, which resulted in lower stiffness of the section. 


\section{TEST RESULTS AND DISCUSSION}

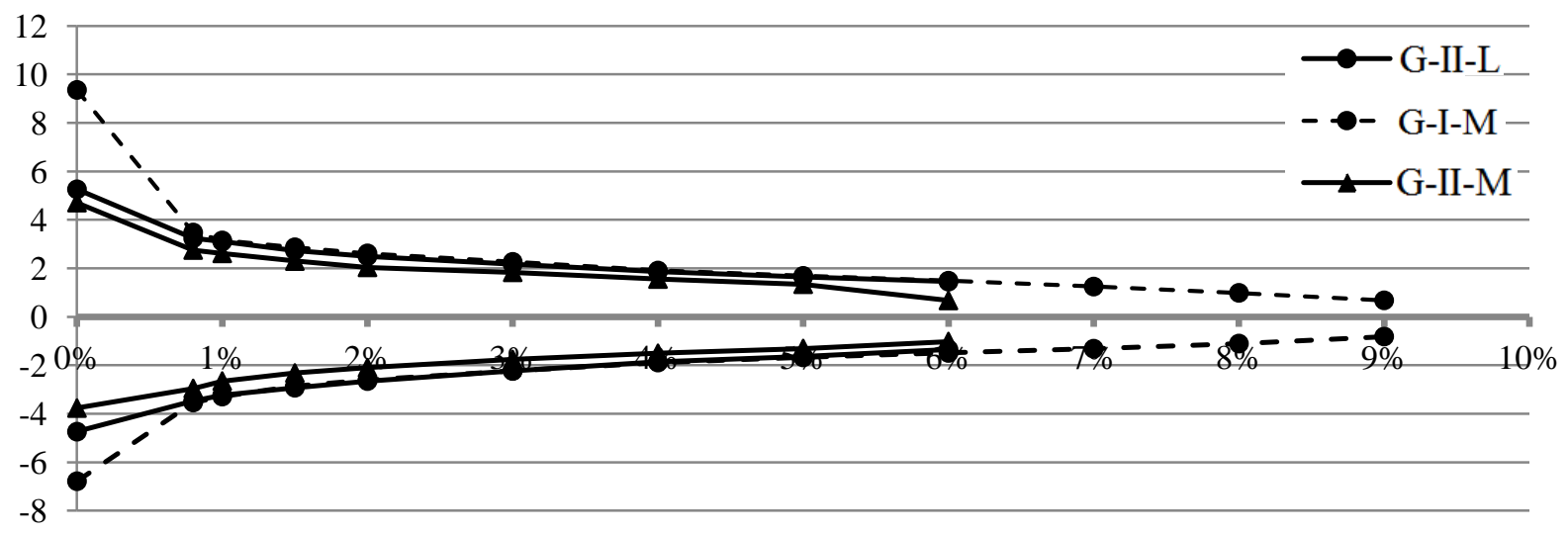

Figure 5.48 - Lateral stiffness of G-II-L. G-II-M, G-I-M

\subsubsection{Energy Dissipation}

Figure 5.49 shows cumulative dissipated energy for the specimens in Series II and specimen G-IM. The magnitudes of dissipated energy corresponding to Specimen G-II-M and G-II-L were approximately the same at all loading stages. Specimen G-I-M exhibited more energy dissipation than the specimens in Series II. The reason was the better bar anchorage that was provided by bent bars in comparison to headed-end bars. The reinforcement anchored by headed-end bars was less restrict against slippage, which resulted in more damage induced to the joint. Consequently more energy was dissipated by crushing the concrete. 


\section{TEST RESULTS AND DISCUSSION}

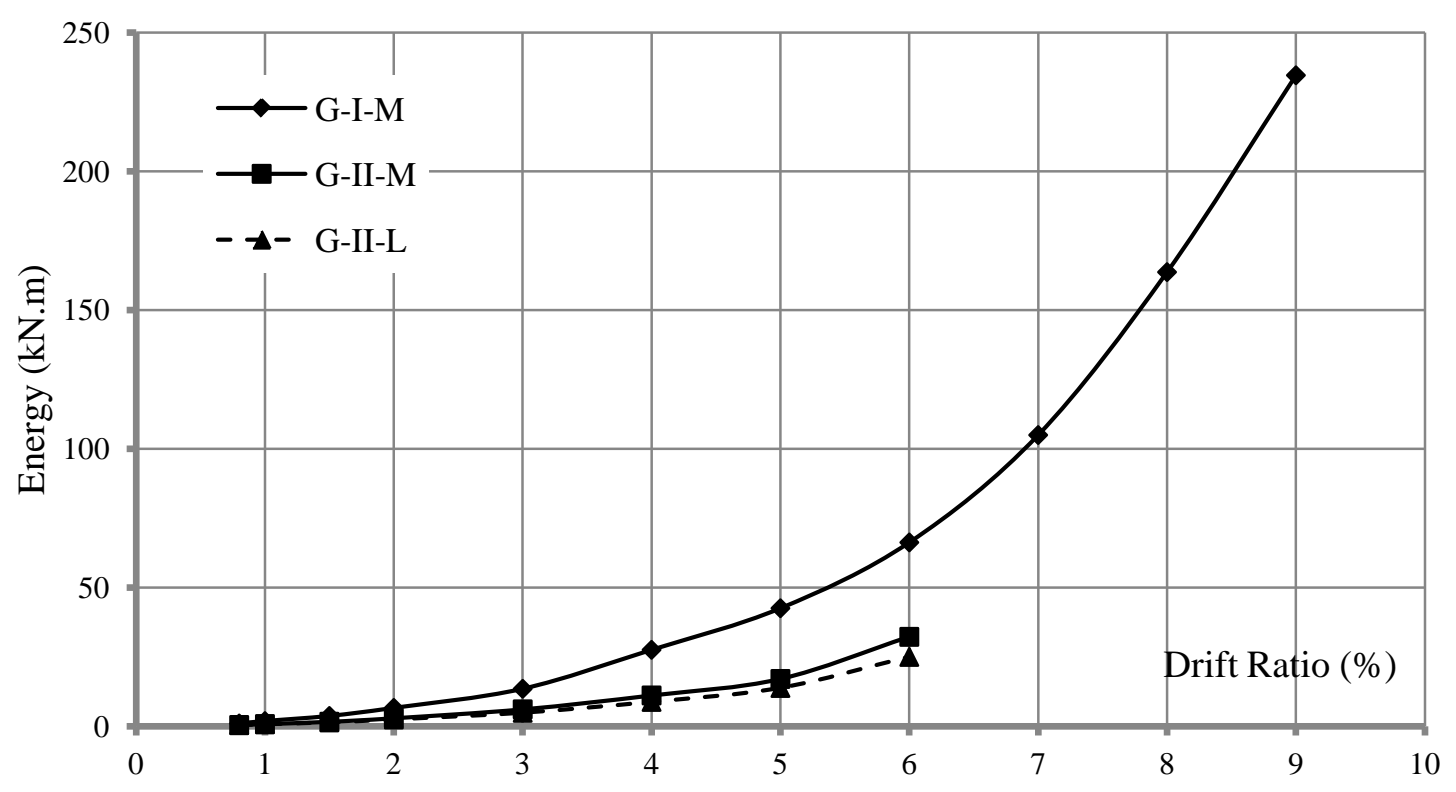

Figure 5.49 - Cumulative energy dissipation of the G-II-M, G-II-L, and G-I-M 


\section{CONCLUSIONS AND FUTURE WORK}

\subsection{Summary and Conclusions}

Six full-scale exterior beam-column joints with lateral beams were designed, constructed, and tested in this study. The specimens were isolated from a multi-story, multi-bay framed structure at points of contra-flexure in the columns mid-height and the beams mid-span. All specimens had the same dimensions, and were tested under reversal cyclic loading to simulate a seismic event. The program included two series.

Four specimens were tested in Series I, three reinforced with GFRP bars (Headed-end bars) and stirrups (G-I-L, G-I-M, G-I-H) and one reinforced with conventional steel (S-I-M). The reinforcement detailing in the GFRP-RC specimens were similar except for the number of longitudinal bars in the main beam. The different beam reinforcement ratios resulted in different shear stress applied to the joint. The primary objective of testing the GFRP-RC specimens was to investigate the shear capacity of exterior beam-column joints reinforced with headed-end GFRP bars and confined with lateral beams. Based on the test outcomes, the joint shear ratio of $1.0 \sqrt{f^{\prime}}{ }_{c}$ (corresponding to Specimen G-I-M) was introduced as the shear capacity of such joints. The steel-RC specimen was designed to have similar applied joint shear stress of $1.0 \sqrt{f^{\prime}}$. The effect of reinforcement type (GFRP or steel) on seismic behaviour of exterior beam-column joints was studied in this series.

In Series II, two specimens were tested, G-II-M and G-II-L. Both specimens were reinforced with GFRP reinforcement; however, bent bars were used instead of headed-end bars to anchor 


\section{CONCLUSIONS AND FUTURE WORK}

beam longitudinal reinforcement in the joint. The primary objective of this series was to investigate the effect of anchorage type on seismic behaviour of exterior beam-column joint (with and without lateral beams).

Specimen G-II-M was similar to Specimen G-I-M except for the beam bars anchorage type. Specimen G-II-L was the only specimen without lateral beams and having an applied joint shear stress of $0.8 \sqrt{f^{\prime}}$ similar to G-I-L.

All specimens were able to reach their design capacity; however, their behaviour and mode of failure was different. Specimen G-I-L (joint shear stress equal to $0.8 \sqrt{f^{\prime}}$ ) showed linear behaviour up to failure, which occurred at 7\% drift ratio. There were no signs of shear damage in the joint and the specimen failed due to tensile failure at the beam.

Both specimens G-I-M and G-I-H were able to withstand a 9\% drift ratio. This magnitude of lateral displacement was beyond the expected lateral drift in a real structure. Both specimens showed stable linear behaviour up to $6 \%$ drift ratio with no signs of shear damage in the joint area. However, after 6\% drift ratio non-linear behaviour and strength reduction occurred due to severe joint damage. Despite the anticipated brittle failure for GFRP-RC specimens, both specimens showed deformable mode of failure.

Specimen S-I-M, on the other hand, exhibited no signs of shear damage in the joint, which indicated the higher shear capacity of steel-RC exterior beam-column joints than the headed-end GFRP-RC ones. S-I-M failed at 7\% drift ratio due to buckling of the beam reinforcement.

Specimen G-II-M (with bent bars) showed significant different behaviour from Specimen G-I-M (with headed-end bars), despite the fact of having the same joint shear ratio. The joint in 
Specimen G-II-M remained intact up to the final stage and the damage was concentrated in the main beam. This indicated that using bent bars can increase the shear capacity of exterior beamcolumn joints. However, removing the lateral beams in Specimen G-II-L caused the failure to occur by concrete crushing in the joint even though Specimen G-II-L was subjected to lower applied shear stress than that of Specimen G-II-M.

Based on the test results, the followings conclusions can be drawn:

1. Exterior beam-column joints confined with lateral beams and reinforced with GFRP headed-end bars were able to withstand joint shear stress of $1.1 \sqrt{f^{\prime}}$ without showing any shear failure at the joint up to $6 \%$ drift ratio.

2. Exterior beam-column joints reinforced with headed-end GFRP bars with joint shear stress of $1.0 \sqrt{f^{\prime}}$ and $1.1 \sqrt{f^{\prime}{ }_{c}}$ showed non-brittle failure and they were able to maintain their design capacity up to 6\% drift ratio. The specimens showed non-linear behaviour after that drift ratio and resisted $60 \%$ of their ultimate capacity at $9 \%$ drift ratio.

3. Specimen G-I-L, with joint shear stress of $0.8 \sqrt{f_{c}^{\prime}}$ and reinforced with headed-end bars, showed linear behaviour up to failure at $7 \%$ drift ratio. The failure occurred due to rupture of beam bars, while the joint remained intact during the test. Minor slippage in some of the beam longitudinal bars resulted in stress increase in the remaining beam bars. This resulted in exceeding the tensile capacity of the bars leading to bar rupture despite of the compression failure mode design. However, the specimen showed stable behaviour up to $7 \%$ drift ratio, which is beyond the expected lateral drift in a building.

4. The joint shear ratio influenced the mode of failure of the exterior beam-column joints reinforced with headed-end GFRP bars. Increasing the joint shear ratio changed the mode 
of failure from a brittle and sudden failure (in G-I-L) to a deformable failure (in G-I-M and G-I-H). High shear stress applied to the joints caused more concrete damage in the joint and minor slippage of the beam longitudinal bars in specimens G-I-M and G-I-H. The damage decreased the stiffness of the specimens, which resulted in the non-linear behaviour.

5. Specimen G-I-M, reinforced with headed-end GFRP bars and joint shear ratio of $1.0 \sqrt{f^{\prime}}$, showed lower joint shear capacity than its counterpart specimen reinforced with conventional steel bent bars (S-I-M). The reason was the formation of wide cracks due to relatively low stiffness of the GFRP reinforcement and slippage of headed-end bars at high drift ratios. However, it should be mentioned that for the drift ratios up to $2.5 \%$, as suggested by building codes, the GFRP-RC specimen showed minimum concrete damage and spalling due to elastic nature of the reinforcement. This less damage is expected to minimize the repair cost following a seismic event.

6. Test results showed that beam longitudinal bars anchorage method significantly influenced the behaviour of exterior beam-column joints. Specimen G-II-M, with joint shear ratio equal to $1.0 \sqrt{f^{\prime}}$ and bent bars, showed linear behaviour without any signs of damage in the joint. Bent bars provided more confinement to the joint which increased the shear capacity of the joint. Moreover, bent bars provided better anchorage and reduced the bars slippage. Consequently, the joint did not show significant stiffness degradation during the test but exhibited a brittle failure. However, it should be mentioned that the bent bars, used in this program, had a deformed cover layer around the bar which was sheared off at high drift ratios of $6 \%$ or higher. 


\section{CONCLUSIONS AND FUTURE WORK}

7. The presence of lateral beams provided more confinement to the concrete in the joints, which significantly increased the shear capacity. Specimen G-II-L, without lateral beams and shear stress of $0.8 \sqrt{f^{\prime}}$, exhibited similar drift capacity to Specimen G-II-M with lateral beams and shear stress of $1.0 \sqrt{f^{\prime}}$.

8. Since the damage induced to the joints reinforced with headed-end bars was more than the counterpart specimen reinforced with bent bars, they exhibited wider loops in the hysteresis diagram. Consequently, defined as the area enclosed by the hysteresis diagram loops, energy dissipation was more in the specimens with headed-end bars. However, it should be mentioned that the difference in dissipated energy among all GFRP-RC specimens was insignificant until reaching drift ratios higher than 5\%.

9. All GFRP-RC specimens with headed-end bars showed similar values of dissipated energy up to $5 \%$ drift ratio. However, at the higher drift ratios, dissipated energy was more in the specimens with the higher joint shear stress. Therefore, limiting the results to the lateral drift limits provided by NBCC (2.5\%), it can be concluded that the joint shear ratio did not have significant effect on the energy dissipation of the exterior beam-column joints reinforced with headed-end bars.

10. Compared to the GFRP-RC specimens, the control steel-RC specimen showed higher values of energy dissipation due to yielding of steel, which resulted in wider loops in the hysteresis diagram.

\subsection{Future Work}

The following are suggestions for further investigations of seismic behaviour of exterior beamcolumn joints reinforced with FRP reinforcement: 
- Studying seismic behaviour of exterior beam-column joints confined with lateral beams and reinforced with FRP bent bars to investigate the shear capacity of such joints.

- Investigation seismic behaviour of other beam-column joint configurations such as: corner joint, knee joints, and interior joints.

- Investigating the effect of other parameters on seismic behaviour of FRP-RC beamcolumn joints such as: concrete strength, column axial load, presence of slabs, column-tobeam flexural strength ratio, etc.

- Investigating the reinforcement detailing required to establish the design capacity of beam-column joints such as: bars lap splice length, tail length of bent bars, bonding behaviour of reinforcement in concrete, etc. 


\section{REFERENCES}

1. ACI Committee 318. (1995). "Building Code Requirements for Structural Concrete (ACI 318-95) and Commentary (318R-95)," American Concrete Institute (ACI), Farmington Hills, Mich., 369 p.

2. ACI Committee 318. (2005). "Building Code Requirements for Structural Concrete (ACI 318-95) and Commentary (ACI 318R-95)," American Concrete Institute, Farmington Hills, Mich., 430 p.

3. ACI Committee 374. (2005). "Acceptance Criteria for Moment frames Based on Structural Testing and Commentary", ACI 374.1-05, American Concrete Institute, Farmington Hills, Mich., 9 p.

4. ACI Committee 440. (2006). "Guid for Design and Concsrtuction of Concrete Reinforced with FRP Bars," ACI 440.1R-06, American Concrete Institute, Farmington Hills, Mich., 44 p.

5. ACI-ASCE Committee 352. (1976). "Recommendations for Design of Beam-Column Joints in Monotonic Reinforced Concrete Structures," ACI Journal, V. 73, No. 7, pp. 375-393.

6. ACI-ASCE Committee 352. (1985). "Recommendations for Design of Beam-Column Joints in Monotonic Reinforced Concrete Structures," ACI Journal, V. 82, No. 3, pp. 266-283. 
$<$ REFERENCES

7. Ahmed, E., El-Salakawy, E. and Benmokrane, B. (2008). "Carbon Fibre Reinforcd Polymer Shear Reinforcement for Concrete Members," CSCE 2008 Annual conference, Quebec, QC, Canada, 10 p.

8. Alsayed, S., Al-Salloum, Y., Qlmusallam, T. and Amjad, M. (1999). "Concrete Columns Reinforced by Glass Fibre Reinforced Polymer Rods," ACI special publication, SP-188, pp. 103-112.

9. Benmokrane, B., Chaallal, O. and Masmoudi, R. (1996). "Flexural Response of Concrete Beams Reinforced with FRP Reinforcing Bars," ACI Structural Journal, V. 91, No. 2, pp. 46-55.

10. Brown, V. and Bartholomew, C (1993). "FRP Reinforcing Bars in Reinforced Concrete Members ," ACI Material Journal, V. 90, No. 1, pp. 34-39.

11. Canadian Standard Association (CSA) (1994). "Design of Concrete Structures" CAN/SCA A23.3-94, Canadian Standard Association, Toronto, Ontario, Canada, 199 p.

12. Canadian Standard Association (CSA). (2002). "Design and Construction of Building Components with Fibre-Reinforced Polymers," CAN/CSA S806-02, Canadian Standard AssociationToronto, Ontario, Canada, 177 p.

13. Canadian Standard Association. (2004). "Design of Concrete Structures," CAN/CSA A23.3-04, Canadian Standard Association, Toronto, Ontario, Canada, 214 p.

14. Canadian Standard Association. (2006). "Canadian Highway and Bridge Design Code," Canadian Standard Association, Toronto, Ontatio, Canada, 733 p 
$<$ REFERENCES

15. Canadian Standard Association (CSA). (2012). "Design and Construction of Building Components with Fibre-Reinforced Polymers," CAN/CSA S806-12, Canadian Standard AssociationToronto, Ontario, Canada, 187 p.

16. Choo, C. C., Harik, I. E. and Gensund, H. (2006). "Strength of Rectangular Concrete Columns Reinforced with Fiber-Reinforced Polymer Bars," ACI Structural Journal, V. 103, No. 3, pp. 452-459.

17. Chopra, A. (2000). "Dynamics of Structures-Theory and Aplications to Earthquake Engineering," Prentice-Hall, Inc., 844 p.

18. Chun, S., Lee, S., Kang, T., Oh, B. and Wallace, J. (2007). "Mechanical Anchorage in Exterior Beam-Column Joints Subjected to Cyclic Loading," ACI Structural Journal, V. 104, No. 1, pp. 102-112.

19. Chung, L. and Shah, S. (1989). "Effect of Loading Rate on Anchorage Bond and BeamColumn Joints," ACI Structural Journal, V. 86, No. 2, pp. 132-142.

20. Ehsani, M. and Wight, J. (1985-a). "Exterior Reinforced Concrete Beam-to-Column Connections Subjected to Earthquake," ACI Journal proceedings, V. 82, No. 4, pp. 492499.

21. Ehsani, M. and Wight, J. (1985-b). "Effect of Transverse Beamsand Slab on Behaviour of Reinforced Beam-to-Column Connections," ACI Journal proceeding, V. 82 No. 2, pp. 188-195. 
$<$ REFERENCES

22. El-Sayed, A., El-Salakawy, E. and Benmokrane, B. (2007). "Mechanical and Structural Characterizatiion of New Carbon FRP Stirrups for Concrete Members," Journal of Composites for Construction, ASCE, V. 11, No. 4, pp. 352-362.

23. Fukuyama, H., Masuda, Y., Sonobe, Y. and Tanigaki, M. (1995). "Structural Performances of Concrete Frame Reinforced with FRP Reinforcement," Non-Metallic (FRP_Reinforcement for Concrete Structures, Chent, Belgium, pp. 275-286.

24. Ghobara, A. and El-Amoury, T. (2005). "Seismic Rehabiliation of Deficient Exterior Concrete Frame Joints," Journal of Composites for Concstruction, ASCE, V. 11, No. 5, pp. 408-416.

25. Grira, M. and Saatcigolu, M. (1999). "Reinforced Concrete Columns Confined with Steel or FRP Grids," Canadian Conference on Earthquake Engineering, Vancouver, Canada, pp. $445-450$

26. Hakuto, S., Park, R. and Tanaka, H. (2000). "Seismic Load Tests on Interior and Exterior Beam-Column Joints with Substandard Reinforcing Details," ACI Structural Journal, V. 97, No.1, pp. 11-25.

27. Hanson, N., and Connor, H. (1967). "Seismic Resistance of Reinforced Concrete BeamColumn Joints," Journal of the Structural Division, Proceeding of the American Society of Civil Engineers (ASCE), V. 93, ST5, pp. 533-560.

28. Hasaballa, M., Mady, M. and El-Salakawy, E.F. (2013). "Influence of Reinforcement Detailing on the Behavior of Beam-Column Joints Reinforced with GFRP Bars.” 
$<$ REFERENCES

Proceedings on CD-ROM, $4^{\text {th }}$ Asian-Pacific Conference on FRP in Structures, Melbourne, Australia, Dec. 11-13, 10 p.

29. Hasaballa, M. and El-Salakawy, E.F. (2012). "Influence of Joint-Shear Stress on Seismic Behaviour of Exterior Beam-Column Joints Reinforced with GFRP Bars and Stirrups." Proceedings on CD-ROM, The 6th International Conference on Advanced Composite Materials in Bridges and Structures (ACMBS-VI), Kingston, Ontario, Canada, May 2225, 7 p.

30. Hasaballa, M. and El-Salakawy, E.F. (2012). "Seismic Performance of Beam-Column Joints Reinforced with GFRP Headed Bars." Proceedings on CD-ROM, Asian-Pacific Conference on FRP in Structures, Hokkaido, Japan, February 2-4, 10 p.

31. Hasaballa, M., El-Ragaby, A. and El-Salakawy, E. (2011). "Seismic Performance of Exterior Beam-Column Joints Reinforced with Glass Fibere Reinforced Polymer Bars and Stirrups," Canadian Journal of Civil Engineering, V. 38, No. 10, pp. 1092-1102.

32. Hasaballa, M. (2010), "Seismic Behaviour of Exterior GFRP-Reinforced Concrete BeamColumn Joints," MSc. Thesis, University of Manitoba, Winnipeg, Manitoba, Canada, 138 p.

33. Hwang, S., Lee, H., Lioa, T., Wang, K. and Tsai, H. (2005). "Role of Hoops on Shear Strength of Reinforced Concrete Beam-Columnoints," ACI Structural Journal, V. 102, No. 3, pp. 445-453. 
$<$ REFERENCES

34. ISIS Canada. (2007). "Reinforcing Concrete Structures with Fibre Reinforced Polymers," Design Manual No.3., ISIS Canada Corporation, University of Manitoba, Winnipeg, Canada, 103 p.

35. Mady, M., Hasaballa, M., El-Ragaby, A. and El- Salakawy, E. F. (2009). "Seismic Behaviour of Exterior Beam-Column Joints Reinforced with GFRP Bars and Stirrups," CSCE 2009 Annual conference, St. John's, Newfoundland and Labrador, Canada, 10 p

36. Murty, C., Rai, D., Bajpai, K. and Jain, S. (2003). "Effectiveness of Reinforcement Details in Exterior Reinforced Concrete Beam-Column Joints for Earthquake Resistance," ACI Structural Journal, V. 100, No. 2, pp. 149-156.

37. NBCC. (2005). "National Building Code of Canada," National Research Council of Canada, Ottawa, Canada, 1167 p.

38. Paramanatham, N. (1993). "Investigation of the Behaviour of Concrete Columns Reinforced with Fiber Reinforced Plastic Rebars," Master of Engineering Scirnce thesis, Lamar University, Beaumont, Texas, 75 p.

39. Park, R. and Paulay, T. (1975). "Reinforced Concrete Structures," John Wiley, New York, 769 p.

40. Paulay, T., Park, R. and Priestley, M. (1978). "Reinforced Concrete Beam-Column Joints Under Seismic Action," ACI Journal, Proceeding, V. 75, No. 11, 585-593.

41. Said, A. M. and Nehdi, M. L. (2004). "Use of FRP for RC Frames in Seismic Zones: Part II. Performance of Steel-Free GFRP-Reinforced Beam-Column Joints," Applied Composite Materials, V. 11, pp. 227-245. 
$<$ REFERENCES

42. Shehata, E., Morphy, R. and Rizkalla, S. (2000). "Fibre Reinforced Polymer Shear Reinforcement for Concrete Members: Behaviour and Design Guideline," Canadian Journal of Civil Engineering, V. 27, No. 5, pp. 859-872.

43. Wallace, J., McConnell, S., Gupta P. and Cote P. (1998). "Use of Headed Reinforcement in Beam-Column Joints Subjected to Earthquake Loads," ACI Structural Journal, V. 95, No. 5, pp. 590-606.

44. Wight, J. and MacGregor, J. (2009). "Reinforced Concrete: Mechanics \& Design," Pearson Prentice-Hall, Inc., 1112 p 


\section{APPENDIX A : DESIGN OF SPECIMEN “G-I-M”}




\section{Design of the Main Beam for Flexural}

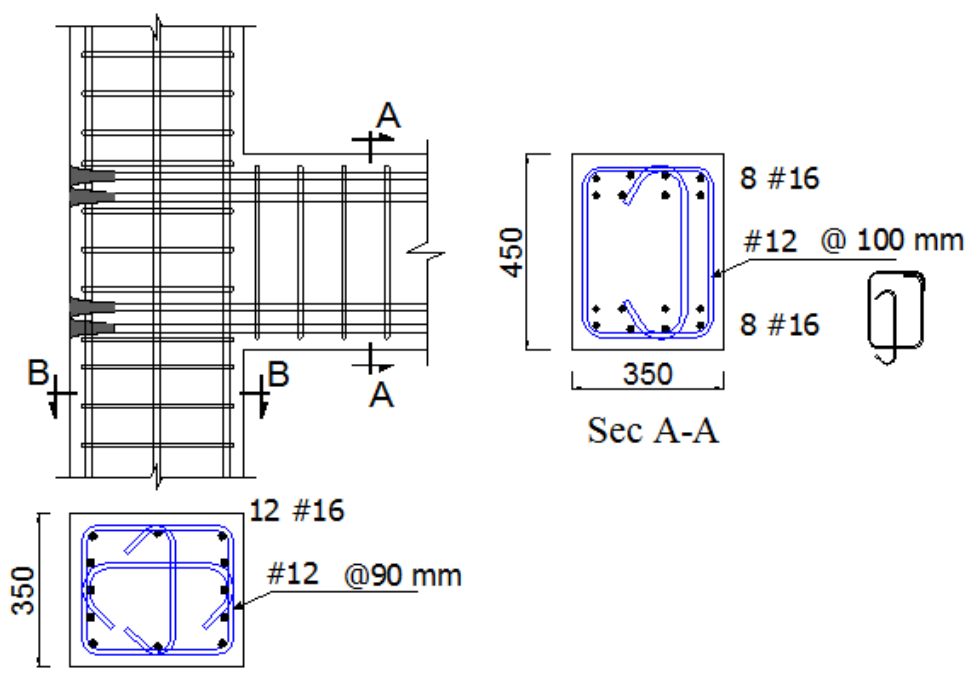

Sec B-B

Figure A.1 - Specimen G-I-M reinforcement detailing

\section{Material and sectional properties}

Concrete properties:

${f^{\prime}}_{c}=35 \mathrm{MPa}, \quad \varphi_{c}=1$, $E_{C}=4500 \sqrt{f^{\prime}{ }_{c}}=4500 \sqrt{35}=26622 \mathrm{MPa}$

$\alpha_{1}=0.85-0.0015 f^{\prime}{ }_{c}=0.80$, $\beta_{1}=0.97-0.0025 f^{\prime}{ }_{c}=0.88$

$\varepsilon_{c u}=0.0035$

GFRP properties:

$f_{F R P, u}=1100 \mathrm{MPa}$

$\varphi_{F R P}=1$

$E_{F R P}=60 \mathrm{GPa}$

$\varepsilon_{F R P, u}=1.83 \%$

Cross section properties:

$h=450 \mathrm{~mm}$

$b=350 \mathrm{~mm}$ 
$A_{F R P}=8 \emptyset 18=8 * 201=1608 \mathrm{~mm}^{2}$

\section{Calculations}

Since there is no provision for the reinforcement detailing in CSA S806-02 and 12, Clause 6.6.5.2 in CSA A23.3-04 was used to calculate the clear distance between parallel bars. According to the clause the distance shall not be less than:

- 1.4 times the bar diameter;

- 1.4 times the maximum coarse aggregate size;

- $30 \mathrm{~mm}$.

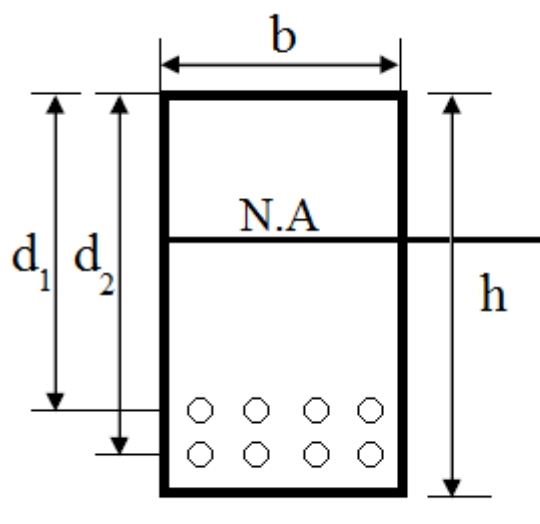

Cross Section
Strain Distribution

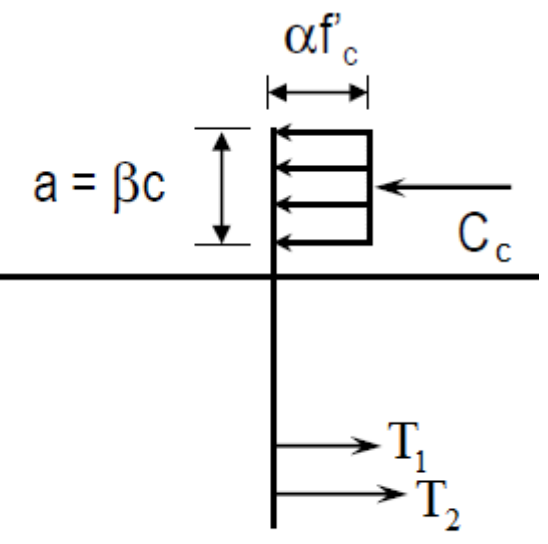

Loads

Figure 1.2 - Compatibility of strain for beam cross section (G-I-M)

Distance between two layers is equal to:

$$
\begin{gathered}
\max (1.4 * 16,1.4 * 20,30)=30 \mathrm{~mm} \\
d_{1}=450-50-30-16=354 \mathrm{~mm} \\
d_{2}=450-50=400 \mathrm{~mm}
\end{gathered}
$$


Contribution of the GFRP bars in the compression section is ignored.

$$
\begin{gathered}
\varepsilon_{1}=0.0035 * \frac{d_{1}-c}{c}=0.0035 * \frac{354-c}{c} \\
\varepsilon_{2}=0.0035 * \frac{d_{2}-c}{c}=0.0035 * \frac{400-c}{c} \\
f_{1}=\varepsilon_{1} * E_{F R P, u}=60000 * 0.0035 * \frac{354-c}{c} \\
f_{2}=\varepsilon_{2} * E_{F R P, u}=60000 * 0.0035 * \frac{400-c}{c} \\
T_{1}=f_{1} * A_{1}=4 * 201 * 210 * \frac{354-c}{c}=168840 * \frac{354-c}{c} \\
T_{2}=f_{2} * A_{2}=4 * 201 * 210 * \frac{400-c}{c}=168840 * \frac{400-c}{c} \\
C_{c}=\varphi_{c} * \alpha_{1} * f^{\prime}{ }_{c} * b * \beta_{1} * c=1 * 0.80 * 35 * 350 * 0.88 * c=8624 * c
\end{gathered}
$$

For the force equilibrium:

$$
\begin{gathered}
C_{c}=T_{1}+T_{2} \\
8624 * c=168840 * \frac{354-c}{c}+168840 * \frac{400-c}{c}
\end{gathered}
$$

Solving the equation for $c \rightarrow c=103.49 \mathrm{~mm}$

$$
\begin{gathered}
a=\beta_{1} * c=0.88 * 103.49=91.07 \mathrm{~mm} \\
\frac{a}{2}=\frac{91.07}{2}=45.54 \mathrm{~mm}
\end{gathered}
$$


As a result:

$$
\begin{gathered}
T_{1}=168840 * \frac{354-103.49}{103.49}=408698 \mathrm{~N} \\
T_{2}=168840 * \frac{400-103.49}{103.49}=483745 \mathrm{~N} \\
C_{C}=8624 * 103.49=892498 \mathrm{~N}
\end{gathered}
$$

Moment about

$$
\begin{aligned}
M_{r} & =408698 *(354-45.54)+483745 *(400-45.54)=2.9754 * 10^{8} \mathrm{~N} . \mathrm{mm} \\
& =297.54 \mathrm{kN} . \mathrm{m}
\end{aligned}
$$

Calculating shear stress in the joint:

$$
\begin{gathered}
V_{\text {col }}=\frac{M_{r, \text { beam }}}{l_{\text {col }}}=\frac{297.54}{3.5}=85.01 \mathrm{kN} \\
T_{f}=T_{1}+T_{2}=408698+483745=892443 \mathrm{~N} \\
=892.44 \mathrm{kN} \\
V_{j}=892.44-85.01=807.43 \mathrm{kN} \\
A_{j}=350 * 400=140000 \mathrm{~mm}^{2} \\
A_{j} * \sqrt{f^{\prime}}=140000 * \sqrt{35}=828251
\end{gathered}
$$

Shear stress in the joint as a coefficient of $\sqrt{f^{\prime}}{ }_{c}$ : 


$$
\frac{807.43}{828.25}=0.97 \cong 1
$$

\section{Design of Main Beam for Shear}

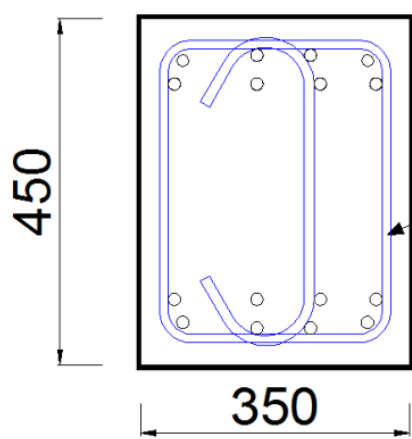

8 \#16

\#12@ $100 \mathrm{~mm}$

$8 \# 16$

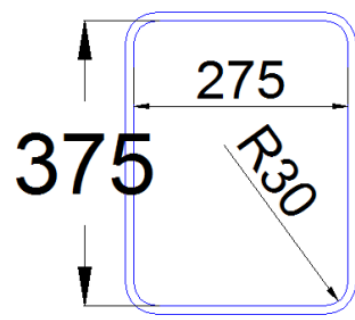

Figure 1.3 - Beam reinforcement detailing for Specimen G-I-M

\section{Material and sectional Properties:}

GFRP properties:

$f_{F R P, u, \text { straight }}=1000 \mathrm{MPa} \quad f_{F R P, u, \text { bent }}=1000 \mathrm{MPa}$

$\varphi_{F R P}=1 \quad E_{F R P}=50 \mathrm{GPa}$

$A_{F R P, v}=$ three branches $\# 12=3 * 113=339 \mathrm{~mm}^{2}$

\section{Calculations}

Assume $V_{c}=0$ for beam because of large deformations at the plastic hinge. CSA-A23.3-04 has same provision for designing steel RC structure in seismic region.

According to beam's flexural design: 


$$
\begin{gathered}
M_{f}=M_{r}=297.54 \mathrm{kN} . \mathrm{m} \\
V_{f}=\frac{M_{\text {beam }}}{l_{\text {beam }}}=\frac{297.54}{2}=148.77 \mathrm{kN} \\
d=\frac{d_{1}+d_{2}}{2}=\frac{354+400}{2}=377 \mathrm{~mm}
\end{gathered}
$$

All the shear stresses should be resisted by FRP stirrups. CSA S806-02 Clause 8.4.4.6:

$$
\begin{gathered}
V_{S F}=\frac{0.4 * \varphi_{F} * f_{F U} * d * A_{v}}{s} \\
V_{S F}=V_{f} \\
s=\frac{0.4 * 1 * 1000 * 377 * 339}{148.77 * 10^{3}}=343.63 \mathrm{~mm}
\end{gathered}
$$

Minimum shear reinforcement is calculated according to CSA S806-02 Clause 8.4.5:

$$
A_{v, \text { min }}=\frac{0.3 * \sqrt{f_{c}^{\prime}} * b_{w} * s}{f_{F H}}
$$

Calculating design strength of stirrups, $f_{F H}$ :

$f_{F H}$ is equal to the least of:

$$
\begin{array}{ll}
\text { - }\left(0.4+-0.015 * \frac{l_{d}}{d_{e}}\right) * f_{v, F R P} & \text { (ISIS } 10.3) \\
\text { - }\left(0.05 * \frac{r_{b}}{d_{b}}+0.3\right) * f_{v, F R P} & \text { (ISIS } 10.3)
\end{array}
$$
- $0.004 * E_{v, F R P}$
(CSA S806-02

- $\varphi_{F R P} * f_{F R P}$

(CSA S806-02

8.4.3.2) 
- The stress corresponding to the failure of corners, hooks, bends, and laps. (CSA S806-02

$$
\text { 8.4.3.2) }
$$

$l_{d}=$ Development length $=65 \mathrm{~mm}$

$d_{e}=$ Effective diameter, equal to $\sqrt{\frac{4 A_{b}}{\pi}}[\mathrm{mm}]=\sqrt{\frac{4 * 113}{3.14}}=12 \mathrm{~mm}$

$r_{b}=$ Radius of bend $=30 \mathrm{~mm}$

$d_{b}=$ Bar diameter $=12 \mathrm{~mm}$

$f_{v, F R P}=$ Ultimate tensile strength $=1000 \mathrm{MPa}$

According the GFRP stirrups properties provided by the manufacturer:

- $\quad 512.5 \mathrm{MPa}$

- $500 \mathrm{MPa}$

- $\quad 0.004 * 50000=200 \mathrm{MPa}$

- $1 * 1000=1000 \mathrm{MPa}$

- $700 M P a$

As a result:

$$
\frac{A_{v} * f_{F H}}{0.3 * \sqrt{f^{\prime}} * b_{w}}=s_{\max }
$$




$$
s_{\max }=\frac{339 * 200}{0.3 * \sqrt{35} * 350}=109.15 \mathrm{~mm}
$$

Check for minimum spacing:

Because there is no provision for minimum spacing in CSA S806-02 for flexural members, clause 21.3.3.2 of CSA A23.3-04 has been used to calculate the spacing of stirrups. According to CSA A23.3-04 spacing between stirrups should be the least of:

- $\frac{d}{4}$

- Eight times the diameter of the smallest longitudinal bars;

- 24 times the diameter of the hoop bars; or

- $300 \mathrm{~mm}$.

In this case:

- $\frac{\frac{400+354}{2}}{4}=94.25 \mathrm{~mm}$

- $8 * 16=128 \mathrm{~mm}$

- $24 * 12=288 \mathrm{~mm}$

- $300 \mathrm{~mm}$ 


\section{Design of Column for Flexure}

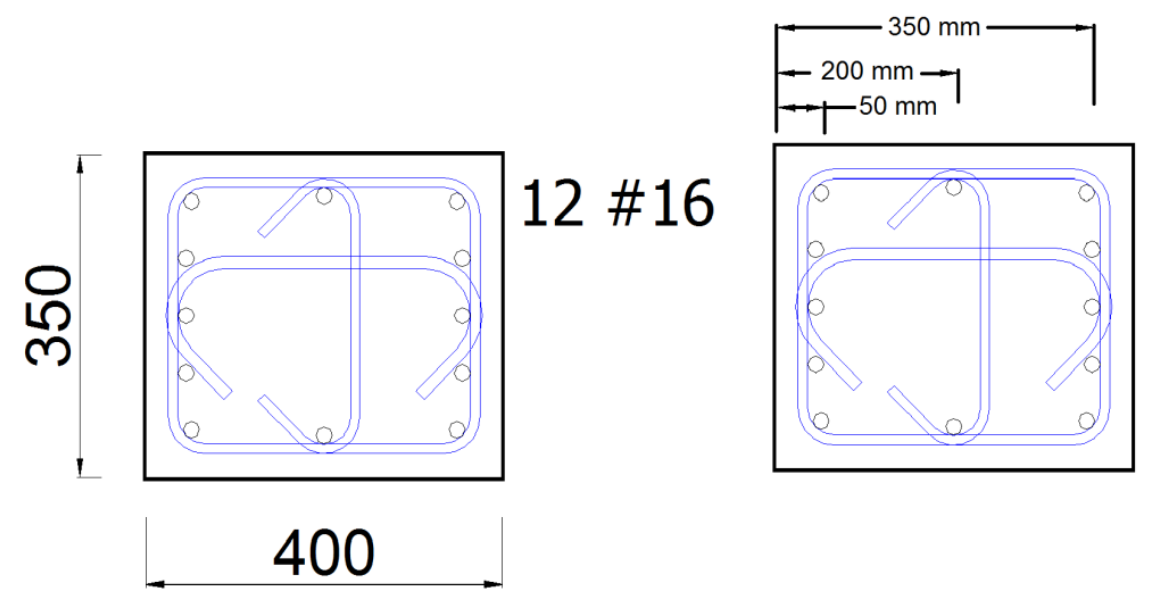

Figure 1.4 - Beam reinforcement detailing for Specimen G-I-M

\section{Material and sectional properties}

Concrete properties:

$f^{\prime}{ }_{c}=35 \mathrm{MPa}, \quad \varphi_{c}=1$,

$E_{c}=4500 \sqrt{f^{\prime}{ }_{c}}=4500 \sqrt{35}=26622 \mathrm{MPa}$

$\alpha_{1}=0.85-0.0015 f^{\prime}{ }_{c}=0.798$,

$\beta_{1}=0.97-0.0025 f^{\prime}{ }_{c}=0.883$

$\varepsilon_{c u}=0.0035$

GFRP properties:

$f_{F R P, u}=1100 \mathrm{MPa}$

$\varphi_{F R P}=1$

$E_{F R P}=60 \mathrm{GPa}$

$\varepsilon_{F R P, u}=1.83 \%$

Cross section properties:

$h=400 \mathrm{~mm}$

$b=350 \mathrm{~mm}$ 


\section{Calculations}

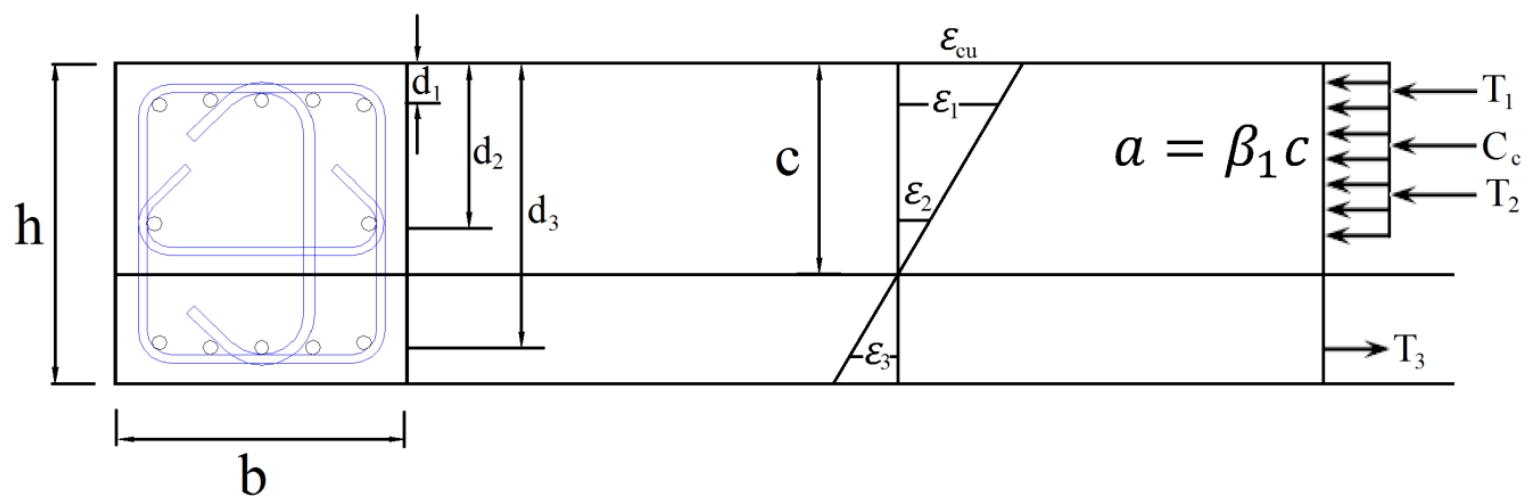

Figure A.5 - Compatibility of strain for column cross section (G-I-M)

Calculating force balanced reinforcement to avoid brittle tension failure:

$$
\begin{gathered}
\frac{\varepsilon_{c u}}{c_{b}}=\frac{\varepsilon_{F u}+\varepsilon_{c u}}{d_{3}} \\
c_{b}=\frac{\varepsilon_{c u}}{\varepsilon_{c u}+\varepsilon_{F u}} * d_{3} \\
\varepsilon_{F u}=\frac{f_{F R P, u}}{E_{F R P}}=\frac{1100}{60000}=0.0183 \\
c_{b}=\frac{0.0035}{0.0035+0.01833} * 350=56.12 \mathrm{~mm} \\
C_{c}=\varphi_{c} * \alpha_{1} * f^{\prime}{ }_{c} * b * \beta_{1} * c=1 * 0.798 * 35 * 350 * 0.883 * 56.12=483866 \mathrm{~N}
\end{gathered}
$$

Assume 2 \#16 at level 2:

$$
\begin{gathered}
\varepsilon_{2}=\varepsilon_{c u} * \frac{d_{2}-c_{b}}{c_{b}}=0.0035 * \frac{200-56.12}{56.12}=0.00897 \\
F_{2}=\varepsilon_{2} * E_{F R P} * A_{2}=0.00897 * 60000 * 2 * 201=216429 \mathrm{~N}
\end{gathered}
$$




$$
C_{c}-F_{2}=483866-216429=267437 N
$$

From equilibrium, required area of GFRP at level 3:

$$
A_{3}=\frac{C_{c}-F_{2}}{f_{F R P, u}}=\frac{267437}{1100}=243.125 \mathrm{~mm}^{2}
$$

If the cross section contains more reinforcement than $243.125 \mathrm{~mm}^{2}$ at the level 3, $c$ would be more than $c_{b}$, consequently column never have brittle tension failure and concrete compression failure occurs first. In this case:

$$
5 * 201>243.125 \mathrm{~mm}^{2}
$$

Axial-Moment interaction diagram:

* Point One (pure axial load)

$P_{1}=0.85 * f^{\prime}{ }_{c} *\left(A_{g}-A_{F}^{\prime}\right)+0.003 * E_{f} * A_{f} \quad$ (Paramanantham and Daniali -1993)

Compressive strength of GFRP is ignored:

$P_{1}=0.85 * 35 *(350 * 400-12 * 201)=4093243 N$

$$
=4093.24 \mathrm{kN}
$$

* Point Two $(c=400 \mathrm{~mm})$

$T_{1}=T_{2}=T_{3}=0$

$C_{c}=1 * 0.80 * 35 * 350 * 0.88 * 400=3449600 \mathrm{~N}$ 


$$
=3449.6 \mathrm{kN}
$$

Moment about centre line of the cross section:

$$
\begin{aligned}
M=3449600 *\left(\frac{400}{2}-\frac{0.88 * 400}{2}\right) & =82790400 N . \mathrm{m} \\
& =82.79 \mathrm{kN} . \mathrm{m}
\end{aligned}
$$

For the section's equilibrium an external load equal to $C_{c}$ should be applied at the centre of the section.

$$
\left(c=400 \mathrm{~mm}, \quad P_{e}=3449.6 \mathrm{kN}, \quad M=82.79 \mathrm{kN} . \mathrm{m}\right)
$$

$$
\begin{aligned}
& \text { * Point Three }(c=350 \mathrm{~mm}) \\
& T_{1}=T_{2}=T_{3}=0 \\
& \begin{aligned}
C_{c}=1 * 0.80 * 35 * 350 * 0.88 * 350= & 3018400 \mathrm{~N} \\
& =3018.4 \mathrm{kN}
\end{aligned}
\end{aligned}
$$

Moment about centre line of the cross section:

$$
\begin{gathered}
M=3018400 *\left(\frac{400}{2}-\frac{0.88 * 350}{2}\right)=138846400 \mathrm{~N} . \mathrm{m} \\
=138.85 \mathrm{kN} . \mathrm{m} \\
\left(\boldsymbol{c}=\mathbf{3 5 0} \mathbf{m m}, \quad \boldsymbol{P}_{\boldsymbol{e}}=\mathbf{3 0 1 8 . 4} \mathrm{kN}, \quad \boldsymbol{M}=\mathbf{1 3 8 . 8 5} \mathrm{kN} . \mathrm{m}\right)
\end{gathered}
$$


* Point Four $(c=300 \mathrm{~mm})$

$T_{1}=T_{2}=0$

$\varepsilon_{3}=0.0035 * \frac{350-300}{300}=0.000583$

$T_{3}=\varepsilon_{3} * E_{F R P} * A_{3}=0.000583 * 60000 * 5 * 201=35155 \mathrm{~N}$

$$
=35.16 \mathrm{kN}
$$

$C_{c}=1 * 0.8 * 35 * 350 * 0.88 * 300=2587200 \mathrm{~N}$

$$
=2587.2 \mathrm{kN}
$$

Moment about centre line of the cross section:

$$
\begin{aligned}
M=2587200 *\left(200-\frac{0.88 * 300}{2}\right)+35155 *(350-200) & =181202850 \mathrm{~N} . \mathrm{m} \\
& =181.20 \mathrm{kN} . \mathrm{m}
\end{aligned}
$$

For equilibrium:

$P_{e}=C_{c}-T_{3}=2587.2-35.16=2552.04 k N$

$$
\left(c=300 \mathrm{~mm}, \quad P_{e}=2552.00 \mathrm{kN}, \quad M=181.20 \mathrm{kN} . \mathrm{m}\right)
$$

Point Five $(c=250 \mathrm{~mm})$

$T_{1}=T_{2}=0$

$\varepsilon_{3}=0.0035 * \frac{350-250}{250}=0.0014$ 


$$
\begin{gathered}
T_{3}=\varepsilon_{3} * E_{F R P} * A_{3}=0.0014 * 60000 * 5 * 201=84420 \mathrm{~N} \\
=84.42 \mathrm{kN} \\
C_{c}=1 * 0.80 * 35 * 350 * 0.88 * 250=2156000 \mathrm{~N} \\
=2156.00 \mathrm{kN}
\end{gathered}
$$

Moment about centre line of the cross section:

$$
\begin{aligned}
M=2156000 *\left(200-\frac{0.88 * 250}{2}\right)+84420 *(350-200) & =206703000 \mathrm{~N} . \mathrm{m} \\
& =206.70 \mathrm{kN} . \mathrm{m}
\end{aligned}
$$

For equilibrium:

$$
\begin{aligned}
& P_{e}=C_{c}-T_{3}= 2156.00-84.42=2071.58 \mathrm{kN} \\
&\left(\boldsymbol{c}=\mathbf{2 5 0} \mathbf{m m}, \quad P_{e}=2071.58 \mathrm{kN}, \quad M=206.70 \mathrm{kN} . \mathrm{m}\right)
\end{aligned}
$$

$$
\text { Point Six }(c=200 \mathrm{~mm})
$$

$T_{1}=T_{2}=0$

$\varepsilon_{3}=0.0035 * \frac{350-200}{200}=0.0026$

$T_{3}=\varepsilon_{3} * E_{F R P} * A_{3}=0.0026 * 60000 * 5 * 201=156780 \mathrm{~N}$

$$
=156.78 \mathrm{kN}
$$

$C_{C}=1 * 0.80 * 35 * 350 * 0.88 * 200=1724800 \mathrm{~N}$ 


$$
=1724.8 \mathrm{kN}
$$

Moment about centre line of the cross section:

$$
\begin{aligned}
M=1724800 *\left(200-\frac{0.88 * 200}{2}\right)+156780 *(350-200) & =216694600 \mathrm{~N} . \mathrm{m} \\
& =216.69 \mathrm{kN} . \mathrm{m}
\end{aligned}
$$

For equilibrium:

$$
\begin{aligned}
& P_{e}=C_{c}-T_{3}=1724.8-156.78=1568.02 \mathrm{kN} \\
& \left(c=200 \mathrm{~mm}, \quad P_{e}=1568.02 \mathrm{kN}, \quad M=216.69 \mathrm{kN} . \mathrm{m}\right) \\
& \text { * Point Seven }(c=150 \mathrm{~mm}) \\
& T_{1}=0 \\
& \varepsilon_{2}=0.0035 * \frac{200-150}{150}=0.0012 \\
& \varepsilon_{3}=0.0035 * \frac{350-150}{150}=0.0047 \\
& T_{2}=\varepsilon_{2} * E_{F R P} * A_{2}=0.0012 * 60000 * 2 * 201=28944 \mathrm{~N} \\
& =28.94 \mathrm{kN} \\
& T_{3}=\varepsilon_{3} * E_{F R P} * A_{3}=0.0047 * 60000 * 5 * 201=283410 \mathrm{~N} \\
& =283.41 \mathrm{kN} \\
& C_{c}=1 * 0.8 * 35 * 350 * 0.88 * 150=1293600 \mathrm{~N}
\end{aligned}
$$




$$
=1293.6 \mathrm{kN}
$$

Moment about centre line of the cross section:

$$
\begin{aligned}
M=1293600 *\left(200-\frac{0.88 * 150}{2}\right)+283410 *(350-200) & =215853900 \mathrm{~N} . \mathrm{m} \\
& =215.85 \mathrm{kN} . \mathrm{m}
\end{aligned}
$$

For equilibrium:

$$
\begin{aligned}
& P_{e}=C_{c}-T_{3}-T_{2}=1293.6-283.41-28.94=986.25 k N \\
& \left(c=150 \mathrm{~mm}, \quad P_{e}=986.25 \mathrm{kN}, \quad M=215.85 \mathrm{kN} . \mathrm{m}\right) \\
& \text { * Point Eight }(c=100 \mathrm{~mm}) \\
& T_{1}=0 \\
& \varepsilon_{2}=0.0035 * \frac{200-100}{100}=0.0035 \\
& \varepsilon_{3}=0.0035 * \frac{350-100}{100}=0.0088 \\
& T_{2}=\varepsilon_{2} * E_{F R P} * A_{2}=0.0035 * 60000 * 2 * 201=84420 \mathrm{~N} \\
& =84.42 \mathrm{kN} \\
& T_{3}=\varepsilon_{3} * E_{F R P} * A_{3}=0.0088 * 60000 * 5 * 201=530640 \mathrm{~N} \\
& =530.64 \mathrm{kN} \\
& C_{c}=1 * 0.80 * 35 * 350 * 0.88 * 100=862400 \mathrm{~N}
\end{aligned}
$$




$$
=862.4 \mathrm{kN}
$$

Moment about centre line of the cross section:

$$
\begin{aligned}
M=862400 *\left(200-\frac{0.88 * 100}{2}\right)+530640 *(350-200) & =214130400 \mathrm{~N} . \mathrm{m} \\
& =214.13 \mathrm{kN} . \mathrm{m}
\end{aligned}
$$

For equilibrium:

$$
\begin{aligned}
& P_{e}=C_{c}-T_{3}-T_{2}=862.4-530.64-84.42=247.34 k N \\
& \left(c=100 \mathrm{~mm}, \quad P_{e}=247.34 \mathrm{KN}, \quad M=214.13 \mathrm{kN} . \mathrm{m}\right) \\
& \text { * Point Nine }(c=90 \mathrm{~mm}) \\
& T_{1}=0 \\
& \varepsilon_{2}=0.0035 * \frac{200-90}{90}=0.0043 \\
& \varepsilon_{3}=0.0035 * \frac{350-90}{90}=0.0101 \\
& T_{2}=\varepsilon_{2} * E_{F R P} * A_{2}=0.0043 * 60000 * 2 * 201=103716 N \\
& =103.72 \mathrm{kN} \\
& T_{3}=\varepsilon_{3} * E_{F R P} * A_{3}=0.0101 * 60000 * 5 * 201=609030 \mathrm{~N} \\
& =609.03 \mathrm{kN} \\
& C_{c}=1 * 0.80 * 35 * 350 * 0.88 * 90=776160 \mathrm{~N}
\end{aligned}
$$




$$
=776.16 \mathrm{KN}
$$

Moment about centre line of the cross section:

$$
\begin{aligned}
M=776160 *\left(200-\frac{0.88 * 90}{2}\right)+609030 *(350-200)= & 215850564 N . \mathrm{m} \\
& =215.85 \mathrm{kN} . \mathrm{m}
\end{aligned}
$$

For equilibrium:

$$
\begin{aligned}
& P_{e}=C_{c}-T_{3}-T_{2}=776.16-609.03-103.72=63.41 \mathrm{kN} \\
&\left(\boldsymbol{c}=\mathbf{9 0} \mathbf{m m}, \quad P_{\boldsymbol{e}}=\mathbf{6 3 . 4 1} \mathrm{kN}, \quad \boldsymbol{M}=\mathbf{2 1 5 . 8 5} \mathrm{kN} . \mathbf{m}\right)
\end{aligned}
$$

* Point Ten (pure bending)

$$
\begin{aligned}
& \varepsilon_{2}=\varepsilon_{c u} * \frac{d_{2}-c}{c}=0.0035 * \frac{200-c}{c} \\
& \varepsilon_{3}=\varepsilon_{c u} * \frac{d_{3}-c}{c}=0.0035 * \frac{350-c}{c} \\
& f_{2}=\varepsilon_{2} * E=0.0035 * 60000 * \frac{200-c}{c}=210 * \frac{200-c}{c} \\
& f_{3}=\varepsilon_{3} * E=0.0035 * 60000 * \frac{350-c}{c}=210 * \frac{350-c}{c} \\
& T_{2}=f_{2} * A_{2}=2 * 201 * 210 * \frac{200-c}{c}=84420 * \frac{200-c}{c} \\
& T_{3}=f_{3} * A_{3}=5 * 201 * 210 * \frac{350-c}{c}=211050 * \frac{350-c}{c} \\
& C_{c}=\varphi_{c} * \alpha_{1} * f^{\prime}{ }^{\prime} * b * \beta_{1} * c=1 * 0.80 * 35 * 350 * 0.88 * c=8624 * c
\end{aligned}
$$


Assuming $c>50 \mathrm{~mm}$, from force equilibrium:

$$
C_{c}=T_{2}+T_{3}
$$

Solving equation above for “c”:

$$
\begin{aligned}
& c=86.87 \mathrm{~mm}(>50 \mathrm{~mm}) \\
& a=0.88 * 86.87=76.45 \mathrm{~mm} \\
& C_{c}=8624 * 86.87=749427 \mathrm{~N} \\
& T_{2}=84420 * \frac{200-86.87}{86.87}=109939 \mathrm{~N} \\
& T_{3}=211050 * \frac{350-86.87}{86.87}=639272 \mathrm{~N} \\
& M=109939 *\left(200-\frac{76.45}{2}\right)+639272 *\left(350-\frac{76.45}{2}\right)=217094409 \mathrm{~N} . \mathrm{m} \\
& =217.09 \mathrm{kN} . \mathrm{m} \\
& \left(c=86.87 \mathrm{~mm}, \quad P_{e}=0.00 \mathrm{kN}, \quad M=217.09 \mathrm{kN} . \mathrm{m}\right)
\end{aligned}
$$




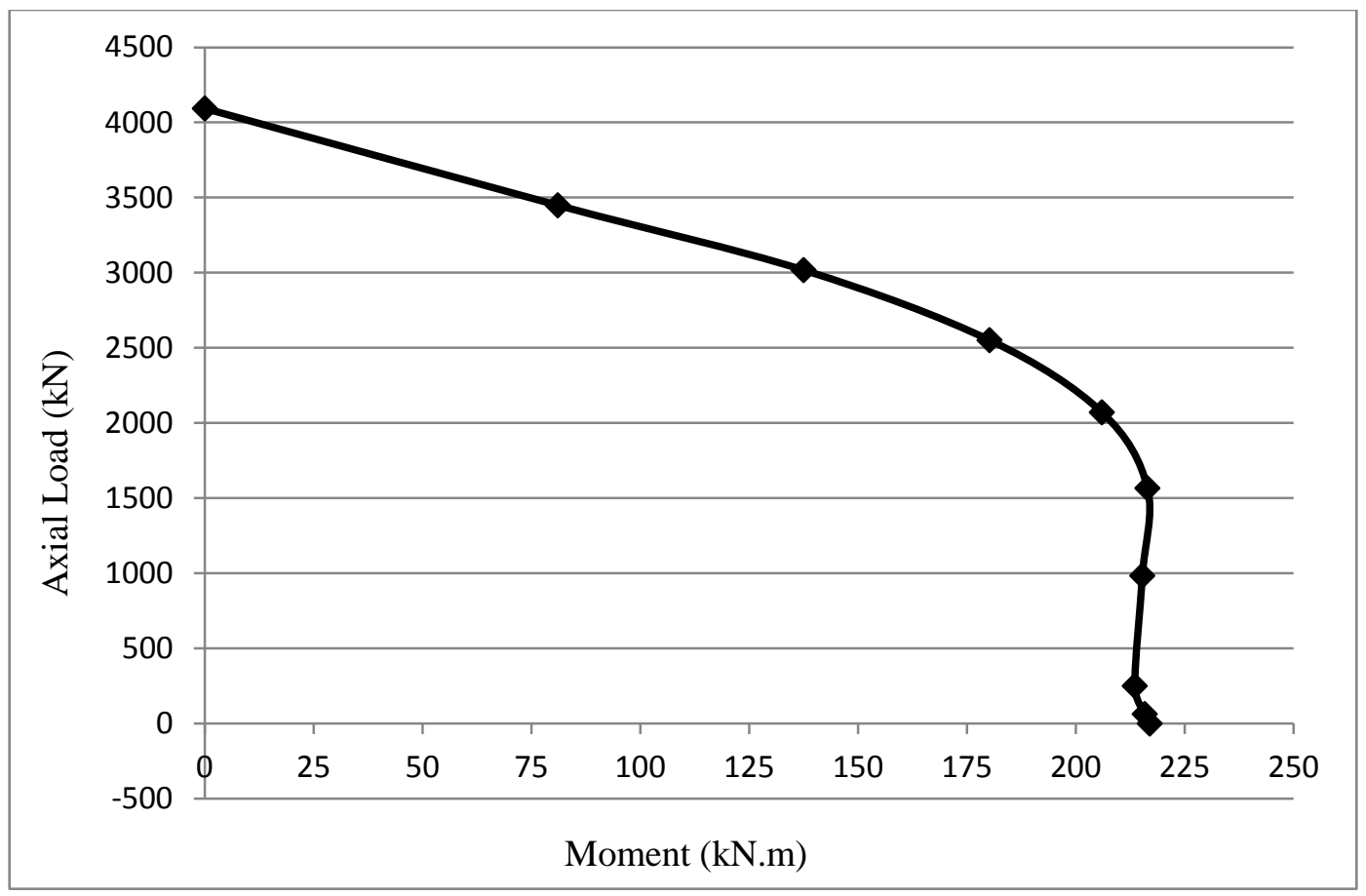

Figure 1.6 - Axial load-moment interaction diagram of column (G-I-M)

The column was be loaded under the axial force equal to $15 \%$ of its ultimate capacity:

$P=0.15 * 4093.24=613.99 k N$

Assuming $c=123 \mathrm{~mm}$

$T_{1}=0$

$\varepsilon_{2}=0.0035 * \frac{200-123}{123}=0.0022$

$\varepsilon_{3}=0.0035 * \frac{350-123}{123}=0.0065$

$T_{2}=\varepsilon_{2} * E_{F R P} * A_{2}=0.0022 * 60000 * 2 * 201=53064 \mathrm{~N}$

$=53.06 \mathrm{kN}$ 


$$
\begin{gathered}
T_{3}=\varepsilon_{3} * E_{F R P} * A_{3}=0.0065 * 60000 * 5 * 201=391950 \mathrm{~N} \\
=391.95 \mathrm{kN} \\
\begin{aligned}
C_{c}=1 * 0.80 * 35 * 350 * 0.88 * 123= & 1060752 \mathrm{~N} \\
= & 1060.75 \mathrm{kN}
\end{aligned}
\end{gathered}
$$

Moment about centre line of the cross section:

$$
\begin{aligned}
M=1060752 *\left(200-\frac{0.88 * 123}{2}\right)+391950 *(350-200) & =213535002 \mathrm{~N} . \mathrm{m} \\
& =213.54 \mathrm{kN} . \mathrm{m}
\end{aligned}
$$

For equilibrium:

$$
\begin{aligned}
& P_{e}=C_{c}-T_{3}-T_{2}=1060.75-53.06-391.95=615.74 k N \\
&\left(\boldsymbol{c}=\mathbf{1 2 3} \mathbf{~ m m}, \quad P_{\boldsymbol{e}}=\mathbf{6 1 5 . 7 4} \mathbf{k N}, \quad M=\mathbf{2 1 3 . 5 4} \mathbf{k N} . \mathbf{m}\right)
\end{aligned}
$$

\section{Design of Column for Shear}

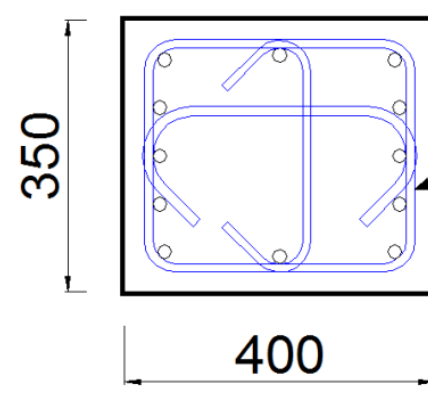

\#12@ $90 \mathrm{~mm}$

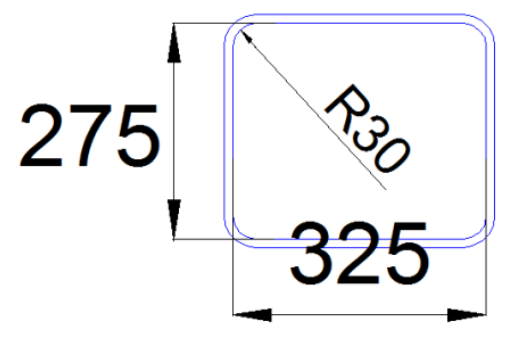

Figure A.7 - Column reinforcement detailing for Specimen G-I-M 


\section{Material and sectional properties}

GFRP properties:

$f_{F R P, u, \text { straight }}=1000 \mathrm{MPa} \quad f_{F R P, u, \text { bent }}=1000 \mathrm{MPa}$

$\varphi_{F R P}=1 \quad E_{F R P}=50 \mathrm{GPa}$

$A_{F R P, v}=$ three branches $\# 12=3 * 113=339 \mathrm{~mm}^{2}$

\section{Calculations}

Contrary to the beams, concrete contribution in shear resistance is not considered zero in columns. According to clause 8.4.4.4 CSA S806-02, shear resistance of the concrete is:

$$
V_{c}=0.0035 * \lambda * \varphi_{c} *\left(f^{\prime}{ }_{c} * \rho_{w} * E_{F R P} * \frac{V_{f}}{M_{f}} * d\right)^{1 / 3} * b_{w} * d
$$

From the flexural design if $c=123 \mathrm{~mm}$ :

$$
\left(P_{e}=615.74 k N, \quad M=213.54 k N . m\right)
$$

$$
\begin{aligned}
& \rho_{w}=\frac{7 * 201}{350 * 350}=0.0115 \\
& V_{f}=\frac{M_{\text {beam }}}{l_{c}}=\frac{297.54}{3.5}=85.01 \mathrm{kN} \\
& M_{f}=0.5 * M_{\text {beam }}=0.5 * 297.54=148.77 \mathrm{kN} . \mathrm{m} \\
& \frac{V_{f}}{M_{f}} * d=\frac{85.01}{148.77} * 0.35=0.2<1
\end{aligned}
$$




$$
\begin{gathered}
V_{c}=0.035 * 1 * 1 *(35 * 0.0115 * 60000 * 0.2)^{1 / 3} * 350 * 350=72475 N \\
=72.48 \mathrm{kN} \\
0.1 * \lambda * \varphi_{c} * \sqrt{f^{\prime}{ }_{c} * b_{w} * d<V_{c}<0.2 * \lambda * \varphi_{c} * \sqrt{f^{\prime}}{ }_{c} * b_{w} * d} \\
0.1 * 1 * 1 * \sqrt{35} * 350 * 350<V_{c}<0.2 * 1 * 1 * \sqrt{35} * 350 * 350 \\
72.47<72.48<144.94 \rightarrow \text { oK } \\
V_{f}>0.5 * V_{c} \rightarrow A_{S F, \text { min }} \text { is needed } \\
85.01 \mathrm{kN}>0.5 * 72.48=36.24 \mathrm{kN}
\end{gathered}
$$

CSA S806-02 Clause 8.4.5(minimum shear reinforcement):

$$
A_{v, \min }=\frac{0.3 * \sqrt{f^{\prime}}{ }_{c} * b_{w} * s}{f_{F H}}
$$

Calculating design strength of stirrups, $f_{F H}$ :

$f_{F H}$ is equal to the least of:

- $\left(0.4+-0.015 * \frac{l_{d}}{d_{e}}\right) * f_{v, F R P} \quad$ (ISIS 10.3)

- $\left(0.05 * \frac{r_{b}}{d_{b}}+-0.3\right) * f_{v, F R P} \quad$ (ISIS 10.3)

- $0.004 * E_{v, F R P} \quad$ (CSA S806-02

- $\varphi_{F R P} * f_{F R P}$

(CSA S806-02

- The stress corresponding to the failure of corners, hooks, bends, and laps. (CSA S806-02 8.4.3.2) 
$l_{d}=$ Development length, $\mathrm{mm}$

$d_{e}=$ Effective diameter, equal to $\sqrt{\frac{4 A_{b}}{\pi}}[\mathrm{mm}]$

$r_{b}=$ Radius of bend, $\mathrm{mm}$

$d_{b}=$ Bar diameter

$f_{v, F R P}=$ Ultimate tensile strength

According the GFRP stirrups properties provided by the manufacturer:

- $\quad 512.5 \mathrm{MPa}$

- $500 \mathrm{MPa}$

- $0.004 * 50000=200 \mathrm{MPa}$

- $1 * 1000=1000 \mathrm{MPa}$

- $700 \mathrm{MPa}$

USE $200 \mathrm{MPa}$

As a result:

$$
\frac{A_{v} * f_{F H}}{0.3 * \sqrt{f^{\prime}{ }_{c}} * b_{w}}=s_{\max }
$$

$s_{\max }=\frac{339 * 200}{0.3 * \sqrt{35} * 350}=109.15 \mathrm{~mm}$

Checking if any stirrups in additional to minimum reinforcement is needed or not: 


$$
V_{S F}=85.01-72.48=12.53 k N
$$

From CSA S806-02 clause 8.4.4.6:

$$
V_{S F}=\frac{0.4 * \varphi_{F} * f_{F U} * d * A_{v}}{S}
$$

Rearranging equation above:

$$
s=\frac{0.4 * \varphi_{F} * f_{F U} * d * A_{v}}{V_{S F}}
$$

As a result:

$$
s=\frac{0.4 * 1 * 1000 * 350 * 339}{19.12 * 10^{3}}=2482 \mathrm{~mm} \gg 109.15 \mathrm{~mm}
$$

Consequently $A_{v, \min }$ is used for whole column length.

Check for minimum spacing:

Clause 21.3.3.2 of CSA A23.3-04 is checked in addition to the provisions in CSA S806-02 for ties spacing in compression members.

According to CSA A23.3-04 clause 21.3.3.2, spacing between stirrups should be the least of:

- $\frac{d}{4}$;

- Eight times the diameter of the smallest longitudinal bars;

- 24 times the diameter of the hoop bars; or

- $300 \mathrm{~mm}$.

In this case: 
- $\frac{350}{4}=87.5 \mathrm{~mm}$;

- $8 * 16=128 \mathrm{~mm}$;

- $24 * 12=288 \mathrm{~mm}$;

- $300 \mathrm{~mm}$.

$$
87.5 \mathrm{~mm} \rightarrow \text { governs }
$$

According to CSA S806-02 clause 8.4.3.3, the spacing of FRP ties shall not exceed the least of the following dimensions:

i. 16 times the diameter of the smallest longitudinal bars or the smallest bar in a bundle;

ii. 48 times the minimum cross-sectional dimension (or diameter) of FRP tie or grid;

iii. the least dimension of the compression member; or

iv. $\quad 300 \mathrm{~mm}$ in compression members containing bundled bars.

In this case:

i. $\quad 16 * 16=256 \mathrm{~mm}$;

ii. $\quad 48 * 12=576 \mathrm{~mm}$;

iii. $\quad 350 \mathrm{~mm}$;

iv. $\quad 300 \mathrm{~mm}$.

$$
256 \mathrm{~mm} \rightarrow \text { governs }
$$

Checking for confinement, CSA S806-02 clause 12.7.2:

Transverse reinforcement shall be spaced at distances not exceeding the least of the following:

a) one-quarter of the minimum member dimension; 

b) $150 \mathrm{~mm}$;
c) 6 times the diameter of the smallest longitudinal bar; or
d) The requirements of Clauses 8.4.3.2 and 8.4.3.3.

In this case:
a) $\frac{350}{4}=87.5 \mathrm{~mm}$;
b) $150 \mathrm{~mm}$;
c) $6 * 16=96 \mathrm{~mm}$; or
d) $256 \mathrm{~mm}$.

$$
256 \mathrm{~mm} \rightarrow \text { governs }
$$

Considering all of clauses above:

\section{USE 3 branches of $\emptyset 12$ at $90 \mathrm{~mm}$}

Clause 12.7.1 should be checked for confinement:

$$
A_{F H}=14 * s * h_{c} * \frac{f^{\prime}{ }_{c}}{f_{F H}} *\left(\frac{A_{g}}{A_{c}}-1\right) * \frac{\delta}{\sqrt{k_{c}}} * \frac{P_{f}}{P_{r o}}
$$

Shorter direction:

$h_{c}: 275+12=287 \mathrm{~mm} \quad$ (Centre to centre of stirrups)

$f_{F H}$ : is the least of:

a) $0.004 * E_{F R P}=0.004 * 50000=200 \mathrm{MPa}$

b) $\varphi_{F R P} * f_{F R P, u}=1 * 1000=1000 \mathrm{MPa}$ 


$$
\begin{aligned}
& A_{g}: 350 * 400=140000 \mathrm{~mm}^{2} \\
& A_{c}:(12+275) *(12+325)=96719 \mathrm{~mm}^{2} \\
& \qquad\left(\frac{A_{g}}{A_{c}}-1\right)=\frac{140000}{96719}-1=0.447>0.3
\end{aligned}
$$

$\delta=0.03$

$k_{c}=0.15 * \sqrt{\frac{h_{c}{ }^{2}}{s * s_{l}}}$

$s_{l}$ : spacing of tie legs or the spacing of grid openings in the cross-sectional plane of the column

$$
s_{l}=\frac{287}{2}=143.5 \mathrm{~mm}
$$

Since $15 \%$ of the column ultimate capacity has been applied as axial load to the column during the test:

$\frac{P_{f}}{P_{\text {ro }}}=0.15 \geq 0.2 \rightarrow$ using 0.2

Substituting values in the equation:

$$
339=14 * s * 287 * \frac{35}{200} *(0.447) * \frac{0.03}{\sqrt{\frac{287^{2}}{143.5 * s}}} * 0.2
$$

Solving equation above for "s":

$$
\rightarrow s=293.41 \mathrm{~mm}>85 \mathrm{~mm}
$$

Consequently selected reinforcing detail fulfills confinement's requirements. 


\section{Lateral Beams}
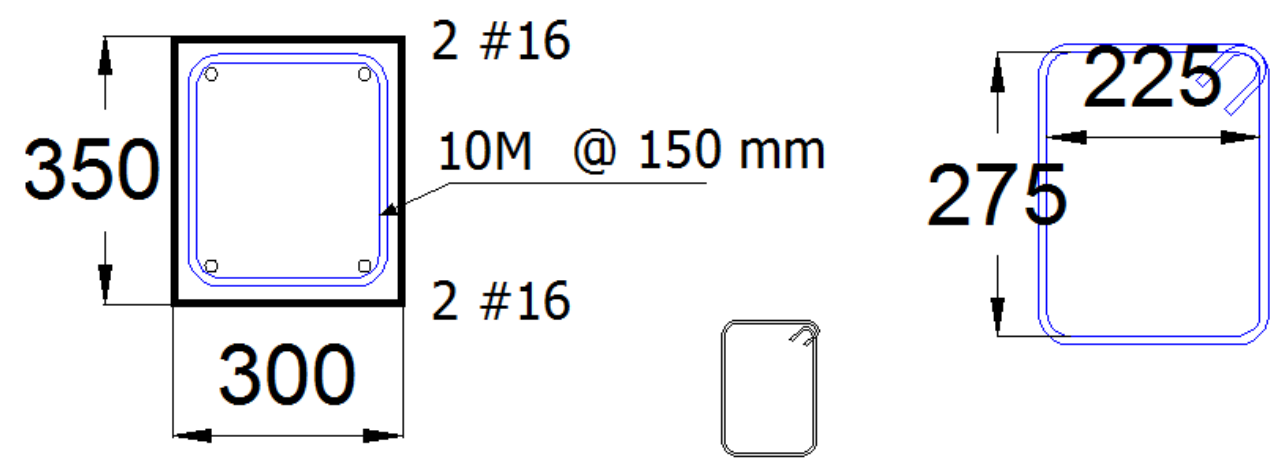

Figure 1.8 - Lateral beams reinforcement detailing for Specimen G-I-M

\section{Material and sectional properties:}

$\underline{\text { Concrete properties: }}$

${f^{\prime}}^{\prime}=35 \mathrm{MPa}, \quad \varphi_{c}=1, \quad E_{c}=4500 \sqrt{{f^{\prime}}_{c}}=4500 \sqrt{35}=26622 \mathrm{MPa}$

$\alpha_{1}=0.85-0.0015 f^{\prime}{ }_{c}=0.80, \quad \beta_{1}=0.97-0.0025 f^{\prime}{ }_{c}=0.88$

$\varepsilon_{c u}=0.0035$

GFRP properties:

$f_{F R P, u, \text { straight }}=1000 \mathrm{MPa} \quad f_{F R P, u, \text { bent }}=1000 \mathrm{MPa}$

$\varphi_{F R P}=1 \quad E_{F R P}=50 \mathrm{GPa}$

\section{Calculations}

Flexural reinforcement: 
Location of the lateral beams is at the end boundary of the frame. We assume that loads applied on these beams by the slab and exterior wall is $25 \%$ of the main beam.

$$
\begin{gathered}
M_{\text {lateral beam }}=0.25 * M_{\text {main beam }} \\
M_{\text {lateral beam }}=0.25 * 297.54=74.38 \mathrm{kN} . \mathrm{m}
\end{gathered}
$$

Designing the beam for the calculated moment:

Using 2-No.16 on top and bottom:

$$
\varepsilon_{F R P}=\varepsilon_{c u} * \frac{d-c}{c}=0.0035 * \frac{300-c}{c}
$$

Assuming $c>d^{\prime}$ :

$$
\begin{gathered}
\varepsilon_{F R P}^{\prime}=\varepsilon_{c u} * \frac{d^{\prime}-c}{c}=0.0035 * \frac{50-c}{c} \\
T_{F R P}=\varepsilon_{F R P} * E_{F R P} * A_{F R P}=0.0035 * \frac{300-c}{c} * 60000 * 2 * 201=84420 * \frac{300-c}{c} \\
C_{c}=\alpha_{1} * f^{\prime}{ }_{c} * \beta_{1} * b * c=0.80 * 35 * 0.88 * 300 * c=7392 * c
\end{gathered}
$$

Ignoring the effect of FRP in compression:

$$
C_{c}=T_{F R P}
$$

$7392 * c=84420 * \frac{300-c}{c}$

Solving the equation for $c$ :

$$
c=53.10 \mathrm{~mm}>50 \mathrm{OK}
$$




$$
\begin{aligned}
& a=\beta_{1} * c=0.88 * 53.10=46.73 \mathrm{~mm} \\
& C_{c}=7392 * 53.10=392515 \mathrm{~N}(392.52 \mathrm{kN}) \\
& T_{F R P}=84420 * \frac{300-c}{c}=392529 \mathrm{~N}(392.53 \mathrm{kN}) \\
& M_{r}=392515 *\left(300-\frac{46.73}{2}\right)=108583387 \mathrm{~N} . \mathrm{mm}(108.58 \mathrm{kN} . \mathrm{m})>74.38 \mathrm{kN} . \mathrm{m} \rightarrow O K
\end{aligned}
$$

\section{Shear reinforcement:}

Two branches of 10M steel stirrups will be used as shear reinforcement.

According to beam's flexural design:

$M_{f}=74.38 \mathrm{kN} . \mathrm{m}$

$V_{f}=\frac{M_{\text {beam }}}{l_{\text {beam }}}=\frac{74.38}{0.83}=89.61 \mathrm{kN}$

Calculating $d_{v}$ :

$$
\operatorname{Max}\{0.9 d \cdot 0.72 h\}=\operatorname{Max}\{0.9 * 300+0.72 * 350\}=\operatorname{Max}\{270,252\}=270 \mathrm{~mm}
$$

CSA-A23.3-04 Clause 11.3.3:

$$
\begin{gathered}
V_{r, \operatorname{Max}}=0.25 * \varphi_{c} *{f^{\prime}}_{c} * b_{w} * d_{v}+V_{p} \\
0.25 * 1 * 35 * 300 * 270+0=708750>74810 \mathrm{~N}
\end{gathered}
$$

All the shear stresses should be resisted by steel stirrups:

$$
V_{S}=V_{f}
$$


CSA-A23.3-04 Clause 11.3.5.1:

$$
V_{S}=\frac{\varphi_{s} * A_{v} * f_{y} * d_{v} * \cot \theta}{S}
$$

CSA-A23.3-04 Clause 21.3.4.2:

$$
\theta=45^{\circ} \quad, \quad \beta=0
$$

As a result:

$s=\frac{1 * 200 * 400 * 270 * 1}{89.61 * 10^{3}}=241.04 \mathrm{~mm}$

CSA-A23.3-04 Clause 11.2.8.2 (minimum shear reinforcement):

$$
\begin{gathered}
A_{v, \text { min }}=0.06 * \sqrt{f^{\prime}{ }_{c}} * \frac{b_{w} * s}{f_{y}} \\
\frac{A_{v} * f_{y}}{0.06 * \sqrt{f^{\prime}{ }_{c}} * b_{w}}=s_{\max }
\end{gathered}
$$

$S_{\text {max }}=\frac{200 * 400}{0.06 * \sqrt{35} * 300}=751.25 \mathrm{~mm}$

Check for minimum spacing:

CSA-A23.3-04 Clause 11.3.8.1 and 11.3.8.3:

$0.125 * \lambda * \varphi_{c} * f^{\prime}{ }_{c} * b_{w} * d_{v}=0.125 * 1 * 1 * 35 * 300 * 270=354375 N>V_{r}=78400 N$

1. $0.7 d_{v}=0.7 * 270=189 \mathrm{~mm}$

2. $600 \mathrm{~mm}$ 
There is no need to check for CSA-A23.3-04 Clause 21.3.3.2 because lateral beams will not be loaded under seismic loading.

USE 2 branches of $10 M @ 150$ 


\section{APPENDIX B : DEDIGN OF SPECIMEN “S-I-M"}


Design of Main Beam for Flexure

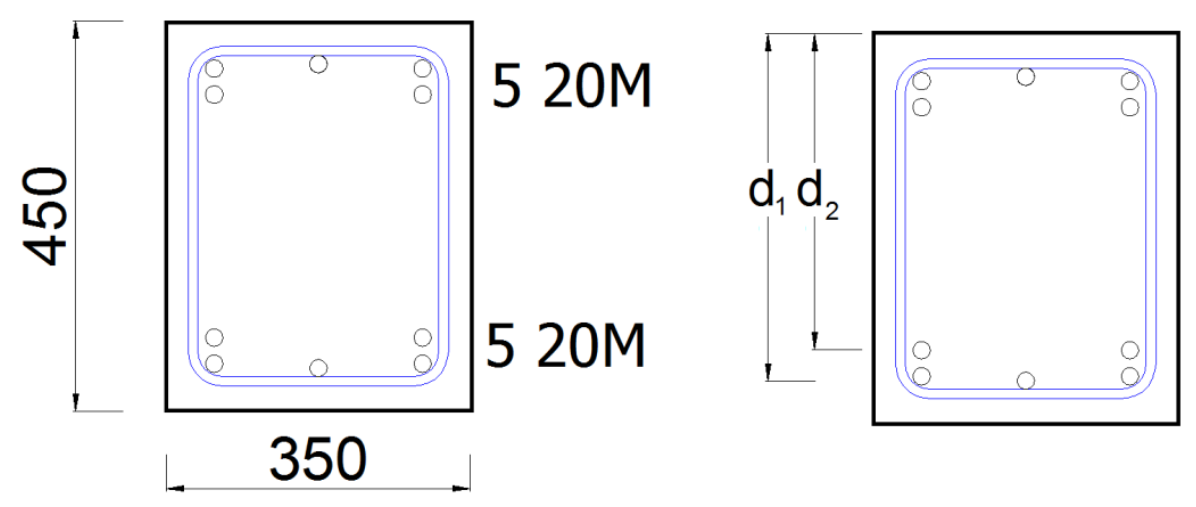

Figure 1.9 - Column reinforcement detailing for Specimen S-I-M

Material and Sectional Properties

Concrete properties:

$f^{\prime}{ }_{c}=35 \mathrm{MPa}, \quad \varphi_{c}=1, \quad E_{c}=4500 \sqrt{f^{\prime}{ }_{c}}=4500 \sqrt{35}=26622 \mathrm{MPa}$

$\alpha_{1}=0.85-0.0015 f^{\prime}{ }_{c}=0.80, \quad \beta_{1}=0.97-0.0025 f^{\prime}{ }_{c}=0.88$

$\varepsilon_{c u}=0.0035$

Steel properties:

$f_{y}=460 \mathrm{MPa} \quad \varphi_{\text {steel }}=1 \quad E_{\text {steel }}=200 \mathrm{GPa}$

$\varepsilon_{y}=0.23 \%$

Cross section properties:

$h=450 \mathrm{~mm} \quad b=350 \mathrm{~mm}$ 
$A_{\text {steel }}=520 M=5 * 300=1500 \mathrm{~mm}^{2}$

\section{Calculations}

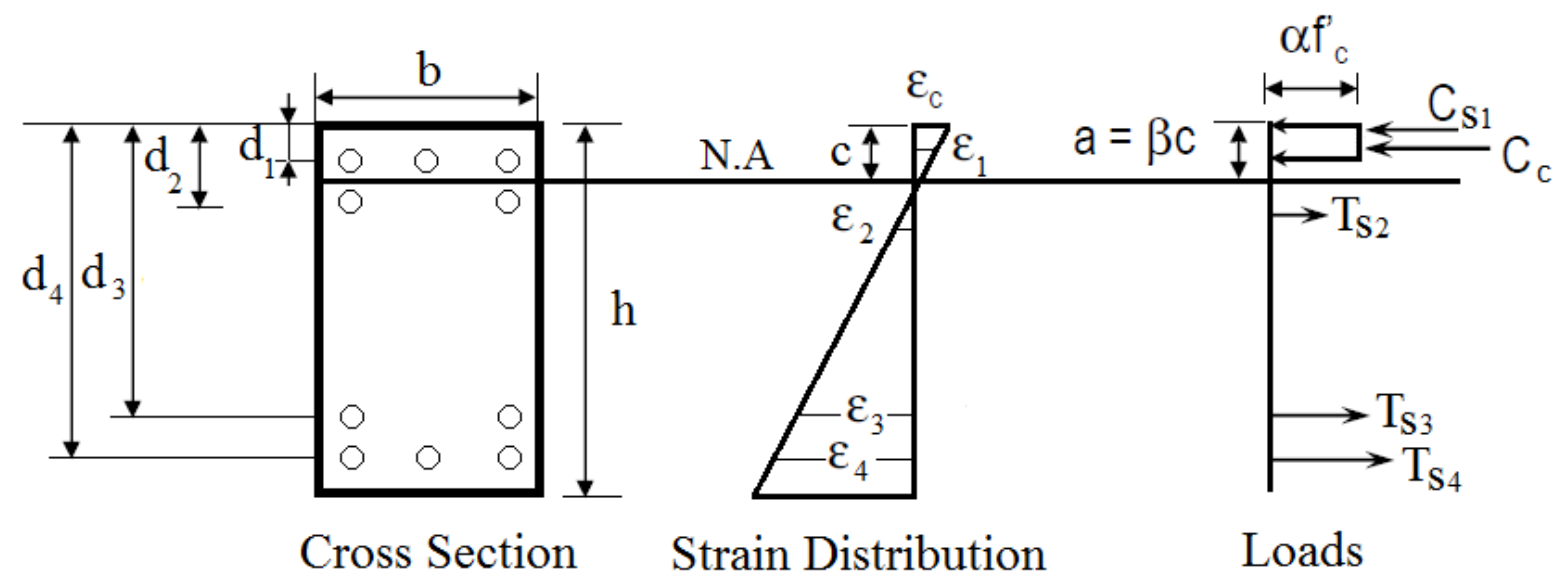

Figure 1.10 - Compatibility of strain for beam cross section (S-I-M)

$$
\begin{gathered}
\varepsilon_{s 1}=\varepsilon_{c u} * \frac{c-d_{1}}{c}=0.0035 * \frac{c-50}{c} \\
C_{s 1}=3 * 300 * 200000 * 0.0035 * \frac{c-50}{c}=630000 * \frac{c-50}{c}
\end{gathered}
$$

Assuming $c<100$ :

$$
\begin{gathered}
\varepsilon_{s 2}=\varepsilon_{c u} * \frac{d_{2}-c}{c}=0.0035 * \frac{100-c}{c} \\
T_{s 2}=2 * 300 * 200000 * 0.0035 * \frac{100-c}{c}=420000 * \frac{100-c}{c} \\
T_{s 3}=1.25 * 460 * 2 * 300=345000 \mathrm{~N} \\
=345 \mathrm{kN}
\end{gathered}
$$




$$
\begin{aligned}
T_{S 4}=1.25 * 460 * 3 * 300= & 517500 \mathrm{~N} \\
& =517.5 \mathrm{kN}
\end{aligned}
$$

Considering the yielding of steel and strain hardening effect:

Using equivalent rectangular block:

$$
C_{c}=\alpha_{1} * f^{\prime}{ }_{c} * b * \beta_{1} * c=0.80 * 35 * 350 * 0.88 * c=8624 * c
$$

From force equilibrium:

$$
\begin{gathered}
C_{c}+C_{s}=T_{s} \\
(8624 * c)+\left(630000 * \frac{c-50}{c}\right)=\left(420000 * \frac{100-c}{c}\right)+345000+517500
\end{gathered}
$$

Solving the equation above for "c":

$$
\begin{gathered}
c=82.09 \mathrm{~mm}<100 \mathrm{~mm} \rightarrow O K \\
a=\beta_{1} * c=0.88 * 82.09=72.24 \mathrm{~mm} \\
\varepsilon_{s 1}=0.0035 * \frac{82.09-50}{82.09}=0.0014 \\
C_{s 1}=3 * 300 * 200000 * 0.0014=252000 \mathrm{~N} \\
\varepsilon_{S 2}=0.0035 * \frac{100-82.09}{82.09}=0.0008 \\
T_{s 2}=2 * 300 * 200000 * 0.0008=96000 \mathrm{~N} \\
\varepsilon_{S 3}=0.0035 * \frac{350-82.09}{82.09}=0.0114>0.0023 \mathrm{OK}
\end{gathered}
$$




$$
\begin{gathered}
\varepsilon_{s 3}=0.0035 * \frac{400-82.09}{82.09}=0.0136>0.0023 \mathrm{OK} \\
C_{c}=0.80 * 35 * 350 * 0.88 * 82.09=707914 \mathrm{~N}
\end{gathered}
$$

Moment about centre of " $C_{c}$ ”:

$$
\begin{array}{rl}
M_{r}=517500 & *\left(400-\frac{72.24}{2}\right)+345000 *\left(350-\frac{72.24}{2}\right)+96000 *\left(100-\frac{72.24}{2}\right) \\
-252000 *\left(50-\frac{72.24}{2}\right) & =299231220 \mathrm{~N} \\
& =299.23 \mathrm{kN} . \mathrm{m}
\end{array}
$$

Calculating shear stress in the joint:

$$
\begin{gathered}
V_{c o l}=\frac{M_{r, \text { beam }}}{l_{\text {col }}}=\frac{299.23}{3.5}=85.49 \mathrm{kN} \\
T_{s}=517.5+345+96=958.5 \mathrm{kN} \\
V_{j}=958.5-85.49=873.01 \mathrm{kN} \\
A_{j}=350 * 400=140000 \mathrm{~mm}^{2} \\
A_{j} * \sqrt{f^{\prime}}=140000 * \sqrt{35}=828251 \mathrm{~N} \\
=828.25 \mathrm{kN}
\end{gathered}
$$

Shear stress in the joint as a coefficient of $\sqrt{f^{\prime}}{ }^{\prime}$ :

$$
\frac{873.01}{828.25}=1.06 \cong 1
$$




\section{Design of Beam for Shear}
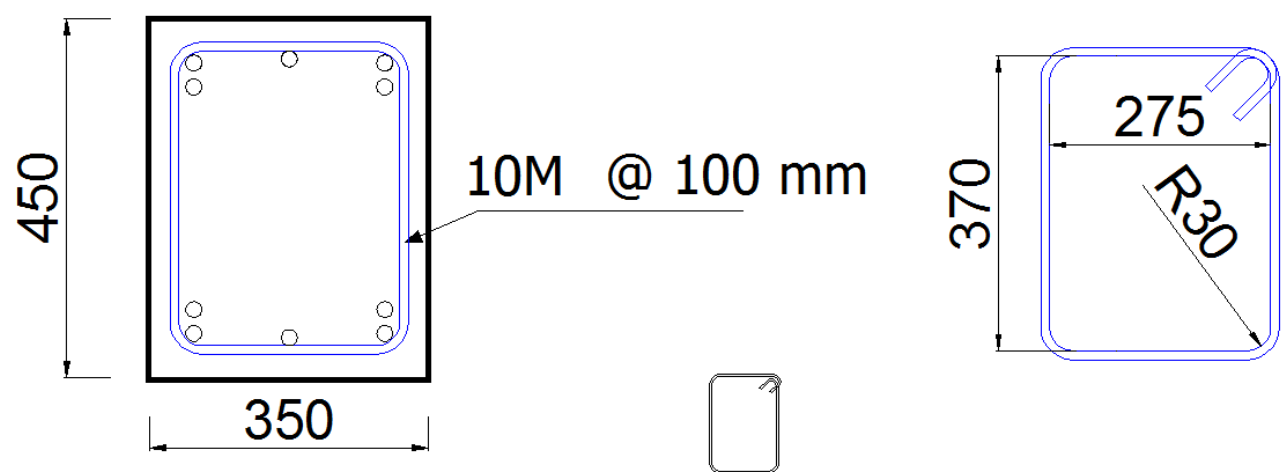

Figure 1.11 - Beam reinforcement detailing for Specimen G-I-M

\section{Material and sectional properties:}

Steel properties:

$f_{y}=460 \mathrm{MPa}$

$\varphi_{\text {steel }}=1$

$E_{\text {steel }}=200 \mathrm{GPa}$

$\varepsilon_{y}=0.23 \%$

$A_{s, v}=$ two branches $10 M=2 * 100=200 \mathrm{~mm}^{2}$

\section{Calculations}

According to CSA-A23.3-04 Clause 21.3.4.2, $V_{c}=0$. It is because of large deformations at the plastic hinge.

According to the beam's flexural design:

$$
\begin{gathered}
M_{f}=299.23 k N . m \\
V_{f}=\frac{M_{\text {beam }}}{l_{\text {beam }}}=\frac{299.23}{2}=149.62 \mathrm{kN}
\end{gathered}
$$




$$
d=\frac{3 * 400+2 * 350}{5}=380 \mathrm{~mm}
$$

Calculating $d_{v}$ :

$$
\operatorname{Max}\{0.9 d, 0.72 h\}=\operatorname{Max}\{0.9 * 380+0.72 * 450\}=\operatorname{Max}\{342,324\}=342 \mathrm{~mm}
$$

CSA-A23.3-04 Clause 11.3.3:

$$
\begin{gathered}
V_{r, \operatorname{Max}}=0.25 * \varphi_{c} *{f^{\prime}}^{\prime} * b_{w} * d_{v}+V_{p} \\
0.25 * 1 * 35 * 350 * 342+0=1047375 N>149620 N
\end{gathered}
$$

All the shear stresses should be resisted by steel stirrups:

$$
V_{S}=V_{f}
$$

CSA-A23.3-04 Clause 11.3.5.1:

$$
V_{S}=\frac{\varphi_{s} * A_{v} * f_{y} * d_{v} * \cot \theta}{s}
$$

CSA-A23.3-04 Clause 21.3.4.2:

$$
\theta=45^{\circ} \quad, \quad \beta=0
$$

As a result:

$$
s=\frac{1 * 200 * 460 * 342 * 1}{149.2 * 10^{3}}=210.29 \mathrm{~mm}
$$

CSA-A23.3-04 Clause 11.2.8.2 (minimum shear reinforcement):

$$
A_{v, \min }=0.06 * \sqrt{f^{\prime}{ }_{c}} * \frac{b_{w} * s}{f_{y}}
$$




$$
\begin{gathered}
\frac{A_{v} * f_{y}}{0.06 * \sqrt{f^{\prime}{ }^{\prime}} * b_{w}}=s_{\text {max }} \\
s_{\text {max }}=\frac{200 * 460}{0.06 * \sqrt{35} * 350}=740.52 \mathrm{~mm}
\end{gathered}
$$

Check for minimum spacing:

CSA-A23.3-04 Clause 11.3.8.1 and 11.3.8.3:

$$
\begin{aligned}
& \begin{aligned}
& 0.125 * \lambda * \varphi_{c} * f^{\prime}{ }_{c} * b_{w} * d_{v}=0.125 * 1 * 1 * 35 * 350 * 342=523688 \mathrm{~N}>V_{r} \\
&=149620 \mathrm{~N}
\end{aligned} \\
& 0.7 d_{v}=0.7 * 342=239.4 \mathrm{~mm} \\
& 600 \mathrm{~mm}
\end{aligned}
$$$$
\text { CSA-A23.3-04 Clause 21.3.3.2: }
$$$$
\text { - } \frac{d}{4} \text {; }
$$

- Eight times the diameter of the smallest longitudinal bars;

- 24 times the diameter of the hoop bars; or

- $300 \mathrm{~mm}$.

In this case:

- $\frac{380}{4}=95 \mathrm{~mm}$

- $8 * 19.5=156 \mathrm{~mm}$ 
- $24 * 11.3=271.2 \mathrm{~mm}$

- $300 \mathrm{~mm}$

USE 2 branches of $10 M @ 100$ mm

\section{Design of Column for Flexure}
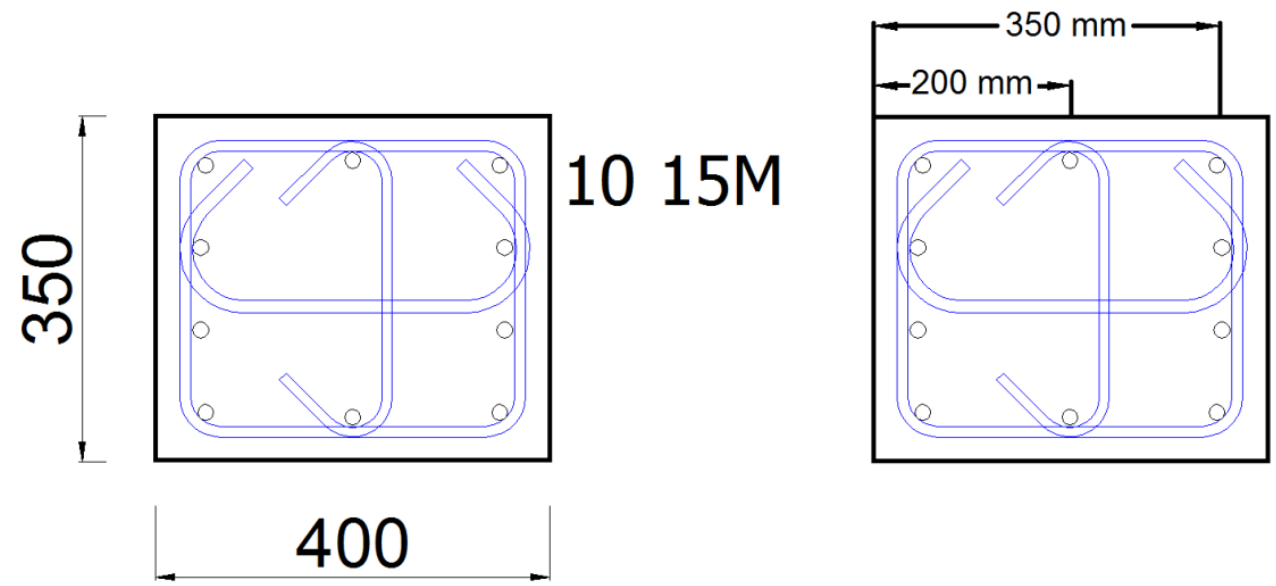

Figure 1.12 - Beam reinforcement detailing for Specimen S-I-M

\section{Material and sectional properties}

Concrete properties:

${f^{\prime}}^{\prime}=35 \mathrm{MPa}, \quad \varphi_{c}=1, \quad E_{c}=4500 \sqrt{f^{\prime}{ }_{c}}=4500 \sqrt{35}=26622 \mathrm{MPa}$

$\alpha_{1}=0.85-0.0015 f^{\prime}{ }_{c}=0.80, \quad \beta_{1}=0.97-0.0025 f^{\prime}{ }_{c}=0.88$

$\varepsilon_{c u}=0.0035$

Steel properties:

$f_{y}=460 \mathrm{MPa} \quad \varphi_{\text {steel }}=1 \quad E_{\text {steel }}=200 \mathrm{GPa}$ 
$\varepsilon_{y}=0.23 \%$

Cross section properties:

$h=400 \mathrm{~mm} \quad b=350 \mathrm{~mm}$

$A_{\text {steel }}=1015 M=10 * 200=2000 \mathrm{~mm}^{2}$

\section{Calculations}

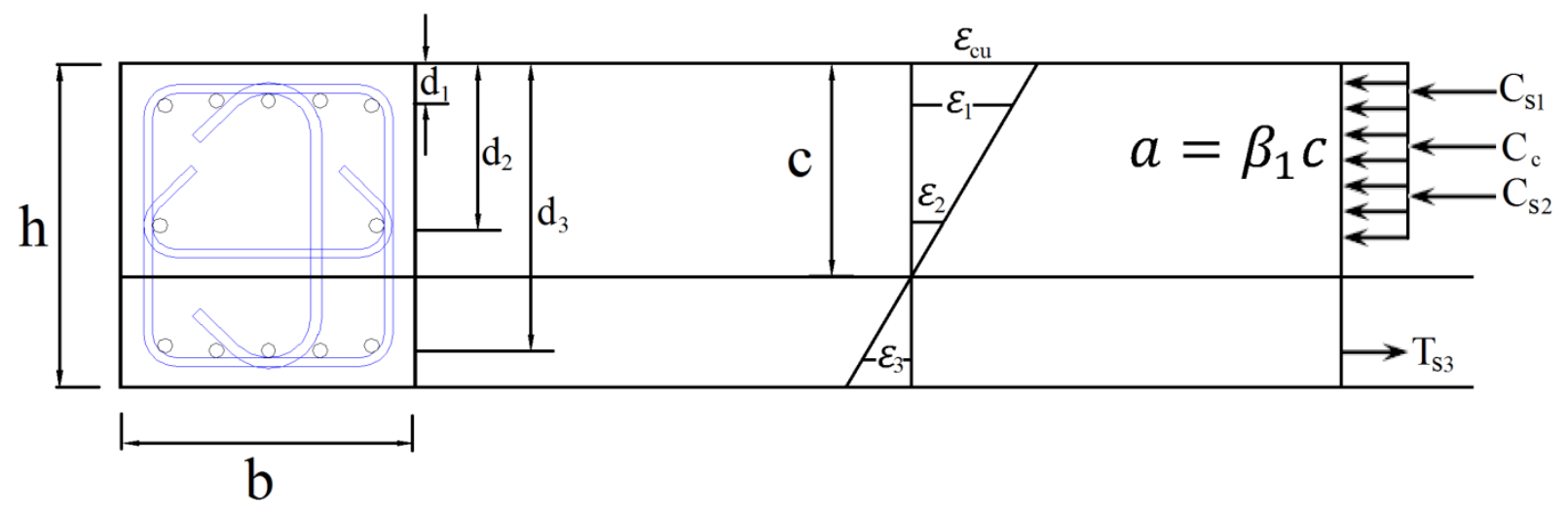

Figure 1.13 - Compatibility of strain for column cross section (S-I-M)

* Pure Axial Load

$$
P=\alpha_{1} * f^{\prime}{ }_{c} *\left(A_{g}-A_{s t}\right)+A_{s t} * f_{y}
$$

$A_{g}=400 * 350=140000 \mathrm{~mm}^{2}$

$A_{s t}=10 * 200=2000 \mathrm{~mm}^{2}$

$P_{n}=0.80 * 35 *(140000-2000)+2000 * 460=4784000 \mathrm{~N}$

$$
=4784.00 \mathrm{kN}
$$

$$
\left(P_{n}=4784.00 k N, \quad M=0 k N . m\right)
$$


Balance condition

$$
c=\frac{\varepsilon_{c u}}{\varepsilon_{y}+\varepsilon_{c u}} * d
$$

$$
\begin{aligned}
& c=\frac{0.0035}{0.0023+0.0035} * 350=211.21 \mathrm{~mm} \\
& \varepsilon_{1}=\varepsilon_{c u} * \frac{c-d_{1}}{c}=0.0035 * \frac{211.21-50}{211.21}=0.0027>0.0023 \\
& \varepsilon_{2}=\varepsilon_{c u} * \frac{c-d_{2}}{c}=0.0035 * \frac{211.21-200}{211.21}=0.0002 \\
& \varepsilon_{3}=0.0023 \\
& C_{s 1}=A_{s 1} * f_{y}=800 * 460=368000 \mathrm{~N}(368 \mathrm{kN}) \\
& C_{s 2}=A_{s 2} * E_{s} * \varepsilon_{2}=400 * 200000 * 0.0002=16000 \mathrm{~N}(16 \mathrm{kN}) \\
& T_{s 3}=A_{s 3} * f_{y}=800 * 460=368000 \mathrm{~N}(368 \mathrm{kN}) \\
& C_{c}=\alpha_{1} * f^{\prime}{ }_{c} * b * \beta_{1} * c=0.80 * 35 * 350 * 0.88 * 211.21=1821475 \mathrm{~N}(1821.47 \mathrm{kN}) \\
& P_{n}=C_{c}+C_{s 1}+C_{s 2}-T_{s 3}=1821.47+368+16-368=1837.47 \mathrm{kN}
\end{aligned}
$$

Moment about cross section centre line:

$M=1821475 *\left(200-\frac{0.88 * 211.21}{2}\right)+368000 *(200-50)+368000 *(200-50)=$ 305420957 N.mm (305.42 kN.m)

$$
\left(c=211.21 \mathrm{~mm}, \quad P_{n}=1837.47 \mathrm{kN}, \quad M=305.42 \mathrm{kN} . \mathrm{m}\right)
$$

$$
\text { * } c=56.5 \mathrm{~mm} \text { (Pure Bending) }
$$




$$
\begin{aligned}
& \varepsilon_{1}=\varepsilon_{c u} * \frac{c-d_{1}}{c}=0.0035 * \frac{56.5-50}{56.5}=0.0004 \\
& \varepsilon_{2}=\varepsilon_{c u} * \frac{c-d_{2}}{c}=0.0035 * \frac{200-56.5}{56.5}=0.0089>0.0023 \\
& \varepsilon_{3}=\varepsilon_{c u} * \frac{c-d_{3}}{c}=0.0035 * \frac{350-56.5}{56.5}=0.0182>0.0023 \\
& C_{s 1}=A_{s 1} * E_{s} * \varepsilon_{1}=800 * 200000 * 0.0004=64000 \mathrm{~N}(64 \mathrm{kN}) \\
& T_{s 2}=A_{s 2} * f_{y}=400 * 460=184000 \mathrm{~N}(184 \mathrm{kN}) \\
& T_{s 3}=A_{s 3} * f_{y}=800 * 460=368000 \mathrm{~N}(368 \mathrm{kN}) \\
& C_{c}=\alpha_{1} * f^{\prime}{ }_{c} * b * \beta_{1} * c=0.80 * 35 * 350 * 0.88 * 56.5=487256 \mathrm{~N}(487.26 \mathrm{kN}) \\
& P_{n}=C_{c}+C_{s 1}-T_{s 2}-T_{s 3}=487.26+64-184-368=-0.74 \mathrm{KN} \cong 0 \mathrm{kN}
\end{aligned}
$$

Moment about cross section centre line:

$$
\begin{aligned}
& M=487260 *\left(200-\frac{0.88 * 56.5}{2}\right)+64000 *(200-50)+368000 *(200-50)= \\
& 150138716 \text { N.mm }(150.14 \text { kN.m })
\end{aligned}
$$

$$
\left(c=56.5 \mathrm{~mm}, \quad P_{n}=0 \mathrm{kN}, \quad M=150.14 \mathrm{kN} . \mathrm{m}\right)
$$

$$
\begin{gathered}
* c=60 \mathrm{~mm} \\
\varepsilon_{1}=\varepsilon_{c u} * \frac{c-d_{1}}{c}=0.0035 * \frac{60-50}{60}=0.0006 \\
\varepsilon_{2}=\varepsilon_{c u} * \frac{c-d_{2}}{c}=0.0035 * \frac{200-60}{60}=0.0082>0.0023 \\
\varepsilon_{3}=\varepsilon_{c u} * \frac{c-d_{3}}{c}=0.0035 * \frac{350-60}{60}=0.0169>0.0023
\end{gathered}
$$




$$
\begin{aligned}
& C_{s 1}=A_{s 1} * E_{s} * \varepsilon_{1}=800 * 200000 * 0.0006=96000 \mathrm{~N}(96 \mathrm{kN}) \\
& T_{s 2}=A_{s 2} * f_{y}=400 * 460=184000 \mathrm{~N}(184 \mathrm{kN}) \\
& T_{s 3}=A_{s 3} * f_{y}=800 * 460=368000 \mathrm{~N}(368 \mathrm{kN}) \\
& C_{c}=\alpha_{1} * f^{\prime}{ }_{c} * b * \beta_{1} * c=0.80 * 35 * 350 * 0.88 * 60=517440 \mathrm{~N}(517.44 \mathrm{kN}) \\
& P_{n}=C_{c}+C_{s 1}-T_{s 2}-T_{s 3}=517.44+96-184-368=61.44 \mathrm{kN}
\end{aligned}
$$

Moment about cross section centre line:

$$
\begin{aligned}
& M=517440 *\left(200-\frac{0.88 * 60}{2}\right)+96000 *(200-50)+368000 *(200-50)= \\
& 159427584 \text { N.mm }(159.43 \text { kN.m })
\end{aligned}
$$

$$
\left(c=60 \mathrm{~mm}, \quad P_{n}=61.44 \mathrm{kN}, \quad M=159.43 \mathrm{kN} . \mathrm{m}\right)
$$

$$
\begin{aligned}
& * c=100 \mathrm{~mm} \\
& \varepsilon_{1}=\varepsilon_{c u} * \frac{c-d_{1}}{c}=0.0035 * \frac{100-50}{100}=0.0018 \\
& \varepsilon_{2}=\varepsilon_{c u} * \frac{c-d_{2}}{c}=0.0035 * \frac{200-100}{100}=0.0035>0.0023 \\
& \varepsilon_{3}=\varepsilon_{c u} * \frac{c-d_{3}}{c}=0.0035 * \frac{350-100}{100}=0.0088>0.0023 \\
& C_{s 1}=A_{s 1} * E_{s} * \varepsilon_{1}=800 * 200000 * 0.0018=288000 \mathrm{~N}(288 \mathrm{kN}) \\
& T_{s 2}=A_{s 2} * f_{y}=400 * 460=184000 \mathrm{~N}(184 \mathrm{kN}) \\
& T_{s 3}=A_{s 3} * f_{y}=800 * 460=368000 \mathrm{~N}(368 \mathrm{kN})
\end{aligned}
$$


$C_{c}=\alpha_{1} * f^{\prime}{ }^{\prime} * b * \beta_{1} * c=0.80 * 35 * 350 * 0.88 * 100=862400 \mathrm{~N}(862.40 \mathrm{kN})$

$P_{n}=C_{c}+C_{s 1}-T_{s 2}-T_{s 3}=862.40+288-184-368=598.40 \mathrm{kN}$

Moment about cross section centre line:

$M=862400 *\left(200-\frac{0.88 * 100}{2}\right)+280000 *(200-50)+368000 *(200-50)=$ $231734400 \mathrm{~N} . \mathrm{mm}(231.73 \mathrm{kN} . \mathrm{m})$

$$
\left(c=100 \mathrm{~mm}, \quad P_{n}=598.40 \mathrm{kN}, \quad M=231.73 \mathrm{kN} . \mathrm{m}\right)
$$

* $c=150 \mathrm{~mm}$

$\varepsilon_{1}=\varepsilon_{c u} * \frac{c-d_{1}}{c}=0.0035 * \frac{150-50}{150}=0.0023=\varepsilon_{y}$

$\varepsilon_{2}=\varepsilon_{c u} * \frac{c-d_{2}}{c}=0.0035 * \frac{200-150}{150}=0.0012$

$\varepsilon_{3}=\varepsilon_{c u} * \frac{c-d_{3}}{c}=0.0035 * \frac{350-150}{150}=0.0047>0.0023$

$C_{s 1}=A_{s 1} * f_{y}=800 * 460=368000 N(368 k N)$

$T_{s 2}=A_{s 2} * E_{s} * \varepsilon_{2}=400 * 200000 * 0.0012=96000 \mathrm{~N}(96.00 \mathrm{kN})$

$T_{s 3}=A_{s 3} * f_{y}=800 * 460=368000 N(368 k N)$

$C_{c}=\alpha_{1} * f^{\prime}{ }_{c} * b * \beta_{1} * c=0.80 * 35 * 350 * 0.88 * 150=1293600 \mathrm{~N}(1293.60 \mathrm{kN})$

$P_{n}=C_{c}+C_{s 1}-T_{s 2}-T_{s 3}=1293.60+368-96.00-368=1197.60 \mathrm{kN}$

Moment about cross section centre line: 
$M=1293600 *\left(200-\frac{0.88 * 150}{2}\right)+368000 *(200-50)+368000 *(200-50)=$ 283742400 N.mm $(283.74 \mathrm{kN} . \mathrm{m})$

$$
\left(c=150 \mathrm{~mm}, \quad P_{n}=1197.60 \mathrm{kN}, \quad M=283.74 \mathrm{kN} . \mathrm{m}\right)
$$

* $c=200 \mathrm{~mm}$

$\varepsilon_{1}=\varepsilon_{c u} * \frac{c-d_{1}}{c}=0.0035 * \frac{200-50}{200}=0.0026>0.0023$

$\varepsilon_{2}=\varepsilon_{c u} * \frac{c-d_{2}}{c}=0.0035 * \frac{200-200}{200}=0$

$\varepsilon_{3}=\varepsilon_{c u} * \frac{c-d_{3}}{c}=0.0035 * \frac{350-200}{200}=0.0026>0.0023$

$C_{s 1}=A_{s 1} * f_{y}=800 * 460=368000 \mathrm{~N}(368 \mathrm{kN})$

$C_{s 2}=A_{s 2} * E_{s} * \varepsilon_{2}=400 * 200000 * 0=0 k N$

$T_{s 3}=A_{s 3} * f_{y}=800 * 460=368000 N(368 \mathrm{kN})$

$C_{c}=\alpha_{1} * f^{\prime}{ }_{c} * b * \beta_{1} * c=0.80 * 35 * 350 * 0.88 * 200=1724800 \mathrm{~N}(1724.80 \mathrm{kN})$

$P_{n}=C_{c}+C_{s 1}-T_{s 2}-T_{s 3}=1724.80+368+0-368=1724.80 \mathrm{kN}$

Moment about cross section centre line:

$M=1724800 *\left(200-\frac{0.88 * 200}{2}\right)+368000 *(200-50)+368000 *(200-50)=$ 303577600 N.mm (303.58 kN.m)

$$
\left(c=200 \mathrm{~mm}, \quad P_{n}=1724.80 \mathrm{kN}, \quad M=303.58 \mathrm{kN} . \mathrm{m}\right)
$$

$$
\text { * } c=250 \mathrm{~mm}
$$




$$
\begin{aligned}
& \varepsilon_{1}=\varepsilon_{c u} * \frac{c-d_{1}}{c}=0.0035 * \frac{250-50}{250}=0.0028>0.0023 \\
& \varepsilon_{2}=\varepsilon_{c u} * \frac{c-d_{2}}{c}=0.0035 * \frac{250-200}{250}=0.0007 \\
& \varepsilon_{3}=\varepsilon_{c u} * \frac{c-d_{3}}{c}=0.0035 * \frac{350-250}{250}=0.0014 \\
& C_{s 1}=A_{s 1} * f_{y}=800 * 460=368000 N(368 \mathrm{kN}) \\
& C_{s 2}=A_{s 2} * E_{s} * \varepsilon_{2}=400 * 200000 * 0.0007=56000 \mathrm{~N}(56 \mathrm{kN}) \\
& T_{s 3}=A_{s 3} * E_{s} * \varepsilon_{3}=800 * 200000 * 0.0014=224000 \mathrm{~N}(224 \mathrm{kN}) \\
& C_{c}=\alpha_{1} * f^{\prime}{ }_{c} * b * \beta_{1} * c=0.80 * 35 * 350 * 0.88 * 250=2156000 \mathrm{~N}(2156.00 \mathrm{kN}) \\
& P_{n}=C_{c}+C_{s 1}-T_{s 2}-T_{s 3}=2156.00+368+56-224=2356.00 \mathrm{kN}
\end{aligned}
$$

Moment about cross section centre line:

$$
M=2156000 *\left(200-\frac{0.88 * 250}{2}\right)+368000 *(200-50)+224000 *(200-50)=
$$$$
282840000 \mathrm{~N} . \mathrm{mm}(282.84 \mathrm{kN.m})
$$

$$
\left(c=250 \mathrm{~mm}, \quad P_{n}=2356.00 \mathrm{kN}, M=282.84 \mathrm{kN} . \mathrm{m}\right)
$$

$$
\begin{gathered}
* c=300 \mathrm{~mm} \\
\varepsilon_{1}=\varepsilon_{c u} * \frac{c-d_{1}}{c}=0.0035 * \frac{300-50}{300}=0.0029>0.0023 \\
\varepsilon_{2}=\varepsilon_{c u} * \frac{c-d_{2}}{c}=0.0035 * \frac{300-200}{300}=0.0012 \\
\varepsilon_{3}=\varepsilon_{c u} * \frac{c-d_{3}}{c}=0.0035 * \frac{350-300}{300}=0.0006
\end{gathered}
$$




$$
\begin{aligned}
& C_{s 1}=A_{s 1} * f_{y}=800 * 460=368000 \mathrm{~N}(368 \mathrm{kN}) \\
& C_{s 2}=A_{s 2} * E_{s} * \varepsilon_{2}=400 * 200000 * 0.0012=96000 \mathrm{~N}(96.00 \mathrm{kN}) \\
& T_{s 3}=A_{s 3} * E_{s} * \varepsilon_{3}=800 * 200000 * 0.0006=96000 \mathrm{~N}(96.00 \mathrm{kN}) \\
& C_{c}=\alpha_{1} *{f^{\prime}}^{\prime} * b * \beta_{1} * c=0.80 * 35 * 350 * 0.88 * 300=2587200 \mathrm{~N}(2587.20 \mathrm{kN}) \\
& P_{n}=C_{c}+C_{s 1}+C_{s 2}-T_{s 3}=2587.20+368+96.00-96.00=2955.20 \mathrm{kN}
\end{aligned}
$$

Moment about cross section centre line:

$$
\begin{aligned}
& M=2587200 *\left(200-\frac{0.88 * 300}{2}\right)+368000 *(200-50)+96000 *(200-50)= \\
& 245529600 \text { N.mm }(245.53 \mathrm{kN.m})
\end{aligned}
$$

$$
\left(c=300 \mathrm{~mm}, \quad P_{n}=2955.20 \mathrm{kN}, \quad M=245.53 \mathrm{kN} . \mathrm{m}\right)
$$

$$
\begin{aligned}
& * c=350 \mathrm{~mm} \\
& \varepsilon_{1}=\varepsilon_{c u} * \frac{c-d_{1}}{c}=0.0035 * \frac{350-50}{350}=0.0030>0.0023 \\
& \varepsilon_{2}=\varepsilon_{c u} * \frac{c-d_{2}}{c}=0.0035 * \frac{350-200}{350}=0.0015 \\
& \varepsilon_{3}=\varepsilon_{c u} * \frac{c-d_{3}}{c}=0.0035 * \frac{350-350}{350}=0 \\
& C_{s 1}=A_{s 1} * f_{y}=800 * 460=368000 \mathrm{~N}(368 \mathrm{kN}) \\
& C_{s 2}=A_{s 2} * E_{s} * \varepsilon_{2}=400 * 200000 * 0.0015=120000 \mathrm{~N}(120 \mathrm{kN}) \\
& T_{s 3}=A_{s 3} * E_{s} * \varepsilon_{3}=800 * 200000 * 0=\mathrm{N}(0 \mathrm{kN}) \\
& C_{c}=\alpha_{1} * f^{\prime}{ }_{c} * b * \beta_{1} * c=0.80 * 35 * 350 * 0.88 * 350=3018400 \mathrm{~N}(3018.40 \mathrm{kN})
\end{aligned}
$$


$P_{n}=C_{c}+C_{s 1}+C_{s 2}-T_{s 3}=3018.40+368+120-0=3506.40 \mathrm{kN}$

Moment about cross section centre line:

$M=3018400 *\left(200-\frac{0.88 * 350}{2}\right)+368000 *(200-50)=194046400 \mathrm{~N} . \mathrm{mm}(194.05 \mathrm{kN})$

$$
\left(c=350 \mathrm{~mm}, \quad P_{n}=3506.40 \mathrm{kN}, \quad M=194.05 \mathrm{KN} . \mathrm{m}\right)
$$

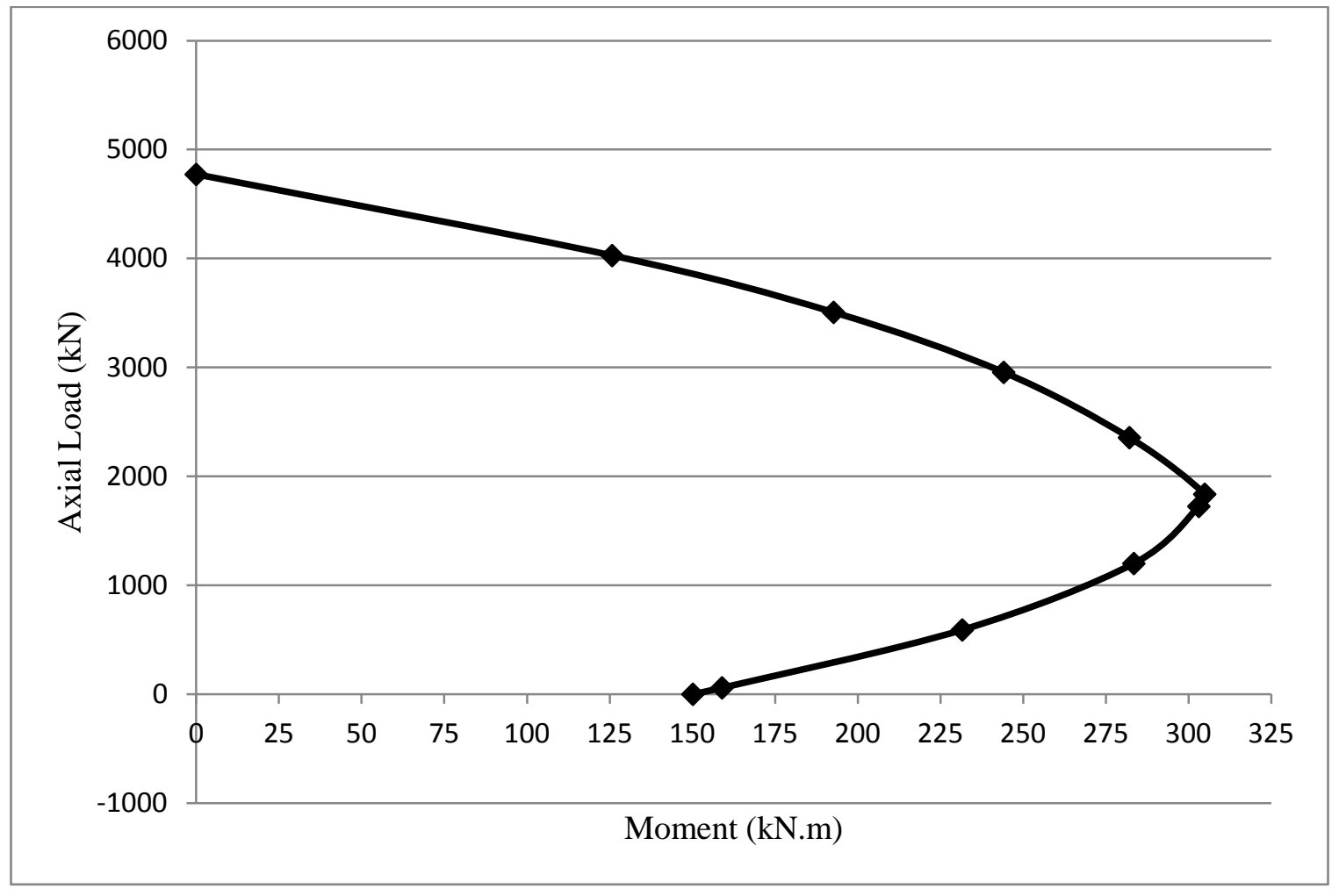

Figure 1.14 - Axial load-moment interaction diagram of column (S-I-M)

The column was be loaded under the axial force equal to $15 \%$ of its ultimate capacity:

$$
P=0.15 * 4784.00=717.60 k N
$$

Assuming: $c=111.5 \mathrm{~mm}$

$\varepsilon_{1}=\varepsilon_{c u} * \frac{c-d_{1}}{c}=0.0035 * \frac{111.5-50}{111.5}=0.0019$ 


$$
\begin{aligned}
& \varepsilon_{2}=\varepsilon_{c u} * \frac{c-d_{2}}{c}=0.0035 * \frac{200-111.5}{111.5}=0.0028>0.0023 \\
& \varepsilon_{3}=\varepsilon_{c u} * \frac{c-d_{3}}{c}=0.0035 * \frac{350-111.5}{111.5}=0.0075>0.0023 \\
& C_{s 1}=A_{s 1} * E_{s} * \varepsilon_{1}=800 * 200000 * 0.0019=304000 \mathrm{~N}(304 \mathrm{kN}) \\
& T_{s 2}=A_{s 2} * f_{y}=400 * 460=184000 \mathrm{~N}(184 \mathrm{kN}) \\
& T_{s 3}=A_{s 3} * f_{y}=800 * 460=368000 \mathrm{~N}(368 \mathrm{kN}) \\
& C_{c}=\alpha_{1} * f^{\prime}{ }^{\prime} * b * \beta_{1} * c=0.80 * 35 * 350 * 0.88 * 111.5=961576 \mathrm{~N}(961.58 \mathrm{kN}) \\
& P_{n}=C_{c}+C_{s 1}-T_{s 2}-T_{s 3}=961.58+304-184-368=713.58 \mathrm{kN} \cong 717.6 \mathrm{kN}
\end{aligned}
$$

Moment about cross section centre line:

$M=961576 *\left(200-\frac{0.88 * 111.5}{2}\right)+304000 *(200-50)+368000 *(200-50)=$ 245940281 N.mm (245.94 kN.m)

$$
\left(c=111.5 \mathrm{~mm}, \quad P_{n}=717.6 \mathrm{kN}, \quad M=2245.94 \mathrm{kN} . \mathrm{m}\right)
$$

Flexural ratio:

$$
\frac{2 * 245.94}{299.23}=1.64
$$




\section{Design of Column for Shear}

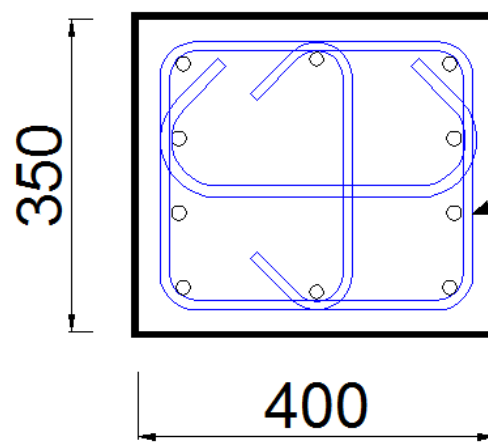

\section{$10 \mathrm{M} @ 90 \mathrm{~mm}$}

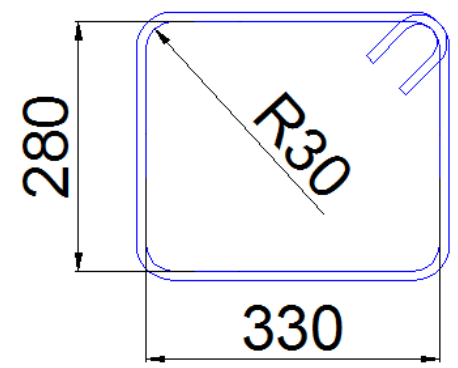

Figure 1.15 - Column reinforcement detailing for Specimen S-I-M

\section{Material and sectional properties}

Steel properties:

$f_{y}=400 \mathrm{MPa}$

$\varphi_{\text {steel }}=1$

$E_{\text {steel }}=200 \mathrm{GPa}$

$\varepsilon_{y}=0.23 \%$

$A_{v}=$ three branches $10 M=3 * 100=300 \mathrm{~mm}^{2}$

\section{Calculations:}

Applied shear force:

$$
V_{r}=\frac{M_{\text {beam }}}{h_{c}}=\frac{299.23}{3.5}=85.49 \mathrm{kN}
$$

Calculating $d_{v}$ :

$$
\operatorname{Max}\{0.9 d .0 .72 h\}=\operatorname{Max}\{0.9 * 350,0.72 * 400\}=\operatorname{Max}\{315,288\}=315 \mathrm{~mm}
$$


CSA-A23.3-04 Clause 11.3.3:

$$
\begin{gathered}
V_{r, \text { Max }}=0.25 * \varphi_{c} *{f^{\prime}}_{c} * b_{w} * d_{v}+V_{p} \\
0.25 * 1 * 35 * 350 * 315+0=964688 N>85490 N \\
V_{r}=V_{c}+V_{s} \\
V_{c}=\varphi_{c} * \lambda * \beta * \sqrt{f^{\prime}{ }_{c}} * b_{w} * d_{v}
\end{gathered}
$$

CSA-A23.3-04 Clause 21.4.5.2:

$$
\beta \leq 0.1 \quad, \quad \theta \geq 45^{\circ}
$$

CSA-A23.3-04 Clause 11.3.6.4:

$$
\varepsilon_{x}=\frac{\left(\frac{M_{f}}{d_{v}}+V_{f}+0.5 * N_{f}\right)}{2 * E_{s} * A_{s}}
$$

$M_{f}=\frac{M_{\text {beam }}}{2}=\frac{299.23}{2}=149.61 \mathrm{kN} . \mathrm{m}$

As a result:

$$
\varepsilon_{x}=\frac{\left(\frac{149.61 * 10^{6}}{315}+85.49 * 10^{3}-0.5 * 717.60 * 10^{3}\right)}{2 * 200000 * 800}=6.30 * 10^{-4}
$$

CSA-A23.3-04 Clause 11.3.6.4:

$$
\beta=\frac{0.4}{\left(1+1500 * \varepsilon_{x}\right)} * \frac{1300}{\left(1000+S_{z e}\right)}
$$

Since $A_{v}>A_{v, \text { Min }}, S_{z e}=300 \mathrm{~mm}$ 
$\beta=\frac{0.4}{\left(1+1500 * 6.3 * 10^{-4}\right)} * \frac{1300}{(1000+300)}=0.21>0.1$

$$
\text { USE } \quad \beta=0.1
$$

CSA-A23.3-04 Clause 11.3.6.4:

$$
\theta=29+7000 * \varepsilon_{x}
$$

$\theta=29+7000 * 6.3 * 10^{-4}=33.41^{\circ}<45^{\circ}$

$$
\text { USE } \quad \theta=45^{\circ}
$$

$\therefore V_{c}=1 * 1 * 0.1 * \sqrt{35} * 350 * 315=65225 \mathrm{~N}(65.22 \mathrm{kN})$

$V_{S}=V_{r}-V_{c}=85.49-65.22=20.27 k N$

CSA-A23.3-04 Clause 11.3.5.1:

$$
s=\frac{\varphi_{s} * A_{v} * f_{y} * d_{v} * \cot \theta}{V_{S}}
$$

$S=\frac{1 * 200 * 400 * 315 * 1}{20.27 * 10^{3}}=1243 \mathrm{~mm}$

CSA-A23.3-04 Clause 11.2.8.2 (minimum shear reinforcement):

$$
\begin{gathered}
A_{v, \text { min }}=0.06 * \sqrt{f^{\prime}{ }_{c}} * \frac{b_{w} * s}{f_{y}} \\
\frac{A_{v} * f_{y}}{0.06 * \sqrt{f^{\prime}{ }_{c}} * b_{w}}=s_{\max }
\end{gathered}
$$


$s_{\max }=\frac{200 * 400}{0.06 * \sqrt{35} * 350}=643.93 \mathrm{~mm}<1033.47 \mathrm{~mm}$

Check for minimum spacing:

CSA-A23.3-04 Clause 11.3.8.1 and 11.3.8.3:

$0.125 * \lambda * \varphi_{c} * f^{\prime}{ }_{c} * b_{w} * d_{v}=0.125 * 1 * 1 * 35 * 350 * 315=482344 N>V_{r}=89610 \mathrm{~N}$

1. $0.7 d_{v}=0.7 * 315=220.5 \mathrm{~mm}$

2. $600 \mathrm{~mm}$

CSA-A23.3-04 Clause 21.4.4.3:

$S_{\text {Max }}$ is equal to the least of:

1. One-quarter of the minimum member dimension $=\frac{350}{4}=87.5 \mathrm{~mm}$

2. Six times the diameter of the smallest longitudinal bar $=6 * 20=120 \mathrm{~mm}$

3. $S_{x}=100+\left(\frac{350-h_{x}}{3}\right)=100+\left(\frac{350-125}{3}\right)=175 \mathrm{~mm}$

Where $h_{x}$ is maximum horizontal center-to-center spacing between longitudinal bars on all faces of the column that are laterally supported by seismic hoops or crosstie legs

\section{USE stirrups 10M@90 mm}

CSA-A23.3-04 Clause 21.4.4.2:

$\underline{h_{c}}=338.6 \mathrm{~mm}$

$$
A_{s h}=\operatorname{Max}\left\{0.2 * k_{n} * K_{p} * \frac{A_{g}}{A_{c h}} * \frac{f^{\prime}{ }_{c}}{f_{y h}} * S * h_{c}, 0.09 * \frac{f^{\prime}{ }_{c}}{f_{y h}} * S * h_{c}\right\}
$$


Where:

$K_{n}=\frac{n_{l}}{\left(n_{l}-2\right)}, k_{p}=\frac{P_{f}}{P_{0}}$

$f_{y h}$ shall not be taken as greater than $500 \mathrm{MPa}$

$n_{l}:$ Total number of longitudinal bars in the column cross - section that are

laterally supported by the corner of hoops or by hooks or seismic crossties

$A_{g}=350 * 400=140000 \mathrm{~mm}^{2}$

$A_{c h}:$ Cross - sectional area of core of a structural member

$A_{c h}=(350-2 * 50+16+2 * 11.3) *(400-2 * 50+16+2 * 11.3)=288.6 * 338.6=$ $97720 \mathrm{~mm}^{2}$

$A_{s h}=200 \mathrm{~mm}^{2}$

$k_{n}=\frac{4}{(4-2)}=2$

$k_{p}=0.15$

$h_{c}$ : Dimension of concrete core of rectangular section measured perpendicular to the direction of the hoop bars to outside of peripheral hoop

$h_{c}=338.6 \mathrm{~mm}$

$S=\frac{A_{s h^{*}} A_{c h} * f_{y h}}{0.2 * k_{n} * K_{p} * A_{g} * f^{\prime}{ }_{c} * h_{c}}=\frac{200 * 97720 * 400}{0.2 * 2 * 0.15 * 140000 * 35 * 338.6}=78.53 \mathrm{~mm}$

$S=\frac{A_{s h^{*} f_{y h}}}{0.09 * f^{\prime}{ }_{c}^{* h_{c}}}=\frac{200 * 400}{0.09 * 35 * 338.6}=75.00 \mathrm{~mm}$ 


$$
\operatorname{Max}\{78.53 \mathrm{~mm}, 75.00 \mathrm{~mm}\}=78.53 \mathrm{~mm}<90 \mathrm{~mm}
$$

As a result another crosstie should be added in this direction. Recalculating stirrups' spacing:

$k_{n}=\frac{6}{(6-2)}=1.5$

$A_{s h}=300 \mathrm{~mm}^{2}$

$S=\frac{A_{S h} * A_{c h} * f_{y h}}{0.2 * k_{n} * K_{p} * A_{g} * f^{\prime}{ }_{c} * h_{c}}=\frac{300 * 97720 * 400}{0.2 * 1.5 * 0.15 * 140000 * 35 * 338.6}=157.06 \mathrm{~mm}$

$S=\frac{A_{s h^{*} f_{y h}}}{0.09 * f^{\prime} c^{* h_{c}}}=\frac{300 * 400}{0.09 * 35 * 349}=112.5 \mathrm{~mm}$

$\operatorname{Max}\{157.06 \mathrm{~mm}, 112.5 \mathrm{~mm}\}=157.06 \mathrm{~mm}>90 \mathrm{~mm}$

$\underline{h_{c}}=288.6 \mathrm{~mm}$

$k_{n}=\frac{6}{(6-2)}=1.5$

$h_{c}=288.6 \mathrm{~mm}$

$S=\frac{A_{s h} * A_{c h} * f_{y h}}{0.2 * k_{n} * K_{p} * A_{g} * f^{\prime}{ }^{*} h_{c}}=\frac{200 * 97720 * 400}{0.2 * 1.5 * 0.15 * 140000 * 35 * 288.6}=122.84 \mathrm{~mm}$

$S=\frac{A_{S h} * f_{y h}}{0.09 * f^{\prime} c^{* h_{c}}}=\frac{200 * 400}{0.09 * 35 * 288.6}=88.00 \mathrm{~mm}$

$\operatorname{Max}\{122.84 \mathrm{~mm}, 88.00 \mathrm{~mm}\}=122.84 \mathrm{~mm}>90 \mathrm{~mm}$ 


\section{Lateral Beams}
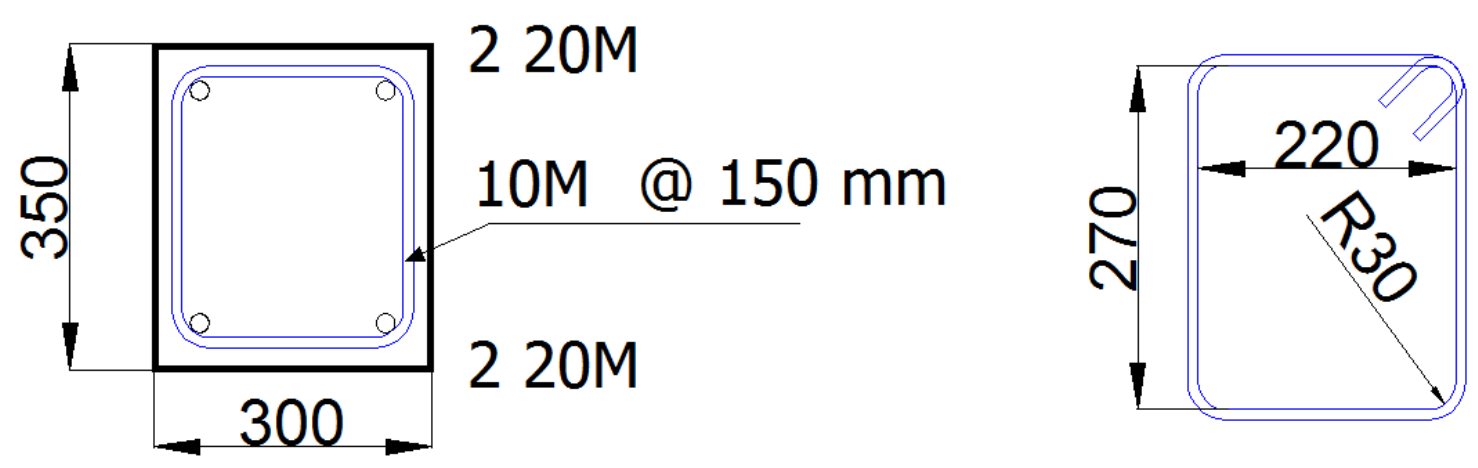

Figure 1.16 - Lateral beams reinforcement detailing for Specimen S-I-M

\section{Material and sectional properties:}

Concrete properties:

$f^{\prime}{ }_{c}=35 \mathrm{MPa}, \quad \varphi_{c}=1, \quad E_{c}=4500 \sqrt{{f^{\prime}}_{c}}=4500 \sqrt{35}=26622 \mathrm{MPa}$

$\alpha_{1}=0.85-0.0015 f^{\prime}{ }_{c}=0.80, \quad \beta_{1}=0.97-0.0025 f^{\prime}{ }_{c}=0.88$

$\varepsilon_{c u}=0.0035$

$\underline{\text { Steel properties: }}$

$f_{y}=460 \mathrm{MPa}$

$$
\varphi_{\text {steel }}=1
$$

$E_{\text {steel }}=200 \mathrm{GPa}$

$\varepsilon_{y}=0.23 \%$

Cross section properties:

$h=350 \mathrm{~mm}$

$b=300 \mathrm{~mm}$

$A_{\text {steel }}=220 M=2 * 300=600 \mathrm{~mm}^{2}$ 
$A_{v}=$ two branches $10 M=2 * 100=200 \mathrm{~mm}^{2}$

\section{Calculations}

\section{Flexural reinforcement:}

Location of the transverse beams is at the end boundary of the frame. We assume that loads applied on these beams by the slab and exterior wall is $25 \%$ of the main beam.

$$
\begin{gathered}
M_{\text {lateral beam }}=0.25 * M_{\text {main beam }} \\
M_{\text {lateral beam }}=0.25 * 299.23=74.81 \mathrm{kN} . \mathrm{m}
\end{gathered}
$$

Designing the beam for the calculated moment:

Using 2-20M on top and bottom:

$$
\begin{gathered}
\varepsilon_{y}=\frac{f_{y}}{E_{\text {steel }}}=\frac{460}{200000}=0.0023 \\
\varepsilon_{s}=\varepsilon_{c u} * \frac{d-c}{c}=0.0035 * \frac{300-c}{c}
\end{gathered}
$$

Assuming $c<d^{\prime}$ :

$$
\varepsilon^{\prime}{ }_{s}=\varepsilon_{c u} * \frac{d^{\prime}-c}{c}=0.0035 * \frac{50-c}{c}
$$

$T_{s}=f_{y} * A_{s}=460 * 2 * 300=276000 \mathrm{~N}(276 \mathrm{kN})$

$C_{c}=\alpha_{1} * f^{\prime}{ }_{c} * \beta_{1} * b * c=0.80 * 35 * 0.88 * 300 * c=7392 * c$

Assume $c<d^{\prime}$ : 


$$
\begin{gathered}
T^{\prime}{ }_{s}=\varepsilon^{\prime}{ }^{\prime} * E_{s} * A_{s}=0.0035 * \frac{50-c}{c} * 200000 * 2 * 300=420000 * \frac{50-c}{c} \\
C_{c}=T_{s}+C_{s}
\end{gathered}
$$

$7392 * c=276000+420000 * \frac{50-c}{c}$

Solving the equation for $c$ :

$$
c=44.44 \mathrm{~mm}<50 \mathrm{OK}
$$

$$
\begin{aligned}
& a=\beta_{1} * c=0.88 * 44.44=39.11 \mathrm{~mm} \\
& C_{c}=7392 * 44.44=328500 \mathrm{~N}(328 \mathrm{kN}) \\
& T_{s}^{\prime}=420000 * \frac{50-44.44}{44.44}=52547 \mathrm{~N}(52.55 \mathrm{kN}) \\
& T_{S}=276000 \mathrm{~N}(276 \mathrm{kN}) \\
& M_{r}=276000 *\left(300-\frac{39.11}{2}\right)+52547 *\left(50-\frac{39.11}{2}\right)=79002613 \mathrm{~N} . \mathrm{mm}(79.00 \mathrm{kN} . \mathrm{m}) \\
& \quad>74.81 \mathrm{kN} . \mathrm{m} \rightarrow O \mathrm{~K}
\end{aligned}
$$

Calculating service moment in the beam at the column face:

$$
\text { Service load }=0.6 * \text { yeilding stregth of steel }
$$

Using Hognestad's stress-strain relationship for concrete:

$$
\alpha=\frac{\varepsilon_{c c}}{\varepsilon_{0}} *\left(1-\frac{\varepsilon_{c c}}{3 * \varepsilon_{0}}\right) \quad, \quad \gamma=1-\frac{\left(\frac{2}{3}-\frac{\varepsilon_{c c}}{4 * \varepsilon_{0}}\right)}{\left(1-\frac{\varepsilon_{c c}}{3 * \varepsilon_{0}}\right)}
$$




$$
\varepsilon_{0}=\frac{2 * f^{\prime}{ }_{c}}{E_{c}}
$$

Where:

$\varepsilon_{c c}$ : strain at the outer most fiber of the concrete in compression:

$\varepsilon_{0}=\frac{2 * 35}{4500 * \sqrt{35}}=0.0026$

Strain at the level of lower layer of steel reinforcement in tension:

$f_{s}=0.6 * 460=276 \mathrm{MPa}$

$\varepsilon_{S}=\frac{276}{200000}=0.0014$

Strain at the level of top layer steel:

$$
\varepsilon^{\prime}{ }_{s}=\varepsilon_{s} * \frac{c-d_{2}}{d_{1}-c}
$$

$\varepsilon^{\prime}{ }_{S}=0.0014 * \frac{c-50}{300-c}$

$$
\varepsilon_{c c}=\varepsilon_{s} * \frac{c}{d_{1}-c}
$$

$\varepsilon_{c c}=0.0014 * \frac{c}{300-c}$

Assume $c=78 \mathrm{~mm}$ :

$\varepsilon^{\prime}{ }_{S}=0.0014 * \frac{78-50}{300-78}=0.0002$

$\varepsilon_{c c}=0.0014 * \frac{78}{300-78}=0.0005$ 


$$
\begin{aligned}
& \alpha=\frac{0.0005}{0.0026} *\left(1-\frac{0.0005}{3 * 0.0026}\right)=0.18 \\
& C_{c}=\alpha *{f^{\prime}}^{\prime}{ } * b * c=0.18 * 35 * 300 * 78=147420 \mathrm{~N}(147.42 \mathrm{kN}) \\
& C_{S}=\varepsilon^{\prime}{ }_{S} * E_{S} * A^{\prime}{ }_{S}=0.0002 * 200000 * 2 * 300=24000 \mathrm{~N}(24 \mathrm{kN}) \\
& T_{S}=0.6 * 460 * 2 * 300=165600 \mathrm{~N}(165.6 \mathrm{kN})
\end{aligned}
$$

For equilibrium:

$$
C_{c}+C_{s}=T_{s}
$$

In this case:

$147.42+24=171.42 k N \cong 165.6 k N$

$\gamma=1-\frac{\left(\frac{2}{3}-\frac{0.0005}{4 * 0.0026}\right)}{\left(1-\frac{0.0005}{3 * 0.0026}\right)}=0.34$

Moment about centre of compressive block:

$M=165600 *(300-0.34 * 78)-24000 *(50-0.34 * 78)=$

44724768 N.mm (44.72 kN.m)

Shear reinforcement:

Two branches of 10M steel stirrups will be used as shear reinforcement.

According to beam's flexural design:

$M_{f}=74.81 \mathrm{kN} . \mathrm{m}$ 
$V_{f}=\frac{M_{\text {beam }}}{l_{\text {beam }}}=\frac{74.81}{0.83}=90.13 \mathrm{kN}$

Calculating $d_{v}$ :

$$
\operatorname{Max}\{0.9 d \cdot 0.72 h\}=\operatorname{Max}\{0.9 * 300+0.72 * 350\}=\operatorname{Max}\{270,252\}=270 \mathrm{~mm}
$$

CSA-A23.3-04 Clause 11.3.3:

$$
\begin{gathered}
V_{r, \operatorname{Max}}=0.25 * \varphi_{c} * f^{\prime}{ }_{c} * b_{w} * d_{v}+V_{p} \\
0.25 * 1 * 35 * 300 * 270+0=708750>74810 \mathrm{~N}
\end{gathered}
$$

All the shear stresses should be resisted by steel stirrups:

$$
V_{S}=V_{f}
$$

CSA-A23.3-04 Clause 11.3.5.1:

$$
V_{S}=\frac{\varphi_{s} * A_{v} * f_{y} * d_{v} * \cot \theta}{s}
$$

CSA-A23.3-04 Clause 21.3.4.2:

$$
\theta=45^{\circ} \quad, \quad \beta=0
$$

As a result:

$S=\frac{1 * 200 * 400 * 270 * 1}{78.4 * 10^{3}}=275.5 \mathrm{~mm}$

CSA-A23.3-04 Clause 11.2.8.2 (minimum shear reinforcement):

$$
A_{v, \min }=0.06 * \sqrt{f^{\prime}{ }_{c}} * \frac{b_{w} * s}{f_{y}}
$$




$$
\frac{A_{v} * f_{y}}{0.06 * \sqrt{f^{\prime}{ }_{c}} * b_{w}}=s_{\max }
$$

$S_{\max }=\frac{200 * 400}{0.06 * \sqrt{35} * 300}=751.25 \mathrm{~mm}$

Check for minimum spacing:

CSA-A23.3-04 Clause 11.3.8.1 and 11.3.8.3:

$0.125 * \lambda * \varphi_{c} * f^{\prime}{ }^{\prime} * b_{w} * d_{v}=0.125 * 1 * 1 * 35 * 300 * 270=354375 N>V_{r}=78400 N$

3. $0.7 d_{v}=0.7 * 270=189 \mathrm{~mm}$

4. $600 \mathrm{~mm}$

There is no need to check for CSA-A23.3-04 Clause 21.3.3.2 because lateral beams will not be loaded under seismic loading.

USE 2 branches of $10 M @ 150 \mathrm{~mm}$ 


\section{APPENDIX C : PROPERTIES OF SPECIMENS}


Table 1.1 indicate the properties of the specimens, calculated based on the concrete strength at the day of testing.

Table 1.1 - Properties of the specimens

\begin{tabular}{|c|c|c|c|c|c|c|c|c|}
\hline \multirow{2}{*}{ Specimen } & \multirow{2}{*}{$f^{\prime}{ }_{c}$} & \multirow{2}{*}{$\rho_{\text {bal }}$} & \multirow{2}{*}{$\rho$} & $\frac{\rho}{\rho_{\text {bal }}}$ & \multicolumn{2}{|c|}{$M_{R}$} & \multirow{2}{*}{ Flexural Ratio } & \multirow{2}{*}{ Shear Ratio } \\
\cline { 1 - 1 } & & & & & Column & Beam & & \\
\hline G-I-L & 44.4 & 0.0044 & 0.0072 & 1.64 & 247 & 307.01 & 1.61 & 0.806 \\
\hline G-I-M & 47.8 & 0.0046 & 0.0122 & 2.65 & 257 & 349.63 & 1.47 & 0.961 \\
\hline G-I-H & 42.2 & 0.0042 & 0.0152 & 3.62 & 240 & 356.43 & 1.35 & 1.065 \\
\hline S-I-M & 40.8 & - & - & - & 263 & 303.05 & 1.73 & 1.003 \\
\hline G-II-L & 41.7 & 0.0057 & 0.0090 & 1.58 & 236 & 302.63 & 1.56 & 0.872 \\
\hline G-II-M & 46.6 & 0.0062 & 0.0141 & 2.27 & 254 & 351.53 & 1.45 & 0.960 \\
\hline
\end{tabular}

For headed bars: $f_{F R P, u}=1100 \mathrm{MPa}$

For bent bars: $f_{F R P, u}=850 \mathrm{MPa}$

Table C.2 compares the deigned and actual capacity of the specimens obtained from the test.

Table C.2 - Design and actual capacity of the specimens

\begin{tabular}{|c|c|c|c|c|c|c|}
\hline \multirow{2}{*}{ Specimen } & \multirow{2}{*}{$\begin{array}{c}\text { Maximum } \\
\text { Drift at Test }\end{array}$} & \multirow{2}{*}{ Design } & \multicolumn{2}{|c|}{ Test } & \multicolumn{2}{|c|}{$\frac{\text { test }}{\text { design }}$} \\
\cline { 3 - 7 } & & & Pushing & Pulling & Pushing & Pulling \\
\hline G-I-L & $7 \%$ & 307.01 & $\begin{array}{c}354.72 \\
(7 \%)\end{array}$ & $\begin{array}{c}328.06 \\
(6 \%)\end{array}$ & 1.16 & 1.07 \\
\hline G-I-M & $9 \%$ & 349.63 & $\begin{array}{c}418.38 \\
(7 \%)\end{array}$ & $\begin{array}{c}371.34 \\
(7 \%)\end{array}$ & 1.20 & 1.06 \\
\hline G-I-H & $9 \%$ & 356.43 & $\begin{array}{c}410.58 \\
(6 \%)\end{array}$ & $\begin{array}{c}386.56 \\
(6 \%)\end{array}$ & 1.15 & 1.08 \\
\hline S-I-M & $7 \%$ & 303.05 & $\begin{array}{c}308.58 \\
(6 \%)\end{array}$ & $\begin{array}{c}297.94 \\
(6 \%)\end{array}$ & 1.02 & 0.98 \\
\hline G-II-L & $6 \%$ & 302.63 & $\begin{array}{c}302.64 \\
(5 \%)\end{array}$ & $\begin{array}{c}279.5 \\
(5 \%)\end{array}$ & 1.00 & 0.92 \\
\hline G-II-M & $7 \%$ & 351.53 & $\begin{array}{c}397.98 \\
(6 \%)\end{array}$ & $\begin{array}{c}345.86 \\
(5 \%)\end{array}$ & 1.13 & 0.98 \\
\hline
\end{tabular}

